Surface and shear-wave velocity modelling of the Tongariro Volcanic Centre, New Zealand, using ambient noise cross-correlation

\author{
Holly Joanne Godfrey
}

A thesis submitted to Victoria University of Wellington

in fulfilment of the requirements for the degree of

Master of Science in Geology

April 2016

School of Geology, Environment and Earth Sciences

Victoria University of Wellington

Te Whare Wānanga o te Upoko o te Ika a Mãui

Wellington, New Zealand 



\section{Abstract}

We use continuous seismic data from permanent and temporary, broadband and shortperiod stations that were operating during 2001 and 2008 to investigate the subsurface velocity structure of the Tongariro Volcanic Centre $(\mathrm{TgVC})$ of New Zealand, particularly the highly active but poorly understood Ruapehu and Tongariro Volcanoes.

Stacks of cross-correlation of two concurrent ambient noise seismograms can be used to estimate the interstation Green's Function, i.e., the impulse response of the earth between the two receivers. The Green's Functions are used to retrieve the dispersion relation (frequency-dependent velocity) of surface waves at different periods, which reflects the shear-wave velocity structure in the Fresnel volume of the propagating surface waves. Several studies have used dispersion measurements from ambient noise cross-correlations to investigate the shallow subsurface shear-wave velocity structure of active volcanoes around the world. Most use vertical components to retrieve the Rayleigh waves, but it is becoming increasingly common to use the horizontal seismogram components in addition to the vertical, giving further constraints to Rayleigh-wave measurements and introducing data relating to Love waves.

We compute $1,048,968$ daily cross-correlations for 955 viable station pairs across the two periods, including all nine-components of the cross-correlation tensor where possible. These daily functions are then stacked into 7458 full-stacks, of which we make group velocity dipsersion measurements for 2641 RR-, RZ-, TT-, ZR- and ZZ-component stacks. Cross-correlation quality varies across the networks, with some station pairs possibly contaminated with timing errors.

We observe both the fundamental and first higher-order modes within our database of dispersion measurements. However, correctly identifying the mode of some measurements is challenging as the range of group velocities measured reflects both presence of multiple modes and heterogeneity of the local velocity structure. We assign modes to over 1900 measurements, of which we consider 1373 to be high quality.

We invert fundamental mode Rayleigh- and Love-wave dispersion curves independently and jointly for one dimensional shear-wave velocity profiles at Ruapehu and Tongariro 
Volcanoes, using dispersion measurements from two individual station pairs and average dispersion curves from measurements within specific areas on/around the volcanoes. Our Ruapehu profiles show little velocity variation with depth, suggesting that volcanic edifice is made of material that is compacting and being hydrothermally altered with depth. At Tongariro, we observe larger increases in velocity with depth, which we interpret as different layers within Tongariro's volcanic system. Slow shear-wave velocities, on the order of 1-2 $\mathrm{km} / \mathrm{s}$, are consistent with both $\mathrm{P}$-wave velocities from existing velocity profiles of areas within the $\mathrm{TgVC}$, and the observations of worldwide studies of shallow volcanic systems that used ambient noise cross-correlation.

A persistent observation across the majority of our dispersion measurements is that group velocities of the fundamental mode Love-wave group velocity measurements are slower than those of fundamental mode Rayleigh-waves, particularly in the frequency range of $0.25-1 \mathrm{~Hz}$. Similarly, first higher-order mode Love-wave group velocities are slower than first higher-mode Rayleigh-wave velocities. This is inconsistent with the differences between synthetic dispersion curves that were calculated using isotropic, layered velocity models appropriate for Ruapehu and Tongariro. We think the Love-Rayleigh discrepancy is due to structures such as dykes or cracks in the vertical plane having greater influence than horizontal layering on surface-wave propagation. However, several measurements where Love-wave group velocities are faster than Rayleigh-wave group velocities suggests that in some places horizontal layering is the stronger influence.

We also observe that the differences between the Love- and Rayleigh-wave dispersion curves vary with the azimuth of the interstation path across Ruapehu and Tongariro Volcanoes. Some significant differences between Rayleigh-wave velocities of measurements with different interstation orientations are also observed, as are differences between Love-wave velocities. This suggests a component of azimuthal anisotropy within the volcanic structures, which coupled with the radial anistropy makes the shear-wave velocity structures of Ruapehu and Tongariro Volcanoes anisotropic with orthorhombic symmetry. We suggest that further work to determine three-dimensional structure should include provisions for anisotropy with orthorhombic or lower symmetry. 


\section{Acknowledgments}

There are several people without whom I would never have been able to present this thesis, from my supervisors, Martha Savage and Bill Fry to my fellow students and the people in the background providing essential support.

The biggest shout-out must be to my supervisors. As much as this is my Master's degree, the time and effort they put into this work means that using the pronoun "I" rather than "we" in this thesis is completely inappropriate. Martha has always been there to explain and discuss things; one could not ask for a better supervisor. I also cannot thank Bill enough for taking time out of his busy schedule to work on this project. Words cannot properly describe just how amazing it is to work under two of the most brilliant minds in the field.

My venture into Geophysics started at the end of 2012, when working on a summer project with Martha and Adrian Shelley, then a PhD student. Aside from the cool research, their enthusiasm rubbed off on me. I fell in love with seismology and together we published my first paper. I will be forever grateful to them for that experience, which changed my life for the better.

Thanks to my parents, who have continuously supported me in my study, and to Zippy, for knowing exactly when I needed cheering up. Also thanks to my sister Hazel for proofreading

Thanks also to everyone at the Institute of Geophysics. It has been an absolute privilege and pleasure to work with such amazing people. I especially appreciate the discussions with Prof. Euan Smith, Adrian Shelley, Katrina Jacobs and Rachel Heckels, who have also helped me a lot in this project. To my office-mates, past and present: Mary Redmayne, Alyssa Thomas, Pablo Iribarren, Tapuwa Marapara, Francesco Civilini, Rachel, Claire Castellazzi, Lucie Capova, Pegah Faegh-Lashgary, Konrad Weaver, Tom Wilson and Gabe Matson, thank-you for putting up with my craziness. Further thanks to Konrad and Gabe for help with LaTeX.

I am massively indebted to Aleksandr Beliaev and Adrian Benson at VUW, who not 
only fix the damage I do when trying to install new software, but always graciously respond to the stupidest questions I ask. I thank David Baylis and Franck Ganachaud at GNS for setting me up on their servers and rapidly responding to my e-mails. Mark Chadwick at GeoNet helped me enormously with properly obtaining the raw seismic data from their permanent network.

I cannot overstate my appreciation for the SGEES admin staff. Kate King and Monika Hanson are true superwomen. How they managed the sudden evacuation of the entire 5th floor due to asbestos (and subsequent relocation/renovation), while still running the rest of the school is beyond impressive. I could always count on them and their ability to manage breakdowns at 20KP (honestly, I would have thought that 19th century house builders would have catered for 18 Geophysicists' computers running constantly for an entire year). Thanks again to Aleksandr for keeping my computer running in such an electronically hostile environment. Thanks also to Cheryl Johanson, Kosta Tashkoff and HOD Rewi Newnham for their efforts, and to Miranda Voke and Patricia Stein for their support since the move back to the refurbished 5th floor.

This project would not have been possible without the generous funding from EQC and the Frank Evison Research Scholarship in Geophysics. I must also thank the benefactors of the Irene Pestov Memorial Scholarship, who enabled me to extend my timeframe and complete this thesis to the standard I think it deserves. Maps used in this manuscript were created using Generic Mapping Tools (GMT; Wessel and Smith, 1998), with alterations using Inkscape open source software (https://inkscape.org/en/, last accessed October 2015). Additional figures constructed using SAC, MATLAB and Inkscape.

Finally, I offer this piece of advice to future students: if you have worked so long into the night that the lazybones cat on your lap has had enough sleep, it's probably time you got some. 


\section{Contents}

Abstract $\quad$ i

Acknowledgments

List of Figures $\quad$ ix

List of Tables $\quad$ xiii

List of Equations $\quad$ xv

List of Notations $\quad$ xvi

1 Research motivation and objectives 1

2 Setting 5

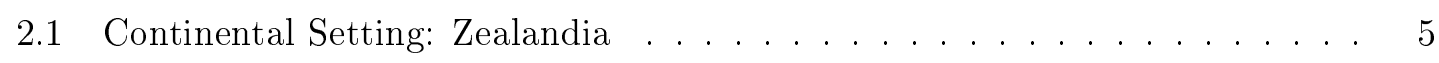

2.2 Regional Setting: The Taupo Volcanic Zone . . . . . . . . . . . . . . . 6

2.3 Study area: The Tongariro Volcanic Centre . . . . . . . . . . . . . 8

$2.3 .1 \quad$ Faults and Seismicity . . . . . . . . . . . . . . 10

2.3.2 Ruapehu Volcano . . . . . . . . . . . . . . . . . 11

2.3.3 Ngauruhoe/Tongariro Volcano . . . . . . . . . . . . . . . . . 13

2.3.4 Other volcanic features of the $\mathrm{TgVC} \ldots \ldots \ldots \ldots$

2.4 Previous geophysical research in the study area . . . . . . . . . . . 16 
2.4 .1 Seismic velocity modelling . . . . . . . . . . . . . . 16

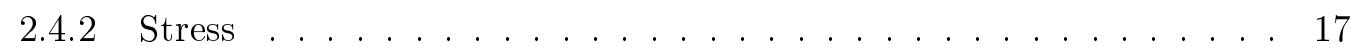

2.4 .3 Seismic Anisotropy . . . . . . . . . . . . . . . . . . . . . 19

2.4 .4 Seismic Attenuation . . . . . . . . . . . . . . 20

2.4.5 Non-seismic methods . . . . . . . . . . . . . . . . . . . . 21

3 Theoretical background $\quad 23$

3.1 Surface-wave propagation . . . . . . . . . . . . . 23

3.2 Ambient noise . . . . . . . . . . . . . . . . 25

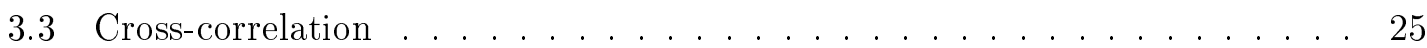

3.3.1 Applications of ambient noise cross-correlation . . . . . . . . . 28

4 Methodology $\quad 31$

4.1 Data . . . . . . . . . . . . . . . . . . . 31

$4.1 .1 \quad$ Noise sources . . . . . . . . . . . . . . . . . . . 34

4.2 Pre-processing. . . . . . . . . . . . . . . . . . 34

4.2 .1 Instrument response . . . . . . . . . . . . . . . . . . 35

4.2 .2 Correlation window preparation . . . . . . . . . . . . 37

4.2 .3 Signal normalisation . . . . . . . . . . . . . . . . . 38

4.3 Cross-correlations . . . . . . . . . . . . . . . . . . . . . 42

4.4 Group velocity dispersion measurements . . . . . . . . . . . . . . . . . 42

4.4 .1 Mode Identification . . . . . . . . . . . . . . . . . . . . . . 49

4.4 Error analysis . . . . . . . . . . . . . . . . . 50

4.4 .3 Average dispersion curves . . . . . . . . . . . . . . 5 50

4.5 Signal-to-noise ratios . . . . . . . . . . . . . . . . 50

4.6 Particle motion . . . . . . . . . . . . . . . . . . . 52 
4.7 Synthetics . . . . . . . . . . . . . . . . . . . . 52

4.7 .1 Input velocity model $1:$ JR $\ldots \ldots \ldots \ldots 3$

4.7 .2 Input velocity model $2:$ FR . . . . . . . . . . . . . 54

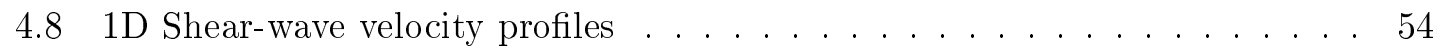

4.8.1 Uncertainty estimates . . . . . . . . . . . . . . . . . 57

5 Results $\quad 59$

5.1 Cross-correlations . . . . . . . . . . . . . . . . . . . . . 59

5.1 .1 Signal-to-noise ratios . . . . . . . . . . . . . . . 64

5.2 Surface-wave dispersion $\ldots \ldots \ldots \ldots \ldots$. . . . . . . . . . . . 67

5.2 .1 Dispersion measurements . . . . . . . . . . . . . . 67

5.2 .2 Mode identification . . . . . . . . . . . . . . . . . 71

5.2 .3 Station pair maps . . . . . . . . . . . . . . . . 75

5.3 Synthetic cross-correlations and dispersion . . . . . . . . . . . . . . . . 81

5.3 .1 Calculated dispersion . . . . . . . . . . . . . . . . . 81

5.3 .2 Cross-correlations . . . . . . . . . . . . . . . . . . 82

5.3.3 Measured vs. calculated Rayleigh-wave dispersion . . . . . . . . . 83

5.4 Primary station pairs . . . . . . . . . . . . . . . . . 88

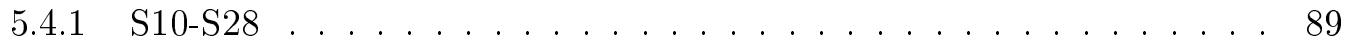

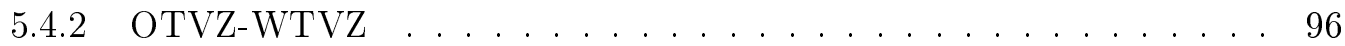

5.5 Average dispersion curves and $V_{s}$ inversions . . . . . . . . . . . . . . . 103

5.5 .1 Ruapehu Volcano . . . . . . . . . . . . . . . . . . . . 103

5.5 .2 Tongariro Volcano . . . . . . . . . . . . . . . . . . . 108

6 Discussion $\quad 115$

6.1 Data quality and accuracy . . . . . . . . . . . . . . . 115 
6.1.1 Cross-correlations . . . . . . . . . . . . . . . . . . 115

6.1.2 Dispersion measurements . . . . . . . . . . . . . . . 119

$6.1 .3 \mathrm{~V}_{S}$ inversions $\ldots \ldots \ldots \ldots \ldots$

6.2 Isotropic velocity structure of the $\mathrm{TgVC} \ldots \ldots \ldots$. . . . . . . . . . . 124

6.2.1 Surface-wave group velocities . . . . . . . . . . . . . . . . 124

6.2 .2 Shear-wave velocities . . . . . . . . . . . . . . . 126

6.3 Anisotropic velocity structure of the $\mathrm{TgVC} \ldots \ldots \ldots . \ldots . \ldots . \ldots 130$

6.3.1 All A-grade measurements . . . . . . . . . . . . . . . . . . . 130

6.3.2 Ruapehu and Tongariro Volcanoes . . . . . . . . . . . . . . 136

6.3 .3 Orthorhombic anisotropy . . . . . . . . . . . . . 139

6.4 Final models and interpretations . . . . . . . . . . . . . . . . . . 140

7 Summary and conclusions $\quad 143$

7.1 Fulfilment of project aims . . . . . . . . . . . . . . . . . . . 143

7.2 Fulfilment of research questions . . . . . . . . . . . . . . . . . . . . 145

7.3 New questions . . . . . . . . . . . . . . . . . . . . . . . . . 147

7.4 Reflections and recommendations . . . . . . . . . . . . . . . . . . 147

Bibliography

149

Appendix A: Station metadata

166

Appendix B: Instrument response functions for SADAR stations 


\section{List of Figures}

1.1 Map of the Tongariro Volcanic Centre $(\mathrm{TgVC}) \ldots \ldots \ldots$. . . . . . . . . 4

2.1 Topographic/bathymetric map of Zealandia . . . . . . . . . . . . 6

2.2 Taupo Volcanic Zone geological map . . . . . . . . . . . . . . . . . 7

$2.3 \mathrm{TgVC}$ geological map $\ldots \ldots \ldots \ldots \ldots$

2.4 TgVC map of GeoNet reported seismicity 2001-2011 _ . . . . . . . . . . 10

2.5 Existing 1D velocity models for the $\mathrm{TgVC} \ldots \ldots \ldots \ldots$

3.1 Schematic of phase vs. group velocities . . . . . . . . . . . . . . . . 24

3.2 Schematic of noise field and bias introduced by non-equipartitioning. . . . . 27

4.1 TgVC simplified geological map with seismographs used in this study . . . . 33

4.2 Instrument response functions for different seismometers . . . . . . . . . . 36

4.3 Progressive effects of pre-processing stages on time series and frequency spectra: Noise . . . . . . . . . . . . . . . . . . . . 40 40

4.4 Progressive effects of pre-processing stages on time series and frequency spectra: Regional earthquake . . . . . . . . . . . . . . . . . 44

4.5 Example daily and full-stack CCFs . . . . . . . . . . . . . . . . . 43

4.6 Workflow of individual dispersion measurements . . . . . . . . . . . . . . 44

4.7 Effect of smoothing parameter on multi-filter plots and dispersion measure-

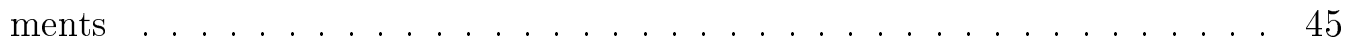

4.8 Examples of dispersion measurements with altered MFT time windows . . . 48 
4.9 Workflow of SNR measurements . . . . . . . . . . . . . . . . . 51

5.1 Record sections for 2001 full-stacks . . . . . . . . . . . . . . . . 60

5.2 Record sections for 2008 full-stacks . . . . . . . . . . . . . . . . . 61

5.3 Map of signal-to-noise ratios of averaged cross-components . . . . . . . . . . 62

5.4 Map of signal-to-noise ratios of averaged cross-components . . . . . . . . . . 63

5.5 Examples of CCF and dispersion analyses with special features . . . . . . 70

5.7 Example station-grouping plots . . . . . . . . . . . . . . 73

5.8 Dispersion measurements with assigned modes . . . . . . . . . . . . . . 74

$5.90 .5 \mathrm{~Hz}$ map of $\mathrm{R} 0 \mathrm{RR}+\mathrm{ZZ}$ and $\mathrm{L} 0 \mathrm{TT}$ group velocities $\ldots \ldots \ldots \ldots$

$5.101 \mathrm{~Hz}$ map of R0 RR+ZZ and L0 TT group velocities . . . . . . . . . . 77

$5.110 .5 \mathrm{~Hz}$ map of $\mathrm{R} 1 \mathrm{RR}+\mathrm{ZZ}$ and $\mathrm{L} 1 \mathrm{TT}$ group velocities $\ldots \ldots \ldots . . \ldots 78$

$5.121 \mathrm{~Hz}$ map of R1 RR+ZZ and L1 TT group velocities . . . . . . . . . . . 79

5.13 Calculated dispersion curves from synthetic models . . . . . . . . . . . . 82

5.14 Record sections for JR model CCF . . . . . . . . . . . . . . . . . . . . 84

5.15 Record sections for FR model CCF . . . . . . . . . . . . . . . . . . . 85

5.16 Synthetic CCF with spectrograms produced for model JR (simulated $20 \mathrm{~km}$ interstation distance $) \ldots \ldots \ldots \ldots$. . . . . . . . . . . 86

5.17 Synthetic CCF with spectrograms produced for model FR (simulated $20 \mathrm{~km}$ interstation distance $) \ldots \ldots \ldots$. . . . . . . . . . . . . 87

$5.18 \mathrm{~S} 10$ and $\mathrm{S} 28$ record sections and $\mathrm{S} 10-\mathrm{S} 28 \mathrm{CCF} \ldots \ldots \ldots \ldots$

5.19 S10-S28 MFT of RR, ZZ and TT CCF . . . . . . . . . . . . . . 91

5.20 S10-S28 particle motion . . . . . . . . . . . . . . . . . . 93

$5.21 \mathrm{~S} 10-\mathrm{S} 28 \mathrm{~V}_{S}$ inversions $\ldots \ldots \ldots \ldots \ldots \ldots \ldots \ldots$

5.22 OTVZ and WTVZ record sections and OTVZ-WTVZ CCF . . . . . . 98

5.23 OTVZ-WTVZ MFT of RR, ZZ and TT CCF . . . . . . . . . . . . 99 
5.24 OTVZ-WTVZ particle motion . . . . . . . . . . . . . . . . . . 100

5.25 OTVZ-WTVZ $v_{S}$ inversions . . . . . . . . . . . . . . . . 102

5.26 Average Ruapehu dispersion curves with individual measurements and paths 104

$5.27 \mathrm{R} 0 / \mathrm{L} 0 \mathrm{~V}_{S}$ inversions of average Ruapehu dispersion curves . . . . . . . . 105

5.28 Oriented average Ruapehu dispersion curves with individual measurements and paths . . . . . . . . . . . . . . . . . . 107

5.29 R0L0 $\mathrm{V}_{S}$ inversions of oriented average Ruapehu dispersion curves $\ldots . .108$

5.30 Average Tongariro dispersion curves with individual measurements and paths 110

$5.31 \mathrm{R} 0 / \mathrm{L} 0 \mathrm{~V}_{S}$ inversions of average Tongariro dispersion curves $\ldots \ldots . . . .111$

5.32 Oriented average Tongariro dispersion curves with individual measurements

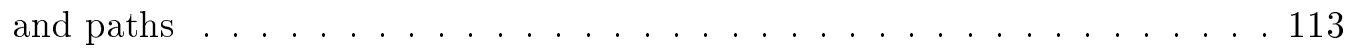

$5.33 \mathrm{R} 0 \mathrm{~L} 0 \mathrm{~V}_{S}$ inversions of oriented average Tongariro dispersion curves . . . . . 114

6.1 Timing errors in daily cross-correlations . . . . . . . . . . . . 117

6.2 Comparison of synthetic RZ and ZR CCF . . . . . . . . . . 118

6.3 Differences between FR and JR dispersion curves . . . . . . . . . . . . . . . 121

6.4 Dinver $\mathrm{V}_{S}$ inversions for fundamental mode synthetic dispersion curves of the JR model . . . . . . . . . . . . . . . . . . . . . . 122

6.5 Dinver $\mathrm{V}_{S}$ inversions for fundamental mode synthetic dispersion curves of the FR model . . . . . . . . . . . . . . . . . . . . . . 123

6.6 Comparison of existing $\mathrm{V}_{S}$ profiles to our inversions and simplified models . 127

6.7 Differences between Love- and Rayleigh-wave dispersion measurements . . . 131

6.8 Differences between synthetic Love- and Rayleigh-wave dispersion curves . . 133

6.9 Map of $\Delta$ L0R0 measurements at 0.5 and $1 \mathrm{~Hz} \ldots \ldots \ldots \ldots$

6.10 Map of $\Delta \mathrm{L} 1 \mathrm{R} 1$ at measurements at 0.5 and $1 \mathrm{~Hz} \ldots \ldots \ldots \ldots$

6.11 $\Delta \mathrm{L} 0 \mathrm{R} 0$ for Ruapehu and Tongariro dispersion measurements and averages . 137

6.12 Schematic of subsurface structure with orthorhomic anisotropy . . . . . . 140 
6.13 Final models of the seismic velocity structure of Ruapehu and Tongariro

Volcanoes . . . . . . . . . . . . . . . . . . . . . . . . . . . 141 


\section{List of Tables}

4.1 Initial alphanumeric dispersion measurement grading scheme $\ldots \ldots$. . . . 47

4.2 Final simplified dispersion measurement grading scheme . . . . . . . . . . . 47

4.3 JR input model for synthetics . . . . . . . . . . . . . . . . 54

$4.4 \quad$ FR input model for synthetics . . . . . . . . . . . . . . . . . . 54

4.5 Starting parameter range for four-layer $\mathrm{V}_{S}$ inversions $\ldots \ldots \ldots \ldots$

5.1 Total number of full-stacks in cross-correlation catalogue, by component . . 64

5.2 Statistics of full-stacks' signal-to-noise ratios, by component . . . . . . . . 65

5.3 Comparison of SNR between sensor types and models . . . . . . . . . 66

5.4 Parameter range used for multiple-filter analysis . . . . . . . . . . . . 67

5.5 Full-stack dispersion measurement confidence . . . . . . . . . . . . . 68

5.6 Numerical breakdown of graded characteristics assigned to dispersion mea-

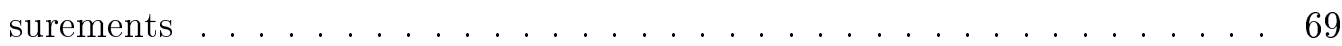

5.7 Breakdown of final dispersion classifications $\ldots \ldots \ldots \ldots$

5.8 Breakdown of full-stacks' assigned modes . . . . . . . . . . . . . . . . 71

$5.9 \mathrm{~S} 10-\mathrm{S} 28 \mathrm{~V}_{S}$ inversions $\ldots \ldots \ldots \ldots \ldots \ldots \ldots$

5.10 OTVZ-WTVZ $\mathrm{V}_{S}$ inversions $\ldots \ldots \ldots \ldots \ldots 10 \ldots \ldots$

6.1 Average dispersion measurement $\%$ uncertainty for four station pairs . . . . 119

6.2 Average $\%$ uncertainties for average dispersion curves . . . . . . . . . . 120

6.3 Modal velocity ranges and statistics of A-grade dispersion measurements. . 125 
6.4 Simplified $V_{S}$ model of Ruapehu with geological interpretation . . . . . . 128

6.5 Simplified $V_{S}$ model of Tongariro with geological interpretation . . . . . . . 129 


\section{List of Equations}

\begin{tabular}{|c|c|}
\hline 3.1 & Group velocity \\
\hline 3.2 & Phase velocity \\
\hline 4.1 & Gaussian filter \\
\hline 42 & Filter passband \\
\hline & Gardner's equation \\
\hline & Dinver misfit function \\
\hline
\end{tabular}




\title{
List of Notations
}

\author{
TgVC Tongariro Volcanic Centre \\ TVZ Taupo Volcanic Zone \\ CVR Central Volcanic Region \\ $M S L \quad$ Mean Sea Level \\ START 2001 Seismic Tomography Around Ruapehu and Tongariro deployment \\ CNIPSE 2001 Central North Island Passive Seismic Experiment deployment \\ SADAR 2008 Spatial Anisotropy Deployment at Ruapehu \\ NGA 2008 Ngauruhoe deployment \\ PdF Piton de la Fournaise Volcano, La Reunion \\ $V_{P} \quad$ Primary/compressional wave velocity \\ $V_{S} \quad$ Shear-wave velocity \\ $S_{H} \quad$ Horizontally polarised shear-waves \\ $S_{V} \quad$ Vertically polarised shear-waves \\ $V_{S H} \quad S_{H}$ velocity \\ $V_{S V} \quad S_{V}$ velocity \\ SWS Shear-wave splitting \\ $C C F \quad$ Cross-correlation function \\ $R R \quad$ Radial-radial CCF component \\ TT Transverse-transverse component \\ $Z Z \quad$ Vertical-vertical component \\ $R Z \quad$ Radial-vertical component \\ $Z R \quad$ Vertical-radial component \\ $R T \quad$ Radial-transverse component \\ $T R \quad$ Transverse-radial component \\ $T Z \quad$ Transverse-vertical component \\ ZT Vertical-transverse component
}


$M_{W} \quad$ Moment magnitude

SNR Signal-to-noise ratio

$J R \quad$ Synthetic 1D velocity profile representing Tongariro Volcano

FR Synthetic 1D velocity profile representing Ruapehu Volcano

$R A \quad$ An approximation of the sum of all Rayleigh modes' synthetic CCF

R0 Fundamental mode Rayleigh waves

$R 1 \quad$ First higher-order mode Rayleigh waves

L0 Fundamental mode Love waves

L1 First higher-order mode Love waves

R0L0 Joint M0 Rayleigh and Love-wave dispersion curve inversion

$\Delta L R \quad$ Difference between Love-wave and Rayleigh-wave dispersion measurement

$\triangle L 0 R 0 \quad$ Difference between $\mathrm{L} 0$ and $\mathrm{R} 0$ dispersion curves

$\Delta L 1 R 1 \quad$ Difference between $\mathrm{L} 1$ and $\mathrm{R} 1$ dispersion curves

$S P \quad$ Short-period sensor

$B B \quad$ Broadband sensor 


\section{Chapter 1}

\section{Research motivation and objectives}

Knowledge of subsurface structure beneath volcanoes is paramount to understanding the processes causing hazardous activity. Seismic studies employ some of the few techniques available that create direct three-dimensional images of subsurface structure, as the seismic velocities depend upon the physical and chemical compositions of subsurface materials.

Comparing S- and $\mathrm{P}$-wave speeds $\left(\mathrm{V}_{S}\right.$ and $\left.\mathrm{V}_{P}\right)$ allows for better determination of Earth properties. For example, materials with large liquid contents have high $V_{P} / V_{S}$ ratios whereas gas filled media have low $V_{P} / V_{S}$ (Nur, 1972). It has also been shown that small perturbations in seismic velocity beneath volcanoes may precede eruptions (Brenguier et al., 2008). This means that velocity modelling could potentially be used for forecasting activity that may otherwise be undetected. A velocity model is required to locate earthquakes; having P- and S-wave models enables both phases to be used for constraining hypocentres, especially depths.

Seismic tomography using earthquake phase arrivals can be used to construct subsurface P- and S-wave models (e.g. Rowlands et al., 2005). These models' resolution, however, is limited by the spatial and temporal distribution of earthquakes as well as uncertain ray paths, making the method unsuitable for observing small variations in seismic velocities through time. A newer technique of ambient noise cross-correlation has not only produced high resolution, 3D velocity models but also enables detection of tiny perturbations in seismic velocities, even those less than one percent, over time periods on the order of a few weeks (Brenguier et al., 2008). 
The Tongariro Volcanic Centre ( $\mathrm{TgVC}$ ) forms the southernmost part of the Taupo Volcanic Zone (TVZ), the onshore component of the back-arc extension associated with the Pacific Plate's ongoing subduction beneath the Australian Plate (Wilson et al., 1995). The TgVC includes the large, active andesitic volcanoes Ruapehu and Tongariro, which pose continuous threats to the substantial human activity in the area (Fig. 1.1). Hazards include hydrothermal and magmatic eruptions, ashfall, lahars, debris avalanches and fumarole gas, which can have secondary effects such as poisoning of flora and fauna, infrastructure damage and disruption to flights.

Due to the active volcanism in the region, the $\mathrm{TgVC}$ has been the focus of many studies using a myriad of petrological, stratigraphic and geochemical methods (see Donoghue and Neall, 1996; Graham et al., 1995 for reviews). Geophysical investigations are also numerous (section 2.4). However, volcanic activity is still largely unpredictable and the physical subsurface structure is difficult to determine.

Velocity modelling has been successfully applied in the TgVC using a variety of techniques (section 2.4); however most represent the larger scale TVZ. Presently, the only 3D modelling focusing solely on the $\mathrm{TgVC}$ is by Rowlands et al. (2005), who used earthquake phase arrival tomography to model the $3 \mathrm{D} \mathrm{V}_{P}$ structure down to $20 \mathrm{~km}$ along with a low resolution, 2D $\mathrm{V}_{P} / \mathrm{V}_{S}$ map. As $\mathrm{S}$-wave velocities are more sensitive to changing fluid composition and partial melt content in media than $\mathrm{V}_{P}$ (e.g. Nur, 1972), changes in the volcanic system are more likely to be observed from $\mathrm{V}_{S}$ than $\mathrm{V}_{P}$. Here, we apply the technique of ambient noise cross-correlation to model the shallow $\mathrm{V}_{S}$ structure of Ruapehu and Tongariro volcanoes.

Our primary aims for this project are to:

- Create a database of daily, reference cross-correlations functions (CCF) for all possible seismograph station pairs and components, operating in 2001 (Jan-June) and 2008.

- Measure group velocity dispersion of Rayleigh- and Love waves in the TgVC.

- Construct and interpret 1D S-wave velocity models of Ruapehu and Tongariro. 
In doing so, we intend to answer the following questions:

- What is the TgVC's S-wave velocity structure?

- How does our model compare to existing models and present geophysical understanding of the TgVC, in particular the magnetotelluric surveys at Mount Ruapehu?

- On what scale can we observe temporal variation of surface- and shear-wave velocities in the $\mathrm{TgVC}$ ?

This thesis is structured into seven chapters. The following two introduce the study area and the theory related to this research. Next, we describe our methods and discuss why we selected each process over alternative approaches. The final three chapters present our results, discussion and conclusions for this project. Additional material is located in the appendices and the full database of cross-correlations and dispersion measurements may be requested from the VUW Institute of Geophysics. 
The Tongariro Volcanic Centre

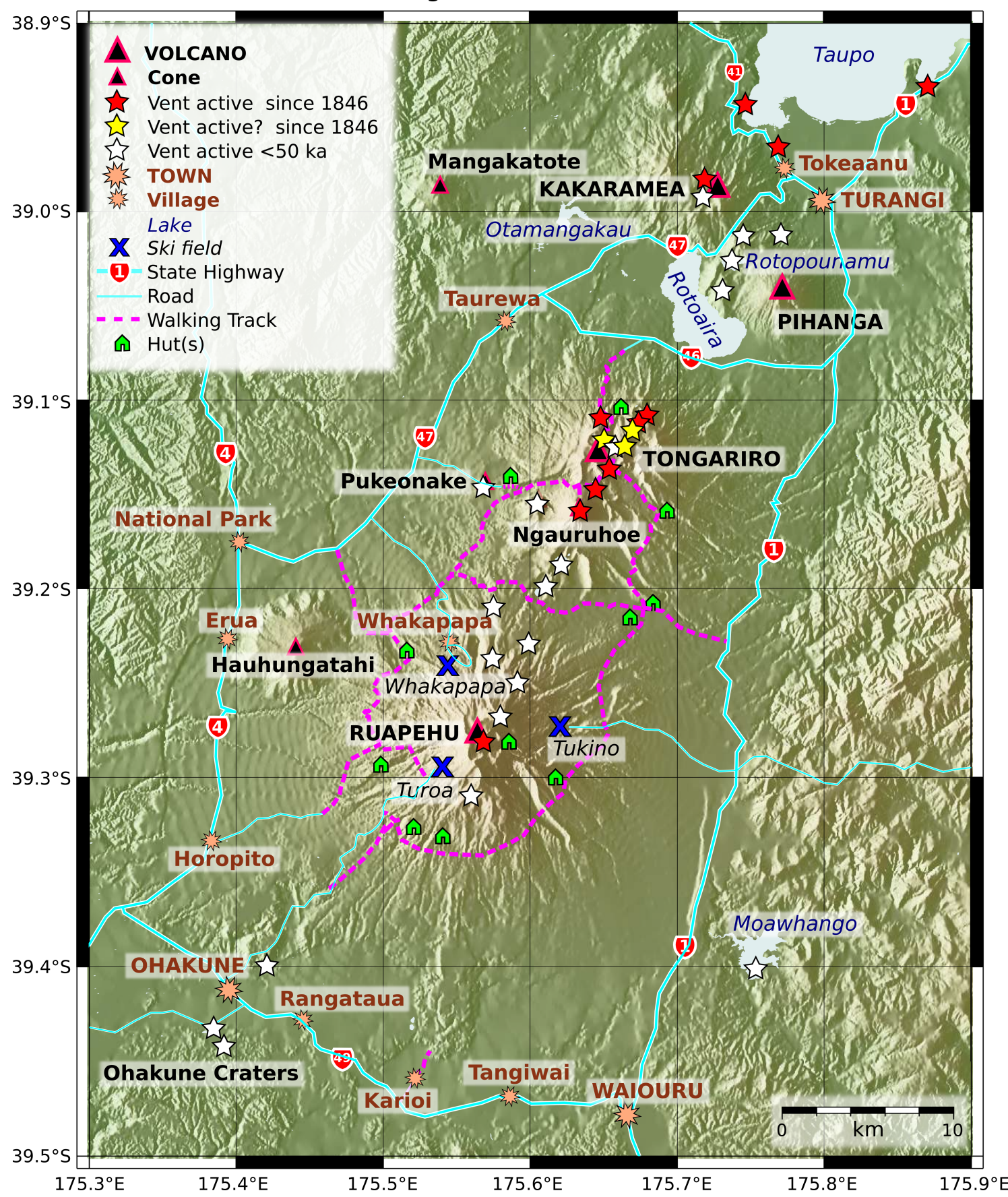

Figure 1.1: Map of the Tongariro Volcanic Centre showing the spatial relationships between volcanism and human occupation. Vent location and activity (including hot springs) compiled from Cole (1990) and Scott and Potter (2014). 


\section{Chapter 2}

\section{Setting}

This chapter presents an introduction to the study area; the Tongariro Volcanic Centre ( TgVC). First, we briefly describe its continental and regional settings. We then summarise the geological characteristics and present understanding of the TgVC's tectonics and volcanism, and historic activity. Finally, we outline previous research in the area relevant to this project.

\subsection{Continental Setting: Zealandia}

New Zealand is located on the largely submerged continent of Zealandia (Campbell and Mortimer, 2014), at the boundary of the colliding Pacific and Australian tectonic plates on the Pacific Ring of Fire (Fig. 2.1). It is a complex boundary, due to continental and oceanic crust on both plates. South of the South Island, at the Puysegur subduction zone, the Australian plate obliquely subducts beneath the Pacific plate, whereas east of the North Island, the Pacific plate subducts at the Hikurangi margin (the southern continuation of the Kermadec Trench). Annual subduction rates with respect to the overlying plate are $34 \mathrm{~mm} / \mathrm{yr}$ NE (Puysegur margin) and $45 \mathrm{~mm} / \mathrm{yr}$ WSW (Hikurangi margin, Stern et al., 2010). The Alpine Fault, running through the South Island, accommodates the transpressive motion in the region between the two subduction interfaces. 


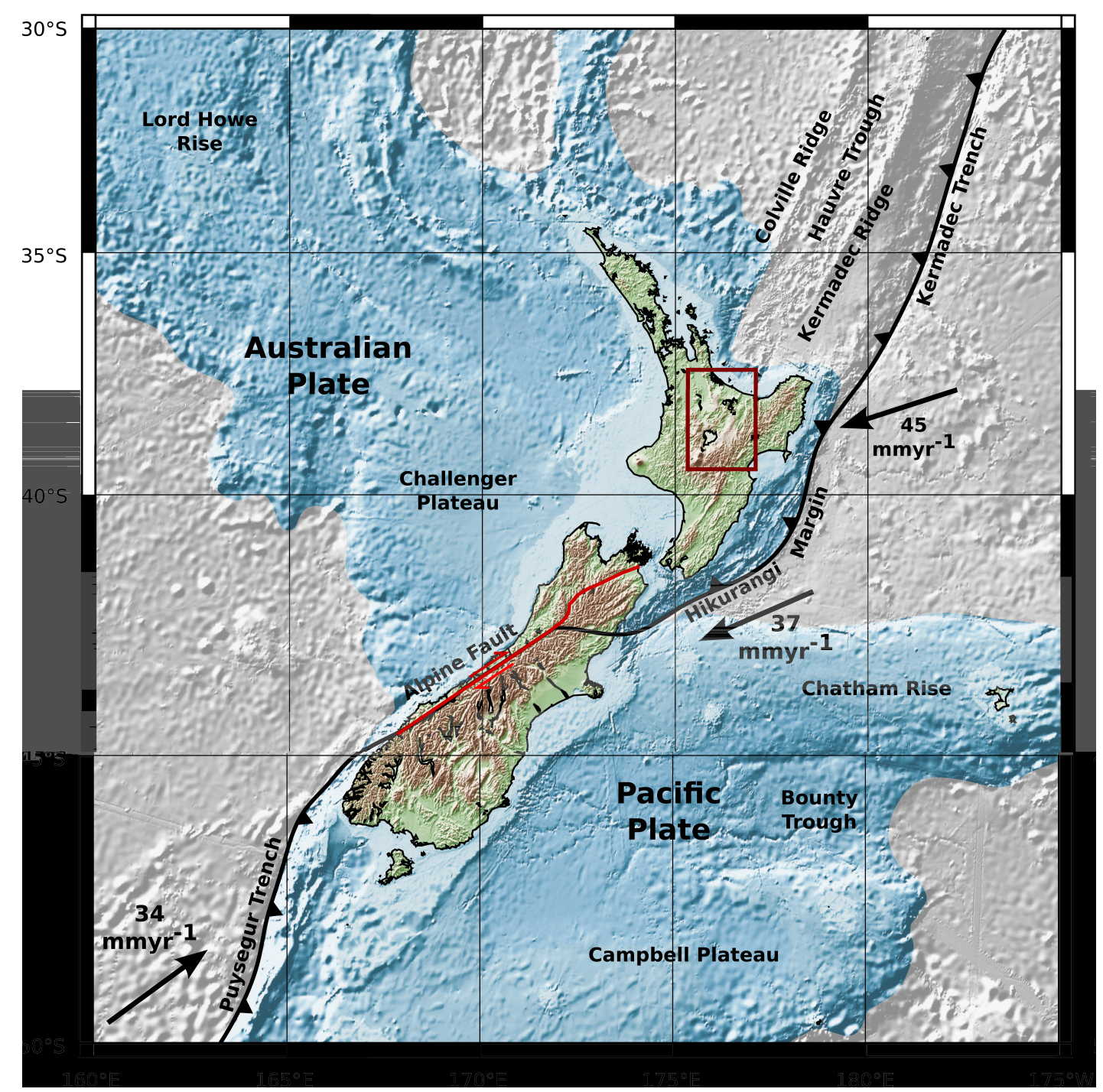

Figure 2.1: Map of the Zealandia's collisional tectonic setting. Coloured and greyscale areas are continental and oceanic crust, respectively. Arrows are plate motions relative to each other, with annual subduction rates given by Stern et al. (2010); black line is plate boundary; triangles represent subduction direction. Red line is the Alpine Fault. Box in the North Island is magnified in next figure.

\subsection{Regional Setting: The Taupo Volcanic Zone}

Due to the Pacific plate's oblique subduction, continental back-arc extension occurs in the central North Island (Cole and Spinks, 2009; Fig. 2.2). This region, known as the Taupo Volcanic Zone (TVZ), is structurally defined by a system of predominately NE striking normal faults and active volcanism in the last 2 million years (Cole and Spinks, 2009), and exceptionally high heat flow (on the order of $700 \mathrm{mWm}^{-2}$, Price et al., 2012). The TVZ also extends approximately $100 \mathrm{~km}$ offshore, before merging with the southern 
Kermadec Ridge (Wilson et al., 1995). The axial rift's orientation is largely NE, with average extension ranging from $19 \mathrm{~mm} / \mathrm{yr}$ in the north to $8 \mathrm{~mm} / \mathrm{yr}$ in the south (Cole and Spinks, 2009; Price et al., 2012).

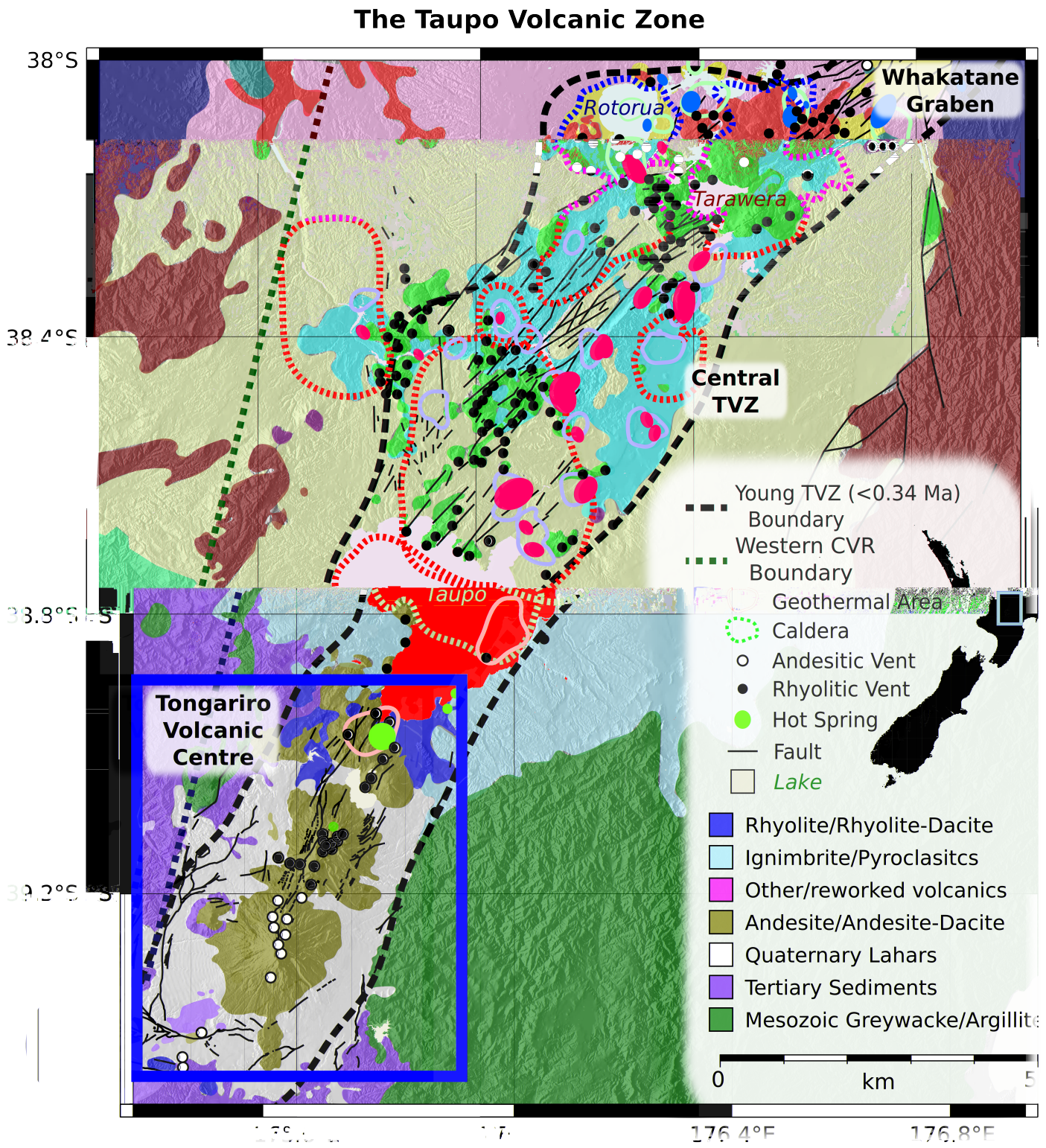

Figure 2.2: Geological map of the Taupo Volcanic Zone. Lithological and regional boundaries compiled from Cole (1990), Cole and Spinks (2009), Gamble et al. (2003), Rogan (1982), Rowland and Sibson (2001), Wilson and Rowland (2015), Villamor and Berryman (2006a) and Villamor and Berryman (2006b). Vent locations compiled from Cole (1990), Healy (1964) and Scott and Potter (2014). Faults from the New Zealand active faults database (data.gns.cri.nz/af/, last accessed June 2015) and Wilson and Rowland (2015). Red box is area magnified in next figure. 
Older volcanic deposits are present to the northwest of the TVZ's accepted boundary and have been described as belonging to the Central Volcanic Region (CVR, Fig. 2.2), which shares southern and eastern boundaries with the TVZ. This wedge shaped geographic area has been defined by geophysical anomalies (e.g. Stern et al., 2010), however debate surrounds the CVR's formation and its relationship to the TVZ (Cole and Spinks, 2009; Wilson et al., 1995).

The TVZ's structure is heterogeneous, with variation in volcanism and kinematics along strike. Volcanically, it can be broken up into three segments; the largest being the Central TVZ, the most active rhyolitic system on Earth. Andesitic volcanism dominates two smaller centres: the Whakatane Graben and the Tongariro Volcanic Centre (Cole and Spinks, 2009; Fig. 2.2). Kinematically, the TVZ is a distributed rift system. Rowland and Sibson (2001) define five discrete segments, each associated with a particular rift axis. These domains broadly correlate with the volcanically defined regions; the Okataina, Central and Taupo Domains form the Central TVZ; the Whakatane Graben and TgVC are individual zones.

\subsection{Study area: The Tongariro Volcanic Centre}

The Tongariro Volcanic Centre is the TVZ's southernmost point. The geographical region is oriented along the TVZ's NE/SW strike and spans from Ohakune to the southern edge of Lake Taupo (Fig. 2.3). The TgVC is characterised by many faults and interlayered geological formations (Fig. 2.3). The areas surrounding the volcanic edifices are accumulated ring plains dominated by Quaternary lahar deposits and Tertiary sediments.

Of all the TgVC's volcanic features, only Ruapehu and Tongariro/Ngauruhoe volcanoes have been historically active. Volcanism is largely andesitic, and thought to be a precursor to the establishment of large rhyolitic systems as the termination of the TVZ propagates southward (Price et al., 2012; Price et al., 2005). Some rhyolitic deposits are present in the TgVC from eruptions elsewhere in the TVZ.

Vents in the $\mathrm{TgVC}$ that have been active within the last 50 ka are strongly aligned NNE-SSW, with the Tongariro Graben and the inferred maximum horizontal principal stress (section 2.4). Many exposed dykes are also on this alignment, as magma intrudes into shallow, fault controlled reservoirs (Cole, 1990). 
The Tongariro Volcanic Centre

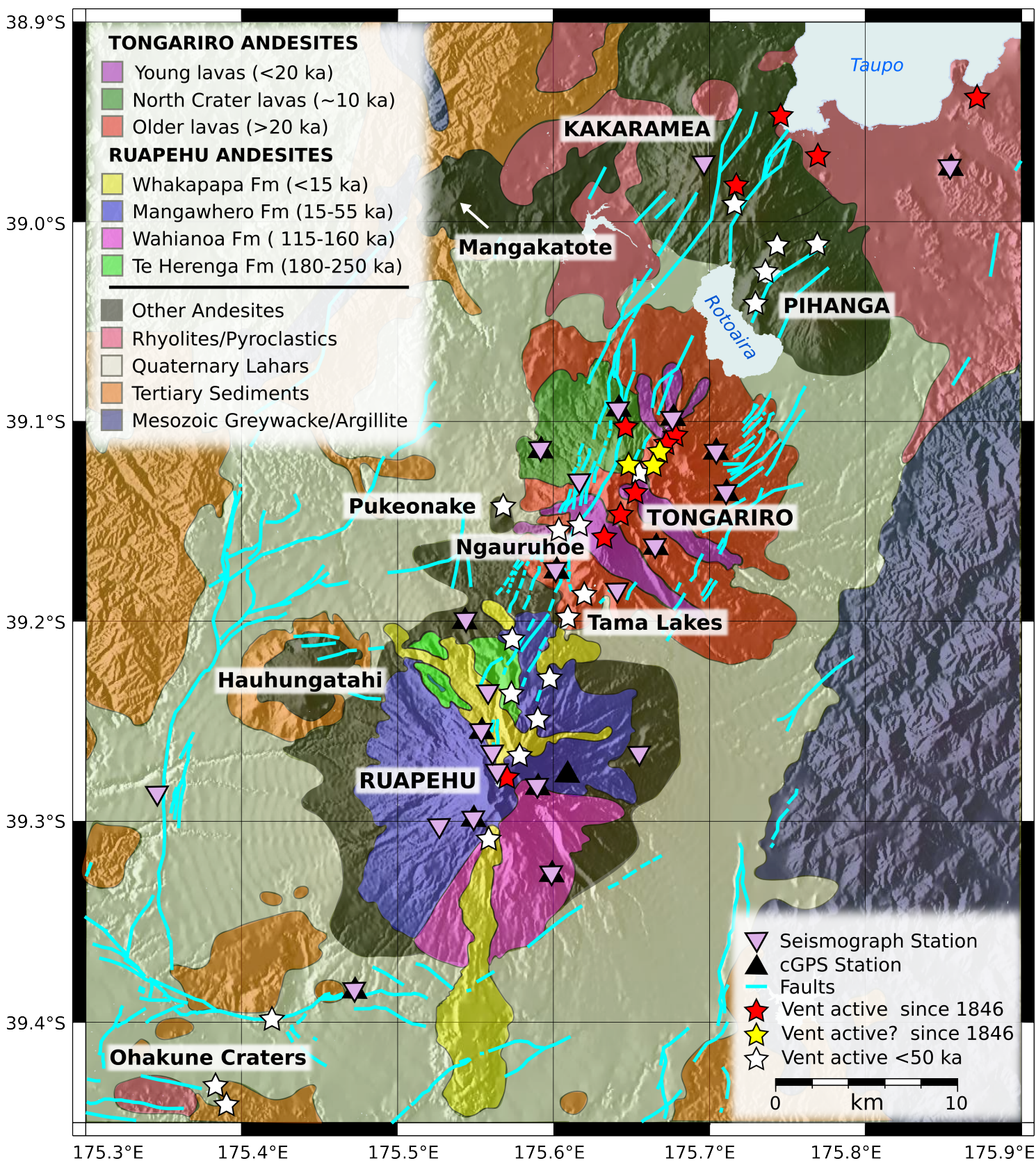

Figure 2.3: Geological map of the Tongariro Volcanic Centre with locations of operational seismographs and cGPS stations as of September 2015 (magma.geonet.org.nz/delta/app, last accessed September 2015). Lithological boundaries and ages compiled from Cole (1990), Gamble et al. (2003), Villamor and Berryman (2006a) and Villamor and Berryman (2006b). Vent location and activity (including hot springs) compiled from Cole (1990) and Scott and Potter (2014). Faults from the New Zealand active faults database (data.gns.cri.nz/af/, last accessed June 2015). 


\subsubsection{Faults and Seismicity}

Faults in the TgVC are normal, Tertiary-Quaternary in age (Villamor and Berryman, 2006b), and classified into four zones. Faults north of Ruapehu's Crater Lake trend approximately $030^{\circ}$ and delineate a $40 \mathrm{~km}$ wide graben, known as the Tongariro Graben (Fig. 2.3). West and SE of Crater Lake, the faults that define the rift zone are aligned approximately $010^{\circ}$ (Villamor and Berryman, 2006b), delineating the Ruapehu Graben.

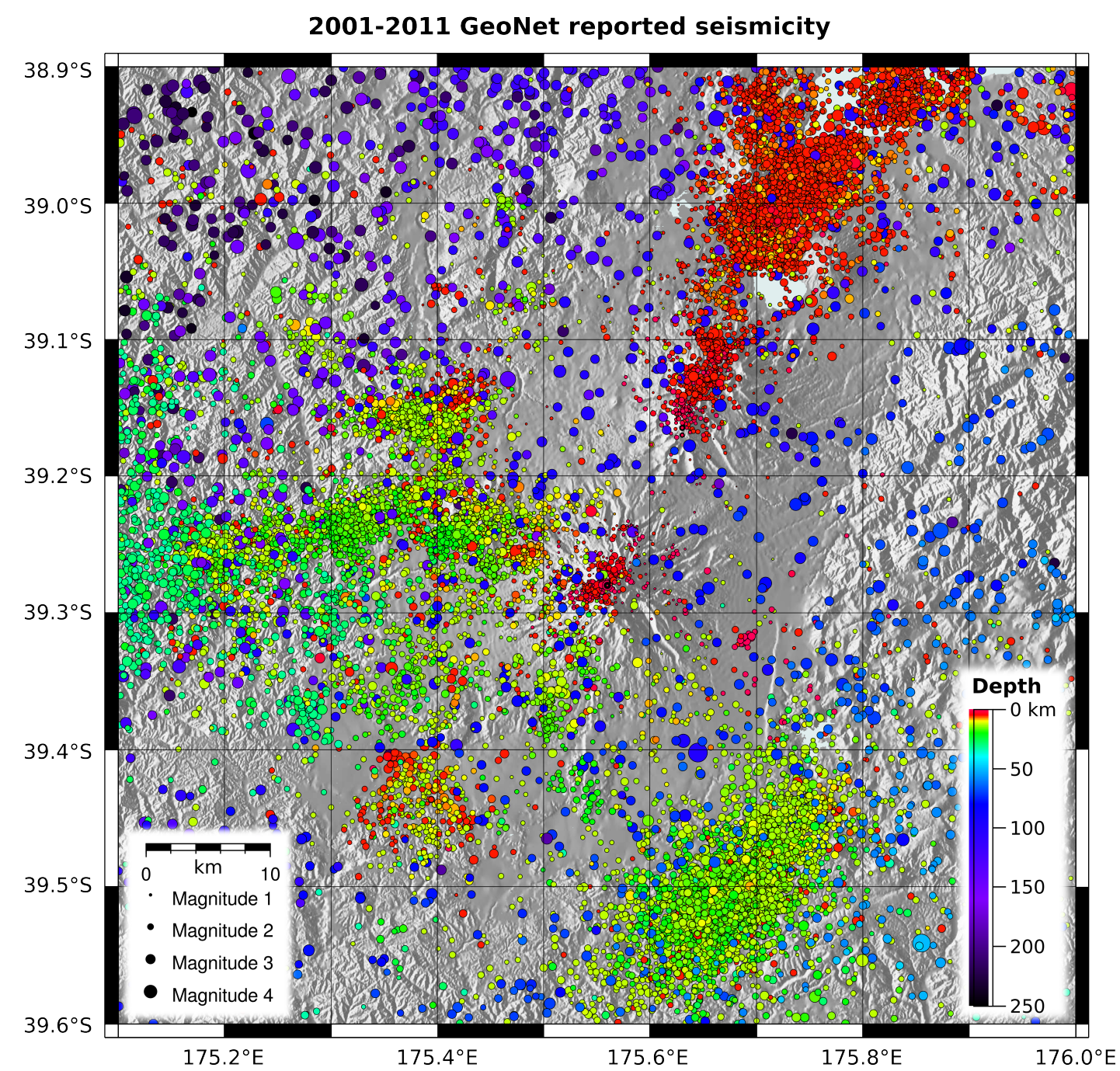

Figure 2.4: Map of the epicentres of reported seismicity in the Tongariro Volcanic Centre during the 2001-2011 period (quakesearch.geonet.org.nz/, last accessed June 2015). Circles are individual events, coloured by depth (N.B. non-linear colour scale) and sized by magnitude. 
South-west of Ruapehu, there are E-W oriented, reactivated tertiary faults (the OhakuneRaetihi fault-set); to the SSE, the Karioi fault-set are oriented approximately NE-SW (Villamor and Berryman, 2006b). Together, the Ruapehu Graben, the Ohakune-Raetihi and Karioi fault-sets give the impression of ring faulting around Mount Ruapehu (Fig. 2.3).

The TgVC is highly active seismically. GeoNet reported events from 2001 to 2011 in the study area (Fig. 2.4; quakesearch.geonet.org.nz, last accessed June 2015), broadly fall into three categories: shallow (hypocentre $<20 \mathrm{~km}$ ) volcanic/tectonic events (Fig. 2.4, red circles), deeper (20-50km) tectonic earthquakes/swarms (yellow/green) and deep (>100km) earthquakes along the subduction interface that deepen north-westward (dark blue/black).

\subsubsection{Ruapehu Volcano}

A sprawling massif, Mount Ruapehu (the volcano's topographic expression) has four peaks, of which Tahurangi (2797 m MSL) is the highest point in the North Island. Ruapehu is an eroded andesite-dacite stratovolcano (composite cone) with interbedded lava flows, pyroclastic deposits and dykes. One reason for its complicated stratigraphy and landforms is the interaction between glacial ice and volcanism during glacial and interglacial periods (Conway et al., 2015). As a result, many volcanic deposits have not been preserved in the geological record and all evidence of some eruptions has been erased.

Hackett and Houghton (1989) categorised four major chronostratigraphic units: Te Herenga (andesite composition), Wahianoa (andesite), Mangawhero (basalt-dacite), Whakapapa (andesite-dacite, Fig. 2.3). Older lava deposits have been identified (Tanaka et al., 1997), and andesitic tephra have been found $100 \mathrm{~km} \mathrm{SW}$ of Ruapehu, suggesting that the onset of volcanism may be as early as $340 \mathrm{ka}$ (Gamble et al., 2003). Approximately $30 \%$ of deposits currently mapped on Mount Ruapehu have glacial origins (Conway et al., 2015).

During its 300 ka history, Ruapehu's topography has periodically built up and collapsed, like many of the world's stratovolcanoes, such as Mount St. Helens (USA), Krakatoa (Indonesia) and Mount Vesuvius (Italy). For the last $50 \mathrm{ka}$, Ruapehu has exhibited frequent effusive activity; the last major collapse occurred approximately $10.5 \mathrm{ka}$, infilling the valley below what is now Whakapapa ski-field (Conway et al., 2015; Fig. 1.1). The magnitude of this collapse is unknown, as the size and shape of this valley is undetermined. Presently, the Mount Ruapehu's topographic volume is approximately $110 \mathrm{~km}^{3}$ (Gamble 
et al., 2003).

The volcanic plumbing system beneath Ruapehu is thought to have many dykes and magma storage bodies (Price et al., 2005). Lavas are mantle-derived arc magmas that likely interact with lower crustal media before moving through the plumbing and erupting on the surface (Price et al., 2005).

Seven vents of Ruapehu Volcano are thought to have been active within the past 50 ka (Cole, 1990; Fig. 2.3), but only the vent beneath Crater Lake is thought to have been active in the past $2 \mathrm{ka}$ (Gamble et al., 2003). Crater Lake is filled by meltwater between eruptions and heated by the volcano's magmatic source via an open vent system (Hurst et al., 1991). Heat flow into the lake is a cyclic process, with temperatures typically ranging $15-40^{\circ} \mathrm{C}$. This cycling is thought to be due to a layer of liquid sulfur at the bottom of Crater Lake, which becomes highly viscous at $150-160^{\circ} \mathrm{C}$, blocking gas escape into the lake. Eruptions can occur when the pressure becomes critical, sometimes without warning (Cronin, 2015). When the sulfur cools or is heated beyond the threshold of high viscosity, energy input into the lake is less impeded (Hurst et al., 1991). The magmatic source enriches the water in toxic chloride, making it highly acidic (e.g. Nairn and Scott, 1996). It is thought that Crater Lake has existed for over 3000 years (Donoghue et al., 2007). The addition of the lake water (with a volume greater than $6 \times 10^{6} \mathrm{~m}^{3}$ ) to phreatic and phreatomagmatic eruptions increases their explosiveness (Starostin et al., 2005).

Although not historically observed, pyroclastic flow deposits have been mapped on $\mathrm{Ru}-$ apehu (Crowly, 2015). Near Tukino Ski-field, on the mountain's eastern flanks, 12 separate pyroclastic flow events have been recorded, however, their poor preservation suggests that many more may have occurred but not been preserved.

Many different eruption styles have been recorded at Ruapehu. The 1995/1996 eruption sequence involved ash, phreatic and phreatomagmatic eruptions as well as sub-plinian and Strombolian type activity (Christenson, 2000). On average, large phreatomagmatic eruptive periods occur at Ruapehu approximately once every 50 years, while smaller scale hydrothermal or phreatic activity occurs approximately every 2.5 years (Scott, 2013).

Since written records began 180 years ago, there have been at least 600 days of observed volcanic activity at Ruapehu (Scott, 2013). These include 35 eruptive periods, with major 
ones in 1895, 1944-46, 1969, 1975 and 1995-96. There has also been 57 days of lahar/dam break activity (Scott, 2013), including a large lahar in 1953, which destroyed the rail bridge across the Whangaehu River near Tangiwai (Fig. 1.1), claiming 151 lives.

The 1995/1996 eruption period was the largest since 1945 (Christenson, 2000), causing an estimated NZ\$130 million in damages to the New Zealand economy (Johnston et al., 2000). Unrest began in early 1995, with volcanic activity strengthening throughout the first half of the year, involving ash ejection and lahars (Scott, 2013). On September 17, 1995, changes in volcanic tremor and the occurrence of volcanic earthquakes preceded a moderate lahar-producing eruption, followed by another eruption on September 19 (Bryan and Sherburn, 1999). The largest eruption began on September 23, generating a $10 \mathrm{~km}$ high ash column, tremor, volcanic earthquakes and sustained lahars. Multiple eruptions occurred until August 1996, including another, major eruption involving a lava flow during the second half of June (Bryan and Sherburn, 1999).

Recent activity at Mount Ruapehu includes a small, phreatic eruption in Crater Lake in October 2006, and a hydrothermally generated block-ash eruption in September 2007 (Scott, 2013). The latter ejected large (up to $2 \mathrm{~m}$ in diameter) ballistics up to $2 \mathrm{~km}$ in the air, and initiated lahars on the volcano's SE and NW flanks (Jolly et al., 2010). Dome Shelter, located $600 \mathrm{~m}$ from Crater Lake, was damaged, seriously injuring one person. The eruption occurred with no apparent warning, although lake temperatures had been declining for approximately six months (Christenson et al., 2010). The latest significant activity at Mount Ruapehu occurred on July 13, 2009, when hydrothermal activity generated small lahars (Scott, 2013).

\subsubsection{Ngauruhoe/Tongariro Volcano}

Slightly north of Ruapehu is Tongariro Volcano (Fig. 2.3), a stratovolcano similar to Galeras (Colombia) and Mount Asama (Japan). Geochemical analysis of erupted material shows that Ruapehu and Tongariro Volcanoes are independent systems (Moebis et al., 2011). Historically, there has been confusion over to what exactly the names Tongariro and Ngauruhoe refer (Scott and Potter, 2014). For clarification, we use "Mount Tongariro" to describe the topographic expression of Tongariro Volcano north of Mount Ngauruhoe (Ngauruhoe), and "Tongariro" as a the whole volcanic system.

Mount Ngauruhoe is the youngest vent of Tongariro Volcano, at 7 ka (Moebis et al., 
2011), (Hobden et al., 2002). It is also Tongariro's largest cone (2291 m MSL), with a volume of $2.2 \mathrm{~km}^{3}$, and a long term growth rate of $0.9 \mathrm{~km}^{3} / \mathrm{ky}$ for the past $2.5 \mathrm{ka}$ (Hobden et al., 2002). Erupted material is andesitic; geochemical analysis suggests that the source of magma is different from the other volcanic features of Tongariro (Moebis et al., 2011). Variation between flows' chemical compositions also indicate Ngauruhoe is an open system that erupts small, short-lived magma batches that have ascended from a deeper, common source (Hobden et al., 2002).

Mount Tongariro (1978 m MSL) is an amalgamation of volcanic cones formed by eruptions from at least 17 vents, sized from $0.3 \mathrm{~km}^{3}$ to $12 \mathrm{~km}^{3}$, with a total volume of approximately $60 \mathrm{~km}^{3}$ (Hobden et al., 1999). The cones are composite, and thought to overlie a NNE-SSW trending concealed fracture zone (Hagerty and Benites, 2003). The dominant rock type is andesite, although small amounts of dacite and basaltic-andesite have been found (Hobden et al., 1999). Deposits from different vents are interlayered, with eruptions apparently spatially and temporally random, beginning approximately 275 ka ago (Hobden et al., 1999). A dense network of NE trending normal faults is located on the massif's eastern flanks (Villamor and Berryman, 2006b).

It is thought that underlying Tongariro is a large vapour-dominated geothermal reservoir, capped by a thick condensate layer (Walsh et al., 1998). The active vents of Mount Tongariro link to this system at depth. Although ultimately from the same source, lavas from different vents vary isotopically, suggesting that small batches of magma ascending from a larger chamber and temporarily sit in one of many small, shallower conduits or chambers (Hobden et al., 1999). There, they chemically interact with the local (heterogeneous) rock, undergo fractional crystallisation or mix with other magma batches before erupting at different vents.

Between 1840 (when records began) and 1975, Ngauruhoe erupted approximately every three years (Cole and Nairn, 1975). Eruption style varied during this period, with effusive, Strombolian, Vulcanian, and sub-plinian eruptions (Hobden et al., 2002), and pyroclastic flows occurring at times (e.g. Nairn and Self, 1978). However, the only activity observed since 1975, are brief periods of repetitious, low frequency earthquakes observed from 2005 to present, which are thought to be caused by changing volume fractions of bubbles in a shallow water/gas or water/steam cavity (Jolly et al., 2012b). 
Historic activity at Mount Tongariro, has predominantly occurred at the Upper Te Maari Crater, although eruptions at Red Crater and hydrothermal activity at Ketetahi have also been observed. The largest historic episode at Mount Tongariro occurred during 1896-1897, with 18 reported eruptions, of which 17 were at Te Maari (Scott and Potter, 2014).

In 2001, a series of shallow, tornillo-type seismic events occurred beneath at Mount Tongariro, near Te Maari (Hagerty and Benites, 2003). Their rate of recurrence was approximately once per month between January and May, however, between June and September, the rate increased, eventually peaking with many events each day. Hagerty and Benites (2003) suggest that these repeating events, with screw-shaped waveforms, were the result of trapped acoustic energy within fluid (of a gas-ash composition) being slowly radiated into surrounding hard rock.

The most recent activity at Mount Tongariro occurred in 2012, at the Upper Te Maari Crater. An earthquake swarm in July preceded two small eruptions on August 6 and November 23. The larger, August eruption is thought to have been the result of an influx of high temperature fluids from an underlying shallow dyke intrusion, which generated a debris avalanche that depressurised the remaining gas system (Jolly et al., 2014a).

\subsubsection{Other volcanic features of the TgVC}

The remnants of older volcanic massifs present in the TgVC align NW-SE, approximately perpendicular to the current NNE/SSW alignment of active vents (Fig. 2.3). East of Lake Rotoaira, Pihanga (1304 m MSL) is a dome shaped, dissected cone (Topping, 1974). The adjacent Kakaramea covers approximately $120 \mathrm{~km}^{2}$ (Cole, 1978). Maungakatote (848 m) and Muangaku (964 m) are two coalescing andesite cones, located WNW of Lake Rotoaira (Fig. 2.3), which are thought to be less than 320 ka (Topping, 1974). Cole and Spinks (2009) postulate that the structural NW/SE alignment may have been caused by either cross-fractures in the TgVC's early development, or formed along the similarly oriented inherited structural grain of the Coromandel.

Ruapehu Volcano has multiple parasitic vents (e.g. the Ohakune Craters and Hauhungatahi, Fig. 2.3), with erupted material being silica-poor basaltic to basalt-andesite in composition (Houghton and Hackett, 1984). Their activity tends to be Strombolian, although phreatomagmatic eruptions have occurred, likely due to shallow/surface water (Houghton 
et al., 1987).

The Upper and Lower Tama Lakes are located between Ruapehu and Ngauruhoe. They fill several explosion vents, which been active within the last $50 \mathrm{ka}$ (Cole, 1990). Pukeonake is a scoria cone located west of Mount Tongariro (Fig. 2.3). The relationships of these features to the TgVC's volcanic systems are poorly understood.

\subsection{Previous geophysical research in the study area}

Scientific interest regarding the $\mathrm{TgVC}$ has been documented for well over a century, with literature dating back to the late 1880's (e.g. Thomas, 1889). Frequent activity at Mount Ngauruhoe, eruptions at Mount Tongariro and multiple floods at Ruapehu during the second half of the nineteenth century (Scott, 2013) have generated interest since the 1840 signing of the Treaty of Waitangi. More recently, the hazard posed by the volcanoes motivated many studies of the region's petrological, geochemical, and geographic characteristics (e.g. Price et al., 2012), and production of a new geological map of the TgVC (Townsend et al., 2013).

Geophysical research in the TgVC began in earnest in the 1970's and 1980's, and focused on Ruapehu. However, since rejuvenation of Tongariro's geothermal system in 2001 (Hagerty and Benites, 2003), earthquake swarms at Ngauruhoe in 2005-2009 and the 2012 eruptions, study of Tongariro Volcano has increased. Rowlands et al. (2005) comprehensively review the geophysical investigations in the TgVC until 2004. We focus on the analyses that are most relevant to this geophysical project, particularly on studies from the last decade.

\subsubsection{Seismic velocity modelling}

Spatially variable models of the TVZ's velocity structure have been made using a variety of techniques. Examples of these include Behr et al. (2011), who used ambient noise crosscorrelation to produce a pseudo-3D S-wave model down to $40 \mathrm{~km}$ with depth resolution on the order of $2 \mathrm{~km}$; Sherburn et al. (2003) from earthquake phase arrival tomography; and Bannister et al. (2004), from receiver functions. The only 3D velocity modelling focusing solely on the TgVC is by Rowlands et al. (2005). Using earthquake phase arrival tomography, they modelled the $3 \mathrm{D} \mathrm{V}_{P}$ structure down to $20 \mathrm{~km}$, with a depth resolution of approximately $1 \mathrm{~km}$. They also produced a low resolution, $2 \mathrm{D} \mathrm{V}_{P} / \mathrm{V}_{S}$ map, finding 
that S-arrivals were more uncertain than P-arrivals due to interfering coda and converted phases. Consequently, they were unable to produce a $3 \mathrm{D} \mathrm{V}_{S}$ model.

Figure 2.5 is a summary of existing $1 \mathrm{D}$ velocity models of the $\mathrm{TgVC}$, of which most describe only $\mathrm{V}(P)$. Structure beneath the peak of Mount Ruapehu, the focus of most models, has been investigated using explosions (Dibble et al., 1985; Olson, 1985; Sissons and Dibble, 1981) and simultaneously inverted for with earthquake location (Hurst, 1998; Hurst and McGinty, 1999; Hurst and McGinty, 1995; Latter, 1981a; Sherburn et al., 1999). Only two models specific to Tongariro Volcano have been published (Jolly et al., 2012a; Jolly et al., 2014b).

Mordret et al. (2010) investigated temporal variation in relative seismic velocities at Ruapehu Volcano, during the 2006/2007 eruptive period, using interferometry of ambient noise cross-correlations (section 3.3). Although they could not positively identify any changes before the larger eruption in 2007, they detected a $0.8 \%$ decrease of relative seismic velocities, at station pairs across Ruapehu's NE flanks, beginning two days before the first eruption in 2006. Mordret et al. (2010) propose that a small magma intrusion increased pressures in a magma chamber in the NE of the volcano, and opened cracks in the overlying rock.

\subsubsection{Stress}

The dominance of normal faulting in the $\mathrm{TgVC}$ indicates that the maximum principal stress $\left(\sigma_{1}\right)$ is vertical (Villamor and Berryman, 2006b). Andersonian faulting (Anderson, 1905) dictates that the maximum horizontal principal stress $\left(\mathrm{S}_{\operatorname{Hax}}\right)$ and second principal stress $\left(\sigma_{2}\right)$, be equal and parallel to fault strike (predominantly NE-SW in the TgVC), and the minimum horizontal principal stress/minimum principal stress $\left(\mathrm{S}_{H \min } / \sigma_{3}\right)$ be orthogonal to it. However, the presence of active normal faults of different orientations in crosscutting relationships indicates that the TgVC's stress state is more complex. Villamor and Berryman (2006b) propose that this is due to the horizontal principal stresses being approximately equivalent in magnitude. Furthermore, they think that the rotation of the eastern part of the North Island and subsequent rifting of the TVZ provides a localised stress tensor with radial extension in the horizontal plane in the TgVC. This theory is supported by the observations of Wallace et al. (2004), who, using GPS measurements and block rotations, showed that due to compression at the TVZ's southern termination, the orientations of horizontal stresses change over short distances. 
1-Dimensional Velocity models

of the Tongariro Volcanic Centre

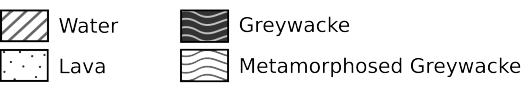

$\because$ Volcanic Sediments

Model Southeast

location Ruapehu

Ruapehu Ruapehu

Crater Lave Crapehu

Latter Dibble et al.

$1981 \quad 1985$

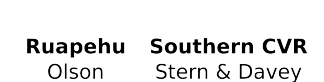

Ruapehu Ruapehu Ruapehu

Ruapehu

Crater Lake Crater Lake

$\begin{array}{cc}\text { Olson } & \text { Stern \& Davey } \\ 1985 & 1987\end{array}$

MeGrinty

Hurst Sherburn et al. McGinty

McGinty
1999

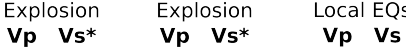

$\begin{array}{cc}\text { Source } & \text { Explosion } \\ \text { Vel. type } & \mathbf{V p} \mathbf{V s}^{*}\end{array}$

$\mathbf{v a}$
$\mathbf{v a s}$
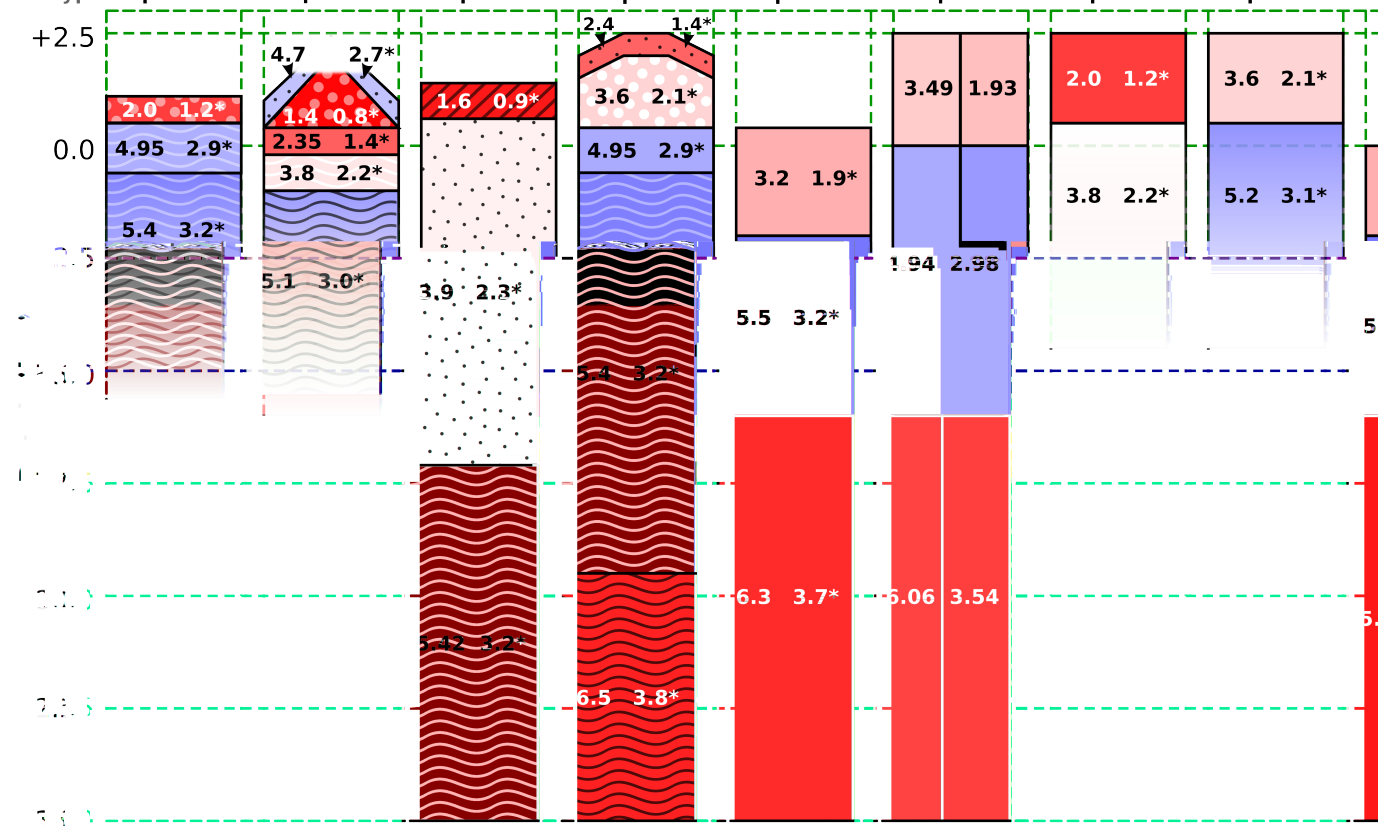

$5.53 .2 *$
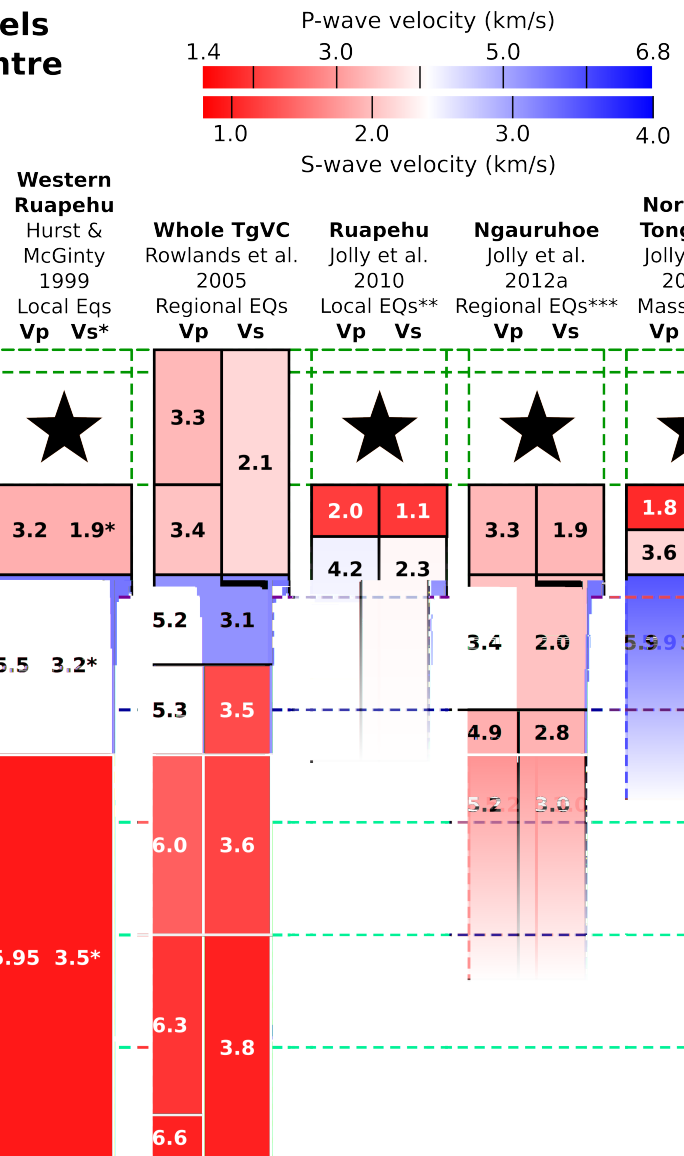

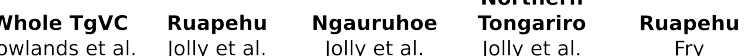

2005 2010. Jolly et Jolly et ald Fry

pers. comm.

Regional EQs Local EQs** Regional EQs*** Mass drops Ambient noise Vp* Vs

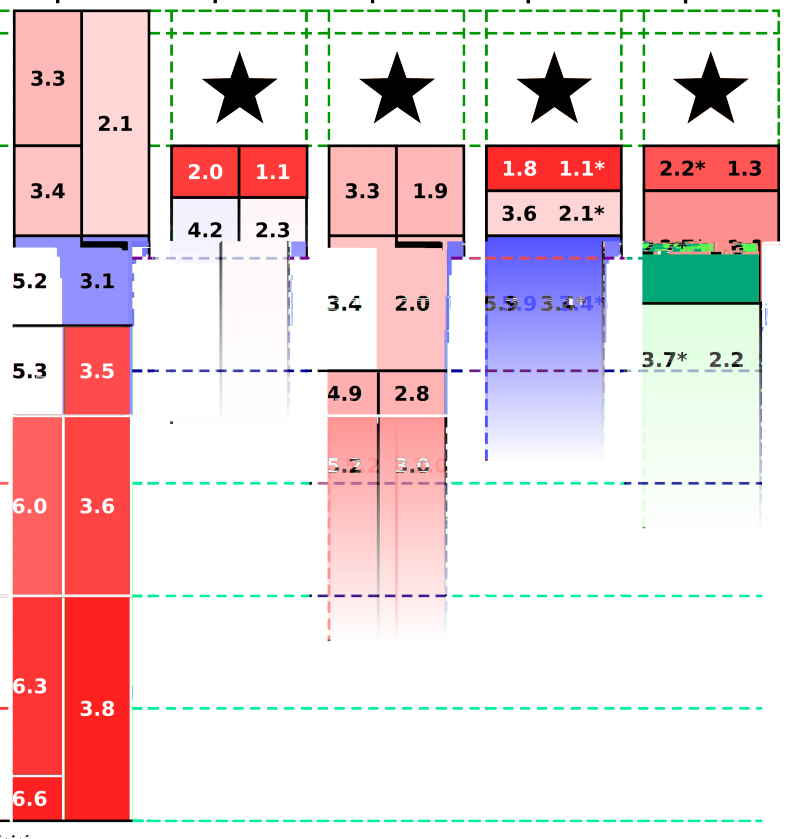

Figure 2.5: Existing one-dimensional velocity models for different areas of the $\mathrm{Tg} V C$, with the elevations presented by their authors - large stars indicate depth below surface rather than MSL. Absolute $V_{P}$ and $V_{S}(\mathrm{~km} / \mathrm{s})$ is given on the left and right of each layer, respectively. Layers are coloured by velocity; patterns show geological interpretation if available. Halfpsaces shown as layers fading out with depth. 
Using focal mechanism inversions, Johnson et al. (2011) measured the variable orientation of $\mathrm{S}_{H \max }$ in the TgVC. They calculated $\mathrm{S}_{\text {Hmax }}$ to be oriented approximately $110^{\circ}$ from north, to the north and west of Mount Ruapehu. South and SE of Ruapehu, however, it is oriented at $8^{\circ}$. To the SW $\mathrm{S}_{H \max }$ is sub-parallel to the Ohakune-Raetihi fault set (section 2.4). Using Coulomb modelling, Johnson et al. (2011) also showed that this variable stress pattern could be explained by a NE-SW oriented dyke-like magma chamber beneath Mount Ruapehu.

\subsubsection{Seismic Anisotropy}

Seismic anisotropy, the property by which seismic velocity depends upon particle motion direction (Crampin, 1981), has been studied in the TgVC using the shear-wave splitting (SWS) technique. SWS measures how horizontally polarised shear-waves $\left(\mathrm{S}_{H}\right)$ are split into perpendicularly polarised components that are governed by the orientation of anisotropy in the propagation medium and the direction of wave travel (e.g. Crampin, 1981).

Temporal variation of the two SWS parameters, the fast direction, $\phi$, and delay time, $\delta \mathrm{t}$, has been the primary focus of most research. Miller and Savage (2001) first observed, and correlated significant changes in the dominant $\phi$ between 1994 and 1998 with the large scale volcanic activity at Ruapehu in 1995/1996. Gerst and Savage (2004) interpreted this, along with further change in 2002, as resulting from stress changes induced by an overpressured magma reservoir (1995) which then deflated (erupted, 1996), prior to reinflation (2002). The similarity in the horizontal principal stresses' magnitudes in the area may facilitate the observation of short-term changes to the local stress regime through SWS methods. Changes were also inferred prior to smaller scale hydrothermal activity at Ruapehu in 2006/2007 (Keats et al., 2011).

Johnson et al. (2011) modelled the heterogeneity of anisotropy in the TgVC using data collected in 2008 and employing tomographic inversions of the splitting parameters. By comparing their SWS measurements to regional fault strikes and estimated stress directions from focal mechanism inversions, Johnson et al. (2011) found that crustal anisotropy is likely dominated by stress orientations near Ruapehu, and structural features at Tongariro. Godfrey et al. (2014) investigated, but were unable to resolve temporal variation in SWS or $\mathrm{V}_{P} / \mathrm{V}_{S}$ that could be associated with the 2012 Te Maari eruptions at Mount Tongariro. They confirmed Johnson et al. (2011)'s conclusion of spatially heterogeneous anisotropy. 
Johnson and Savage (2012) performed spatial tomography of the SWS parameters on data from small temporary deployments in 1994, 1995, 1998 and 2002 around Ruapehu, and major deployments across the entire TgVC in 2001 and 2008. They observed the same changes as Miller and Savage (2001) and Gerst and Savage (2004), as well as changes in $\phi$ and $\delta \mathrm{t}$ at Tongariro between 2001 and 2008, which they attributed to changing conditions in the geothermal system. The occurrence of anomalous seismic events at the volcano shortly after the 2001 deployment ended supports this conclusion (Hagerty and Benites, 2003).

\subsubsection{Seismic Attenuation}

Attenuation, the loss of seismic energy during wave propagation through media, has also been investigated in the TgVC. The energy is lost, not only due to geometrical spreading of the waves, but also to the presence of absorbing (intrinsic attenuation) and scattering materials (scatttering atteunation), which transfer energy from direct body waves to later in the coda (e.g. Titzschkau et al., 2010). Consequently, studies of seismic attenuation can be useful in investigations of earth structure (e.g. Latter, 1981a). Furthermore, observation of temporal variation in seismic attenuation have been assoicated with crustal stress changes and volcanic activity in various places on Earth, and may aid hazard monitoring (Londoño and Sudo, 2002).

In the TgVC, Latter (1981a) first studied shear-wave attenuation from local earthquakes to investigate the upper crustal structure beneath Ruapehu and Ngauruhoe. He observed areas of anomalously high attenuation beneath Ruapehu and near Ngauruhoe, which he attributed to partially molten magmatic intrusions and faulting, respectively.

Using earthquakes from the highly active Waiouru swarm (SE of Mount Ruapehu), Titzschkau et al. (2010) recorded slight temporal variation in coda attenuation between 1990-2005. During the eruptive period of 1995/1996, they also observed more distinct changes in relative attenuation and frequency dependence, which were coincident with the recorded changes in SWS, and were attributed to stress changes.

Syuhada (2010) investigated the link between shear-wave attenuation and the direction of wave polarisation. He found that in the upper crust, shear-wave attenuation is high, but anisotropic, with greater attenuation in the E/W direction. However, the lower crust, especially along the NE/SW direction, is much less attenuative, which may be attributed 
to interconnected melt that is aligned with the TVZ's NE/SW extension.

\subsubsection{Non-seismic methods}

Structural studies of the TgVC using other geophysical techniques have primarily focused on Ruapehu and the Tama Lakes area (Fig. 2.3). Horspool (2003) produced high-resolution 2D gravity profiles across Ruapehu and the Tama Saddle (both oriented approximately EW), which are further constrained by seismic refraction west of the mountain. In the Ruapehu summit profile, Horspool (2003) identified two gravitational anomalies; a broad anomaly which could correspond to dense basement rock being displaced by lower density material and a short-wavelength anomaly, possibly due to a dense andesite dyke within the lower density volcanic massif.

Several magnetotelluric surveys have been conducted in the $\mathrm{TgVC}$ (e.g. Ingham et al., 2009). This technique uses measurements of the earth's time-varying magnetic and electric fields to determine the subsurface electrical structure. Jones et al. (2008) produced a $3 \mathrm{D}$ resistivity model of the shallow ( $<2 \mathrm{~km}$ depth) structure beneath Ruapehu's summit plateau, using data from 10 sites slightly to the north of Crater Lake. Within a background of low resistivity material (likely due to extensive hydrothermal alteration), they identified two areas of high resistivity, which they interpreted as the result of higher than previously thought temperatures altering clay materials and producing chlorite.

In a larger scale study, Ingham et al. (2009) produced 1D, 2D and 3D models of Ruapehu's resistivity structure to a depth of approximately $10 \mathrm{~km}$. Their compiled 1D soundings show that just beneath a surface layer of resistive unaltered ash and volcanic material is a highly conductive layer that mirrors the above topography, and corresponds with the low resistivity material observed by Jones et al. (2008). On the volcano's flanks, this layer is approximately $1 \mathrm{~km}$ thick, which Ingham et al. (2009) interpret as the region where volcanic/hydrothermal fluids interact with groundwater and flow downslope. However, beneath Crater Lake, the conductive region is more than $2 \mathrm{~km}$ thick, likely representing the substantial hydrothermal system near Ruapehu summit, and hydrothermally altered rocks in its proximity. Ingham et al. (2009) also infer the presence of a narrow, NE trending dyke at $8 \mathrm{~km}$ depth, which may connect to a larger feeder deeper down. They suggest that this feeder extends to the NE, beyond the limits of their study, linking Ruapehu and Tongariro volcanoes together. 
Cassidy et al. (2009) used an integrated gravitational, multi-level aeromagnetic and magnetotelluric approach to produce a E-W oriented 2D profile across the Tama Saddle. They first created models using data from each method independently, and then combined them for their final model. They found strong correlations between certain structures across the different approaches, including the variation of the depth to the greywacke basement along the profile (between 100-700 m MSL). They also observed a relatively magnetised layer above non-magnetised material (above the greywacke), both characterised by low density and resistivity. Cassidy et al. (2009) interpreted these layers as mixed volcanic deposits and tertiary sediments, respectively. 


\section{Chapter 3}

\section{Theoretical background}

Here we briefly review the fundamental concepts upon which this research is based. This includes how seismic wave propagation depends upon Earth structure and how we can use signal processing of seismic records to obtain information about Earth properties. In particular, we focus on surface waves, ambient noise and cross-correlation.

\subsection{Surface-wave propagation}

Surface waves are seismic waves propagating at the Earth's free surface, of which a fundamental property is dispersion - the phenomenon by which harmonic waves of different frequencies (or periods) travel at different velocities. There are two types; Rayleigh waves and Love waves.

Rayleigh waves are a combination of compressional waves (P-waves) and vertically polarised shear-waves ( $S_{V}$-waves) which exist at the surface (Stein and Wysession, 2009). At the surface, Rayleigh-wave particle motion is retrograde elliptical and changes to prograde elliptical at depth, with linear motion in between. In isotropic, layered media, displacement due to Rayleigh waves at the surface is recorded on the vertical and radial (horizontal axis oriented parallel to the raypath) seismograph components.

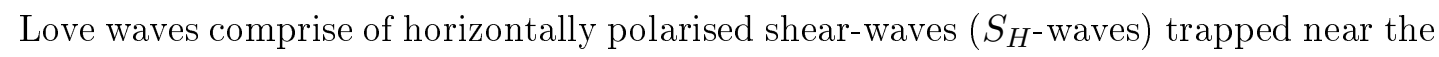
surface due to a stratified structure (Stein and Wysession, 2009). Displacement records on the seismograph's transverse component (the horizontal axis oriented perpendicular to the raypath). 
As the displacements of Rayleigh and Love waves are angular functions, waves must travel at specific certain velocities to exist at a given frequency. To satisfy the boundary conditions of surface-wave propagation, there must be zero traction at the free surface and displacements must be continuous at layer boundaries (Stein and Wysession, 2009) and propagating waves can travel only at certain frequencies. These solutions to the wave equations are known as modes. The fundamental mode is the wave that exists with the lowest wavenumber. The next lowest is the first higher-order mode, then the second higherorder mode, etc.
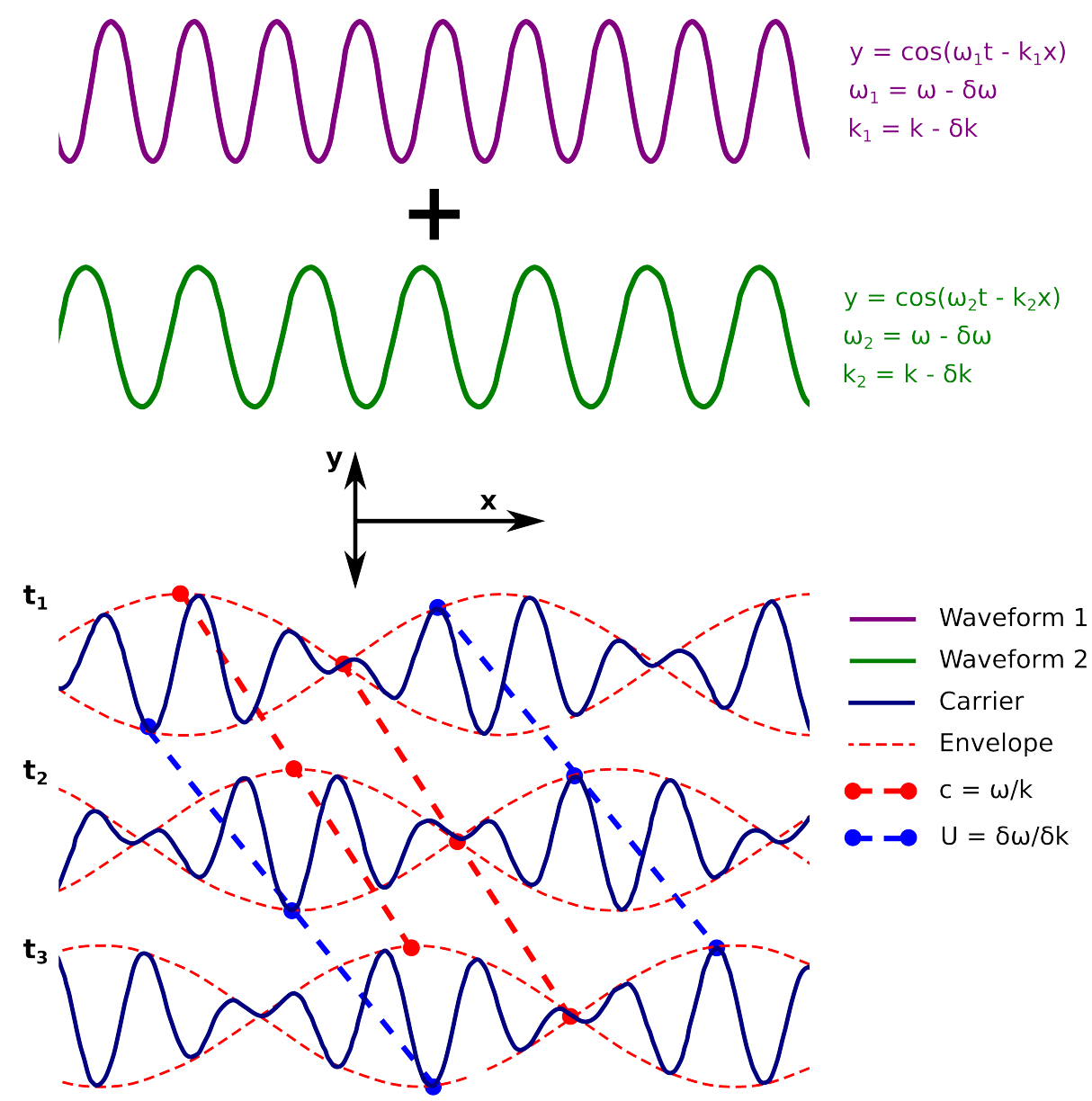

Figure 3.1: Schematic of group vs. phase velocities in the case of two superimposed angular functions at three time periods. Adapted from figure 2.8-1 from Stein and Wysession (2009)

A packet of surface waves, each with different angular frequencies, travelling past a point gives ground oscillation with a characteristic envelope (Fig. 3.1). The speed at which a specific point on this envelope (e.g. the crest) propagates is the group velocity (U; Fig.3.1; equation 3.1). Conversely, the phase velocity (c) is the speed at which a specific point (also known as a carrier), such as the peak or trough on the underlying oscillation 
itself propagates for a specific period wave (c; Fig. 3.1; equation 3.2). Both velocities are related to wave frequency; the group velocity is the phase velocity's derivative (Stein and Wysession, 2009). Although the group velocity can be derived from the phase velocity, the phase velocity cannot be derived from the group velocity alone (Bensen et al., 2007), because the integration requires a constant.

$$
\begin{gathered}
U=\delta \omega / \delta k \\
c=\omega / k
\end{gathered}
$$

Surface-wave velocities depend upon the subsurface shear-wave velocity $\left(V_{S}\right)$ structure. Generally, longer period waves are more sensitive to deeper structure than higher frequencies. Consequently, a dispersion curve (a representation of velocity variation with period) can be used to construct a one-dimensional (vertical) S-wave velocity profile for the material encountered by the source-receiver raypath (Stein and Wysession, 2009). By adding data regarding the lateral variation of dispersion curves for different raypaths and employing tomographic methods, a three-dimensional model can be constructed.

\subsection{Ambient noise}

Seismograms are measurements of ground motion from all seismic waves arriving at the instrument site. The characteristics of waves from each source represent both the source generation function and the properties of the materials through which they propagate to reach the receiver. Energy within the noise field is mostly carried by surface waves travelling in all directions and is typically largest for long periods waves of $3-10 \mathrm{~s}$ due to ocean waves interacting with each other and the solid earth (Ardhuin et al., 2011; Lacoss et al., 1969; Longuet-Higgins, 1950). Local weather conditions, especially wind coupling the atmosphere to the ground, trees and buildings, can also be strong noise sources (Yang and Ritzwoller, 2008). In New Zealand the energy peaks at two periods; primarily at 6 $9 \mathrm{~s}$ and secondarily at $14-17 \mathrm{~s}$ (Brooks et al., 2009).

\subsection{Cross-correlation}

A cross-correlation is an operation used to determine the similarity between two signals, i.e. to find phases common to both, with a time delay between them. Aki (1957) first demonstrated that it is theoretically possible for ambient noise cross-spectra to be used to extract information about surface waves, provided by a diffuse noisefield. The theory 
proving that the Earth's impulse response (the Green's function) could be retrieved from stacked cross-correlations of seismic signals with sources in many different directions was then given by Claerbout (1968). This means that stacked cross-correlations of recorded waveforms from two seismographs give the seismogram that would have been recorded at one station, had the other been the source of impulse energy. Using normal mode theory, Lobkis and Weaver (2001) show that cross-correlation of recorded ambient noise leads to the Green's function, and prove their theorem using measurements of ultrasonic waves in an aluminium block. Weaver and Lobkis (2004) then expand this derivation to diffuse fields in open systems, such as the Earth's structure.

The early development of noise cross-correlation research assumed that the noise wavefield is equipartitioned, i.e. fully diffuse (as shown by Gouedard et al., 2008; SánchezSesma and Campillo, 2006). This means that within the Earth's noisefield, there are components travelling in all directions, because every point along the raypath of each of many sources is a scatterer - a point source of a spherical wave front (Huygens' Principle; Pao and Varatharajulu, 1976). Although this assumption is often not fulfilled, practical applications have shown that valuable information can still be obtained from the noise cross-correlations, which become estimated Green's functions (e.g. Behr et al., 2010).

Campillo and Paul (2003) used cross-correlation of earthquake codas to determine the Green's function. In doing so, they proved that surface waves propagating between the two cross-correlated stations can be extracted, and the full Green's tensor can be reconstructed using correlations between different components. Shapiro and Campillo (2004) present one of the first practical applications of ambient noise cross-correlation to retrieve the Green's function. They showed that fundamental mode Rayleigh (R0) waves should be observed, allowing dispersion measurements to be made for any station pairing. Campillo (2006) showed that in the frequency range of 0.1-0.5 Hz, surface waves dominate the crosscorrelations using regional-continental scale seismic networks.

In stacking cross-correlations, components propagating in directions other than between the two stations essentially cancel each other out (Snieder and Fleury, 2010; Tsai, 2009). The cross-correlations are calculated in both directions between the stations, giving positive and negative time-lag signals as the roles of source and receiver reverse. These are called the "causal" and "acausal" portions of the cross-correlation function (CCF). In a perfectly equipartitioned wavefield, these functions would be identical (Fig. 3.2a), therefore their 
symmetry (or lack thereof, Fig. 3.2b-c) can be used to identify bias in, and gauge the quality of, dispersion measurements. Adding the causal and acausal portions to make a symmetric function reduces the effect of a heterogeneous noise field. Waveforms that are not in phase (and likely biased by the noise field) cancel out, increasing the signal-to-noise ratio, which is used as part of quality control on dispersion measurements.

\section{Effect of noise directivity on cross-correlation symmetry}

a)
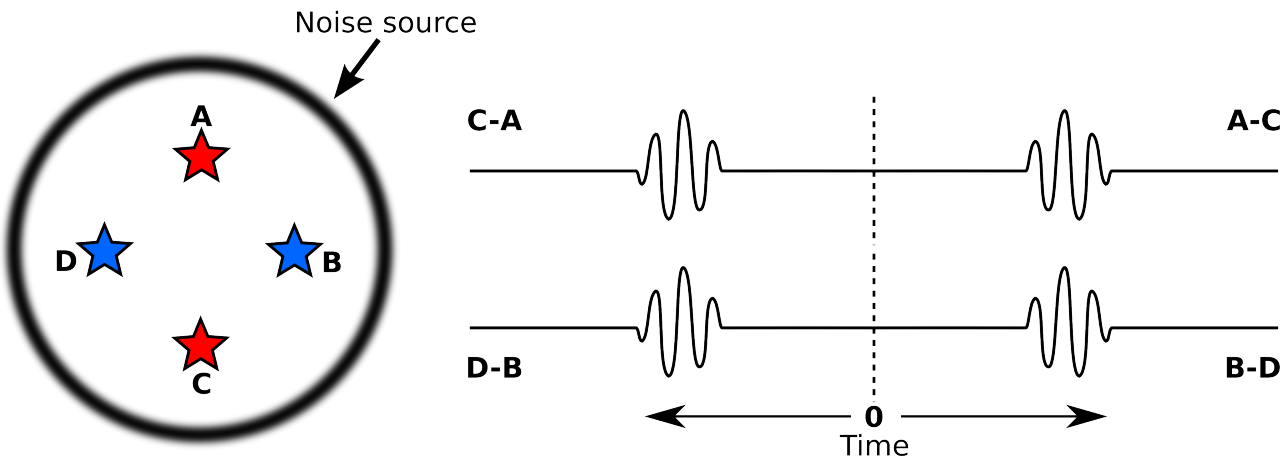

b)
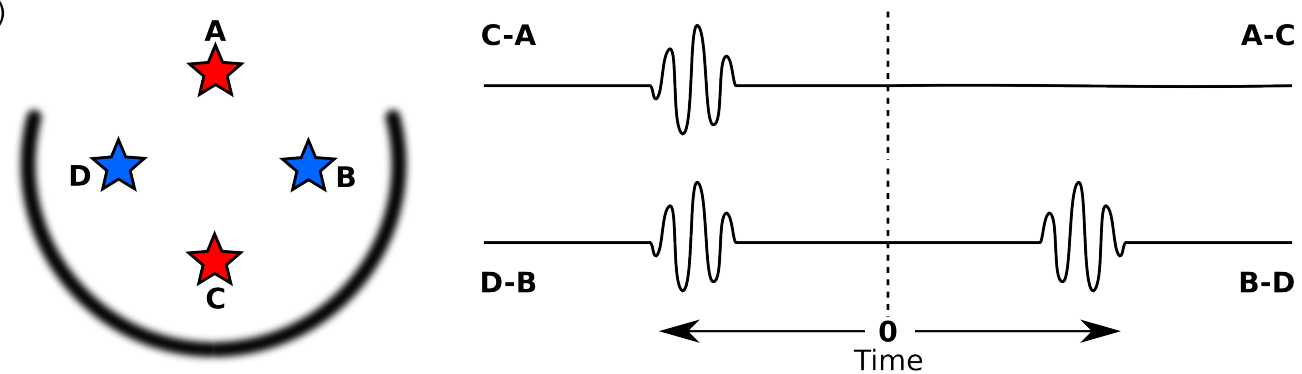

c)
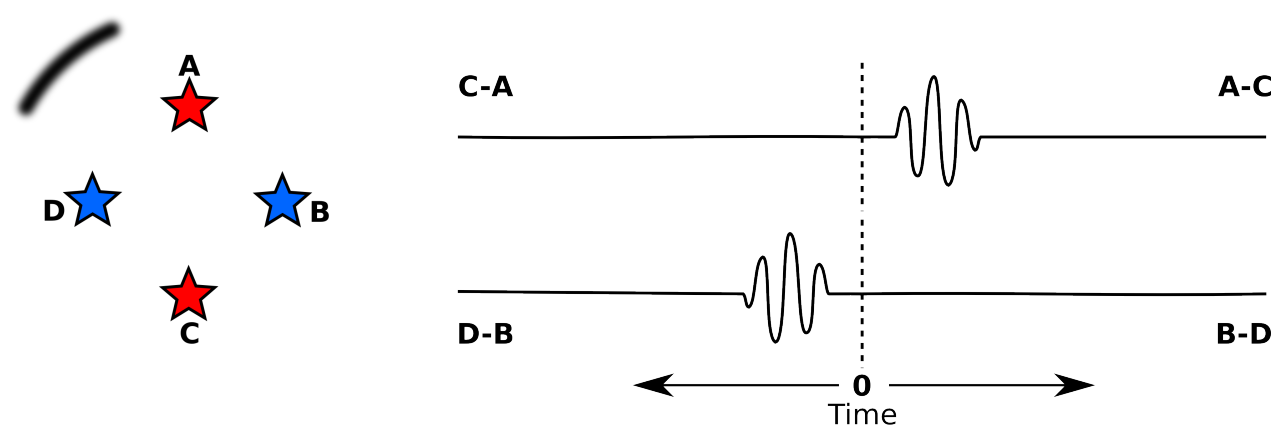

Figure 3.2: Schematic of cross-correlation symmetry and delay time bias due to distribution of noise sources. Stars represent stations; circle/arcs represent direction of noise sources: a) perfectly equipartitioned noise field; b) symmetric, but non-equipartitioned field; c) nonequipartitioned and non-symmetric field. 
For a seismograph network of $n$ stations, there are $n(n-1) / 2$ potential seismograph pairs (Bensen et al., 2007) for which cross-correlation can be performed. Furthermore, crosscorrelation can be applied to all nine possible combinations of the three seismograph components (Radial/R, Transverse/T and Vertical/Z) to create the cross-correlation tensor. Of these, transverse-transverse (TT) CCF yields information regarding Love-wave propagation and vertical/radial components CCF (ZZ, RR, RZ, ZR relate to Rayleigh waves. The TT, RR, ZZ, RZ and ZR components can be referred to as the isotropic components in the cross-correlation tensor. In isotropic, layered media, transverse cross-component correlations (RT, TR, TZ and ZT) are zero-functions. Analysis of these CCF may be used for observing and quantifying anisotropy (Durand et al., 2011; Fry et al., 2014).

Unlike phase arrival tomography, or cross-correlating earthquake records, ambient noise cross-correlation is not limited by the spatial and temporal distribution of seismicity. This makes it a powerful tool in modern seismology. However, ambient noise cross-correlation is limited by station geometry and the requirement that the seismic noise wave field is reasonably diffuse (Shapiro and Campillo, 2004). Additionally, the Green's function may be a very weak signal in the CCF. This is typically because noise sources are rarely perfectly equipartitioned, which can introduce bias into velocity measurements (Tsai, 2009). Stacking CCF over long time periods reduces this effect (e.g. Fry et al., 2010). As the scale of observation increases, more CCF are needed to produce reliable Green's functions, as signal strength decreases with interstation distance.

\subsubsection{Applications of ambient noise cross-correlation}

Determining the shear-wave velocity $(\mathrm{Vs})$ structure beneath a seismograph network is one application of the ambient noise cross-correlation technique. This has been done for regions on many different scales, from small, local networks (e.g. Brenguier et al., 2007) to state/national networks (e.g. Shapiro et al., 2005), and continents (e.g. Yang et al., 2007). Lin et al. (2007) used ambient noise cross-correlation to model the velocity structure of the whole of New Zealand. Models of individual regions of the country have also been created for the TVZ (Behr et al., 2011), Northland (Behr et al., 2010) and Canterbury (Savage et al., 2013; Fry et al., 2014).

Brenguier et al. (2007) published the first study using ambient noise tomography in a shallow volcanic setting, producing a 3D Vs model of Piton de la Fournaise volcano (la Réunion) down to $3 \mathrm{~km}$ depth. Mordret et al. (2015) improve this model by jointly inverting 
Rayleigh and Love-wave group velocity dispersion measurements for the 3D Vs structure down to $6 \mathrm{~km}$. They model the volcano's isotropic and radial anisotropic structure to account for discrepancies between the Rayleigh- and Love-wave measurements. Stankiewicz et al. (2010) observed the magma chambers beneath Toba caldera (Sumatra). In their 3D shear-wave model that extends to $7 \mathrm{~km}$ depth, Masterlark et al. (2010) imaged the low velocity magma reservoir beneath the Okmok volcano (Alaska) caldera. Jay et al. (2012) also observed a low velocity zone at 1.9-3.9 km depth beneath Uturuncu Volcano (Bolivia) in their 3D shear-wave model, however, unlike the previous studies, they used Love-, not Rayleigh-wave measurements.

Many studies focus on using ambient noise to observe temporal changes in relative seismic velocities. These type of studies typically use the Moving Window Cross Spectral technique (Clarke et al., 2011) or the stretching technique (Sens-Schonfelder and Wegler, 2006), which can detect velocity variations as small as $0.1 \%$. These techniques are especially applicable in the context of monitoring volcanic activity (e.g. Brenguier et al., 2008; Duputel et al., 2009). In New Zealand, Mordret et al. (2010) used the stretching technique to investigate potential variation in $\mathrm{ZZ}$ cross-correlations from around Ruapehu during unrest in 2006 and 2007 (section 2.4).

More recently, Brenguier et al. (2014) showed that ambient noise can be used to map the crust's susceptibility to seismic velocity changes in response to dynamic stress perturbations. Using data from the Japanese seismic network following the 2011, Mw 9.0 Tohoku-Oki earthquake, they found that regions of pressurised fluids (such as those beneath active volcanoes) are more sensitive to co-seismic deformation and shaking.

The use of cross-component pairs (RT, TR, TZ, ZT, RZ and ZR), in addition to the more common ZZ, RR and TT correlograms, has also increased over time (e.g. Durand et al., 2011; Savage et al., 2013), although the ZZ remains the most popular (e.g. Brenguier et al., 2014). The RZ/ZR components relate to Rayleigh waves, however appropriate phase corrections need to be applied (Haney et al., 2012). Additionally, these cross-components can be used to estimate the Green's function where noise directionality may introduce bias into velocity measurements (van Wijk et al., 2011).

Others study anisotropic structure. Fry et al. (2010) invert noise-derived phase-velocity measurements to characterise layered azimuthal anisotropy in the European Alpine litho- 
sphere. Using a similar approach with group velocities, Fry et al. (2014) described variation with depth of azimuthal anisotropy in the central South Island of New Zealand. Jaxybulatov et al. (2014) use ambient noise tomography to observe radial anisotropy due to layering of partially molten sills beneath Toba caldera. The RT, TR, TZ and ZT components can also be used for investigating anisotropy, however, their energy can indicate a non-diffuse noise field (Roux, 2009). Durand et al. (2011) used the full, nine component cross-correlation tensor to observe temporal variation in the azimuthal polarisation of surface waves following the $2004 \mathrm{Mw} 6.0$ earthquake in Parkfield, California.

Roux et al. (2005) proved that body waves could be extracted from ambient noise cross-correlations from a closely spaced network, although with much lower amplitudes than surface waves. Further studies propose methods to reliably determine the Green's function of structures deeper than that which typically influences surface-waves (e.g. Poli et al., 2012b). Poli et al. (2012a) observe mantle discontinuities using body-waves in ambient noise. Further afield, Sens-Schönfelder and Larose (2010) used seismic data from the 1970's Apollo 17 lunar network to investigate the Moon's noise spectrum, seismic structure and temperature variations. 


\section{Chapter 4}

\section{Methodology}

Our method has five primary phases: pre-processing, cross-correlation, group velocity dispersion measurements, synthetic CCF/dispersion and 1D Vs inversions. We also calculate signal-to-noise ratios (SNR) and plot particle motion. In this chapter, we describe the data we use and outline the context and theoretical basis of each step, and compare our approach to other studies.

\subsection{Data}

Data used in this project come primarily from temporary instruments operational in 2001 and 2008 (Fig. 4.1). We also use records from permanent GeoNet stations (https://magma. geonet.org.nz/delta/app, last accessed April 2014) in operation during these times. The networks contain short-period and broadband instruments of various models and manufacturers (Appendix A). For most stations, data are not continuous for the entire deployment period due to technical difficulties or maintenance. Some stations do not operate on occasional days; others have longer gaps of some weeks. Dropouts may occur on only one or two channels; some stations are subject to frequent, large amplitude glitches.

The largest deployment in 2001 is the Seismic Tomography Around Ruapehu and Tongariro deployment (START, (Rowlands, 2004; Rowlands et al., 2005), with 26 broadband stations, of which the majority were deployed in January and retrieved in June (Fig. 4.1, yellow triangles). Coverage of the TgVC by permanent GeoNet stations was sparse at this time; we obtained data for five instruments for January-June 2001; four single (ver- 
tical) component short-period sensors and FWVZ, a broadband station (Fig. 4.1, orange squares). Broadband station LMOW, from the Central North Island Passive Seismic Experiment (CNIPSE) was also located within our study area and operating at the same time. In total, we use data from 32 stations from 2001, of which $87.5 \%$ have three-component broadband sensors. The average number of available days for 2001 stations is 116 ; there are 437 viable station pairs.

The 2008 data come from 34 stations from three deployments, making 518 potential station pairs. Fifteen stations (12 broadband, 3 short-period) constitute the Spatial Anisotropy Deployment at Ruapehu (SADAR, Fig. 4.1, pink inverted triangles; Johnson, 2011), which was active for most of the year. We consider broadband station MAKA a vertical-component sensor, as its horizontal components never correctly recorded simultaneously. Sixteen permanent GeoNet stations recorded throughout 2008 (two broadband, 14 short-period; Fig. 4.1, purple circles). A further three broadband seismographs operated between January 15 and February 7 on Mount Ngauruhoe (NGA deployment; Fig. 4.1, dark pink triangles; Jolly et al., 2012b). The average number of available days for the 2008 stations is 241 . Only $50 \%$ of the 2008 instruments are broadband, a much lower proportion than 2001 .

We downloaded all data from permanent GeoNet stations in SAC (Seismic Analysis Code, Goldstein and Snoke, 2005) format using GeoNet's online continuous-waveformbuffer (CWB) query tool (http://info.geonet.org.nz/display/appdata/Continuous + Waveform + Buffer, last accessed September 2014). The raw SADAR data were stored as 2-12 hour traces in miniseed format, which we merged and converted to SAC. Most data have initial sampling rates of $100 \mathrm{~Hz}$, however some 2001 GeoNet stations were at $40 \mathrm{~Hz}$. To decrease the size of our dataset, we immediately resampled the raw seismograms at $20 \mathrm{~Hz}$. Downsampling is often applied post instrument response removal, rather than prior to it, however, we found no difference in the waveforms and subsequent CCF in a small test dataset involving all stations for five consecutive days. 


\section{Seismograph distribution across the TgVC}

$\begin{array}{ll}\triangle 2001 \text { START* } & \nabla 2008 \text { SADAR** }^{* *} \\ 2001 \text { GeoNet } & \bigcirc 2008 \text { GeoNet } \\ 2001 \text { CNIPSE } & \triangle 2008 \text { Ngauruhoe }\end{array}$

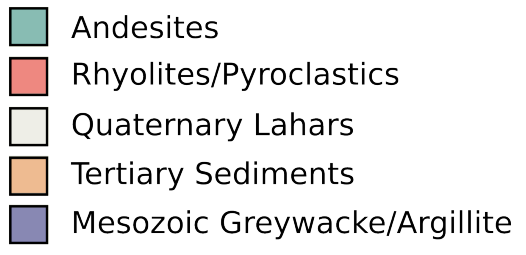

* Stations S20, S21 \& S22 are off map to the west

** Stations BALD, KBEL, MOA \& PEN2 are off map to the south; ATKR off map to the east

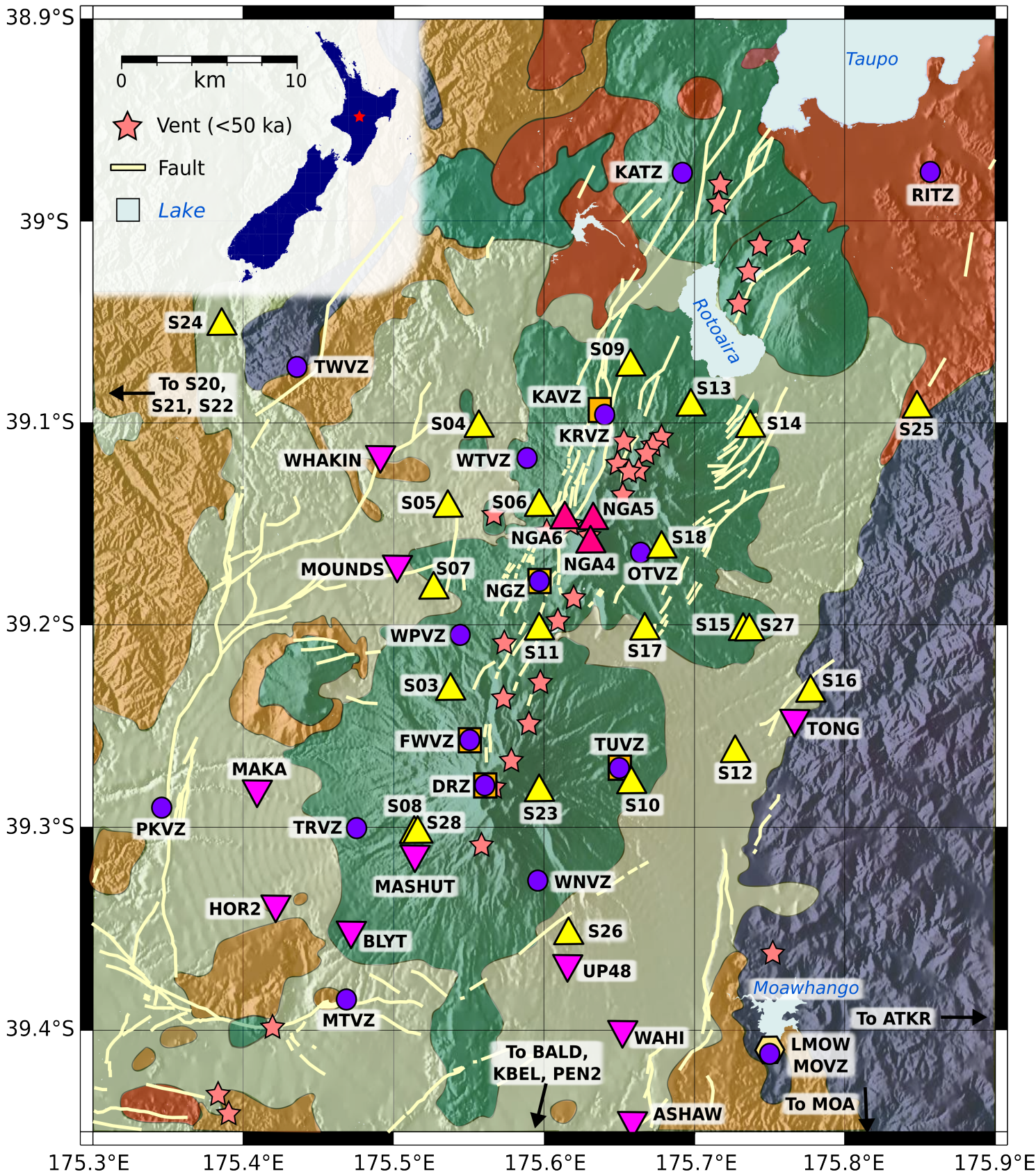

Figure 4.1: Simplified geological map of the TgVC showing the distribution of most seismographs used in this study, grouped by deployment. Geological features compiled from same sources as Fig. 2.3 


\subsubsection{Noise sources}

Behr et al. (2011) performed plane wave beamforming and slant stacking upon seismograms recorded on the START array for 130 days to describe noise directionality in the central North Island. They concluded that although less energy was travelling from the NNENE direction due to the highly attenuative TVZ, the azimuthal distribution of noise was homogeneous to a first approximation for their periods of interest of 6.1 and $10 \mathrm{~s}$.

\subsection{Pre-processing}

The raw data must be prepared before any cross-correlation computation is attempted. This is necessary to decontaminate the desired noise from gaps and transient perturbations such as earthquakes, instrument glitches and other undesired noise. Should the waveform be contaminated with such features, the velocity measurements derived from the CCF may be biased, especially due to directionality of noise sources and resulting non-diffuse wavefield (Yao and Van Der Hilst, 2009). Thus, the ultimate goal of the pre-processing scheme is to obtain a set of waveforms that reflect a temporally and spatially uniform noise field (Roux, 2009).

As a whole, the pre-processing scheme of a dataset is typically unique to that dataset. Some steps, e.g. instrument response deconvolution, are standard to most studies, however more complex techniques such as spectral normalisation are widely varied in their application (Bensen et al., 2007). Choosing to apply bandpass filters or decimate the signal's sampling rate depends upon the state of the available raw data, the frequency spectrum of interest and station spacing. The instruments' geological and tectonic settings and the sensor's capabilities exert the primary control on the appropriate approach and what can be achieved from different procedures (Poli et al., 2013).

For each of the station components in 24 hour long traces, we remove the mean, trend, the mean again, and apply a cosine taper with a width of $1 \%$, using SAC. Tapering removes any discontinuity between the waveform's two ends, preventing the record's length wrongfully contributing to the frequency spectrum, an effect known as spectral leakage (e.g. Grandke, 1983). 


\subsubsection{Instrument response}

The relationship between the amplitudes and phases of frequencies contained in the sensor's output signal and those of the true ground motion is called the frequency response function (Scherbaum, 2007), which varies between sensors (Fig. 4.2). Short-period instruments have their highest gain at a single frequency (the instrument's natural/resonant frequency/period) on the order of $1 \mathrm{~Hz}$, producing a non-flat curve in the frequencyamplification space (Fig. 4.2, Marks L4 sensor). Broadband sensors have their greatest response at a range of frequencies, producing a flat response for a wider passband (Fig. 4.2, Guralp sensors). Fractions of seconds may have significant impact on the apparent velocities of the phases in the calculated cross-correlations; equalising the instrument response between sensors is extremely important.

We recover the true ground motion by deconvolving the frequency response function from the digital signal within the frequency band of interest. The operation alters the amplitudes and phases of the signal's constituent frequencies. Phase arrival times are corrected for the lag time between the ground motion and induced voltage within the sensor. Amplitudes change by a factor proportional to the inverse of the expected gain of each frequency in the frequency response function (Havskov and Alguacil, 2010). As the difference between a frequency and the range of highest gain increases, the higher the magnitude of the frequency amplification. If the range includes very long periods that are dominated by continuous instrumental noise rather than natural signals, the output may be too contaminated and unusable (Havskov and Alguacil, 2010). To avoid this, we deconvolve the instrument response with a lower frequency limit of $0.05 \mathrm{~Hz}$.

Our data involves short-period and broadband sensors of many different manufacturers and models. We deconvolved the instrument response for each component and 24 hour trace that had undergone the initial processing described above. Where possible, we used station specific response functions in RESP format, using the EVALRESP option of the TRANSFER function in SAC for the deconvolution. This function uses spectral division to remove the instrument response and then spectral multiplication to create a consistent response for all data. 
Instrument response functions for different seismometers

שGuralp CMG-40TD“ Guralp CMG-3TD*

ש Guralp CMG-3ESP* Marks L4*

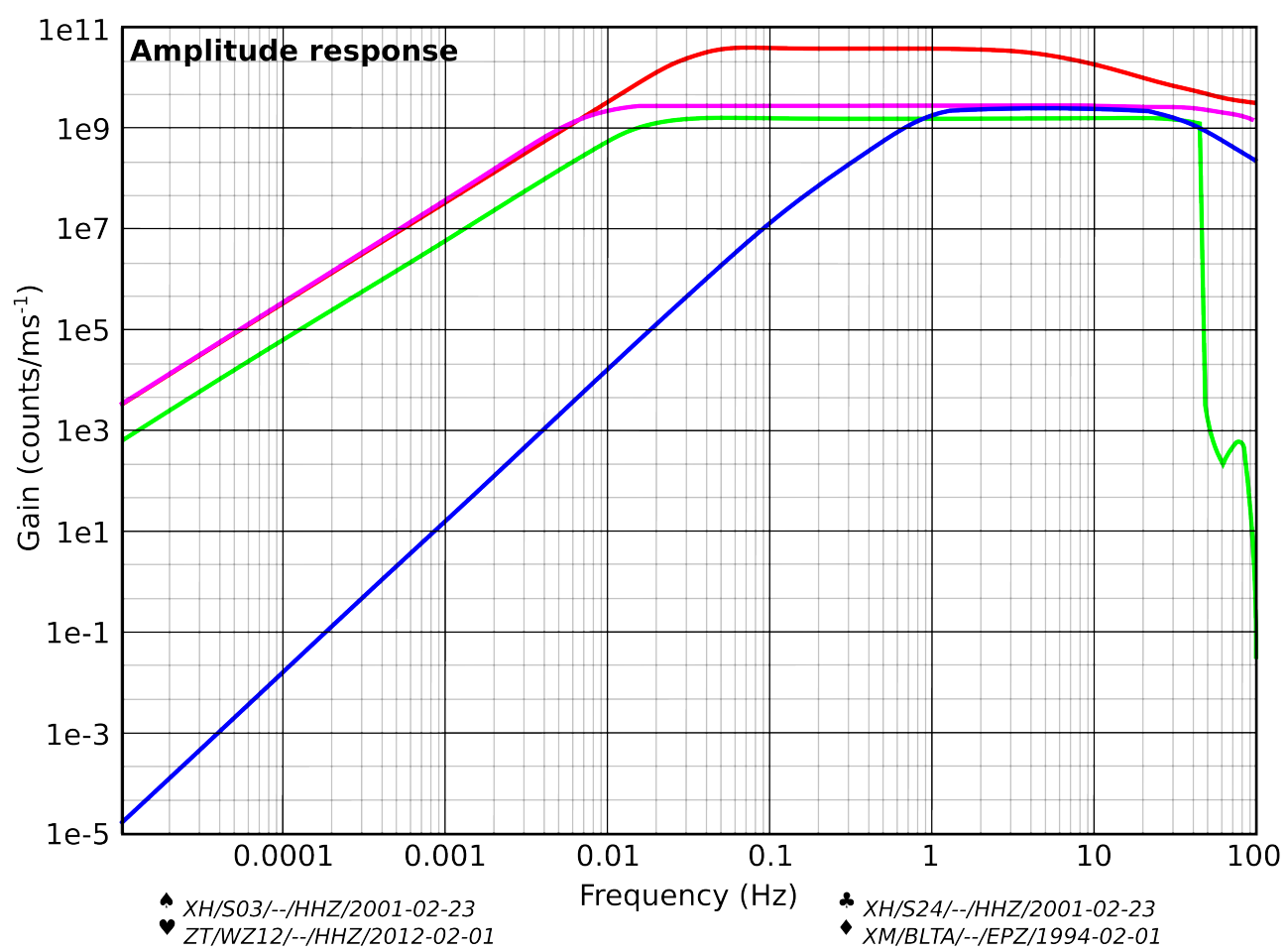

Compiled from queries on service.iris.edu/irisws/evalresp/1 (last accessed June 2015) for network/station/location/channel/time

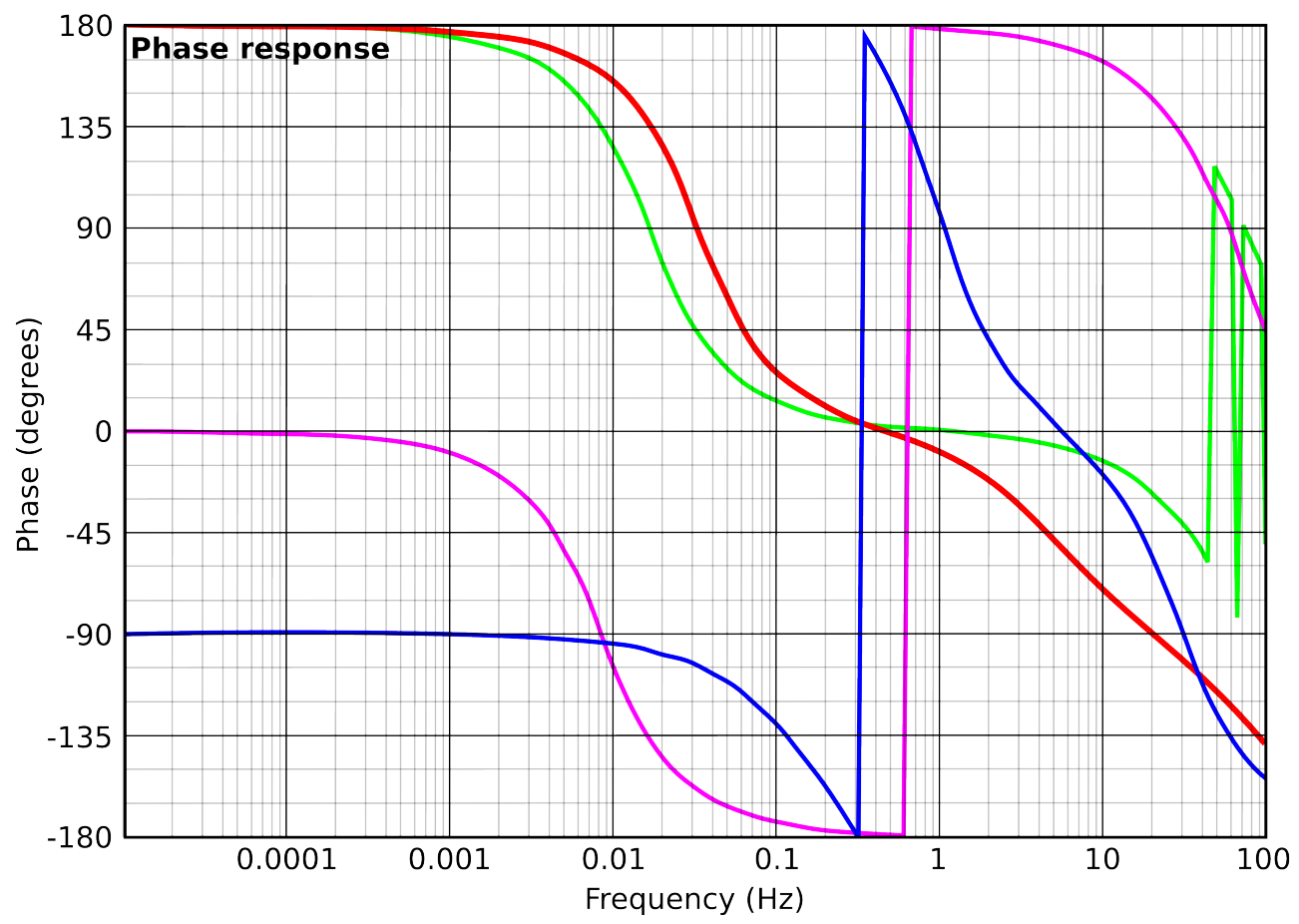

Figure 4.2: Bode plots of instrument frequency and phase response for different sensors, compiled from queries on service.iris.edu/irisws/evalresp/1 (last accessed June 2015). Guralp models are broadband; Marks L4 is short-period. Note the logarithmic scales for frequency and gain. 
Station specific response files for permanent and temporary GeoNet stations can be downloaded from ftp://ftp.geonet.org.nz/seed (last accessed April 2014). For broadband Guralp sensors from the SADAR deployment (models 40T, 6T and 3ESP), we calculated pole-zero files from the calibration files specific to each sensor's serial number (Appendix B). The serial number for station MASHUT (3ESP sensor) is undocumented, therefore we averaged the values of differential velocity for the other 3ESP stations (ASHAW, ATKR, BALD, HOR2, KBEL AND MAKA) to calculate the constant. The poles and zeroes for the 3ESP stations are the same for all sensors and components. For the $2 \mathrm{~Hz}$ short-period Marks L-4A sensors, which do not have calibration information available (PEN2, TONG, UP48), we use the nominal $5500 \Omega$ RESP file available from IRIS (http://www.iris.edu/NRL/sensors/sercel/sercel_14a_sensors.html, last accessed December 2014). RESP files for the START (network code XH) deployment are available at http://service.iris.edu/irisws/resp/1/ (last accessed December 2014).

To check our instrument response corrections are accurate, we look at local and teleseismic earthquakes. Local earthquakes contain significant energy at $2-8 \mathrm{~Hz}$, which is included in our sensors' range of highest gain. If the instrument response is correct, there should not be observable changes between local earthquake waveforms pre- and post- correction at a specific station. At low frequencies, the post-correction waveforms should look very similar for teleseismic earthquakes at all stations (broadband and short-period), due to the almost identical source-receiver paths. We also use teleseismic signals to ensure the component polarities are consistent across the network. We checked all stations' components using at least two local and two teleseismic events and did not identify any issues.

\subsubsection{Correlation window preparation}

For every possible station pair operating simultaneously on a specified day, we rotate the horizontal component (North and East) records for both stations into the radial (R, interstation path parallel) and transverse ( $\mathrm{T}$, interstation path perpendicular) orientations. We do not take into consideration different station elevations for this. Next we bandpass the three components (Radial, Transverse and Vertical) using a Butterworth filter, with corner frequencies of 0.05 and $9 \mathrm{~Hz}$. We cut the day long seismograms into 15 minute windows. We remove the first and last 15 minutes of the day, to avoid any ill effects of tapering and any small discrepancies in the start and end times. 


\subsubsection{Signal normalisation}

We apply signal normalisation in the frequency and time domains to remove glitches and ballistic impulses in the waveforms, in order to get a dataset as close as possible to a temporally and spatially uniform noise field. Signal normalisation also increases the CCF's SNR (Bensen et al., 2007). There are many methods of temporal normalisation; there is no consensus between researchers as to which way is best. Each method has its advantages and disadvantages; the process selected depends upon the characteristics of the dataset to which it is being applied. For this research, we employ frequency whitening prior to a 1-bit temporal normalisation, for the reasons stated below.

\section{Frequency whitening}

Spectral whitening smoothes the frequency spectrum's energy distribution (Bensen et al., 2007; Figs. 4.3, 4.4). This is achieved by dividing the noise spectrum's amplitude by its absolute value, without changing the phase (Stehly et al., 2009). By whitening, we increase the CCF's frequency range and decrease its variability between stations (Roux, 2009). Whitening also ensures persistent energy peaks from specific sources do not dominate the spectrum and bias the CCF (Bensen et al., 2007). Such sources include the primary and secondary ocean microseisms (6-9 and 14-17 s for New Zealand, Brooks et al., 2009), and earthquake signals $(2-8 \mathrm{~Hz})$. Furthermore, whitening removes the temporal variation of the noise spectrum between different days (Stehly et al., 2009). Many studies employ temporal normalisation in conjunction with whitening, however, some solely whiten (e.g. Stehly et al., 2009), if the resulting Green's functions are distinct.

\section{Temporal normalisation}

The goal of temporal normalisation is to remove the transient perturbations from the waveforms. Such examples include earthquakes, anthropogenic noise and instrument glitches. Common methods of temporal normalisation are: clipping, automated event detection and removal, running-absolute-mean normalisation and 1-bit normalisation (Bensen et al., 2007).

Clipping reduces the amplitudes of phases above a threshold amplitude to that maximum, usually related to the root-mean-square, or standard deviation of the trace (e.g. Roux, 2009). As the highest amplitudes of a seismogram are typically earthquakes that we wish to remove from the trace, clipping reduces their impact in the CCF. However, very 
small events may not be removed if their amplitudes are not as significant as other noise sources, or in highly seismic regions, the trace's root-mean-square or standard deviation may be overestimated due to the sheer number of events in the trace. As the volcanic and tectonic forces acting in the $\mathrm{TgVC}$ produce many different types of seismicity of varying frequency spectra, we have chosen to not clip the amplitudes of our traces.

The automated event detection and removal method (e.g. Bensen et al., 2007) replaces high amplitude phases (or glitches) with a zero-function of a certain width about the perturbation. The maximum amplitude and window width selected would be subjective and vary between stations. In regions of high seismicity, a significant amount of the waveform may be removed; therefore this method is unsuitable for this project.

Running-absolute-mean normalisation preserves amplitude information. The waveform is first bandpass filtered in the frequency range in which unwanted earthquake noise is expected to be present. This trace is then smoothed and the original is inversely weighted by the smoothed, filtered trace (Behr, 2011). Although the process effectively removes earthquake signals, instrumental glitches remain in the noise waveform (Bensen et al., 2007), which is why we do not use it.

Applying the one-bit normalisation reduces the waveform into a binary sequence, with +1 and -1 denoting positive and negative amplitude phases (Figs. 4.3, 4.4; Cupillard et al., 2011). While counter-intuitive, information regarding relative amplitudes of phases is preserved through the 1-bit normalisation, for spatially diffuse noise fields (Cupillard et al., 2011).

The one-bit normalisation is the most common technique used in ambient noise studies (e.g. Brenguier et al., 2011; Durand et al., 2011; Savage et al., 2013). This may be because it is the easiest method to apply, especially in cases where there are a number of spectrally different, non-uniform or transient noise sources impacting the waveforms. Additionally, one-bit noise correlations are not impacted by instrument glitches in the waveforms. As our study area is subject to many different kinds of seismicity (e.g. Sherburn et al., 1999) and weather patterns, we think it is the most appropriate technique to use for this project, over the other options outlined above. 
Progressive effects of pre-processing stages on time series and frequency spectra

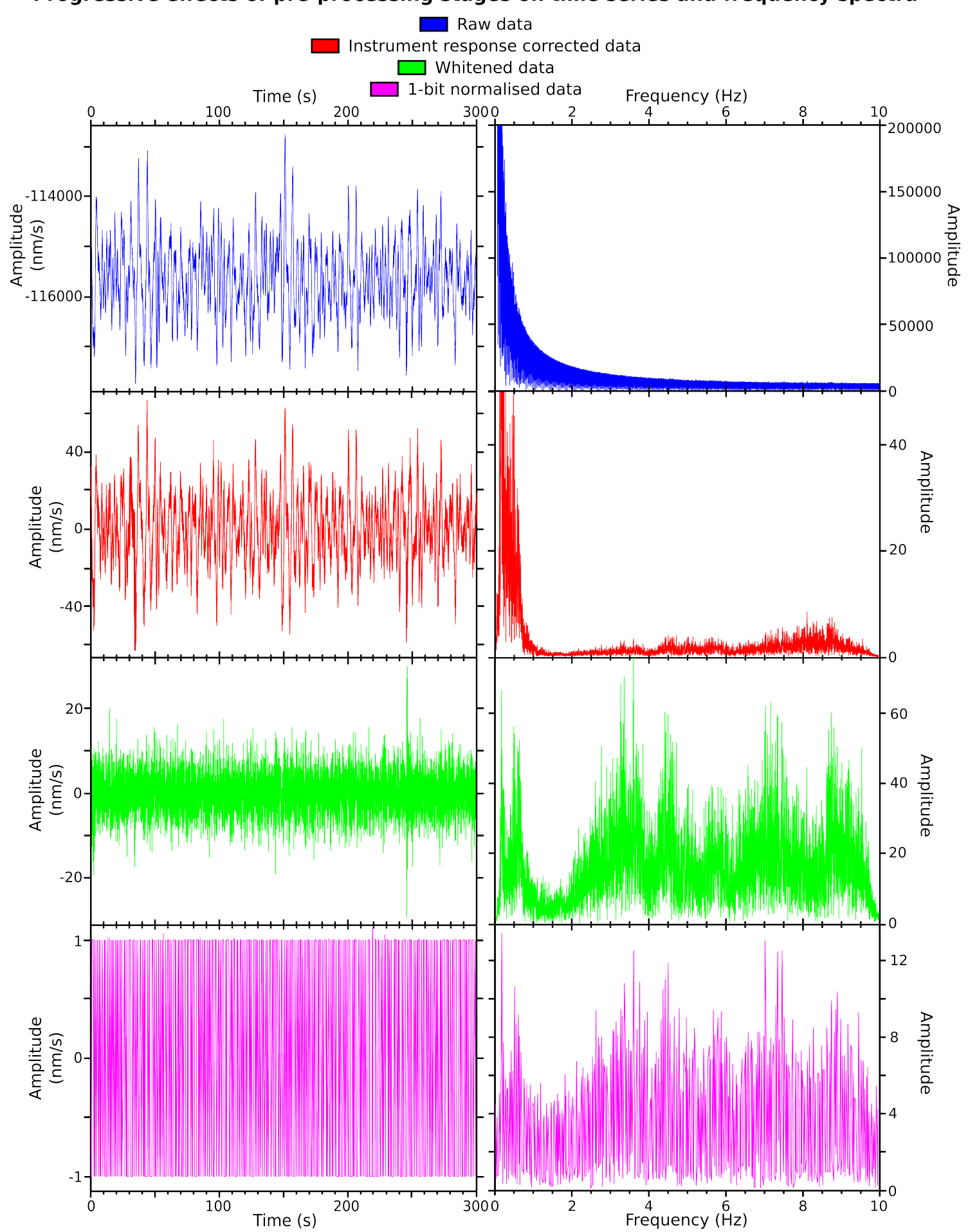

Figure 4.3: Example of a five-minute raw ambient noise recording (time series and frequency spectra), representative of most of our dataset, progressing through the instrument response correction whitening and one-bit normalisation stages of pre-processing. Note the different amplitude scales between stages and the clipped amplitudes of low frequencies for raw and instrument response corrected spectra. 
Progressive effects of pre-processing stages on time series and frequency spectra $\square$ Raw data

$\square$ Instrument response corrected data

Whitened data

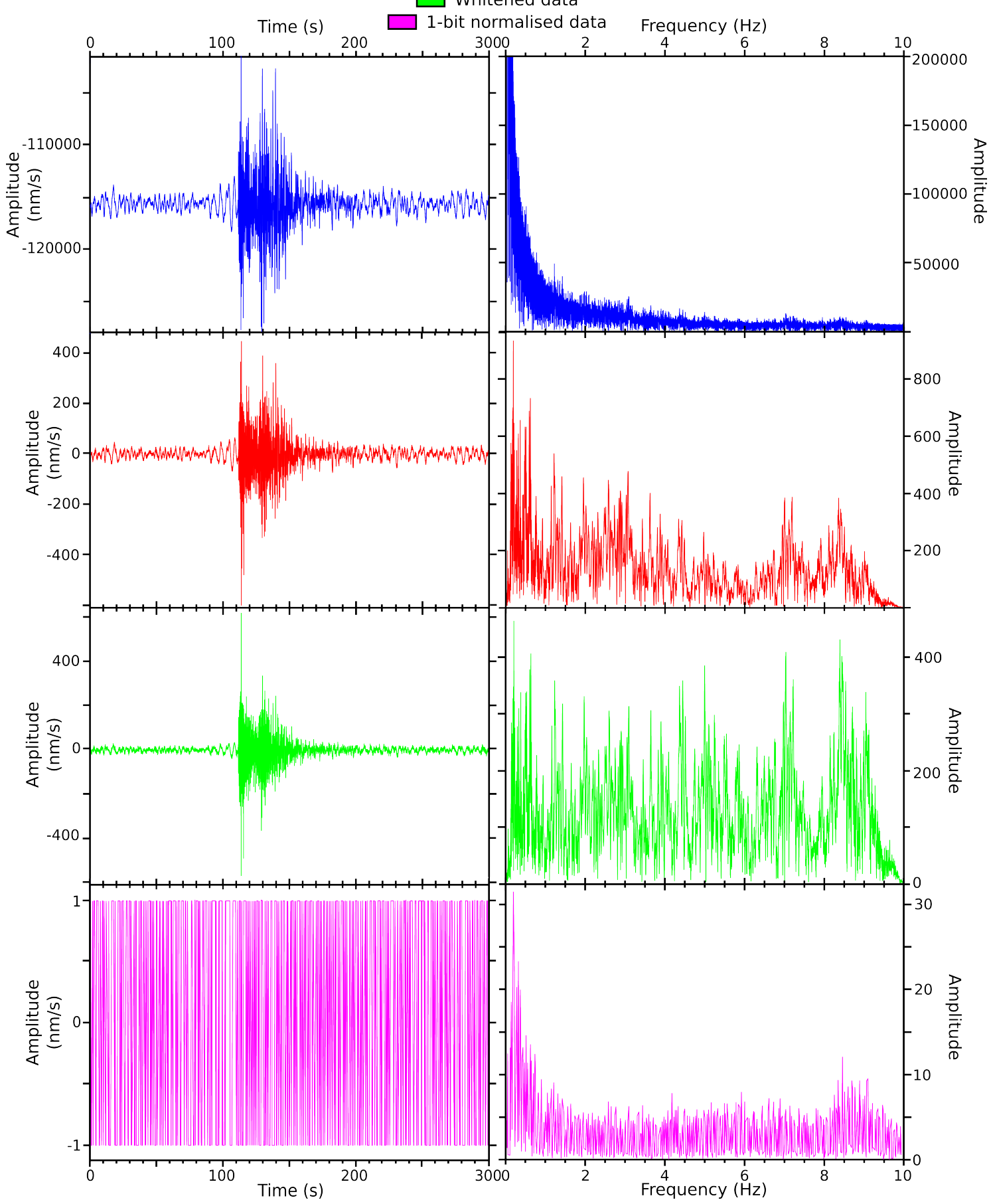

Figure 4.4: Example of a five-minute recording with a regional earthquake present, progressing through the instrument response correction whitening and one-bit normalisation stages of pre-processing. Note the different amplitude scales between stages and the clipped amplitudes of low frequencies for raw and instrument response corrected spectra. 
For our 1-bit normalisation, we divide the whitened time series' amplitude by its absolute value. Prior to division, we add $0.0001 \mathrm{~nm} / \mathrm{s}$ to the absolute value of each point, to avoid dividing some points by zero. Although this addition introduces an error into the $\mathrm{CCF}$, its magnitude is much less than the velocity measurement uncertainty.

\subsection{Cross-correlations}

For each station pair, we compute the causal and acausal CCF for the 94, 15 minute traces for each day (first and last 15 of the day are removed), and stack them, using SAC. Due to the output data's size, once the whole day was stacked we do not keep the individual 15 minute cross-correlations. We repeat this for all possible cross-correlation components for every station pair (nine components: RR, RT, RZ, TT, TR, TZ, ZR, ZT and ZZ, for a three/three-component station pair; ZR, ZT, ZZ for a one/three-component pair; ZZ, for a one/one-component pair).

We identify and remove the daily cross-correlation stacks that failed to correctly compute (typically due to persistent glitches or dropouts), from our catalogue of daily CCF. We then stack all the daily functions for each component and station pair into single stacks (henceforth termed full-stacks), and normalise them by dividing the resulting function's amplitude by the number of traces included (e.g. Fig. 4.5). Some 2008 stations have sensor changes during their deployment (TUVZ, ATKR and HOR2); however, we still stack all available data as we do not observe any significant changes between the dialy CCF.

\subsection{Group velocity dispersion measurements}

Using MATLAB, we measure the group velocity, using a two-station, multiple-filter approach based on that of Fry et al. (2010); Meier et al. (2004); Stehly et al. (2009), modified for group, rather than phase velocity measurements. We do not apply phase corrections to the RZ and ZR components prior to measuring dispersion. This means that there are systematic differences present in their dispersion curves, which we later correct in the time domain by a $1 / 4$ wavelength subtraction from the $\mathrm{ZZ}$ component. 


\title{
Example daily and full cross-correlation stacks
}

\author{
$\square$ Single day stack \\ $\square$ Full stack
}
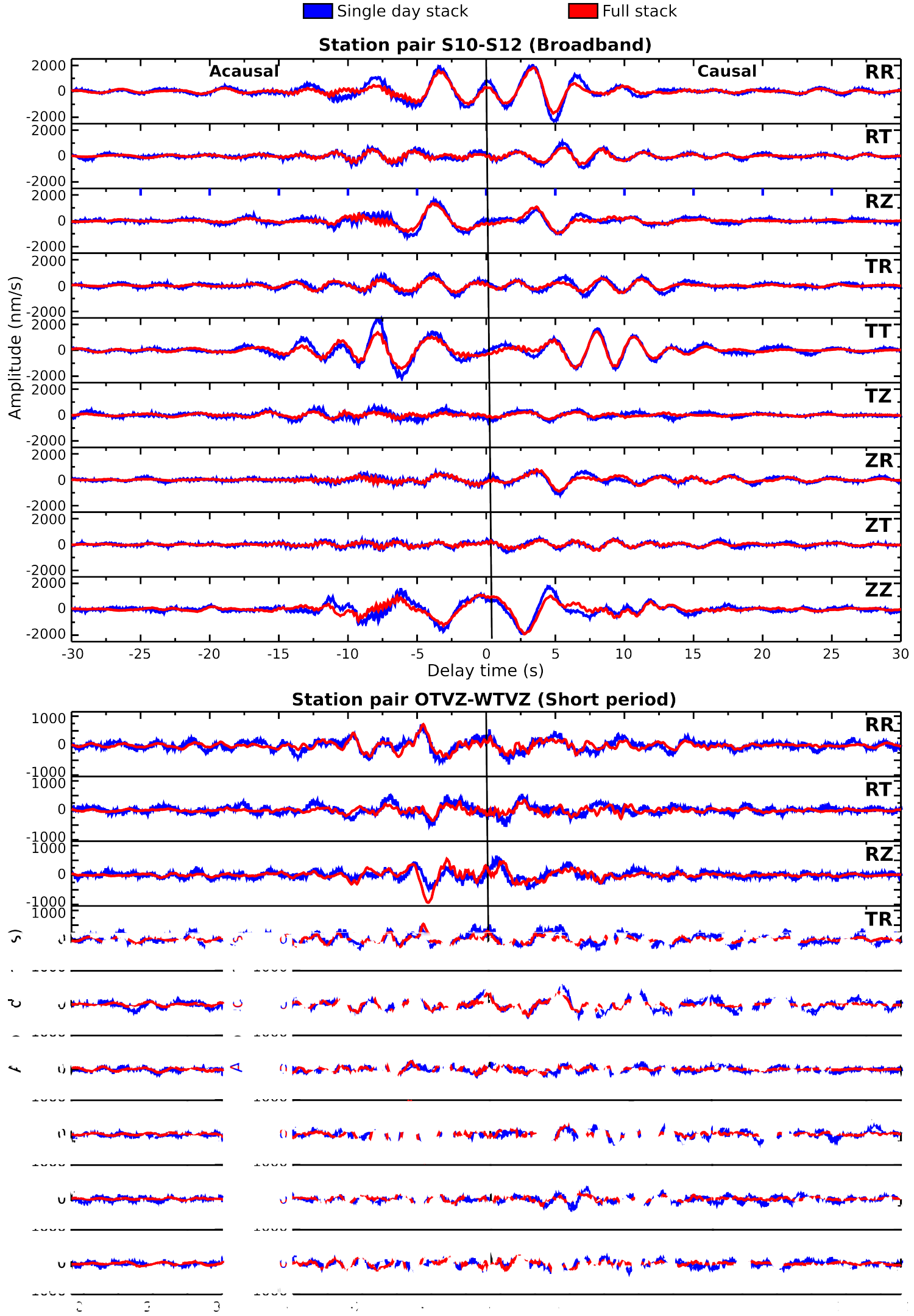

Figure 4.5: Examples of daily and full-stack nine-component cross-correlations for two station pairs of similar interstation distance: Top and bottom are pairs of broadband (105 day full-stacks) and short-period (365 day full-stacks) sensors, respectively. 
Workflow of cross-correlation dispersion measurements

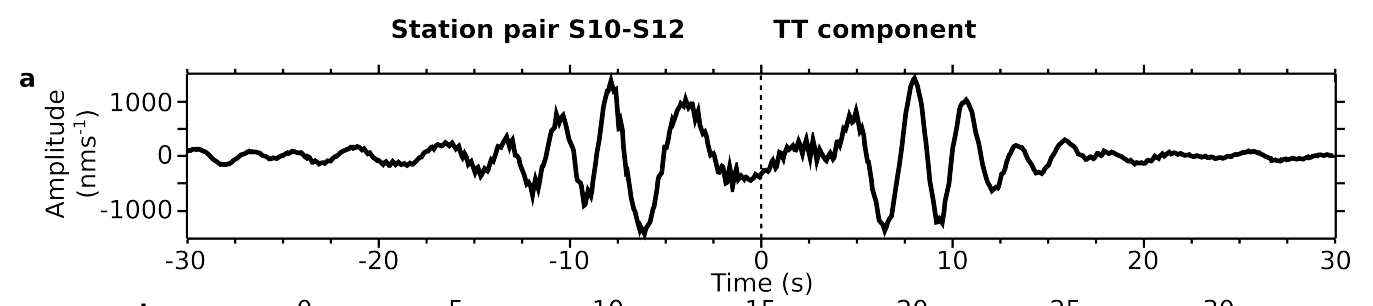

b
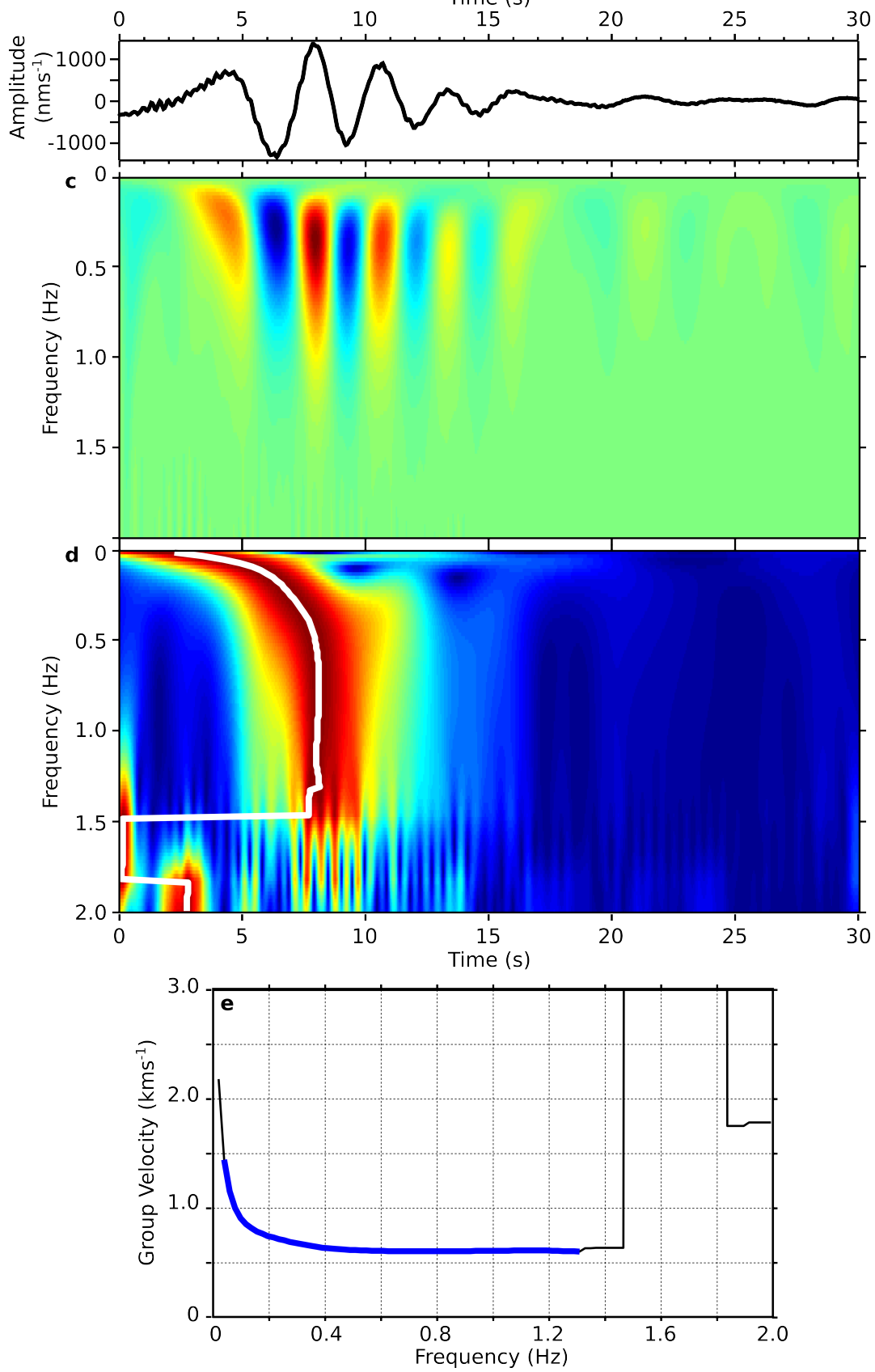

Figure 4.6: Workflow of dispersion measurements: a) unfiltered, two-sided crosscorrelation; b) symmetric cross-correlation; c) spectrogram of b); d) best multiple-filtered frequency-time (MFT) plot, with $\gamma=1.0$. White line is automatically picked dispersion measurement; e) dispersion measurement from one-sided cross-correlation. Black line is automatically picked measurement from d); superimposed blue line is manually refined, final dispersion curve. 
Effect of smoothing parameter $(y)$ on dispersion measurements
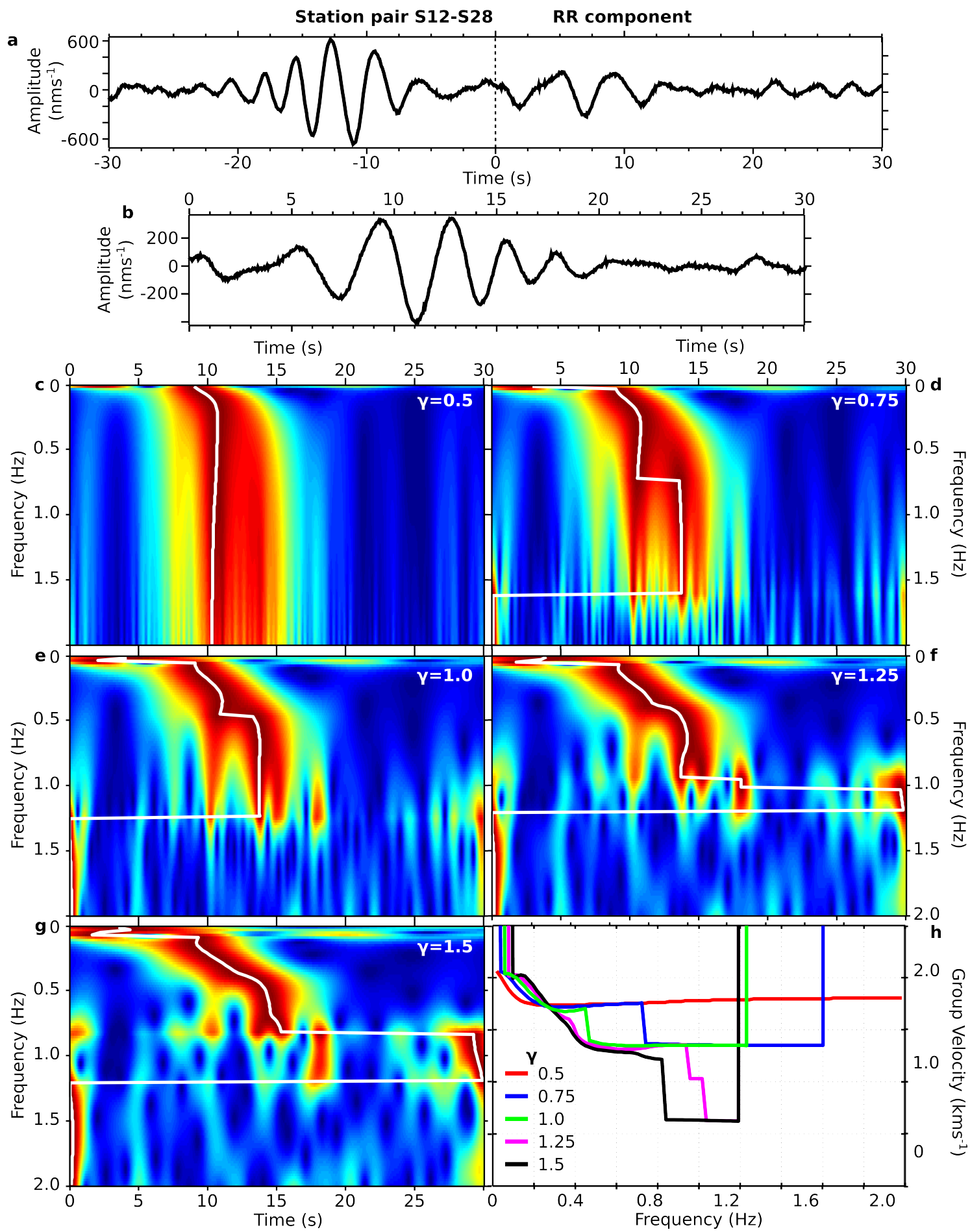

Figure 4.7: MFT plots for a cross-correlation where smoothing parameter, $\gamma$, varies: a) unfiltered, two-sided cross-correlation; b) symmetric cross-correlation; c) MFT for $\gamma=0.5$; d) $\gamma=0.75$; e) $\gamma=1.0$; f) $\gamma=1.25$; g) $\gamma=1.5$; h) automatically picked dispersion curves for $c-g$ (white lines), coloured by $\gamma$ (superimposed in order of increasing $\gamma$ ). 
First, we average the full-stack's causal and acausal portions (Fig. 4.6a)to make a symmetric function. We then cut this function to a 60 second window (beginning at zero) and detrend and taper it (Fig. 4.6b). Next, multiple (overlapping) Gaussian filters (Equation 4.1) are applied, with the passband width depending on the smoothing parameter, $\gamma$ (Equation 4.2). The frequency spacings of maximum response (bin width) is determined by the detrended/tapered CCF's frequency range and total number of bins given. We use bin widths of $0.03 \mathrm{~Hz}$ for the full dataset, but re-measure the RR, TT and ZZ dispersion using $0.02 \mathrm{~Hz}$ bin widths for the analyses of primary station pairs S10-S28 and OTVZ-WTVZ.

$$
\begin{gathered}
g(f)=e^{-\alpha\left(f-f_{0}\right)^{2}} \\
\alpha=2 \pi f_{0} \cdot \gamma^{2}
\end{gathered}
$$

Next, the amplitudes at each frequency are normalised so that the absolute value of the maximum is one, regardless of the delay time, and a multiple-filtered frequency-time plot is produced (MFT plot, e.g. Fig. 4.6d). A curve is automatically produced by linearly interpolating the amplitude maxima of the different filtered waveforms together in frequency-time space. This then becomes the automatic dispersion curve with group velocity derived from the pair's interstation distance, and is superimposed on the MFT plot (e.g. Fig. 4.6d). Finally, we manually separate the parts of the curve which accurately reflect the group velocity of surface waves in the cross-correlation and assign them alpha-numeric grades that reflect the measurement quality and confidence, and certain characteristics of, or features in the cross-correlation and the dispersion curve, if present (Table 4.1). Later, we assign a second, simpler grade to the measurements, which we use to decide which measurements are suitable for inversions (Table 4.2).

The $\gamma$ parameter must be kept as small as possible, to gain the highest possible resolution for the dispersion measurement. However, if $\gamma$ is too small, the moveout is not preserved and the dispersion curve becomes a flat line (e.g. Fig. 4.7c). For best results, $\gamma$ must be set independently for each measurement. In order to do this, we produce MFT plots with automatic dispersion picks for $\gamma=0.5,0.75,1$ and 1.25 for all symmetric functions. Each is inspected (e.g. Fig. 4.7c-f) and the best plot chosen for measurement picking, selected for the dispersion quality and confidence (Table 4.1). If more smoothing is required, the stack is reprocessed at $\gamma=1.5$ and re-inspected (e.g. Fig. $4.7 \mathrm{~g}$ ), with $\gamma$ increased again if necessary. In general, short-period stations and pairs with long interstation 
distances require higher values of $\gamma$ than broadband and close stations.

\begin{tabular}{|c|c|c|}
\hline Type & Grade & Description \\
\hline \multirow{4}{*}{ 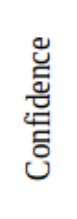 } & 1 & Very confident in measurement \\
\hline & 2 & Confident in measurement \\
\hline & 3 & Uncertain in measurement \\
\hline & 4 & Very uncertain in measurement \\
\hline \multirow{5}{*}{$\stackrel{\Xi}{\stackrel{\Xi}{\Xi}}$} & $\mathrm{L}$ & Ultra-high quality dispersion with frequency range $>0.7 \mathrm{~Hz}$ \\
\hline & 0 & High quality dispersion with a wide frequency range $>0.7 \mathrm{~Hz}$ \\
\hline & A & High quality dispersion only $<0.5 \mathrm{~Hz}$ \\
\hline & AA & High quality dispersion only $<0.3 \mathrm{~Hz}$ \\
\hline & $\mathrm{H}$ & High quality dispersion only $>0.4 \mathrm{~Hz}$ \\
\hline \multirow{8}{*}{ 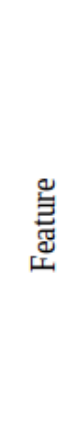 } & B & High amplitude phase unable to be removed completely by non-default preonset values \\
\hline & $\mathrm{F}$ & Apparently low quality cross-correlation \\
\hline & $\mathrm{J}$ & Automatic dispersion line jumps around \\
\hline & M & Multiple clearly defined phases (possibly modes) observed \\
\hline & S & Red region around automatic dispersion line has large time range \\
\hline & $\mathrm{W}$ & Group velocity increases with frequency, with a steep gradient $<0.2 \mathrm{~Hz}$ \\
\hline & $\mathrm{Z}$ & Cross-correlation contains strong $2-3 \mathrm{~Hz}$ ringing \\
\hline & $\mathrm{V}$ & Strong, extremely low velocity phase present $(0.2-0.6 \mathrm{~km} / \mathrm{s})$ \\
\hline
\end{tabular}

Table 4.1: Initial alpha-numeric grading scheme for dispersion measurements. Grade L is the highest possible, $O, A, A A$ and $H$ are equivalent in quality but differ by frequency range. All grades contain a quality letter and confidence number.

\begin{tabular}{|c|c|c|c|}
\hline $\begin{array}{l}\text { Final } \\
\text { Class }\end{array}$ & Confidence & Qualifying initial grades & Examples \\
\hline A & $1 \& 2$ & $\begin{array}{l}\text { Quality A, AA, H, O, or L with any B, J, } \\
\text { S, V or Z features }\end{array}$ & $\begin{array}{l}\text { LV1 } \\
\text { OJZ2 }\end{array}$ \\
\hline A2 & 1 & $\begin{array}{l}\text { Quality A, AA, H, O, or L with any M } \\
\text { features* }\end{array}$ & $\begin{array}{r}\text { HM1 } \\
\text { LMZ1 }\end{array}$ \\
\hline B1 & 1 & $\begin{array}{l}\text { Quality A, AA, H, O, or L with any F, M } \\
\text { or W features* }\end{array}$ & $\begin{array}{l}\text { AAMW1 } \\
\text { LWZ1 }\end{array}$ \\
\hline B2 & 2 & $\begin{array}{l}\text { Quality A, AA, H, O, or L with any F, M } \\
\text { or W features* }\end{array}$ & $\begin{array}{l}\text { AAMW2 } \\
\text { LMZ2 }\end{array}$ \\
\hline $\mathrm{C}$ & $3 \& 4$ & All & $\begin{array}{c}\text { AMZ3 } \\
\text { HF4 }\end{array}$ \\
\hline
\end{tabular}

Table 4.2: Final dispersion classification scheme. ${ }^{*}$ in conjunction with any $B, J, S, V$ or $Z$ features. 


\section{Examples of dispersion measurements with non-default time windows}
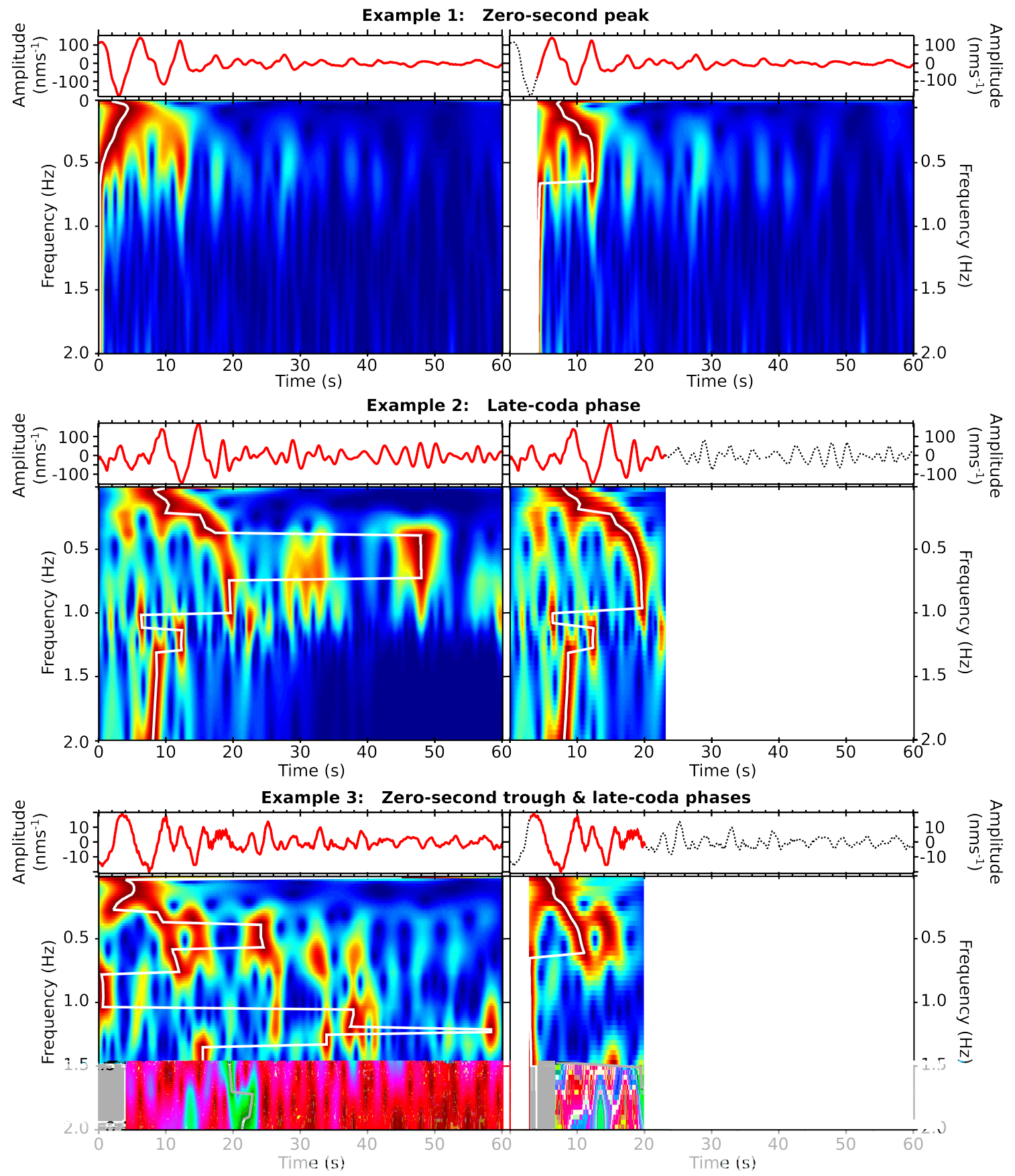

Figure 4.8: Three example cross-correlations where non-default time windows are required to obtain dispersion measurements. For each, the solid red line represents the window of the symmetric cross-correlation used in producing the MFT plot and automatically picked dispersion; dashed black line shows portion of cross-correlation excluded. Left-hand side shows default 0-60 second window, right-hand side shows adjusted window with improved measurement: 1) $4 \mathrm{~s}$ pre-onset used; 2) $23 \mathrm{~s}$ cut-off; 3) $3 \mathrm{~s}$ pre-onset and $20 \mathrm{~s}$ cut-off. 
One disadvantage of this method is that any high amplitude phases present in the cross-correlation, even if they are not surface waves, are automatically picked. To remove them from the function, we refine our 60 second time window. Such phases are typically present either towards the zero-delay time (Fig. 4.8, examples 1 and 3), or very late in the coda (with apparent velocities of 0.2 to $0.6 \mathrm{~km} / \mathrm{s}$, Fig. 4.8 , example 2).

\subsubsection{Mode Identification}

Our method of picking dispersion curves cannot differentiate between different modes. In most cases we are unable to confidently identify the picked phase's mode from solely looking at the MFT plot and spectrograms of each function independently. Incorrect mode identification will result in large errors in any further analysis or inversion. However, correct identification can be difficult, as higher modes do not have distinct characteristics to easily separate them from the fundamental (Fah, 2010).

Complex relationships may exist between modes, depending on the velocity structure, particularly fundamental and first-higher order (Fah, 2010; O’Neill and Matsuoka, 2005). Usually, the fundamental has the highest energy, and most structural studies using ambient noise solely focus on it (section 3.3.1). Higher-order modes have been observed, however, and may even dominate the Green's function (O'Neill and Matsuoka, 2005). Although this is mostly observed in studies concerned with scales much smaller than our own (e.g. Louie, 2001; Xia et al., 2000; Xia et al., 2003), there are cases that are of comparable scale to our research (e.g. Savage et al., 2013). One mechanism by which dominant higher modes may occur is the presence of strong impedance contrasts that trap energy and force it to resonate (Fah, 2010; Savage et al., 2013). Such conditions likely exist in our study area, as slower sediments lie upon basement greywacke (section 2.4.1).

To assign modal classifications to our dispersion measurements, we have devised a simple routine, which we henceforth refer to as the station-grouping method. We plot the dispersion measurements involving a particular station together and look for clustering of the curves to indicate the group velocity ranges of different modes (see section 5.2.2). We plot the in-phase Rayleigh-wave CCF components (RR and ZZ) together and the TT (Love) independently, and highlight the few measurements to which we confidently ascribed modes during the MFT analysis. We do not think it is appropriate to assign modes to the $\mathrm{RZ} / \mathrm{ZR}$ measurements due to the required phase correction. 
The study area's diverse structure is such that we must consider each station independently, as the velocity ranges for different modes vary significantly and sometimes overlap. We can, however, compare certain stations with others located nearby (e.g. TUVZ/S10, NGA4/NGA5/NGA6) and to the synthetic dispersion curves (section 4.7). In doing this, we progressively identify to which mode the curves are most likely to relate. Finally, measurements that appear as though they could belong to more than one mode for both cross-correlated stations are rejected.

\subsubsection{Error analysis}

The algorithm used for group velocity dispersion analysis does not quantify measurement error. However, uncertainty must be considered when inverting these measurements for structure. Therefore, for the curves we inverted for one-dimensional shear-wave structure, we elected to use the measurement stability through the study period as a proxy for error. We split the full-stack of available data into multiple, approximately equal time periods, henceforth termed "blocks", made dispersion measurements on each and calculated the standard deviation of the blocks' dispersion at each frequency. The full-stack dispersion measurement's uncertainty is $+/$ - one standard deviation. The blocks are of different length for different curves due to the variation of number of days in the full-stacks. As this is a time intensive process, we determined the error only for a select few measurements from station pairs S10-S28, OTVZ-WTVZ, KRVZ-NGZ and WNVZ-WPVZ.

\subsubsection{Average dispersion curves}

We calculate average dispersion curves for Ruapehu and Tongariro from high quality measurements from localised station pairs to create general models of the volcanoes. We re-inspect the MFT plots of all measurements included in the average calculations to ensure the accuracy of our mode identification and measurement quality. We calculate the average R0, R1, L0 and L1 dispersion curves as the average of all relevant measurements at every discrete frequency. The standard deviation $(+/-)$ of the input measurements at each frequency is adopted as the average dispersion curve's uncertainty.

\subsection{Signal-to-noise ratios}

Signal-to-noise ratios (SNR) of seismic signals are primarily used for assessing data quality, with the higher the SNR, the better the quality. SNR of cross-correlations indicates the 
estimated Green's functions' strength and likelihood of retrieving useful information about the subsurface structure. However, in a completely isotropic structure, the RT, TR, TZ and ZT cross-correlation components are expected to have SNR of 0 . Therefore SNR values can be ambiguous and require careful interpretation. Here we use SNR to look at the quality of our cross-correlation stacks and indicate anisotropy.

\section{Signal-to-noise ratio workflow}

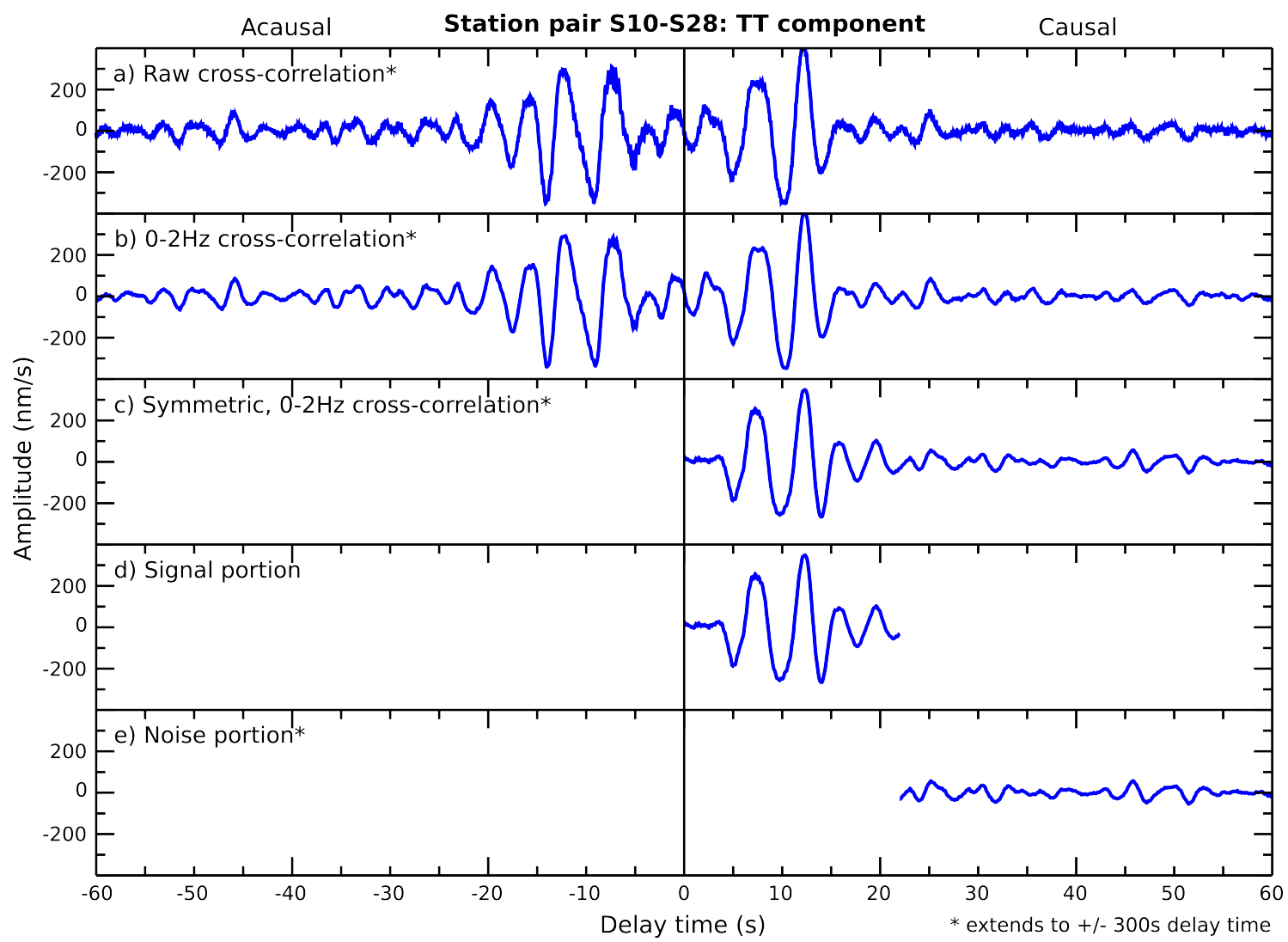

Figure 4.9: Breakdown of steps involving in calculating signal-to-noise-ratios. Final SNR is the maximum absolute amplitude of the signal portion divided by the standard deviation of the absolute amplitudes of the noise portion.

We calculate SNR on all our full-stacks, following the approach of Stehly et al. (2009) with some modifications (Fig. 4.9). Using SAC, we first taper the raw cross-correlation and apply a $2 \mathrm{~Hz}$ lowpass filter. We then make the cross-correlation symmetric by calculating the average of the causal and acausal portions. Next, we cut this filtered, symmetric CCF into signal (times $>0.6 \mathrm{~km} / \mathrm{s})$ and noise portions (times $<0.6 \mathrm{~km} / \mathrm{s})$.

Using MATLAB, we make the waveform amplitudes positive, and calculate the SNR as the signal's maximum amplitude divided by the standard deviation of the noise. Dispersion 
measurements from stacks with SNR $<7$ are reclassified as class $\mathrm{C}$ (section 4.4).

\subsection{Particle motion}

We analyse particle motion for the primary station pairs (section 5.4) to ensure that the dispersion measurements we invert conform to that expected for fundamental mode surfacewaves. To do this, we select a time window of the cross-correlation component based on its MFT plot and dispersion measurements. Using SAC, we then plot the particle motion with two CCF providing axes. For Rayleigh waves, we do this for the RR/RZ (RR with RZ), RR/ZR, RZ/ZZ, ZR/ZZ, RZ/ZR and RR/ZZ components. We plot the RR/TT and $\mathrm{TT} / \mathrm{ZZ}$ for Love waves.

For fundamental mode Rayleigh waves we expect the RR/RZ, RR/ZR, RZ/ZZ and $\mathrm{ZR} / \mathrm{ZZ}$ components, which are $1 / 4 \lambda$ out of phase, to have elliptical particle motion with amplitude maxima on the axes. We expect linear (on the diagonal) particle motion for the in-phase $\mathrm{RR} / \mathrm{ZZ}$ and $1 / 2 \lambda$ out of phase RZ/ZR components. The relative speeds of the Rayleigh and Love waves dictate RR/TT and TT/ZZ plots' characteristics.

\subsection{Synthetics}

We calculate group velocity dispersion curves and simulate causal CCF with the intention of identifying the different modes present in our real data. $\mathrm{V}_{S}$ inversions of the calculated dispersion curves will indicate model resolution of our measurement inversions. Using the Gpdc open source software package, associated with the Geopsy project (GpdcWiki; http://www.geopsy.org/wiki/ index.php/Gpdc, last accessed August 2015), we calculate fundamental and first higher-order mode group velocity dispersion curves for Rayleigh and Love waves. A limitation of this tool is that the minimum frequency in the calculation is approximately $0.3 \mathrm{~Hz}$ for R1/L1.

We make synthetic CCF using the normal mode summation module of the Computer Programs in Seismology (CPS) software package (Herrmann, 2013). We calculated CCF for the fundamental mode, the sum of the first two modes and the sum of the first 10 modes (an approximation of the sum of all modes). The software does not automatically produce seismograms for isolated higher-order modes; we subtract the fundamental CCF from the two mode sum to isolate the first higher-order mode. 
We calculate the RR, RZ, ZR, and ZZ component CCF using the same two models as the calculated Gpdc curves. For both models, we use single point sources at $750 \mathrm{~m}$ depth, (following Savage et al., 2013). We simulate CCF for source-receiver distances of 1, 1.5, $2,3,4,5,6,8,10,12,14,16,18,20,25,30,35,40,50,60,70$ and $80 \mathrm{~km}$, representing the range of our real dataset. We make group velocity dispersion measurements on the synthetic R0, R1 and RA CCF using the method described in section 4.4 (with $\gamma=1.0$ ).

Many one-dimensional P-wave models have been derived for various locations in the TgVC (section 2.4.1), however, there is much variability between the velocities and layer structures due to structural complexity. We expect to produce models of only the top few kilometres of the crust from our data. For comparison with synthetics, we require a starting velocity model which has reasonable resolution at that depth range, but which is simple enough to be able to act as a proxy for a substantial region.

The existing models with the highest resolution at shallow depths do not extend deep enough to be used exclusively for our synthetics, and it is likely to be inappropriate to use them as approximations for the entire region. Similarly, the models which do extend deeper than a couple of kilometres do not have the shallow resolution we require. For this reason, we experimented with merged models (e.g. tables $4.3 ; 4.4$, and elected to use two - one for each of Tongariro and Ruapehu.

Both CPS and Gpdc require layered $\mathrm{V}_{P}$ and $\mathrm{V}_{S}$ models and a density structure. We convert $\mathrm{V}_{P}$ to $\mathrm{V}_{S}$ (and vice-versa) using a $\mathrm{V}_{P} / \mathrm{V}_{S}$ values of 1.75 where necessary, and calculate the density by applying Gardner's relation (Gardner et al., 1974; equation 4.3) to each layer of the $\mathrm{V}_{P}$ model.

$$
\rho=1.74 V_{P}^{0.25}
$$

\subsubsection{Input velocity model 1: JR}

Our first model (JR), uses the P-wave model derived by Jolly et al. (2014b) for depths 0-2 $\mathrm{km}$ and Rowlands (2004) for depths 2-6 km. Below $6 \mathrm{~km}$, we assume a halfspace with a $\mathrm{V}_{P}$ of $6 \mathrm{~km} / \mathrm{s}$. The synthetics derived from this input model are intended to be compared to our real data for the Tongariro area.

Jolly et al. (2014b) used high-impact mass-drops to resolve a local velocity structure in the vicinity of Mount Tongariro, after the 2012 eruptions. This model, of $2 \times 1 \mathrm{~km}$ thick 
layers over a halfspace, was used to locate the earthquake swarm prior to the first eruption (Hurst et al., 2014).

\begin{tabular}{|c|c|c|c|c|}
\hline Layer & Depth $\mathbf{( k m )}$ & $\mathbf{V p}(\mathbf{k m} / \mathbf{s})$ & Vs (km/s) & Density (gcc-1) \\
\hline 1 & $0-1$ & 1.8 & 1.0 & 2.0 \\
2 & $1-2$ & 3.6 & 2.1 & 2.4 \\
3 & $2-4$ & 5.2 & 3.1 & 2.6 \\
4 & $4-6$ & 5.5 & 3.5 & 2.7 \\
Halfspace & $6+$ & 6.0 & 3.6 & 2.7 \\
\hline
\end{tabular}

Table 4.3: JR input model for synthetics

\subsubsection{Input velocity model 2: FR}

For depths 0-2km, our second model, FR (Table 4.4), uses the S-wave velocity structure derived from a Bayesian inversion of the RR (as the first higher-order mode) and ZZ (fundamental mode) dispersion curves for station pair S10-S28 (Figs. 2.5, 4.1; Bill Fry, pers. comm.). Below $2 \mathrm{~km}$, the FR and JR models are identical. This model is intended to represent Ruapehu Volcano.

\begin{tabular}{|c|c|c|c|c|}
\hline Layer & Depth $\mathbf{( k m )}$ & $\mathbf{V p}(\mathbf{k m} / \mathbf{s})$ & $\mathbf{V s}(\mathbf{k m} / \mathbf{s})$ & Density (gcc-1) \\
\hline 1 & $0-1$ & 2.2 & 1.3 & 2.0 \\
2 & $1-2$ & 2.9 & 1.6 & 2.4 \\
3 & $2-4$ & 5.2 & 3.1 & 2.6 \\
4 & $4-6$ & 5.5 & 3.5 & 2.7 \\
Halfspace & $6+$ & 6.0 & 3.6 & 2.7 \\
\hline
\end{tabular}

Table 4.4: FR input model for synthetics

\subsection{D Shear-wave velocity profiles}

We generate isotropic one-dimensional (vertical) $\mathrm{V}_{S}$ profiles using the Dinver open source software package, associated with the Geopsy project (DinverWiki; http://www.geopsy.org /wiki/index.php/Dinver, last accessed July 2015). This software uses a neighbourhood algorithm (Sambridge, 1999), modified after Wathelet (2008), to search for the best fitting model to input data in a multi-parameter space with irregular boundaries. The algorithm achieves convergence towards the best fitting model by using a pseudo-random generator (Wathelet et al., 2004), in order to solve a non-linear, Bayesian inversion process in a timely manner. First, the process randomly selects different values for the parameters required for 
a subsurface model (i.e. all velocities and depths) and analytically solves for the dispersion curve(s) to which that model would correspond. Comparing this forward model dispersion and the input data determines a misfit value, given by equation 4.4 , where $x_{d i}$ is the input data's velocity at frequency $f_{i}, x_{c i}$ is the forward calculated curve's velocity at $f_{i}, \sigma_{i}$ is the uncertainty of $x_{d i}\left(x_{d i}\right.$ replaces $\sigma_{i}$ if uncertainty is not given) and $n_{F}$ is the number of points in the input data curve (Wathelet et al., 2004).

$$
\text { misfit }=\sqrt{\sum_{i=0}^{n_{F}} \frac{\left(x_{d i}-x_{c i}\right)^{2}}{\sigma_{i}^{2} n_{F}}}
$$

After randomly sampling across the parameter space, the algorithm compares the misfit values from different areas and narrows its search ranges to investigate the areas of low misfit more closely. As random processes are involved, there is a risk of the algorithm converging towards a local minimum. This effect can be mitigated by the user carefully selecting the permitted search ranges and running the process multiple times (Wathelet et al., 2004). However, $V_{S}$ profile solutions to dispersion curve inversions are often nonunique (e.g. Foti et al., 2009), therefore running the process using different search ranges is also recommended. Jointly inverting multiple modes also reduces ambiguity by increasing the constraints on the model.

Our dispersion measurements and uncertainty have been calculated in terms of group velocities. However, Dinver computations are based on slowness; all input velocities are converted. As a consequence, the uncertainty is an approximation only - an arithmetic average (DinverWiki).

We resample all input dispersion curves to maintain consistency between dispersion measurements, especially when they are simultaneously inverted. Different sampling methods have different effects on the inversion due to different distributions across the frequency range. A linear sampling rate in frequency or period units gives higher weights on high and low frequencies, respectively (DinverWiki). A sampling rate in log space somewhat mitigates this effect, which is why we use it. Our data is resampled uniformly in log space so that there are 45 points between 0.1 and $1 \mathrm{~Hz}$. Each point within the resampled curve is given equal weight in the inversion. Points on the input curve outside these limits are removed; we do not extrapolate points if the input does not span the entire 0.1-1 $\mathrm{Hz}$ range. 
To simplify the inversion process, we consider only the shear-wave structure from group velocity dispersion measurements, so we link the $\mathrm{V}_{P}$, Poisson's ratio and density parameters of each layer to the search for Vs and depth to the bottom of each layer. We allow the inversion to search within large ranges for $\mathrm{V}_{P}$ and Poisson's ratio to reduce the impact they could have on the models. We fix density to $2000 \mathrm{kgm}^{-3}$ as it has very little effect on dispersion (Wathelet et al., 2004).

To avoid over-parameterising our models, we start with a simple case of one homogeneous layer over a halfspace and progressively add homogeneous layers to gain a better fit, until the total misfit begins to stabilise. By balancing simplicity with fit, we select the number of layers for the final inversions. This is a time intensive process. After investigation with three input curves from Ruapehu and Tongariro volcanoes each, we observed that four layers over a halfspace was invariably the optimum structure, and subsequently used that as a starting point for all further analyses (Table 4.5).

\begin{tabular}{|c|cc|}
\hline Layer & Vs range (m/s) & Depth range (m) \\
\hline $\mathbf{1}$ & $800-2000$ & $100-1500$ \\
$\mathbf{2}$ & $800-2000$ & $500-2000$ \\
$\mathbf{3}$ & $1000-2500$ & $800-2500$ \\
$\mathbf{4}$ & $1000-2500$ & $1000-3500$ \\
Halfspace & $1000-3500$ & - \\
\hline
\end{tabular}

Table 4.5: Initial parameter range for four-layer $\mathrm{V}_{S}$ inversions

We begin each inversion with wide, but reasonable ranges for $\mathrm{V}_{S}$ and depth for each layer (Table 4.5). After the computation of 50000 forward inversions (one run), we reevaluate and adjust the search parameter range, taking into consideration the misfit of $\mathrm{V}_{S}$ and depth of each layer within the final model (as projected in two-dimensional space). This refines the output model and ensures that the algorithm does not converge towards a false minimum. We repeat this process until the final output between runs stabilises.

For our average Ruapehu and Tongariro dispersion curves (section 5.5) and certain station pairs (section 5.4), we invert the R0 and L0 dispersion curves independently and jointly, for one dimensional Vs profiles. We henceforth refer to these as the R0, L0 and R0L0 inversions, respectively. 


\subsubsection{Uncertainty estimates}

Error estimates from the posterior distribution of the 50000 forward inversions of each run is very complex and not attempted in this project. Instead, we give uncertainty estimates to our Vs inversions from the range of velocities and depths of the profiles of the final run, which have calculated dispersion curves that fall within the uncertainty estimates of our input, measured dispersion. This means that any profile with a dispersion curve within a specific range is a viable model.

Although the dispersion uncertainty is symmetric above and below the curve, the nature of the inversion process is such that the "best" velocities and depths may not be in the middle of the acceptable range. It is for this reason that we refer to the velocities and depths of an inversion as having a "best" and an "acceptable range" of values, rather than the more commonly denoted best $+/$ - uncertainty.

However, some of our inversions that use multiple dispersion curves jointly, do not contain forward inversions that completely cover the measured dispersion's uncertainty range. In these cases, we cannot quantify an "acceptable range" of the absolute $\mathrm{V}_{S}$ structure. 


\section{Chapter 5}

\section{Results}

This chapter is composed of five sections, each relating to a different phase of our research: the cross-correlation database, surface-wave dispersion measurements, synthetic CCF and dispersion, $\mathrm{V}_{S}$ inversions of individual station pairs, and average dispersion inversions.

\subsection{Cross-correlations}

There are 1,048,968 daily cross-correlation stacks in our database. Eighty percent of these are from 2008, which involves two more stations and more than double the average number of operational days than 2001 (Appendix A). These daily stacks form 7458 full-stacks. The number of full-stacks in the database varies between the nine components (Table 5.1). This is primarily due to one-component sensors increasing the number of stacks involving a $\mathrm{Z}$ component. As expected, in 2001 and 2008, the RR and TT, and the RT and TR CCF have the same number of stacks.

We plot record-sections of the full-stacks by year and component, lowpassed at $1 \mathrm{~Hz}$ (Figs. 5.1, 5.2). In the 2001 dataset there are strong phases with moveout on the RR, RZ, TT, ZR and ZZ components travelling approximately $2-3 \mathrm{~km} / \mathrm{s}$ (Fig. 5.1). The RZ and ZR record-sections are most alike, with the ZZ component appearing slightly faster. The $\mathrm{RR}$ record-section contains faster phases, and the TT moveout is the slowest of the five components. All these signals' strengths decrease with increasing interstation distance, especially from $25 \mathrm{~km}$. 
2001 record sections $<1 \mathrm{~Hz}$

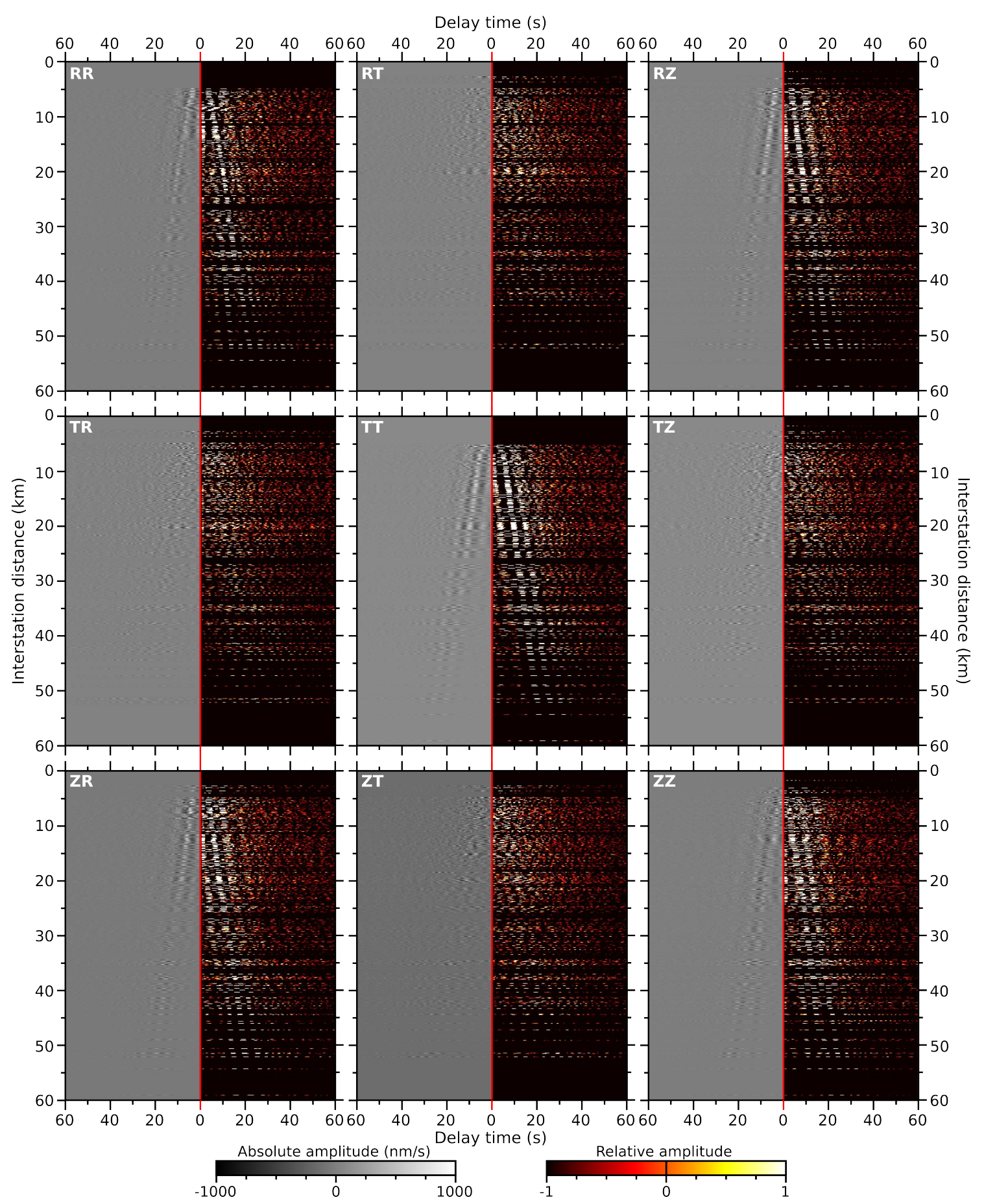

Figure 5.1: Record sections for 2001 full-stacks, lowpass filtered at $1 \mathrm{~Hz}$. Left (greyscale) plots are record sections with real amplitudes; right (colour) plots are record sections with each cross-correlation's amplitudes normalised to one. N.B. on the RR, RZ, TT, ZR and ZZ components, 5-7 stacks (1.3-2.3\% of the 2001 catalogue) are not plotted due to amplitudes exceeding $\pm 1000 \mathrm{~nm} / \mathrm{s}$. 
2008 record sections $<1 \mathrm{~Hz}$

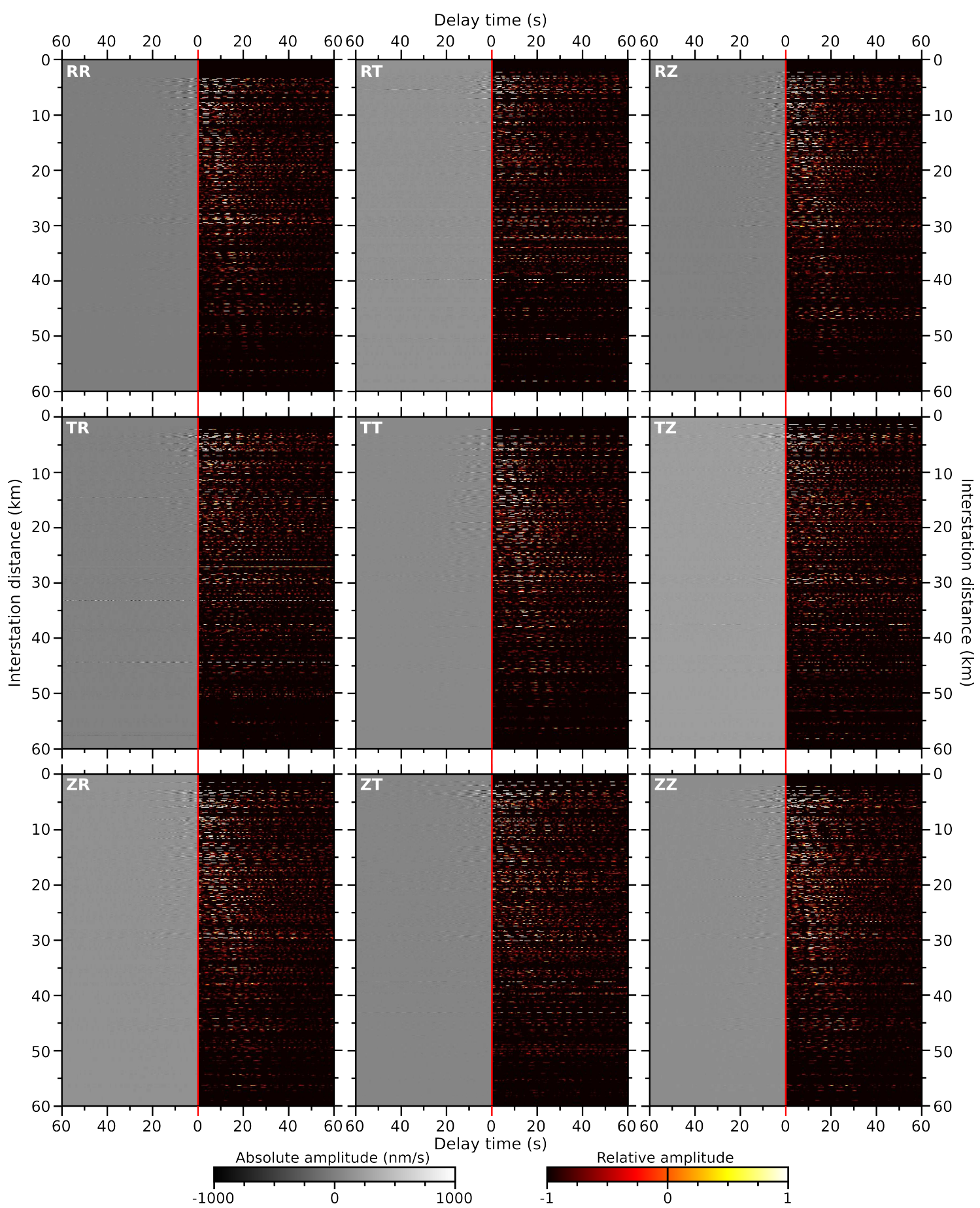

Figure 5.2: Record sections for 2008 full-stacks, lowpass filtered at $1 \mathrm{~Hz}$. Left (greyscale) plots are record sections with real amplitudes; right (colour) plots are record sections with each cross-correlation's amplitudes normalised to one. N.B. on the RR, RZ, TT, ZR and ZZ components, 3-15 stacks (0.6-1.8\% of the 2008 catalogue) are not plotted due to amplitudes exceeding $\pm 1000 \mathrm{~nm} / \mathrm{s}$. 


\section{RR, ZZ and TT component SNR}

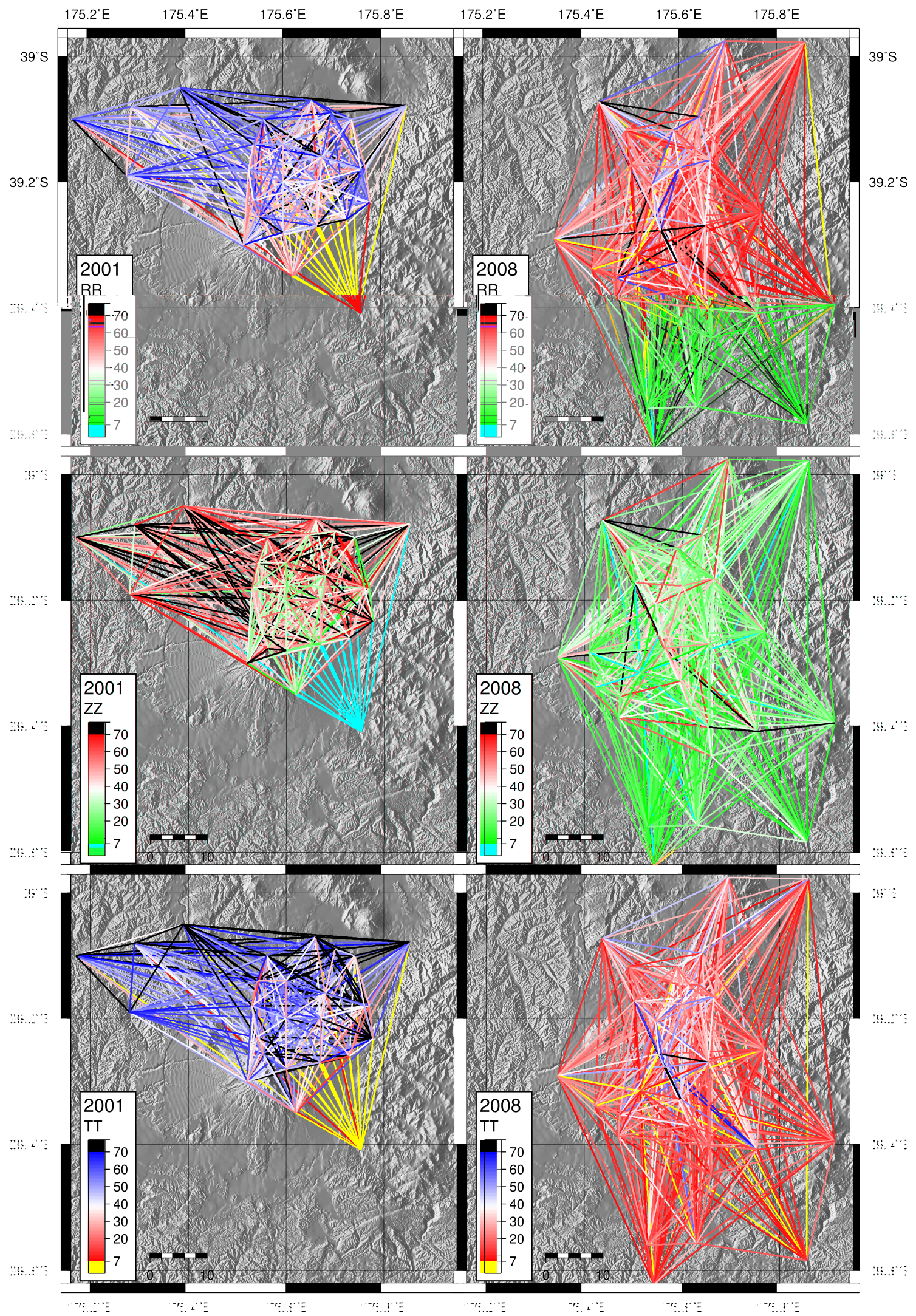

Figure 5.3: Map of RR, ZZ and TT cross-correlations' signal-to-noise ratios, coloured by magnitude and plotted by interstation path for each station pair. Left and right plots are 2001 and 2008 cross-correlations, respectively. 


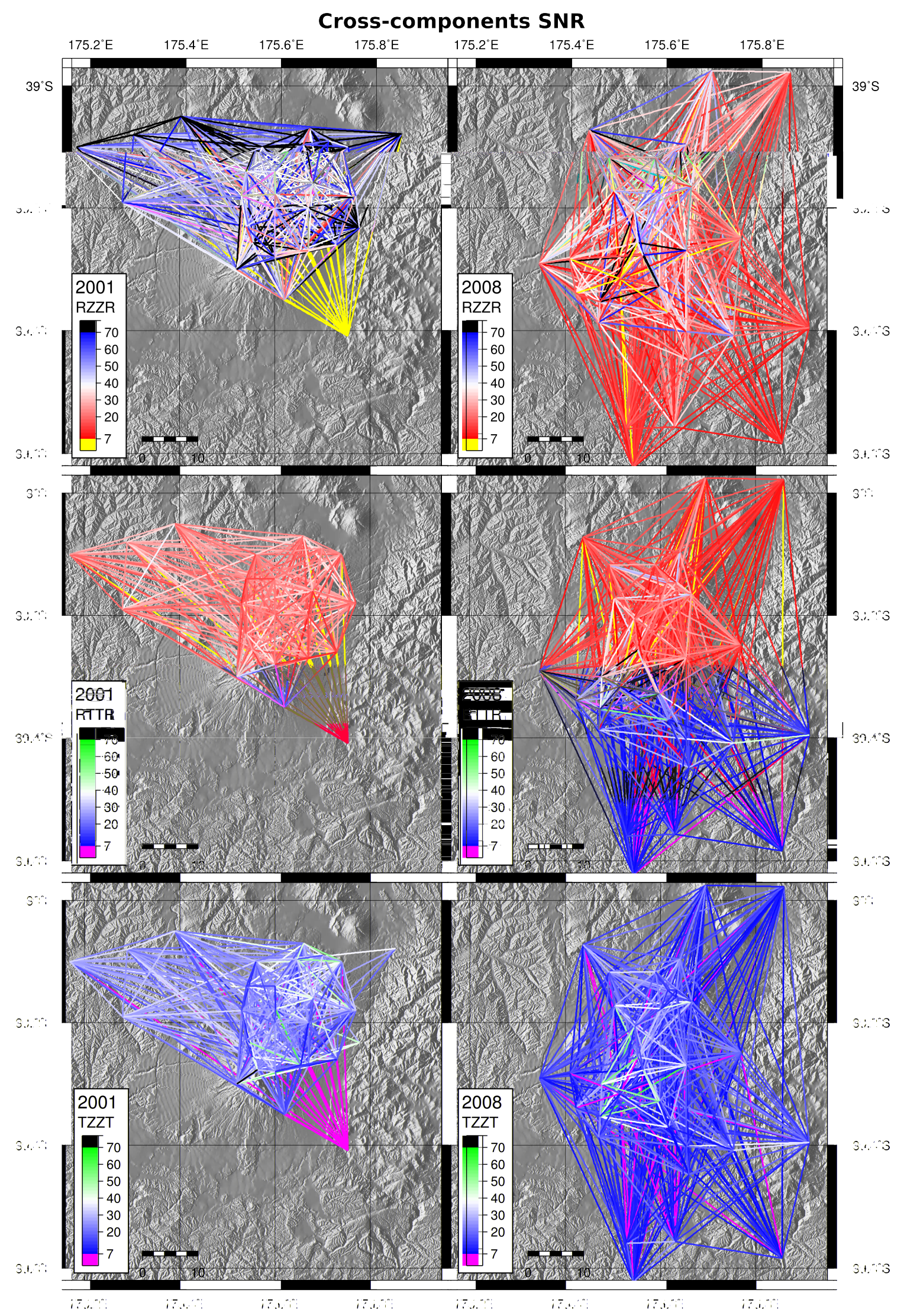

Figure 5.4: Map of averaged cross-components' signal-to-noise ratios, coloured by magnitude and plotted by interstation path for each station pair. Left and right plots are 2001 and 2008 cross-correlations. 
The 2001 RT, TR, TZ and ZT (transverse cross-component) record-sections show some weak moveout (Fig. 5.1). Although barely visible in the record-sections with unaltered amplitude (greyscale plots), the phases can be traced through the entire distance range in the normalised amplitude plots.

The 2008 RR, RZ, TT, ZR and ZZ record-sections also contain phases with moveout, with similar apparent velocities as the 2001 components; however, they are much weaker (Fig. 5.2). Phase moveout in 2008 is most coherent at interstation distances of $15-40 \mathrm{~km}$ (Fig. 5.2). At shorter distances, the CCF amplitudes are stronger, but the phases are less coherent. The TT record-section is the clearest from 2008, with clear phases traceable to $55 \mathrm{~km}$ in the normalised plot.

\begin{tabular}{|c|cc|c|}
\hline Component & $\mathbf{2 0 0 1}$ & $\mathbf{2 0 0 8}$ & Total \\
\hline RR & 331 & 464 & 795 \\
RT & 281 & 491 & 772 \\
RZ & 359 & 474 & 833 \\
TR & 281 & 491 & 772 \\
TT & 331 & 464 & 795 \\
TZ & 309 & 500 & 809 \\
ZR & 406 & 482 & 888 \\
ZT & 356 & 511 & 867 \\
ZZ & 434 & 493 & 927 \\
\hline Total & $\mathbf{3 0 8 8}$ & $\mathbf{4 3 7 0}$ & $\mathbf{7 4 5 8}$ \\
\hline
\end{tabular}

Table 5.1: Total number of full-stacks in cross-correlation catalogue by component

\subsubsection{Signal-to-noise ratios}

To visually illuminate bad stations and look for any spatial variation across the TgVC, we plot SNR of all the symmetric full-stacks by interstation path (Figs. 5.3, 5.4). Calculated SNR vary little between the RZ and ZR, RT and TR, and TZ and ZT CCF for individual station pairs across both years; therefore we average the two SNR values for each station pair, if present, and count them as one component when mapping (henceforth referred to as the RZZR, RTTR and TZZT components).

Very few full-stacks involving station LMOW, the southern-most station in 2001 (Fig. 4.1) have SNR values higher than our cut-off of 7 (Figs. 5.3, 5.4). No other full-stacks have SNR $<7$ in the 2001 dataset. Many stacks involving 2008 station MASHUT, on the 
south-western flanks of Mount Ruapehu, also have low SNR values. The 2008 stations south of $39.4^{\circ} \mathrm{S}$ also have poor SNR. The SNR for RR and ZZ stacks for 2001 are lower for interstation paths crossing Ruapehu and Tongariro (Fig. 5.4) than for paths outside them. Conversely, the SNR values for all components in 2008 are greatest for paths crossing Ruapehu and Tongariro on all components (Figs. 5.3, 5.4). The TZZT SNR in 2001 are unexpectedly high for paths crossing Tongariro (Fig. 5.3, 5.4).

\subsubsection{Component averages}

The standard deviations for all components are comparable between the two years. Average SNR values for the isotropic RR, ZZ, TT, RZ and ZR CCF from the 2001 deployments ( $87.5 \%$ broadband stations) are similar, but much higher than in 2008 (50\% broadband), with a difference of 25 between the averages when the five components are grouped together (Table 5.2). The mean SNR of the 2001 RT, TR, TZ and ZT CCF are slightly higher than in 2008. However, for all components and groupings, there is a significant difference between the means of 2001 and 2008 at the 99 th percentile.

\begin{tabular}{|c|ccc|ccc|ccc|}
\hline \multirow{2}{*}{ Component } & \multicolumn{2}{|c|}{ 2001 SNR } & \multicolumn{3}{|c|}{ 2008 SNR } & \multicolumn{3}{c|}{ 2001+2008 SNR } \\
& N.Stacks & $\boldsymbol{\mu}$ & $\boldsymbol{\sigma}$ & N.Stacks & $\boldsymbol{\mu}$ & $\boldsymbol{\sigma}$ & N.Stacks & $\boldsymbol{\mu}$ & $\boldsymbol{\sigma}$ \\
\hline RR & 331 & 44 & 18 & 464 & 24 & 16 & 795 & 32 & 20 \\
ZZ & 434 & 50 & 22 & 492 & 28 & 16 & 926 & 38 & 22 \\
TT & 331 & 52 & 22 & 464 & 24 & 14 & 795 & 36 & 22 \\
\hline RZ & 359 & 55 & 25 & 474 & 27 & 20 & 833 & 39 & 26 \\
ZR & 406 & 53 & 22 & 482 & 27 & 16 & 888 & 39 & 23 \\
\hline RT & 281 & 22 & 9 & 491 & 16 & 11 & 772 & 18 & 11 \\
TR & 281 & 22 & 9 & 491 & 17 & 10 & 905 & 19 & 11 \\
TZ & 309 & 25 & 11 & 500 & 17 & 10 & 809 & 20 & 11 \\
ZT & 356 & 25 & 10 & 511 & 16 & 10 & 867 & 20 & 11 \\
\hline RZZR & 434 & 52 & 22 & 488 & 27 & 17 & 922 & 39 & 23 \\
RTTR & 281 & 22 & 7 & 489 & 16 & 10 & 770 & 18 & 9 \\
TZZT & 384 & 25 & 10 & 515 & 16 & 9 & 899 & 20 & 10 \\
\hline Isotropic & 1861 & 51 & 22 & 2376 & 26 & 17 & 4237 & 37 & 23 \\
T-cross* & 1227 & 24 & 10 & 1993 & 16 & 10 & 3220 & 19 & 11 \\
\hline
\end{tabular}

Table 5.2: Statistics of full-stack signal-to-noise ratios, by component (and averaged crosscomponents). $\mu$ denotes mean, $\sigma$ denotes standard deviation. ${ }^{*}$ T-cross (transverse crosscomponent) values are calculated using individual RT, TR, TZ and ZT, not RTTR and TZZT. 


\subsubsection{Sensor averages}

To examine the difference between cross-correlation stacks of short-period and broadband data, and to guage the performance of different sensor models, we look at the average SNR of the RR, ZZ, TT, RZ and ZR stacks, which we expect to have high SNR. We observe significant differences between the average SNR of different types and models for 2001 and 2008 (Table 5.3). In 2001, the dataset is dominated by broadband-broadband (BB-BB) pairs. There is a large difference between the average SNR for BB-BB pairs and shortperiod/short-period (SP-SP) pairs. Mixed type pairs (BB-SP and SP-BB) also have high SNR in 2001. The only Guralp 3T station is LMOW, which we have already identified as having very poor SNR.

\begin{tabular}{|c|c|c|c|c|c|c|c|}
\hline \multirow{2}{*}{\multicolumn{2}{|c|}{ Sensor }} & \multicolumn{3}{|c|}{2001} & \multicolumn{3}{|c|}{2008} \\
\hline & & N.Stacks & $\mu$ & $\sigma$ & N.Stacks & $\boldsymbol{\mu}$ & $\sigma$ \\
\hline \multirow{3}{*}{ 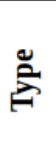 } & BB-BB & 1655 & 53 & 23 & 459 & 21 & 16 \\
\hline & BB-SP/SP-BB & 200 & 39 & 16 & 1307 & 23 & 15 \\
\hline & SP-SP & 6 & 25 & 10 & 610 & 34 & 18 \\
\hline \multirow{12}{*}{$\begin{array}{l}\overline{\mathrm{d}} \\
\overline{\mathrm{c}}\end{array}$} & ${ }^{\text {PSercel L4C (1D) }}$ & 206 & 38 & 16 & - & - & - \\
\hline & 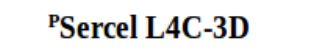 & - & - & - & 1656 & 28 & 17 \\
\hline & ${ }^{\mathrm{T} M a r k s ~ L-4 A}$ & - & - & - & 456 & 21 & 9 \\
\hline & ${ }^{\mathrm{T} G u r a l p ~ 3 E S P ~}$ & - & - & - & 571 & 15 & 8 \\
\hline & TGuralp 3ESP/40T* & - & - & - & 274 & 17 & 8 \\
\hline & ${ }^{\mathrm{T}}$ Guralp 3T & 100 & 5 & 1 & - & - & - \\
\hline & ${ }^{\mathrm{T}}$ Guralp 3TD & 271 & 56 & 21 & - & - & - \\
\hline & ${ }^{\mathrm{P} G u r a l p ~ 40 T}$ & 110 & 52 & 21 & 309 & 36 & 18 \\
\hline & ${ }^{\mathrm{T}}$ Guralp 40T & - & - & - & 309 & 23 & 13 \\
\hline & ${ }^{\mathrm{T}}$ Guralp 40TD & 1814 & 51 & 22 & - & - & - \\
\hline & T'Guralp 6T (NGA) & - & - & - & 315 & 25 & 11 \\
\hline & TGuralp 6T (SADAR) & - & - & - & 374 & 25 & 20 \\
\hline
\end{tabular}

Table 5.3: Statistics of RR, ZZ, TT, RZ and ZR full-stacks' signal-to-noise ratios by sensor type and model. For different models, all stacks where there is at least one station with that model are included. $\mu$ denotes mean, $\sigma$ denotes standard deviation. $\mathrm{P}$ and $\mathrm{T}$ denote sensors were permanent and temporary, respectively. All Guralp sensors are broadband (BB), Sercel/Marks sensors are short-period (SP).*Sensors ATKR and HOR2 initially model $3 \mathrm{ESP}$ but replaced by $40 \mathrm{~T}$ during deployment.

Unexpectedly, in 2008, the SP-SP stacks have an average SNR higher than the stacks with at least one broadband station. However, the permanent broadband Guralp 40T sensors have the highest SNR in 2008. By far the worst performing model is the broadband 
Guralp 3ESP. The average SNR for this sensor (15) is even lower than the transverse-cross component stacks' average in 2008 (Table 5.2). The 2008 SP-SP SNR is also much greater than the 2001 SP-SP. This is likely because all the GeoNet stations in 2001 were upgraded from single-component Sercel L4C sensors to three-component L4C-3Ds.

\subsection{Surface-wave dispersion}

\subsubsection{Dispersion measurements}

We are able to measure group velocity dispersion for 3646 of the 4235 symmetric, full-stacks for which the MFT analysis was performed. Dispersion for stacks involving the START and NGA deployment data typically have higher grades than the GeoNet or SADAR data. The full measurement log containing the MFT parameters as well as the initial and final grades for all the stacks is available on request.

\begin{tabular}{|c|c|c|c|c|c|c|}
\hline Parameter & 2001 & $\%$ & 2008 & $\%$ & Total & $\%$ \\
\hline$Y=0.5$ & 728 & 40.1 & 390 & 21.2 & 1118 & 30.7 \\
\hline$Y=0.75$ & 351 & 19.3 & 837 & 45.7 & 1188 & 32.6 \\
\hline$\gamma=1$ & 426 & 23.5 & 334 & 18.2 & 760 & 20.8 \\
\hline$Y=1.25$ & 183 & 10.1 & 64 & 3.5 & 247 & 6.8 \\
\hline$Y=1.5$ & 106 & 5.8 & 161 & 8.8 & 267 & 7.3 \\
\hline$Y=1.75$ & 12 & 0.6 & 46 & 2.5 & 58 & 1.6 \\
\hline$\gamma>2$ & 8 & 0.4 & 0 & 0 & 8 & 0.1 \\
\hline Preonset $=0 *$ & 1649 & 90.9 & 1673 & 91.3 & 3322 & 91.1 \\
\hline Preonset $=1-4 \mathrm{~s}$ & 137 & 7.6 & 134 & 7.3 & 271 & 7.4 \\
\hline Preonset $=5-9 \mathrm{~s}$ & 17 & 0.9 & 14 & 0.8 & 31 & 0.9 \\
\hline Preonset $>10 \mathrm{~s}$ & 11 & 0.6 & 12 & 0.7 & 23 & 0.6 \\
\hline Cut $=60 s^{*}$ & 1811 & 99.8 & 1825 & 99.7 & 3636 & 99.7 \\
\hline Cut $=30-59 s$ & 1 & 0.06 & 0 & 0 & 1 & 0.02 \\
\hline Cut $<29$ & 2 & 0.1 & 8 & 0.4 & 10 & 0.3 \\
\hline
\end{tabular}

Table 5.4: Parameter range used for MFT analysis. *default value. Percentages rounded to nearest $0.1 \%$, calculated from total number of full-stacks (1863, 2372 and 4235 for 2001, 2008 and total, respectively).

Only eight full-stacks have dispersion measurements with $\gamma$ (smoothing parameter, section 4.4) greater than 1.75 (Table 5.4). For the 2001 data, $\gamma$ varies from 0.5 to 3.5, with a mean of 0.81 and standard deviation of 0.34 , while for our 2008 dataset, $\gamma$ varies from 0.5 to 1.75 , with a mean of 0.85 and standard deviation of 0.31 . For both data sets, the 
median value of $\gamma$ is 0.75 .

Overall, $9 \%$ of the 2001 and $7 \%$ of the 2008 data require non-default time-windows. Measurement confidence is much higher for the 2001 data than for 2008, with $90 \%$ of 2001 measurements having grades 1 or 2 , compared to $63.3 \%$ for 2008 . These percentages are similar to the proportion of broadband stations deployed in each time period $(87.5 \%$ and $50 \%$, respectively). Furthermore, the percentage of grade 1 measurements in 2001 is more than double that of 2008 .

Only $8.3 \%$ of the unpickable full-stacks are from the 2001 dataset. Almost half of these involve LMOW, the station with the poorest SNR (section 5.1.1) and a quarter involve at least one, single-component short-period GeoNet stations (DRZ, KAVZ, NGZ or TUVZ). Only 15 unpickable stacks involves a pair of 2001 broadband stations, $0.8 \%$ of the 2001 measurements. Conversely, over one fifth of 2008 stacks are unpickable. At least one SADAR station was involved in $85 \%$ of these; $32 \%$ include at least one Guralp 3ESP sensor.

Approximately a quarter of inspected MFT plots contain multiple phases (grade M, table 5.6), a proportion constant across both time periods. The most significant difference between the grades of the two years is the proportion of the highest quality grade $\mathrm{L}$ measurements, which, in 2008 is approximately a third of that in 2001. Additionally in 2008, there are significantly more stacks with group velocities considerably slower at low frequencies than high.

\begin{tabular}{|c|cc|cc|cc|}
\hline Confidence & $\mathbf{2 0 0 1}$ & $\mathbf{\%}$ & $\mathbf{2 0 0 8}$ & $\mathbf{\%}$ & Total & $\mathbf{\%}$ \\
\hline $\mathbf{1}$ & 1434 & 77 & 890 & 37.5 & 2324 & 54.9 \\
$\mathbf{2}$ & 255 & 13.7 & 611 & 25.8 & 866 & 20.4 \\
$\mathbf{3}$ & 99 & 5.3 & 288 & 12.1 & 387 & 9.1 \\
$\mathbf{4}$ & 26 & 1.4 & 43 & 1.8 & 69 & 1.6 \\
Unpickable & 49 & 2.7 & 540 & 22.8 & 589 & 13.9 \\
\hline Total & $\mathbf{1 8 6 3}$ & $\mathbf{1 0 0}$ & $\mathbf{2 3 7 2}$ & $\mathbf{1 0 0}$ & $\mathbf{4 2 3 5}$ & $\mathbf{9 9 . 9}$ \\
\hline
\end{tabular}

Table 5.5: Full-stack dispersion measurement confidence. Percentages rounded to nearest $0.1 \%$.

Overall, Love wave dispersion measurements are overrepresented at higher classes (Table 5.7, R:L). Although the number of Rayleigh-wave measurements is far greater, there 
are higher proportions of Love measurements in classes A and A2 than in the total datasets of both years.

\begin{tabular}{|c|cc|cc|cc|}
\hline Grade & $\mathbf{2 0 0 1}$ & $\mathbf{\%}$ & $\mathbf{2 0 0 8}$ & $\mathbf{\%}$ & Total & \% \\
\hline L & 843 & 45.3 & 384 & 16.2 & 1227 & 29 \\
$\mathbf{O}$ & 306 & 16.4 & 307 & 12.9 & 613 & 14.4 \\
$\mathbf{A}$ & 325 & 17.4 & 844 & 35.6 & 1169 & 27.6 \\
$\mathbf{A A}$ & 40 & 2.1 & 54 & 2.3 & 94 & 2.2 \\
$\mathbf{H}$ & 278 & 14.9 & 241 & 10.2 & 519 & 12.3 \\
\hline B & 0 & 0 & 1 & 0 & 1 & 0 \\
$\mathbf{F}$ & 85 & 4.6 & 348 & 14.7 & 433 & 10.2 \\
$\mathbf{J}$ & 37 & 2 & 65 & 2.7 & 102 & 2.4 \\
$\mathbf{M}$ & 447 & 24 & 560 & 23.6 & 1007 & 23.8 \\
$\mathbf{S}$ & 5 & 0.3 & 3 & 0.1 & 8 & 0.2 \\
$\mathbf{W}$ & 118 & 6.3 & 141 & 5.9 & 259 & 6.1 \\
$\mathbf{Z}$ & 172 & 9.2 & 571 & 24.1 & 743 & 17.5 \\
$\mathbf{V}$ & 68 & 3.7 & 76 & 3.2 & 144 & 3.4 \\
\hline
\end{tabular}

Table 5.6: Numerical breakdown of grade characteristics assigned to dispersion measurements (see Table 4.1 for explanations). Percentages rounded to nearest $0.1 \%$ and are out of the total number of full-stacks (1863, 2372 and 4235 for 2001, 2008 and 2001+2008, respectively). N.B. most stacks contain multiple characteristics; stacks with multiple measurements have only one grade.

\begin{tabular}{|c|ccc|ccc|ccc|}
\hline Final Class & $\mathbf{2 0 0 1}$ & $\mathbf{\%}$ & $\mathbf{R : L}$ & $\mathbf{2 0 0 8}$ & $\mathbf{\%}$ & $\mathbf{R : L}$ & Total & \% & R:L \\
\hline A & 1180 & 64.2 & $78: 18$ & 838 & 43 & $79: 21$ & 2018 & 53.3 & $81: 19$ \\
A2 & 297 & 16.2 & $75: 25$ & 326 & 16.7 & $82: 18$ & 623 & 16.5 & $78: 22$ \\
B1 & 76 & 4.1 & $84: 16$ & 77 & 4 & $87: 13$ & 153 & 4 & $86: 14$ \\
B2 & 160 & 8.7 & $87: 13$ & 366 & 18.8 & $81: 19$ & 526 & 13.9 & $83: 17$ \\
C & 125 & 6.8 & $86: 14$ & 341 & 17.5 & $83: 17$ & 466 & 12.3 & $84: 16$ \\
\hline Total & $\mathbf{1 8 3 8}$ & $\mathbf{1 0 0}$ & $\mathbf{7 8 : 1 8}$ & $\mathbf{2 4 8 8}$ & $\mathbf{1 0 0}$ & $\mathbf{8 5 : 1 5}$ & $\mathbf{4 3 2 6}$ & $\mathbf{1 0 0}$ & $\mathbf{8 4 : 1 6}$ \\
\hline
\end{tabular}

Table 5.7: Numerical breakdown of final dispersion classifications. R:L are the numbers of Rayleigh- and Love-wave measurements per 100 curves within each class (rounded to the nearest integer). Percentages rounded to nearest $0.1 \%$. N.B. totals differ from those in above tables as some cross-correlation stacks having two measurements for different modes are counted separately.

\subsubsection{Additional features}

While making the dispersion measurements, we observed strong phases with group velocities on the order of $0.4 \mathrm{~km} / \mathrm{s}$ in approximately $3 \%$ of the CCF and their MFT plots (Fig. 5.5a). We refer to these unexpected phases as $\mathrm{V}$, due to their very long delay times in 
the CCF. The V-phase most often occurs in CCF with low SNR, and might be naively regarded as an artefact from bad data, especially at station LMOW.

\section{Example MFT analyses with special features}
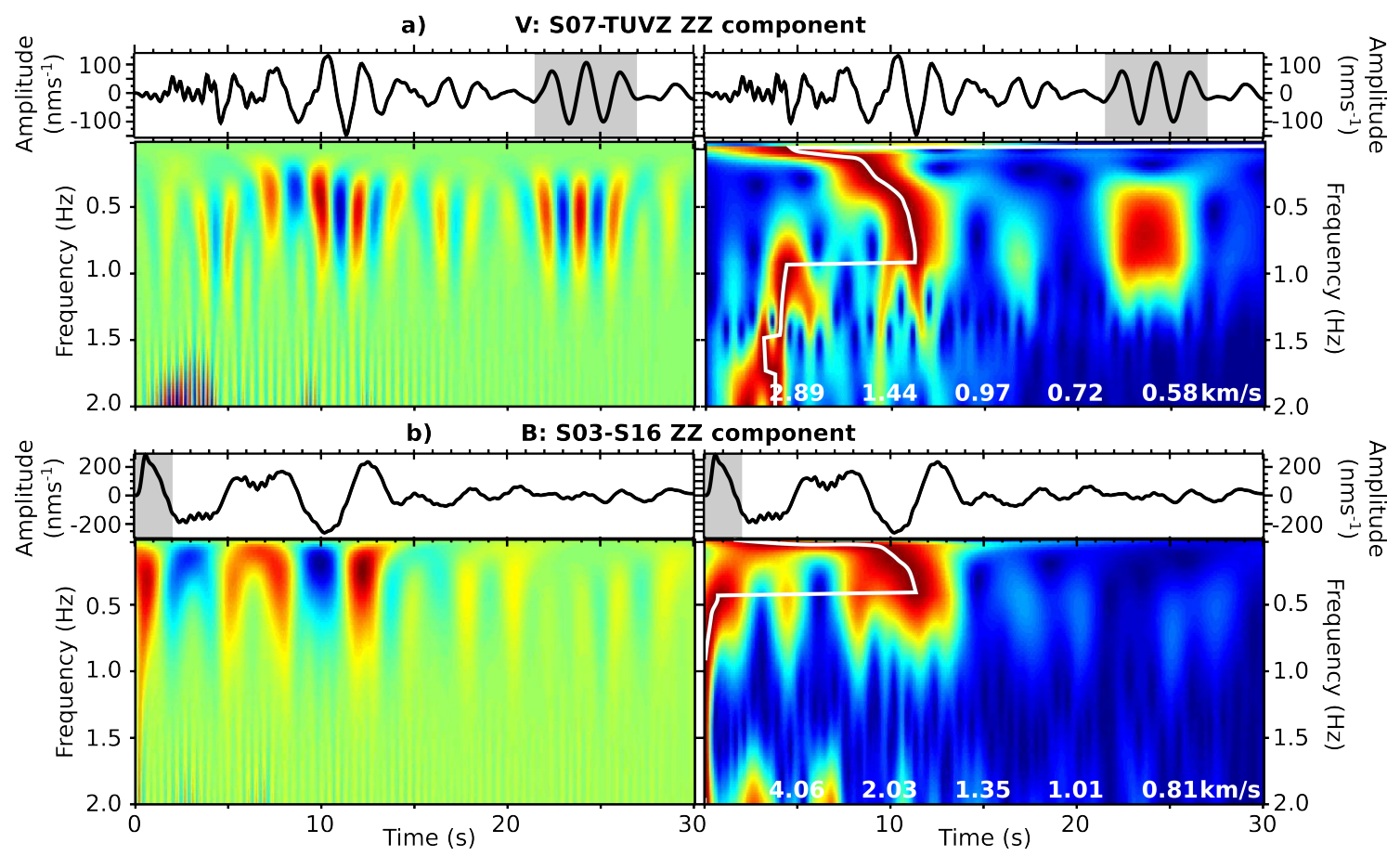

Figure 5.5: Examples of CCF and dispersion analyses with special features. Grey shaded area of waveform is the phase of interest, left plots are spectrograms, right are MFT with automatically picked dispersion as white line. White numbers are group velocities at the marked delay times; note the non-linear scale: a) phase with a very slow apparent velocity; b) peak at zero delay time.

However, in some cases, the $\mathrm{V}$ phase occurs in what we otherwise consider to be high quality data, and appears to be real (e.g. Fig. 5.5a). There does not appear to be any relationships between the occurrence of "real" V-phases with CCF component, year or interstation path.

Many full-stacks contain high amplitude peaks at $0 \mathrm{~s}$ (Fig. 5.5b). Although we can largely eliminate their interference with the desired dispersion measurement, we cannot ignore their presence. These peaks may be artefacts from non-diffuse noise sources at oblique angles to, or somewhere along the interstation path. These phases would then be recorded by the stations at approximately the same time, giving a high apparent velocity in the cross-correlation (e.g. Fig. 3.2c). 
In approximately $6 \%$ of our dispersion measurements, we observe low frequency energy travelling slower than high frequency energy, which we describe as having characteristic W (Table 5.6). This is similar to the Airy phases we observe in our synthetic data (section 5.3.2).

\subsubsection{Mode identification}

We confidently identify the mode of the dispersion measurement in only 633 or our 3646 full-stacks (17\%). Of these, 176 are the fundamental mode (R0/L0, e.g. Fig. 5.6a) and 240 are the first higher order mode (R1/L1, e.g. Fig. 5.6b). In a further 40 stacks, we identify and measure both modes, making 80 measurements (e.g. Fig. 5.6c\&d).

Using the station-grouping method (section 4.4.1), we assign modes to more than 1600 further RR, ZZ and TT measurements. Most stations have at least one measurement with a mode already assigned to it. Some stations show obvious measurement clustering, (e.g. Fig. 5.7, MOVZ-RR + ZZ), however for others, mode identification is difficult (e.g. Fig. 5.7, S16-RR+ZZ). Below approximately $0.3 \mathrm{~Hz}$, classification is particularly problematic as the fundamental and first higher-order mode sometimes appear to seamlessly merge in the MFT plot.

\begin{tabular}{|c|cc|cc|cc|cc|cc|}
\hline \multirow{2}{*}{ Identified from } & \multicolumn{2}{|c|}{ RR } & \multicolumn{2}{c|}{ ZZ } & \multicolumn{2}{c|}{ TT } & \multicolumn{2}{c|}{ RZ } & \multicolumn{2}{c|}{ ZR } \\
& $\mathbf{R 0}$ & $\mathbf{R 1}$ & $\mathbf{R 0}$ & $\mathbf{R 1}$ & $\mathbf{L 0}$ & $\mathbf{L 1}$ & $\mathbf{R 0} *$ & $\mathbf{L 0} *$ & $\mathbf{R 0} *$ & L0* \\
\hline Spectrogram/MFT 2001 & 20 & 29 & 26 & 25 & 28 & 39 & 21 & 29 & 17 & 27 \\
Spectrogram/MFT 2008 & 24 & 20 & 24 & 29 & 18 & 30 & 18 & 27 & 23 & 27 \\
Station-grouping 2001 & 140 & 113 & 175 & 167 & 132 & 84 & 0 & 0 & 0 & 0 \\
Station-grouping 2008 & 142 & 129 & 157 & 140 & 174 & 74 & 0 & 0 & 0 & 0 \\
\hline Total & $\mathbf{3 2 6}$ & $\mathbf{2 9 1}$ & $\mathbf{3 8 2}$ & $\mathbf{3 6 1}$ & $\mathbf{3 5 2}$ & $\mathbf{2 2 7}$ & $\mathbf{3 9}$ & $\mathbf{5 6}$ & $\mathbf{4 0}$ & $\mathbf{5 4}$ \\
\hline A/A2 Grade 2001 & 125 & 128 & 150 & 159 & 137 & 107 & 15 & 27 & 14 & 20 \\
A/A2 Grade 2008 & 90 & 87 & 114 & 96 & 127 & 53 & 11 & 15 & 16 & 19 \\
\hline
\end{tabular}

Table 5.8: Breakdown of full-stacks' assigned modes. *indicates measurements without appropriate phase corrections applied.

For the majority of stations, there are clearer group velocity boundaries for the two modes in the TT component plot than for the $\mathrm{RR}+\mathrm{ZZ}$ plot (i.e smaller uncertain regions; Fig. 5.7, yellow areas). Consequently, fewer TT dispersion measurements were rejected for being too difficult to classify. 


\section{Example MFT analyses with identifiable modes}
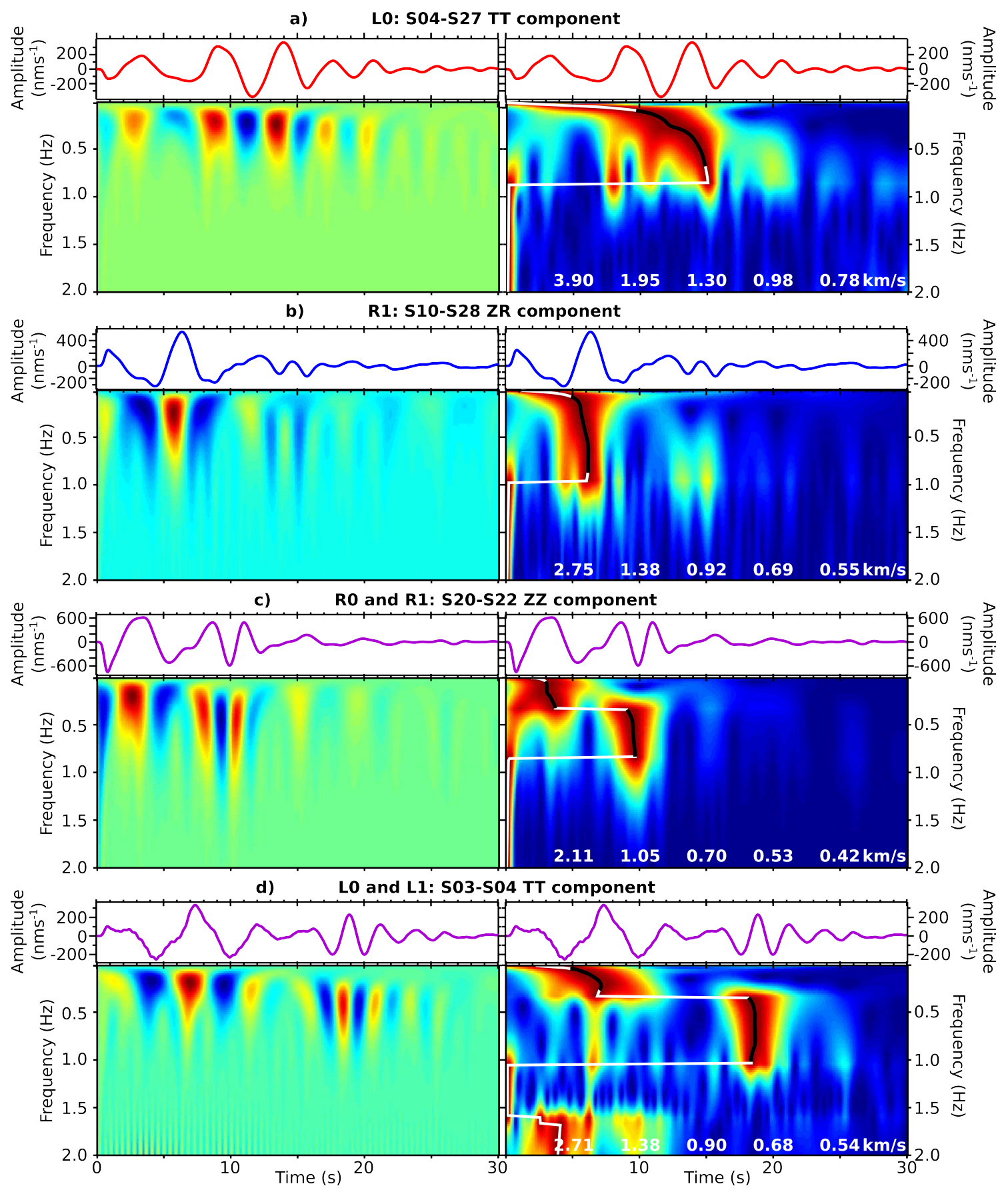

Figure 5.6: Examples of dispersion analyses where the measurement's mode is identifiable.

Left plots are spectrograms, right are MFT with automatically picked dispersion curve as white line and manually refined measurement as superimposed black line(s). Note different stations pairs have different interstation paths and distances, white numbers are group velocities at the marked delay times: a) L0; b) R1; c) R0 and R1 double measurement; d) LO and L1. 


\section{Station-grouping plots for mode identification}

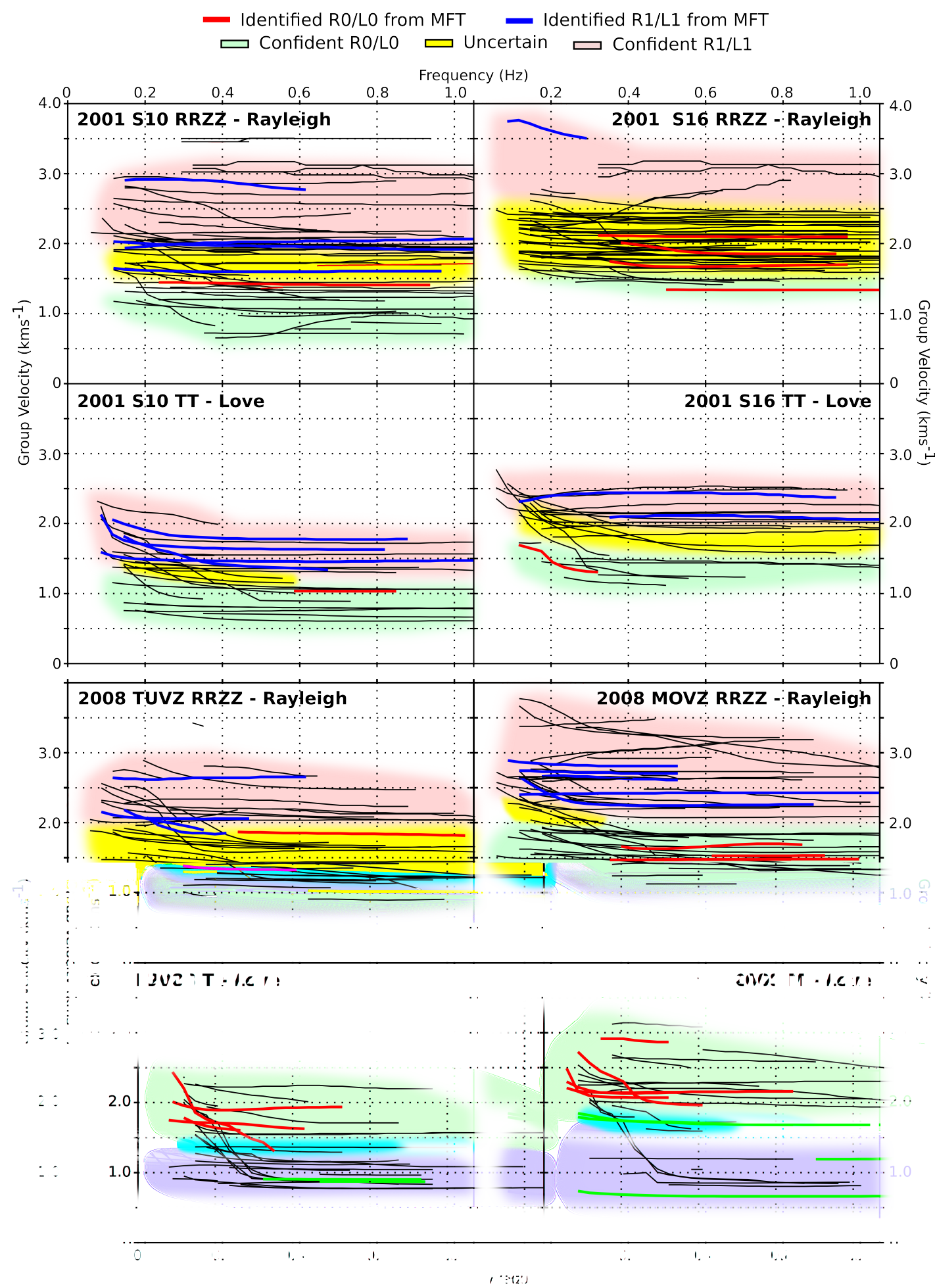

Figure 5.7: Example station-grouping plots, presented as the $R R+Z Z$ and TT measurements for "slow" (left) and "fast" (right) stations from 2001 (top) and 2008 (bottom). All A, A2, B1 and B2 grade dispersion curves are included in the plots. Thick coloured lines indicate measurement with mode identified during MFT analysis. Measurements within the green and pink regions have been assigned modes based on measurement clustering; yellow region shows curves that could belong to either mode. 
Manually refined group velocity dispersion measurements with assigned modes

- R0/L0 - R1/L1 Only R0/L0 R0/L0 and R1/L1 overlapping ص Only R1/L1
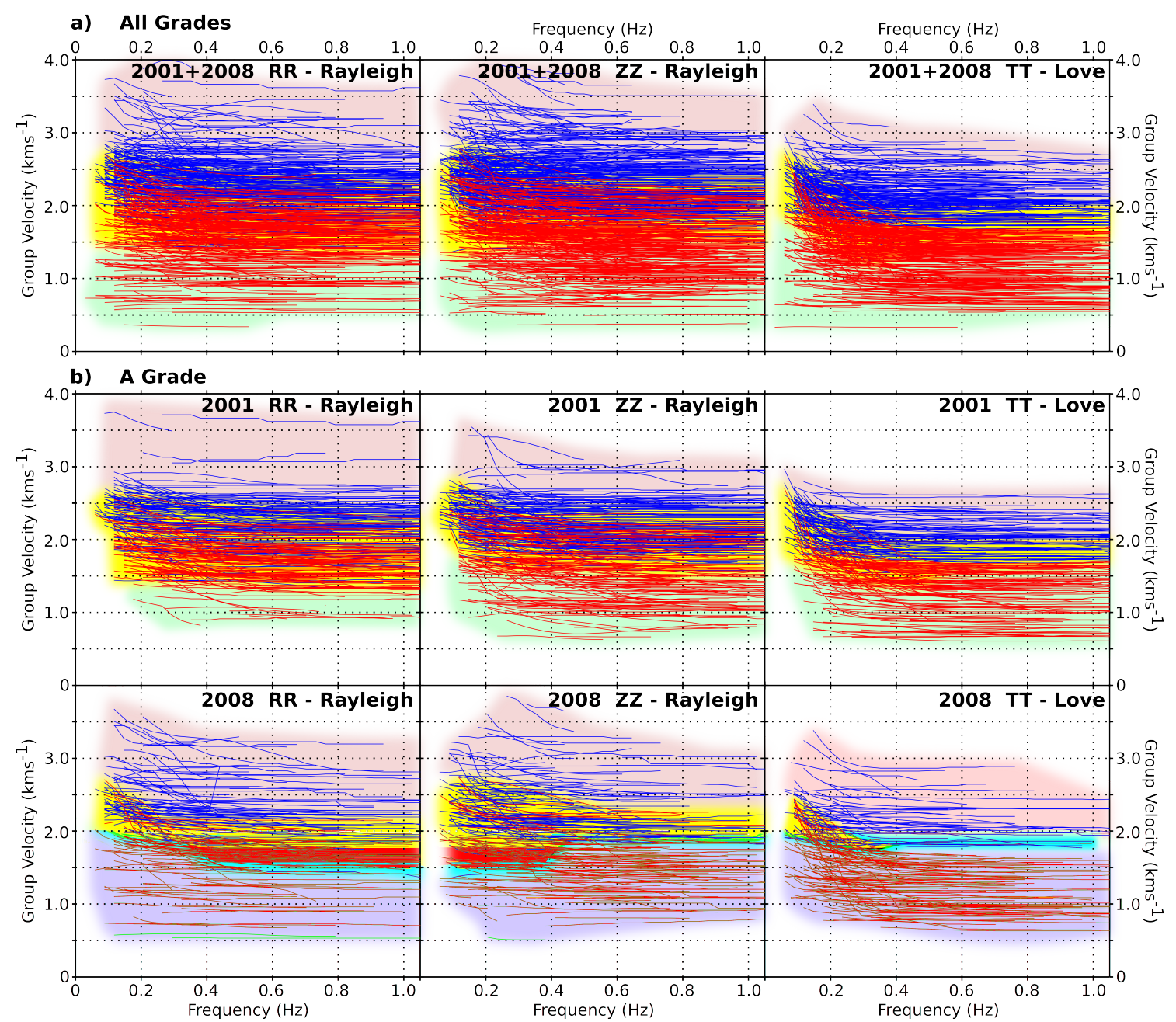

Figure 5.8: Dispersion measurements for the TgVC with assigned modes, plotted by CCF component. Lines are individual measurements; coloured areas indicate frequency and group velocity range in which measurements for each mode, or both modes are present: a) all grades (A, A2, B1, B2 and C) for 2001 and 2008 plotted together; b) A-grade measurements only, separated by year. Note fundamental mode curves are plotted over the higher-mode.

Across both years, plots for similarly located stations have similar group velocity ranges for the modes (e.g. Fig. 5.7, S10 and TUVZ, Fig. 4.1). However, we observe significant differences in the modal ranges for stations in different settings. Stations located on/near the greywacke ranges surrounding the TgVC (e.g. Fig. 5.7, S16 and MOVZ) and the southernmost SADAR stations tend to have faster measurements than stations located on/near the volcanoes (e.g. S10 and TUVZ). The R1 velocity range of the "fast" stations also tends to be greater than that of the "slow" stations.

In total, we have 2128 dispersion measurements with assigned modes (Table 5.8), of 
which 1510 are grade A or A2. On all three components, there is significant overlap of group velocity ranges for which we have identified modes (Fig. 5.8, yellow areas), except for the A-grade TT measurements in 2008. The distribution of A-grade RR and ZZ measurements is consistent within each year, but the 2001 data contains fewer measurements below 0.9 $\mathrm{km} / \mathrm{s}$ and above $2.8 \mathrm{~km} / \mathrm{s}$ (Fig. 5.8, left and centre plots). In both years, there are many more TT component A-grade measurements below $1 \mathrm{~km} / \mathrm{s}$ than the RR or ZZ components, and very few above $2.5 \mathrm{~km} / \mathrm{s}$ (Fig. 5.8, right-hand side plots).

\subsubsection{Station pair maps}

We produce maps showing the group velocity of A/A2 grade dispersion measurements. For the remainder of this section, we refer only to these measurements. We separate the fundamental mode (R0/L0) data from that of the first higher-order mode (R1/L1) and plot the RR and ZZ group velocity measurements together to represent Rayleigh waves $(\mathrm{R})$, and the TT (Love waves, L) separately. We make R0, L0, R1 and L1 group velocity maps for 2001, 2008 and 2001+2008 (Figs. 5.9-5.12), at $0.5 \mathrm{~Hz}$ and $1 \mathrm{~Hz}$. These frequencies approximately correspond to depths of 2 and $1 \mathrm{~km}$, respectively. We do not present maps for lower frequencies due to the potential of mode jumping within the measured dispersion curves.

Overall, data coverage in the north of the TgVC was much better in 2001 than in 2008, however there are no measurements from the west or south of Ruapehu. There is a lack of data west of Ruapehu (all latitudes) and east of Mount Tongariro in 2008. There are fewer measurements for 2008 than 2001 across both frequencies and modes, and very few 2008 measurements at $1 \mathrm{~Hz}$ (both modes, Figs. 5.10, 5.12).

Across all time periods and modes, there are more measurements at $0.5 \mathrm{~Hz}$ than 1 Hz. There does not appear to be any significant change in velocities between the two frequencies for either modes or time periods, however, significant differences in the data distribution between the frequencies makes comparison difficult.

Measurements from 2001 and 2008 appear to be consistent across both frequencies and modes, with one exception. The western flanks of Mount Tongariro appear to be slower in 2008 than 2001 in the $0.5 \mathrm{~Hz}$ L0 measurements (Fig. 5.9). This may also be apparent in the $1 \mathrm{~Hz} \mathrm{L0}$ data (Fig. 5.10), however, there are not enough crossing paths to provide compelling evidence. 


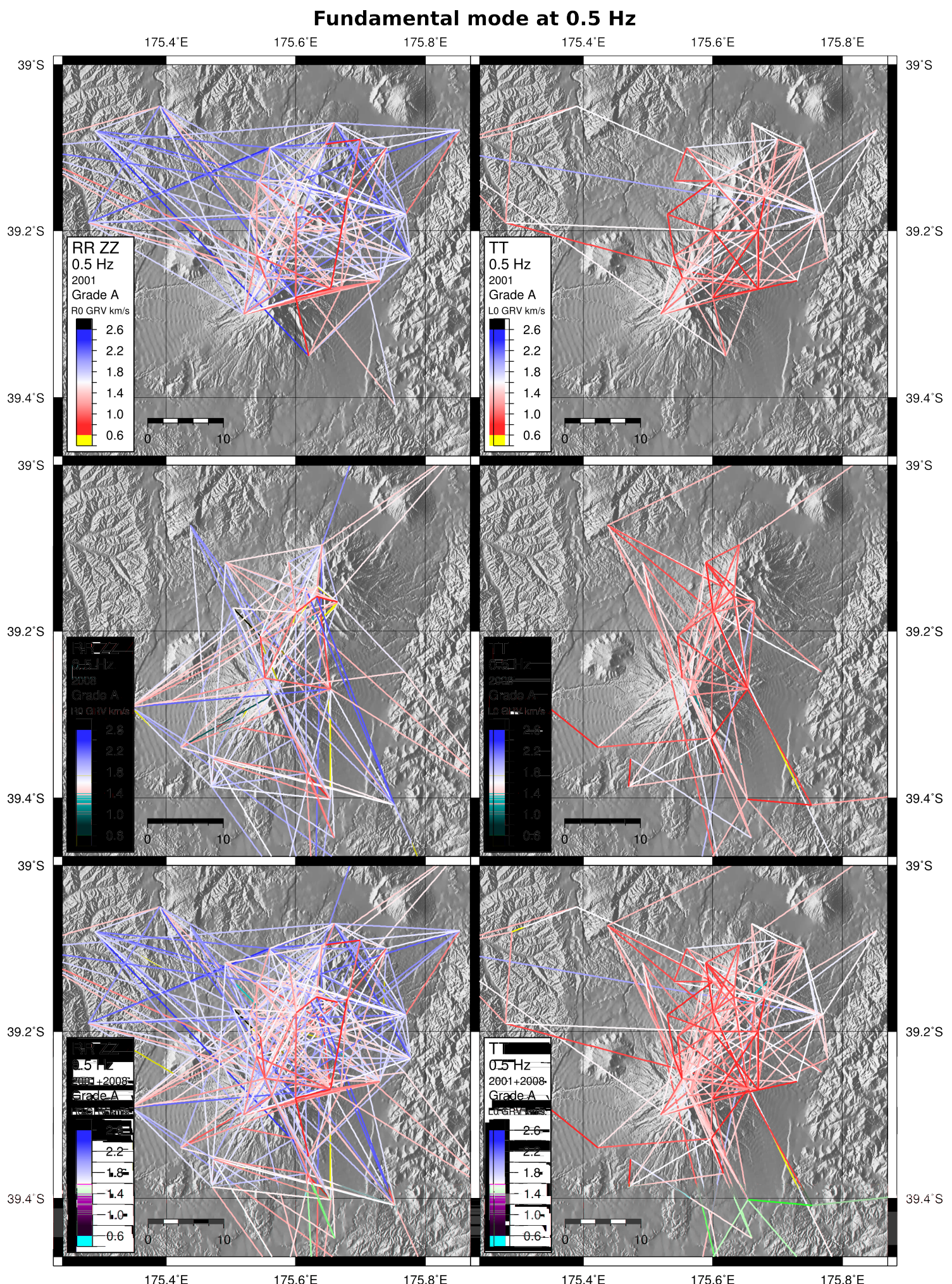

Figure 5.9: Fundamental mode, A-grade group velocity measurements at $0.5 \mathrm{~Hz}$, plotted by interstation path and coloured by velocity. Left and right plots are Rayleigh (from RR and ZZ CCF components) and Love (from TT CCF component), respectively; top, middle and bottom are 2001, 2008 and 2001+2008, respectively. 


\section{Fundamental mode at 1 Hz}

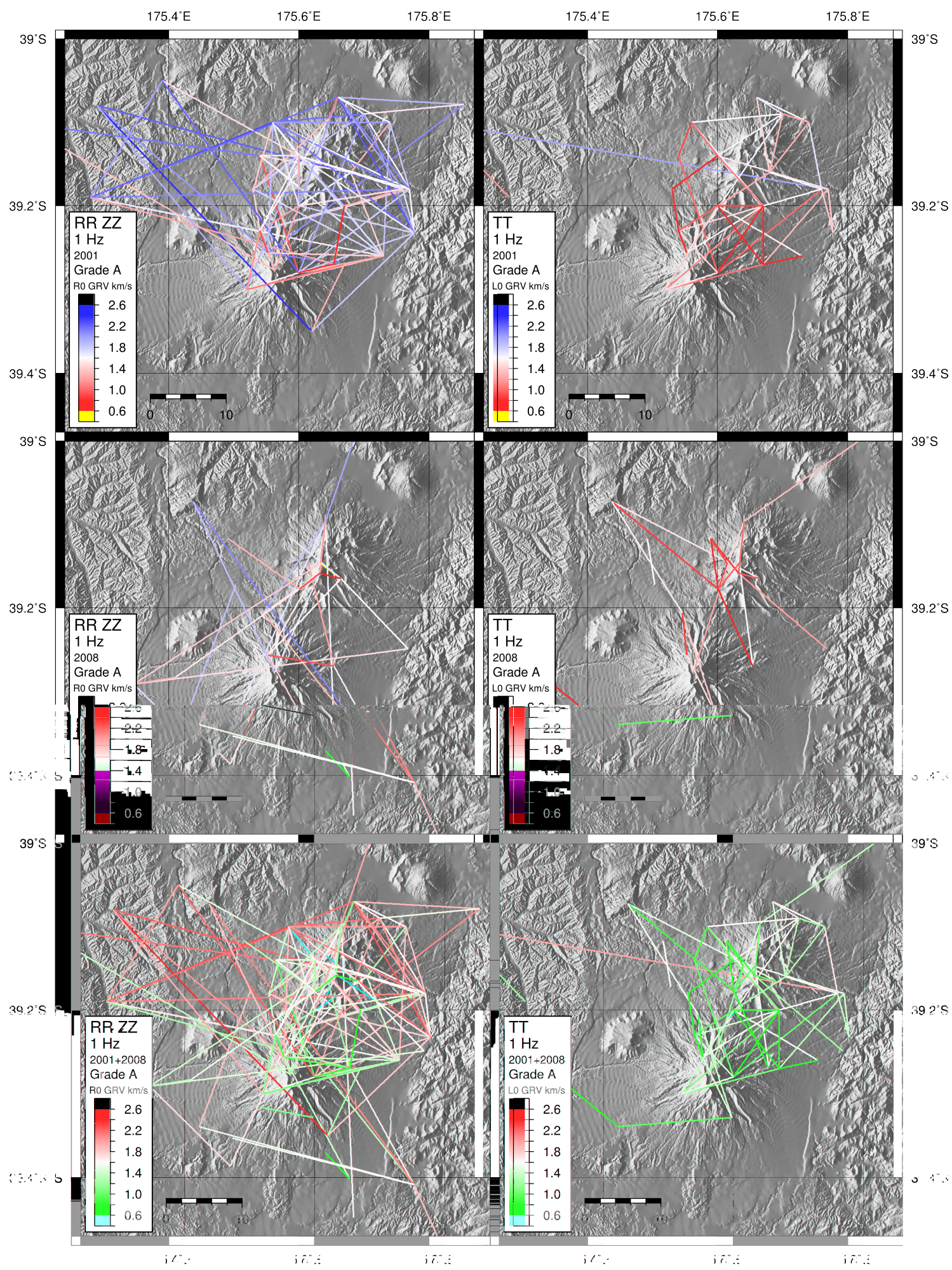

Figure 5.10: Fundamental mode, A-grade group velocity measurements at $1 \mathrm{~Hz}$, plotted by interstation path and coloured by velocity. Left and right plots are Rayleigh (from RR and ZZ CCF components) and Love (from TT CCF component), respectively; top, middle and bottom are 2001, 2008 and 2001+2008, respectively. 
First higher-order mode at $0.5 \mathrm{~Hz}$

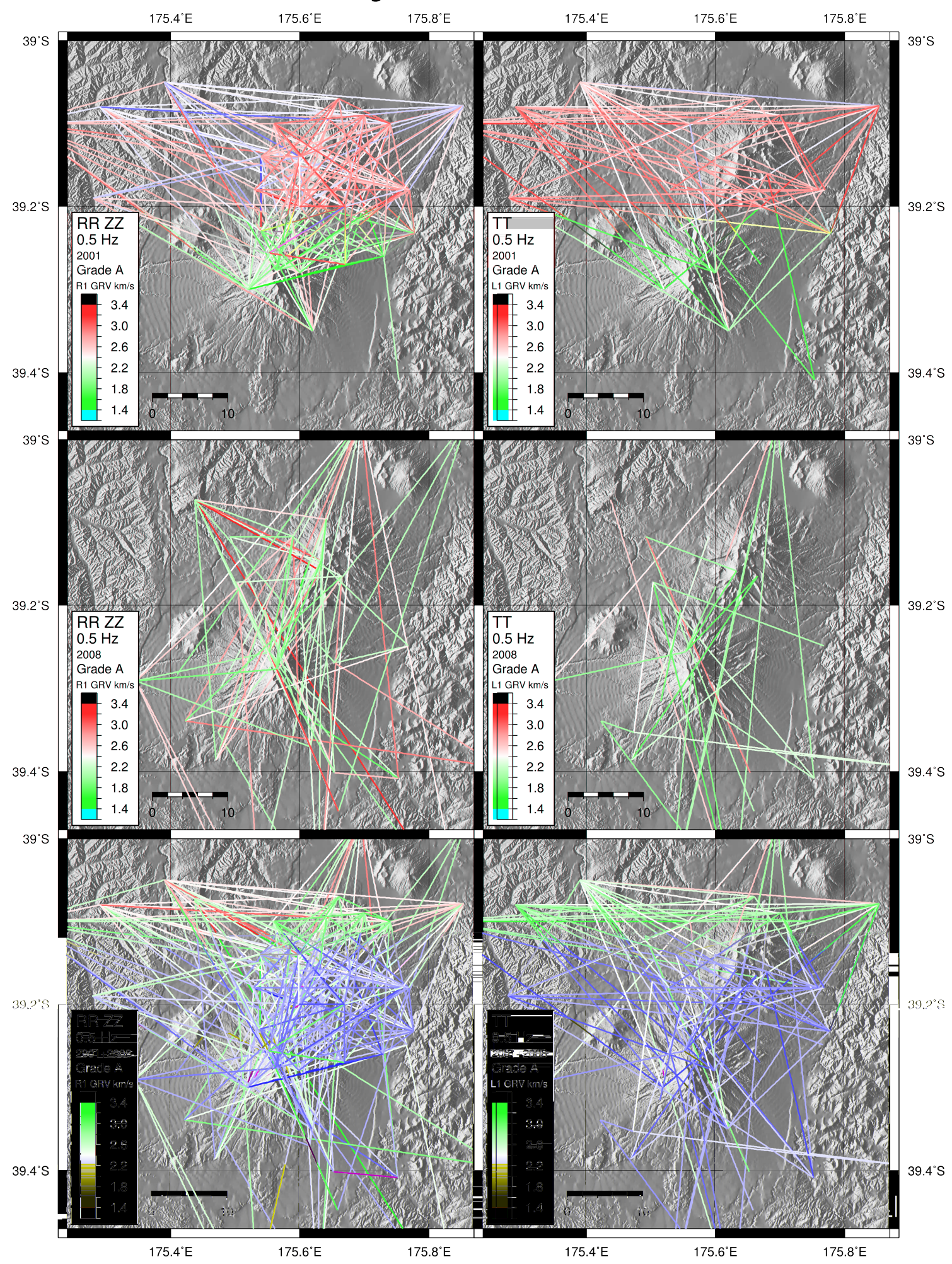

Figure 5.11: First higher-order mode, A-grade group velocity measurements at $0.5 \mathrm{~Hz}$, plotted by interstation path and coloured by velocity. Left and right plots are Rayleigh (from RR and ZZ CCF components) and Love (from TT CCF component), respectively; top, middle and bottom are 2001, 2008 and 2001+2008, respectively. 
First higher-order mode at $1 \mathrm{~Hz}$

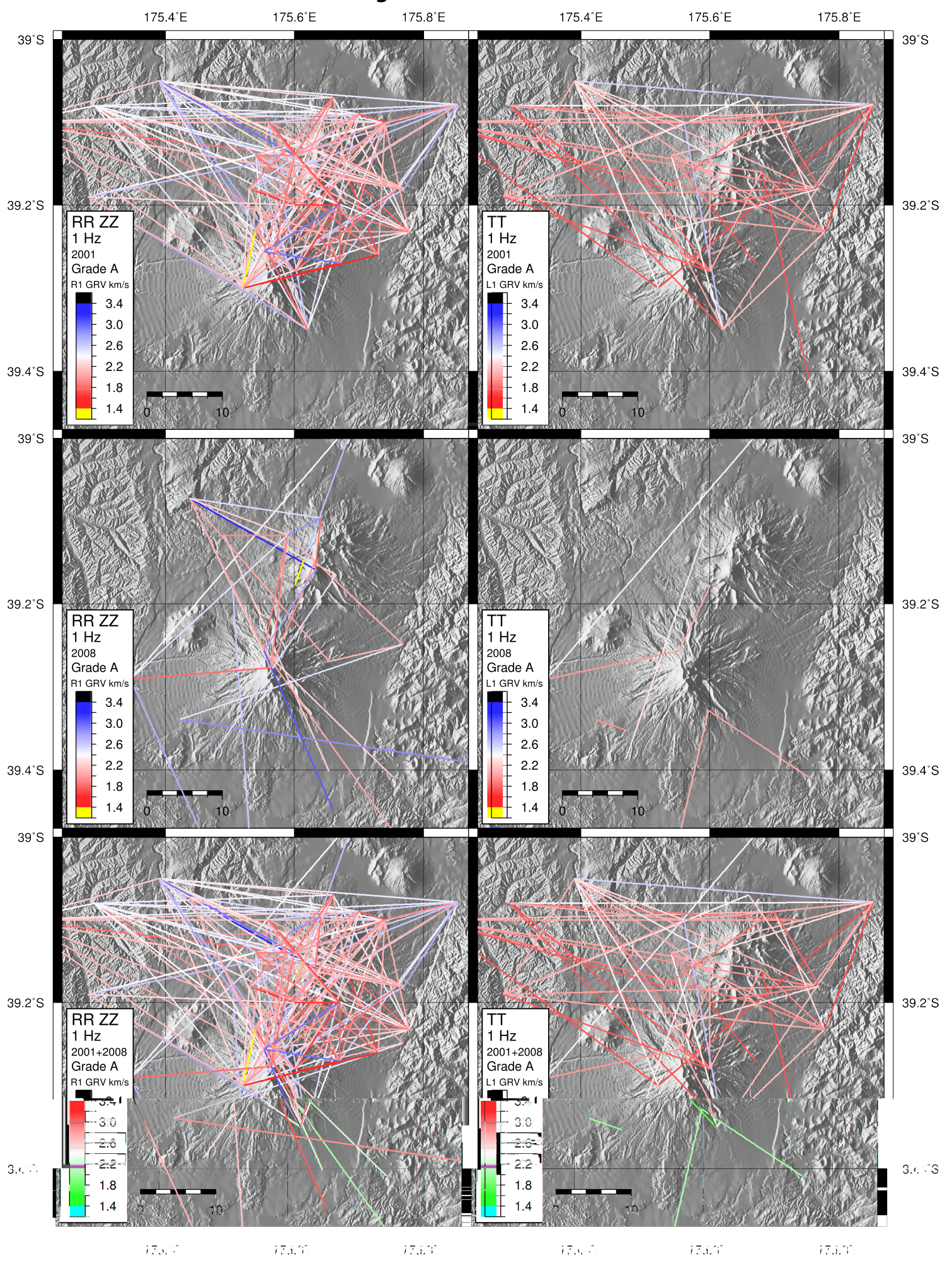

Figure 5.12: First higher-order mode, A-grade group velocity measurements at $1 \mathrm{~Hz}$, plotted by interstation path and coloured by velocity. Left and right plots are Rayleigh (from $R R$ and ZZ CCF components) and Love (from TT CCF component), respectively; top, middle and bottom are 2001, 2008 and 2001+2008, respectively. 


\subsubsection{Fundamental mode}

The R0 group velocities across both frequencies are spatially varied and mostly range from 1-2.5 km/s (Figs. 5.9, 5.10). The fastest measurements occur for stations located directly on Mesozoic greywacke (Fig. 4.1). The region slightly to the E/NE of Mount Tongariro also appears to be comparably fast, containing paths from 2001 stations S14, S15, S25 and S27. The slowest R0 measurements are for paths crossing Ngauruhoe (NGA stations) and the eastern flanks of Mount Ruapehu (stations S10, S23 and TUVZ).

With a group velocity range of approximately $0.8-1.6 \mathrm{~km} / \mathrm{s}$, there is less variation in the L0 group velocities than the R0 velocities. There are too few L0 paths, however, in the identified NW R0 fast area for comparison.

Across both frequencies, the L0 velocities appear slower than the R0 velocities, especially for paths across Tongariro and the Tama Lakes areas (Figs. 5.9, 5.10). Very few R0 paths have group velocities less than $1.2 \mathrm{~km} / \mathrm{s}$, however, L0 measurements with such velocities are common. Conversely, few L0 measurements are above $1.6 \mathrm{~km} / \mathrm{s}$, whereas a significant proportion of the R0 group velocities are between $1.5-2.2 \mathrm{~km} / \mathrm{s}$. The difference between the R0 and L0 dispersion is approximately equal for 2001 and 2008 .

\subsubsection{First higher-order mode}

The proportion of measurements with interstation distances greater than $20 \mathrm{~km}$ is greater for the higher order-mode maps (Figs. 5.11, 5.12) than the fundamental mode maps (Figs. 5.9, 5.10). There are few measurements crossing Ruapehu and Tongariro volcanoes, especially at $1 \mathrm{~Hz}$ (Fig. 5.12). Similarly, the R0/L0 data contain the majority of pairs less than $10 \mathrm{~km}$ apart, particularly across Ruapehu and Tongariro.

The R1 (RR ZZ) data range from approximately $1.6-3.2 \mathrm{~km} / \mathrm{s}$, with most data below 2.5 $\mathrm{km} / \mathrm{s}$. There is less spatial variation of $\mathrm{R} 1$ group velocities than for R0 (RR ZZ), however the NW area does appear faster in 2001. The eastern flanks of Ruapehu and Tongariro appear to have the slowest R1 group velocities, however their distribution appears more random than the $\mathrm{R} 0$ velocities.

The group velocities for the L1 data range from 1.6-2.4 km/s. Variation appears to be random, probably due to the lack of L1 measurements with small interstation distances. 
Unlike the R0/L0 data, there does not appear to be any significant differences between the R1 and L1 group velocities. L1 velocity measurements including the outer TgVC stations in 2001 appear slightly slower than the R1 measurements. Due to the lack of shortmedium distance L1 paths, we cannot compare the R1 and L1 velocities across Ruapehu and Tongariro.

\subsection{Synthetic cross-correlations and dispersion}

\subsubsection{Calculated dispersion}

The calculated R0, L0 and L1 group velocity dispersion curves for the JR and FR models have similar shape (Fig. 5.13). With increasing frequency, the curves begin with high velocities that rapidly decrease to a minimum before slightly increasing. There are differences between the frequency and group velocity ranges for which changes occur, e.g. for the L1 curve, the steep velocity decrease occurs approximately $0.2 \mathrm{~Hz}$ higher than for the $\mathrm{R} 0$ and L0 curves. In contrast, at low frequencies, $\mathrm{R} 1$ dispersion is similar to $\mathrm{R} 0$ dispersion; the velocities significantly increase before decreasing and merging with the R0 curve at high frequencies.

The two models' curves share some characteristics. Between 0.15 and $0.3 \mathrm{~Hz}, \mathrm{R} 0$ velocities are faster than L0 velocities; where defined, R1 velocities are slightly faster than R0 velocities. Additionally, L0 velocity is faster than R0 velocity above $0.3 \mathrm{~Hz}$. For both models, the minimum $\mathrm{R} 0$ group velocity is approximately half the $\mathrm{V}_{S}$ of the top layer.

There are, however many differences between the two models' curves. The minimum $\mathrm{R} 0$ and L0 velocities occur at frequencies approximately $0.05 \mathrm{~Hz}$ lower in the FR model than in the JR. The minimum L1 velocity occurs at a frequency $0.2 \mathrm{~Hz}$ lower in the FR model. In the JR model, the $\mathrm{R} 0$ and $\mathrm{R} 1$ group velocities are approximatly equal from 0.25- $0.35 \mathrm{~Hz}$ and above $1 \mathrm{~Hz}$ (Fig 5.13a), whereas they appear to merge from $0.8 \mathrm{~Hz}$ in the FR model (Fig. 5.13b). The differences between R0 and R1 dispersion do not exceed 800 $\mathrm{m} / \mathrm{s}$ for any frequency in model JR, whereas in model FR, the difference exceeds $800 \mathrm{~m} / \mathrm{s}$ at $0.35-0.5 \mathrm{~Hz}$. The average R0-R1 dispersion differences at $0.3-1 \mathrm{~Hz}$ are $470 \mathrm{~m} / \mathrm{s}$ (JR model) and $430 \mathrm{~m} / \mathrm{s}(\mathrm{FR})$. 


\section{Calculated dispersion curves}

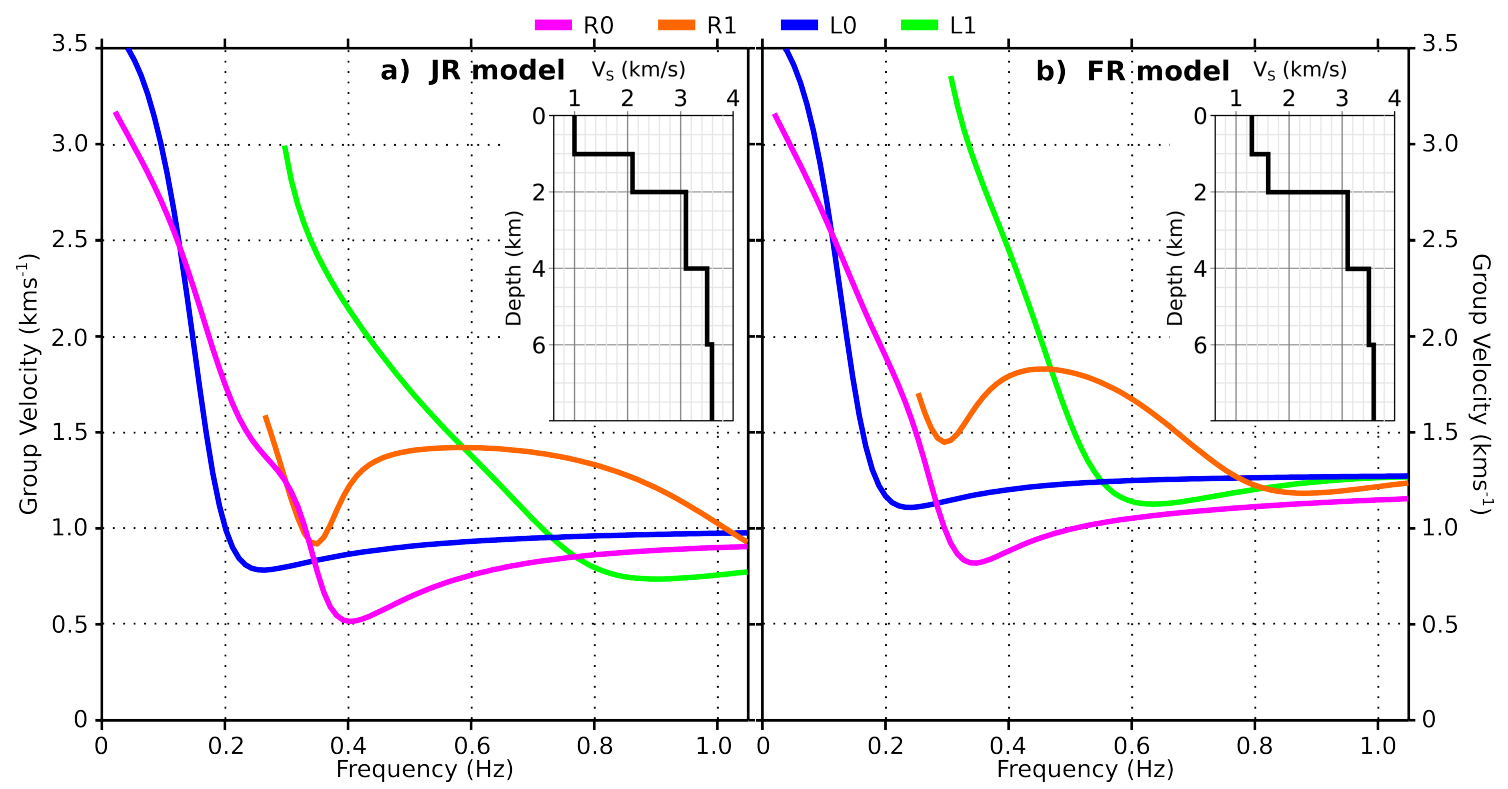

Figure 5.13: Calculated dispersion curves for fundamental and first higher-order mode Rayleigh (R0, R1) and Love waves (LO, L1) group velocities: a) JR velocity model; b) FR model.

\subsubsection{Cross-correlations}

Our calculated dispersion curves (Fig. 5.13) do not give any information regarding the energy strength at different frequencies. For each model, source-receiver distance and component, we simulated three sets of CCF for the Rayleigh-wave components, to investigate the differences between calculated and measured dispersion and the effects of the smoothing applied in MFT analyses. To fully represent our real data, we determine the modal sum of R0-R10, which we denote RA. We also isolate the R0 and R1 CCF.

To see the effects of R0 and R1 on RA CCF (approximation of the sum of all modes) in the two models, we plot record-sections of the synthetic RR and ZZ CCF (Figs. 5.14, 5.15). Although we recognise different characteristics of the R0 and $\mathrm{R} 1 \mathrm{CCF}$ at different velocities for both components and models, we do not observe any changes in their properties or effects at specific velocities in RA at different source-receiver distances.

In both models' RR component CCF the strongest energy comes from R1 phases containing frequencies below $1 \mathrm{~Hz}$, travelling at $1.3-1.5 \mathrm{~km} / \mathrm{s}(\mathrm{JR}$ model) and $1.5-2 \mathrm{~km} / \mathrm{s}(\mathrm{FR}$ model). (Figs. 5.14a, 5.15a, pink regions; 5.16c,5.17c). 
On both components and models, low velocity R0 waveforms (Figs. 5.14, 5.15; green areas) are characterised by strong low frequency energy travelling at slower velocities than high frequency energy (Figs. 5.16a\&b,5.17a\&b). Slow, low frequency energy is also apparent for R1 on both components for the JR model (Fig. 5.14,5.16c\&d), however the amplitudes have the opposite sign to those of R0. The opposing R0 and R1 phases largely cancel out in the RA CCF (Fig. 5.16e).

We think this strong energy, which resembles some of our dispersion measurements assigned characteristic W (section 5.2.1.1), reflects the presence of Airy phases (Aki and Richards, 2002), which can occur in seismograms where the dispersion curves contain maxima or minima, as is the case for our calculated R0, L1 and R1 dispersion curves section 5.3.1). The $\mathrm{R} 0$ and $\mathrm{R} 1$ dispersion curves for the JR model contain sharper inflections than those for the FR model, which may be why the Airy phases in the JR CCF last longer than in the FR CCF.

\subsubsection{Measured vs. calculated Rayleigh-wave dispersion}

We look at the relationships between the group velocity measurements of the synthetic CCF and the calculated Rayleigh-wave dispersion at frequencies below $1.05 \mathrm{~Hz}$, as most of our real dispersion measurements (section 5.2.1) lack energy at higher frequencies. We do not manually refine the automatic dispersion measurements, to see how they compare with the calculated dispersion curves; however, we ignore portions of the curves where the wavelength (velocity/frequency) is less than the interstation distance.

Although the dominance of the R0 and R1 energy on the RA CCF at specific velocities does not appear to change with interstation distance, the highest amplitude, and automatic dispersion measurements do (Figs. $5.16 \mathrm{~g} \& \mathrm{~h} ; 5.17 \mathrm{~g} \& \mathrm{~h}$ ). Most changes appear to be systematic with interstation distances, rather than random. In both models, the RR and ZZ dispersion measurements mostly fit with the calculated $\mathrm{R} 1$ and $\mathrm{R} 0$ dispersion, respectively.

For both models and components, the dispersion measurements do not resolve the inflections of the calculated dispersion curves at approximately $0.3 \mathrm{~Hz}$. This is likely because of the smoothing applied during MFT analysis (section 4.4). 


\section{Synthetic model JR record sections}

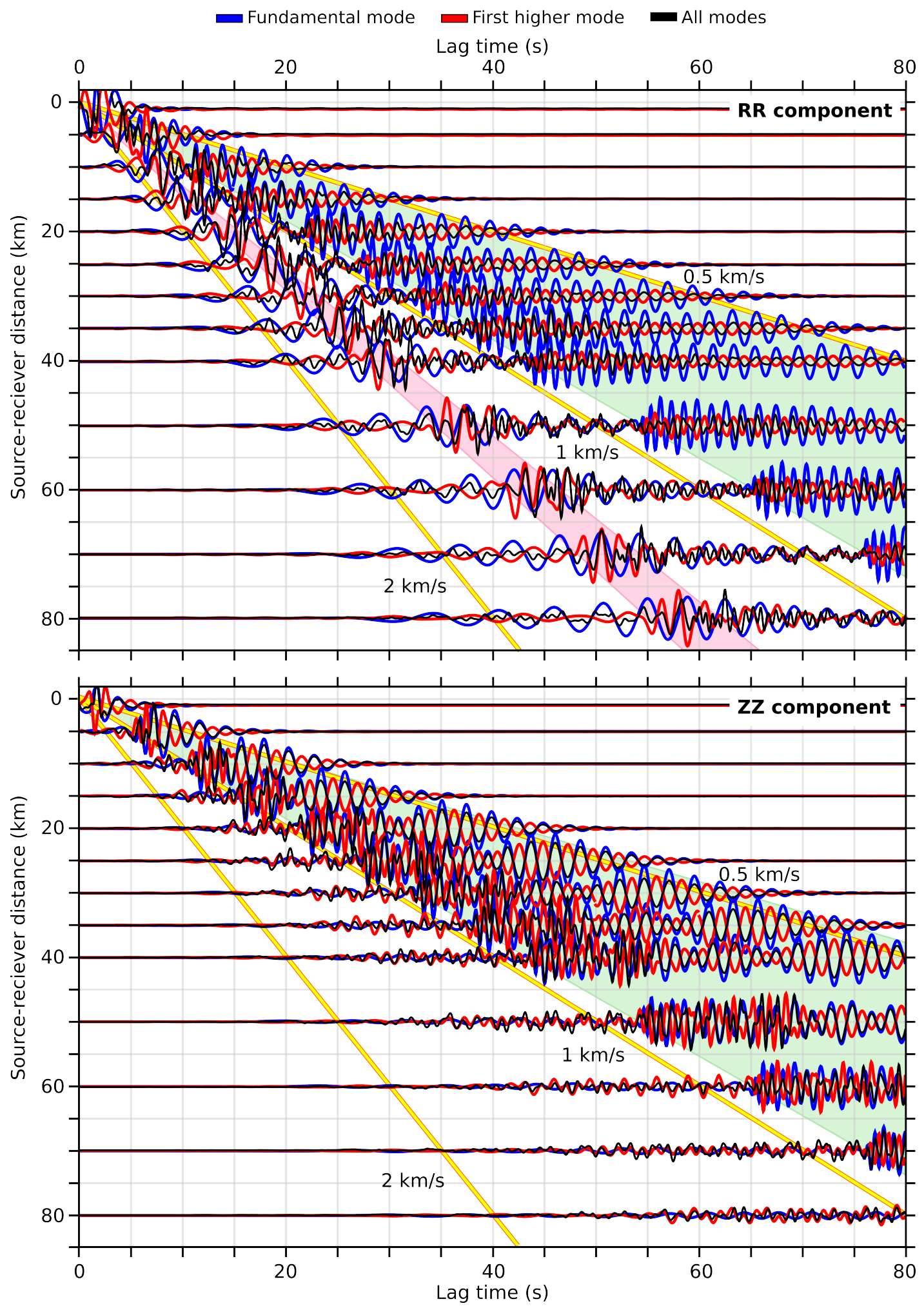

Figure 5.14: Record sections for synthetic cross-correlations generated from the JR input model. Coloured waveforms represent isolated modes; black line is modal sum (RA). Pink and green areas highlight where $R A$ 's phases are dominated by the $R 1$ and Ro, respectively: a) $R R$ component; b) $Z Z$ component. 


\section{Synthetic model FR record sections}

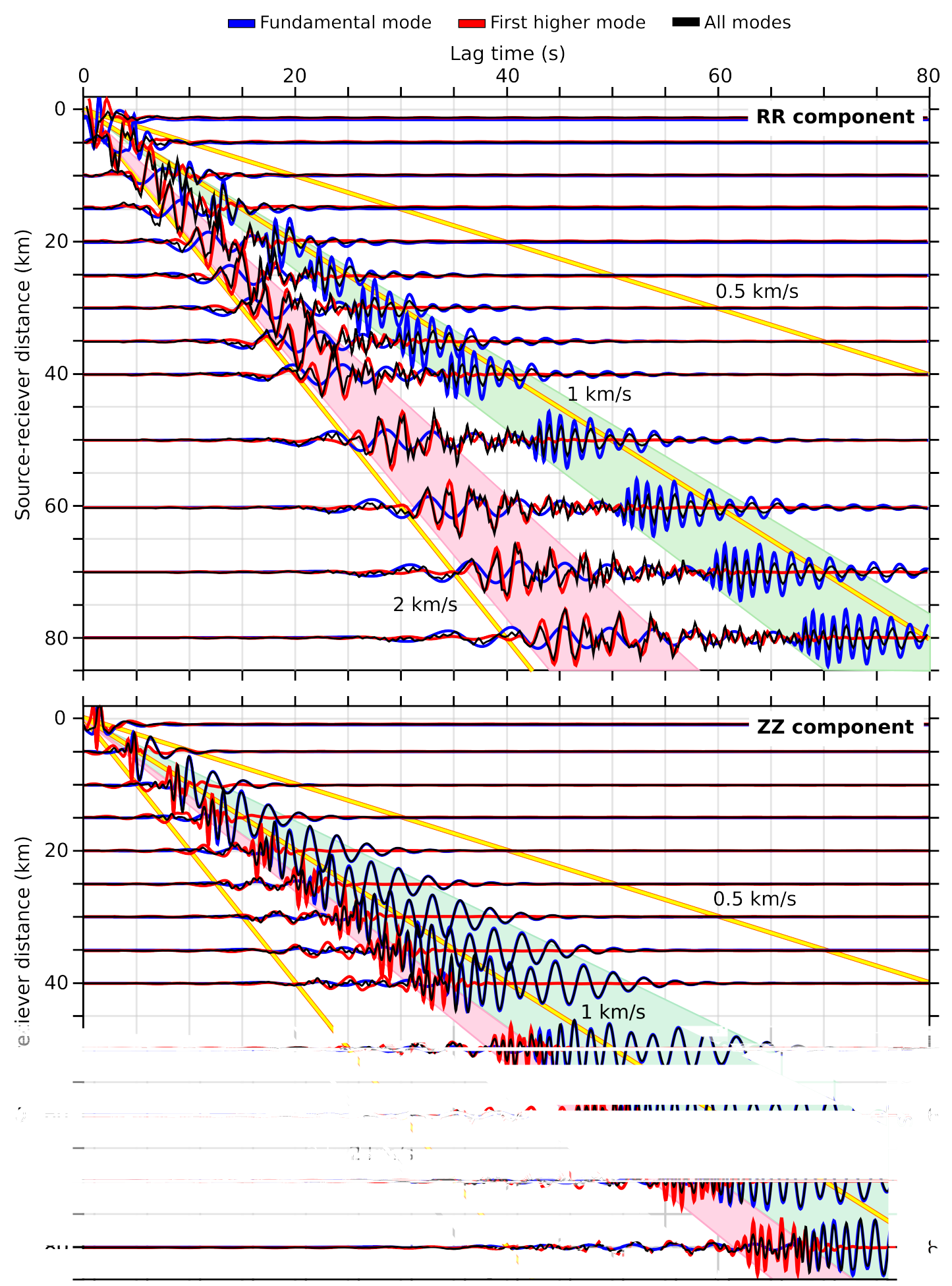

เ.8า:1 1.8)

Figure 5.15: Record sections for synthetic cross-correlations generated from the FR input model. Coloured waveforms represent isolated modes; black line is modal sum (RA). Pink and green areas highlight where $R A$ 's phases are dominated by $R 1$ and Ro, respectively: a) $R R$ component; b) ZZ component. 


\section{JR model synthetic spectrograms and dispersion}
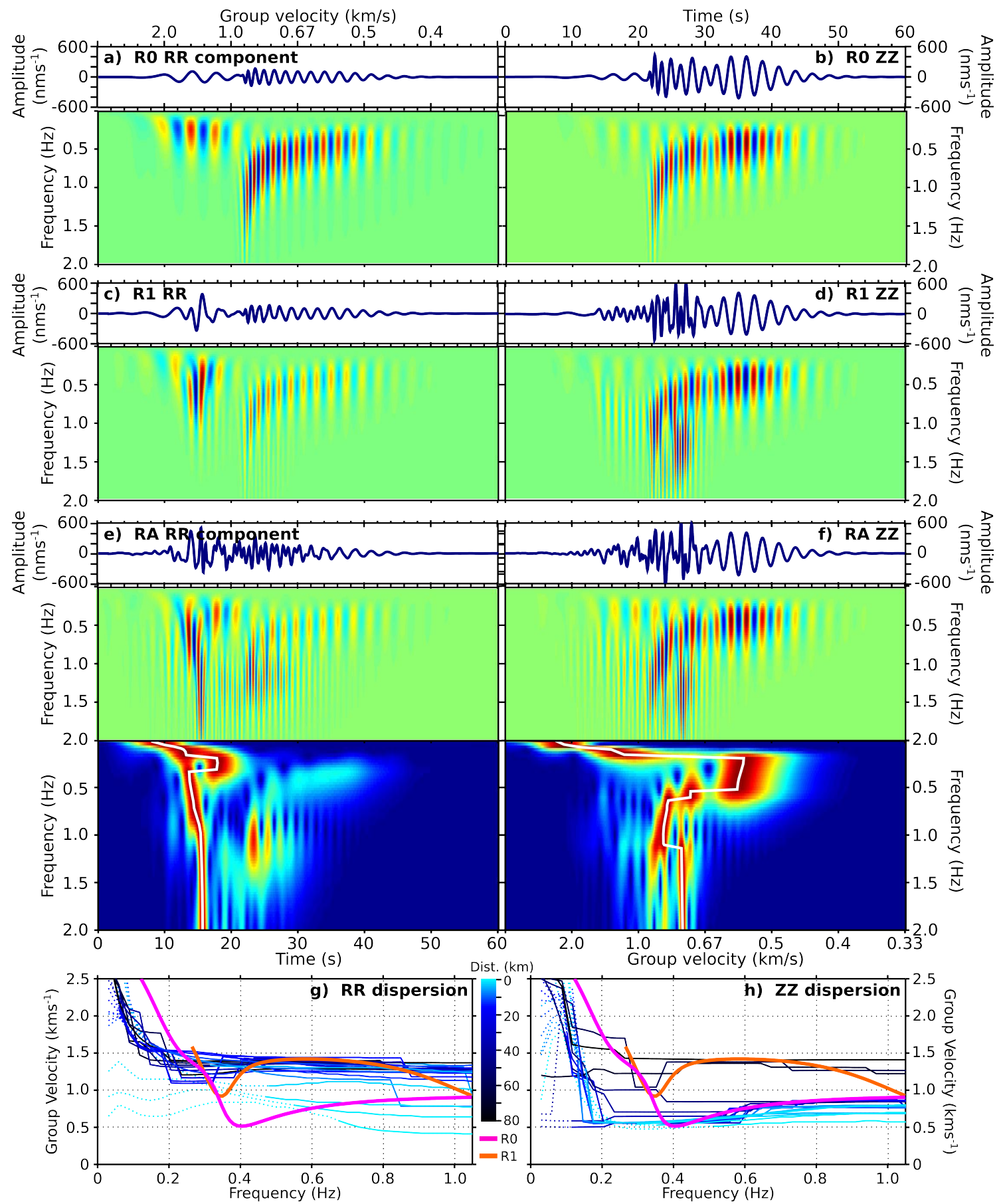

Figure 5.16: Synthetic cross-correlations and spectrograms produced for model JR with a simulated interstation distance of $20 \mathrm{~km}$ : a) R0, RR component; b) RO, ZZ; c) R1, RR; d) R1, ZZ; e) RA spectrogram and MFT plot with superimposed automatically picked dispersion measurement; f) ZZ RA, with MFT and automatic dispersion; g) calculated R0 (pink line) and $R 1$ (orange) Rayleigh-wave dispersion vs. measured (automatic) dispersion of $R A, R R C C F$ for 22 simulated interstation distances. Solid and dotted lines are portions of the measured dispersion passing and failing the $1 \lambda$ between stations criterion, respectively; h) calculated Rayleigh-wave dispersion vs. ZZ, RA measured dispersion, coloured by interstation distance. 
FR model synthetic spectrograms and dispersion
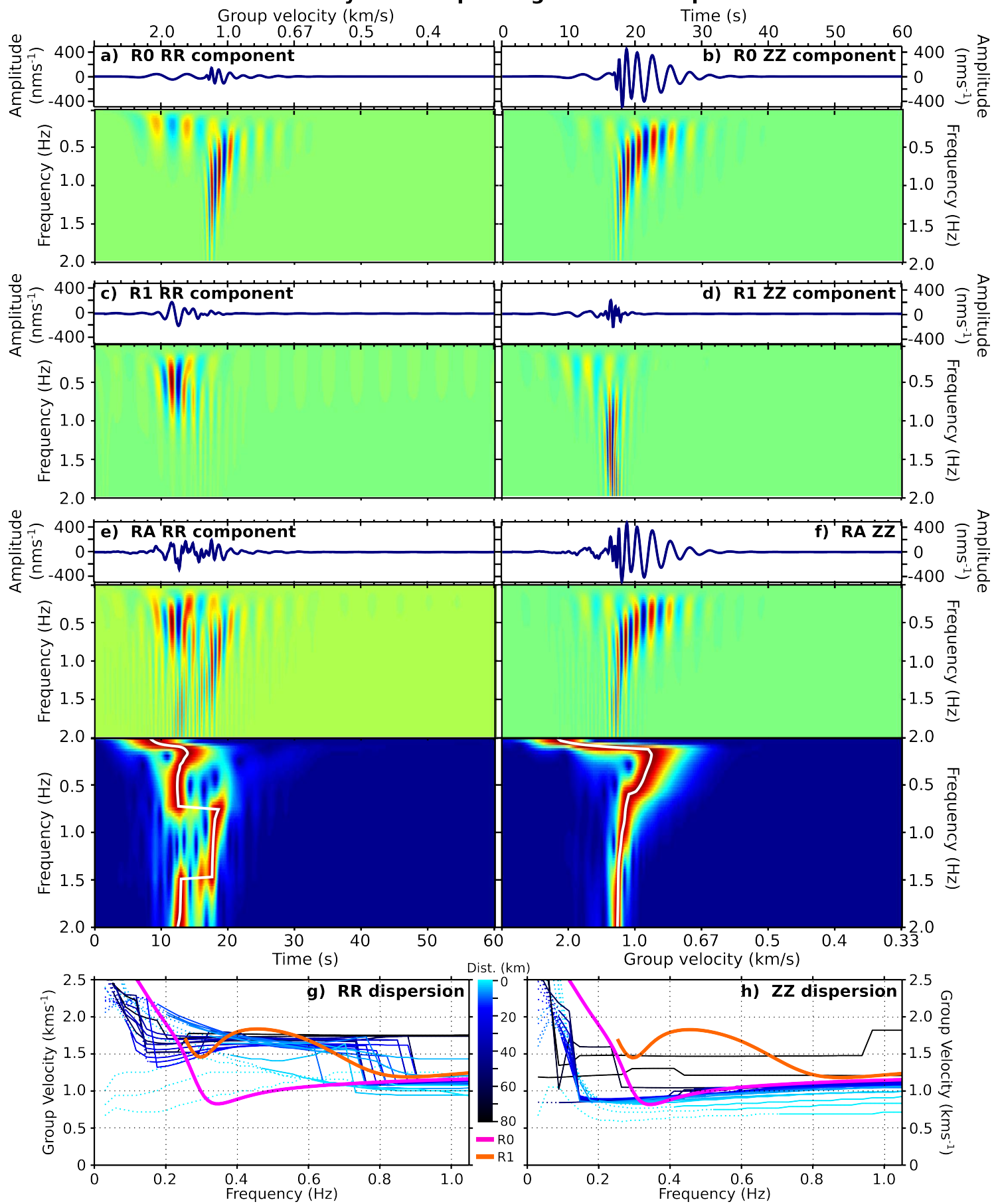

Figure 5.17: Synthetic cross-correlations and spectrograms produced for model FR with a simulated interstation distance of $20 \mathrm{~km}$ : a) $R 0, R R$; b) $R 0, Z Z$; c) $R 1, R R$; d) $R 1$, $Z Z$; e) $R A, R R ; f) R A, Z Z$; g) calculated vs. measured $R A, R R$ dispersion; h) calculated vs. measured RA, ZZ dispersion. All colours and features have same meaning as previous figure. 
For both components in the JR model, we do not observe any behaviour where the automatic measurement jumps from one mode to the other within the frequency range of 0.4-1 Hz. The measured RR dispersion fits with the calculated $\mathrm{R} 1$ at $0.4-0.8 \mathrm{~Hz}$ and distances greater than $5 \mathrm{~km}$, with the difference between measured and calculated values decreasing with interstation distance (Fig. $5.16 \mathrm{~g}$ ). At $0.2-0.3 \mathrm{~Hz}$, the calculated R0 and $\mathrm{R} 1$ dispersion are so similar that it is impossible to distinguish them in the measurements. Below $0.3 \mathrm{~Hz}$, measurements with interstation distances $\geq 3 \mathrm{~km}$ cluster together, with sharp velocity increases below $0.2 \mathrm{~Hz}$.

On the JR ZZ component, the measurements match the calculated R0 dispersion for distances below $50 \mathrm{~km}$, above $0.4 \mathrm{~Hz}$ (Fig. 5.16h). Above $0.6 \mathrm{~Hz}$, the difference between the measured and calculated dispersion decreases with increasing distance, as on the RR component. The measurements at interstation distances of 60,70 and $80 \mathrm{~km}$ fit the R1 dispersion at $0.4-0.8 \mathrm{~Hz}$.

On the FR model's RR component, the dispersion measurements are similar to the calculated R1 at $0.3-0.6 \mathrm{~Hz}$ (Fig. 5.17g). However, the measurements' group velocities do not follow the variation with frequency of the calculated dispersion, rather, they are flat lines. From approximately $0.75 \mathrm{~Hz}$, where the calculated R0 and R1 dispersion begin to merge, the measured dispersion curves jump from their flat line group velocity to approximately $1 \mathrm{~km} / \mathrm{s}$, similar to both calculated modes. Different measurements jump at different frequencies, with no apparent relationship to distance. Above $0.8 \mathrm{~Hz}$, longer distance RR measurements travel faster than at shorter distances and are closer to the calculated R0 dispersion.

Most ZZ measurements match the calculated R0 dispersion above $0.3 \mathrm{~Hz}$ (Fig. 5.17h). Up to $50 \mathrm{~km}$, the difference between the calculated and measured dispersion decreases with increasing interstation distance. The 70 and $80 \mathrm{~km}$ measurements behave differently, falling between the two calculated modes at $0.3-0.7 \mathrm{~Hz}$. Above $0.8 \mathrm{~Hz}$, the $70 \mathrm{~km}$ measurement is approximatly equal to the calculated $\mathrm{R} 1$ dispersion, and the $80 \mathrm{~km}$ measurement is faster than it.

\subsection{Primary station pairs}

We select a single station pair with high quality cross-correlations and dispersion measurements for Ruapehu (S10-S28) and Tongariro (OTVZ-WTVZ, Fig. 4.1), which we refer 
to as our primary pairs. To confirm our assessments of the measured dispersive phases, we look at the RR, ZZ and TT record-sections for all pairs involving each of the four stations, as well as the particle motion of the pair's CCF in a time window chosen based upon the energy present in the spectrograms. Then, we invert the ZZ and TT dispersion measurements as the fundamental mode Rayleigh-wave (R0) and fundamental mode Love (L0) dispersion, respectively.

\subsubsection{S10-S28}

S10 and S28 are broadband stations from the 2001 START deployment (section 4.1), with an interstation path of $13.8 \mathrm{~km}$ traversing the summit of Ruapehu Volcano on an ENE/WSW orientation (Fig. 4.1). Both sensors are Guralp 40TD models, with very similar instrument response functions. We select this pair as the Ruapehu primary pair because it has the highest quality data of all viable pairs in the area.

\subsubsection{Cross-correlations}

The RR, ZZ and TT record-sections for S10 and S28 (correlated against all other stations) lowpassed at $1 \mathrm{~Hz}$ each show moveout of strong phases for stacks with interstation distances less than $40 \mathrm{~km}$ (Fig.5.18a). For both stations, two phases can be observed on the ZZ and TT components, whereas the RR component only shows one. The differences between the velocities of the two phases are $1.2-1.5 \mathrm{~km} / \mathrm{s}$ (TT component) and $0.7 \mathrm{~km} / \mathrm{s}(\mathrm{ZZ})$, suggesting the presence of multiple modes. The single RR phase has a velocity inbetween the two $\mathrm{ZZ}$ phases; dispersion measurements of this phase at both stations have been classified as the higher mode in the station-grouping analysis (section 5.2.2). The TT phases are slower than the corresponding ZZ at both stations. The S28 phases are slightly faster than S10 for all components.

Although S10-S28 as a pair was viable for only 28 days, the full-stacks are very high quality, with an average SNR of 50 for the symmetric, isotropic CCF (Fig. 5.18bii). Of the two-sided full-stacks, phases in the acausal CCF have larger amplitudes than their causal counterparts, except for the RT and TT components (Fig. 5.18b). This indicates that the noise waves travelling from the east (S10 to S28) are stronger than those travelling from the west (S28 to S10). However, if amplitudes are disregarded, the two sides are reasonably symmetric on most components. 
S10-S28
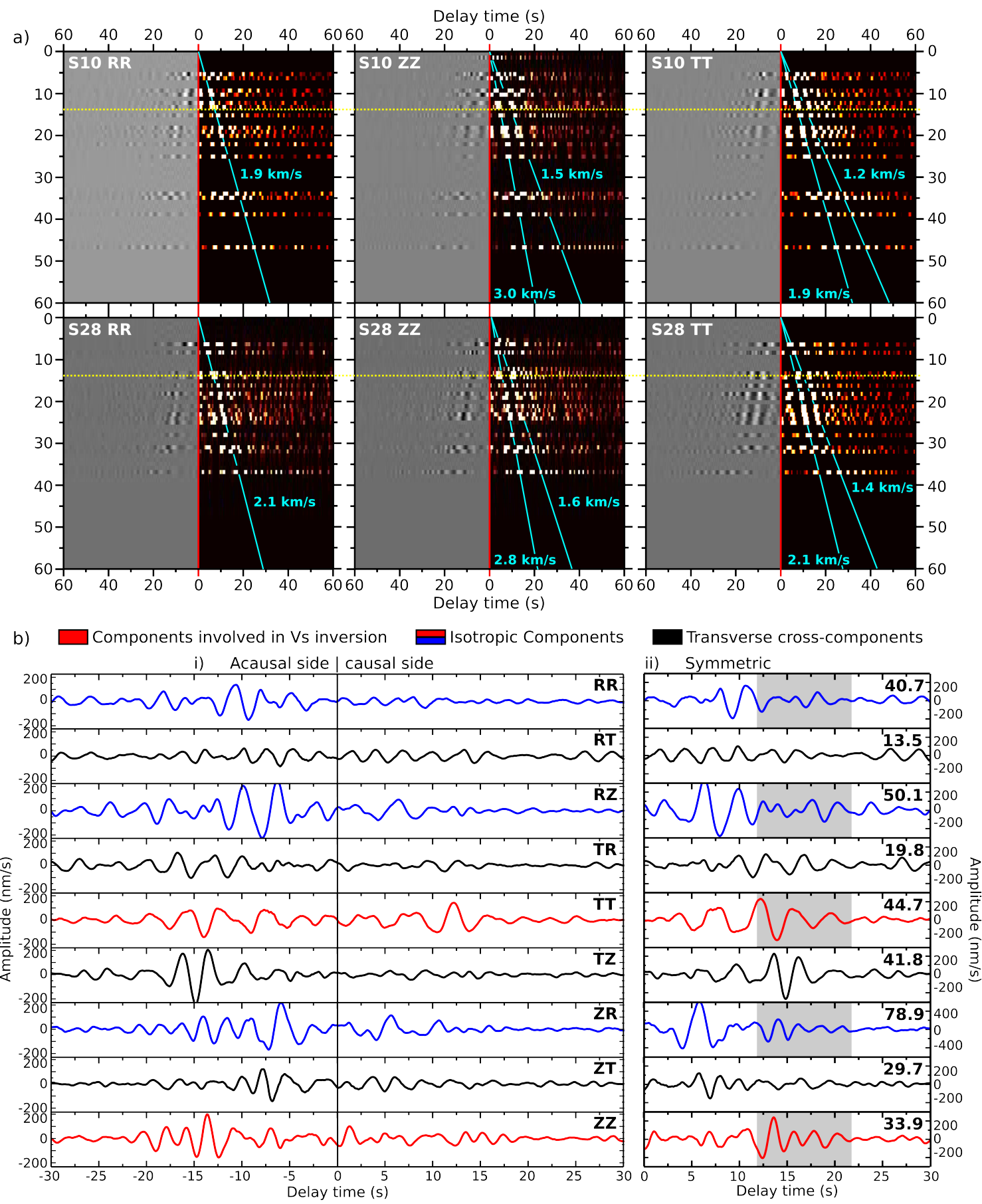

Figure 5.18: Cross-correlations of S10 and S28: a) RR, ZZ and TT record sections ( $<1 \mathrm{~Hz})$ of all station pairs involving S10 (top) and S28 (bottom). Left (greyscale) plots are unaltered amplitudes, right (colour) plots have CCF amplitudes normalised to 1. Superimposed yellow dotted line is interstation distance of S10-S28 pair; blue lines indicate phase moveout, with approximate velocity. b) nine-component full-stacks for S10-S28 at 0.2-2 Hz. Colours represent component type/use, : i) the two-sided functions; ii) symmetric CCF. Top-right numbers are SNR; grey area shows time window for particle motion. 


\section{S10-S28 MFT and dispersion measurements}
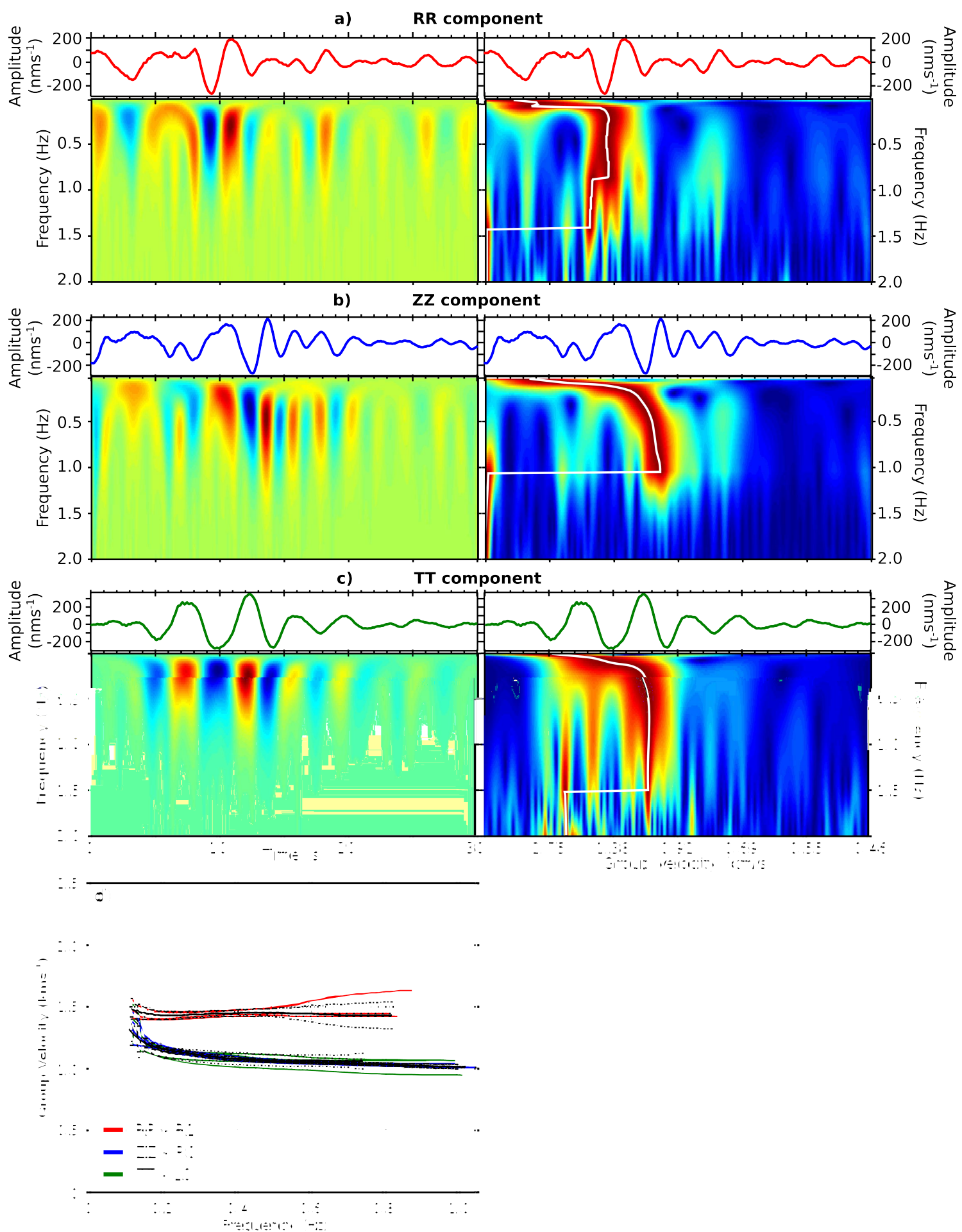

Figure 5.19: Dispersion measurement summary for station S10-S28: a) RR component full stack spectrogram and MFT analysis with automatically picked dispersion; b) full stack ZZ component; c) full stack TT component; d) RR, ZZ and TT dispersion curves, with mode identification. Coloured lines represent dispersion picks for blocks, black lines represent pick for full stack, with error bars from standard deviations of blocks. 
Of all nine components, the RZ and ZR have strongest phases, and highest SNR. Being out of phase by $180^{\circ}$ (or $1 / 2 \lambda$ ), these components should be inverses of each other, i.e. completely cancelling out if added together. However, this is not what we observe. At delay times of 0-10 s, the RZ and ZR CCF appear almost in phase, with the ZR component very slightly leading the RZ CCF on the causal and acausal functions (Fig. 5.18bi).

There is a very strong phase in the TZ CCF, occurring at 12-18 s. It is present in all 28 daily TZ stacks, but only on the acausal side (not shown). This is odd for a component that we expect to have a low SNR (section 4.5). The lack of energy on the causal CCF means the phase is almost unchanged in the symmetric function.

\subsubsection{Dispersion}

The ZZ and TT component MFT analyses for S10-S28 produce very high quality dispersion measurements (grade L1), while the RR is high quality (grade O2), as it is slightly less dispersive (Fig. 5.19). The dispersion curves for all three components vary little with frequency above $0.3 \mathrm{~Hz}$. The ZZ and TT dispersion curves are very similar at all frequencies; their difference does not exceed $23 \mathrm{~m} / \mathrm{s}$ above $0.2 \mathrm{~Hz}$. The TT dispersion curve does not extend beyond $0.7 \mathrm{~Hz}$ due to the lack of energy at higher frequencies. The RR dispersion has the highest group velocities, which are approximately $0.5 \mathrm{~km} / \mathrm{s}$ faster the other two components (Fig. 5.19d).

Due to the pair's short duration, to determine the dispersion curve error, we split the stack into four blocks of seven days. The resulting average standard deviations per component are very low above $0.2 \mathrm{~Hz}(55,13$ and $48 \mathrm{~m} / \mathrm{s}$, for the RR, ZZ and TT components, respectively, Fig. 5.19). Below this lower limit, the uncertainty increases; however, we think the ZZ and TT curves contain usable data down to $0.17 \mathrm{~Hz}$ for the $\mathrm{V}_{S}$ inversions.

\subsubsection{Particle motion}

The ZR/ZZ particle motion is the strongest plotted (Fig. 5.20d). It is highly elliptical, with maximum and minimum amplitudes $( \pm 400 \mathrm{~nm} / \mathrm{s})$ on the $\mathrm{ZR}$ axis, indicating that we have isolated $\mathrm{R} 0$ in the $12-22 \mathrm{~s}$ window. The weaker amplitude $\mathrm{RR} / \mathrm{RZ}$ particle motion is also elliptical (Fig. 5.20a). The RZ/ZZ and RR/ZR particle motion (Fig. 5.20b\&d) have maximum amplitudes on the RZ and RR components, respectively, and are more linear 


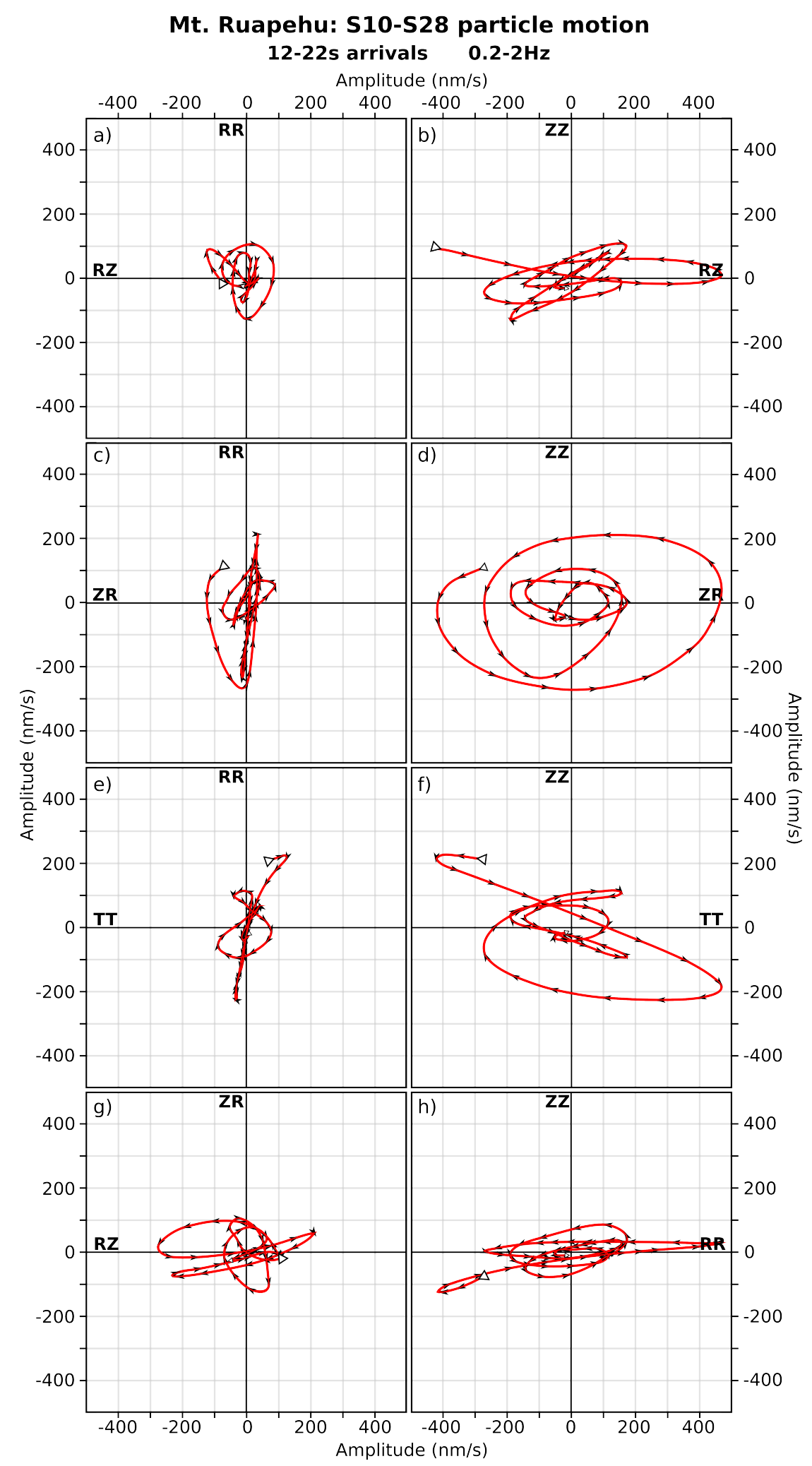

Figure 5.20: Particle motion for fundamental mode time window (Fig. 5.18, grey area), plotted for different CCF component pairs. Larger white triangle denotes starting point, small white triangle denotes end. Small triangles indicate direction of movement: a) $R R / R Z$; b) $R Z / Z Z$; c) $R R / Z R$; d) $Z R / Z Z$; e) $R R / T T$; f) $T T / Z Z$; g) $R Z / Z R$; h) $R R / Z Z$. 
than the RR/RZ and ZR/ZZ. However, these pairs exhibit some weakly elliptical motion. The the RZ/ZR and RR/ZZ particle motion are similarly quasi-elliptical (Fig. 5.20g\&h). The RZ/ZR shows that the two CCF are not $180^{\circ}$ out of phase with each other in the time window.

The RR/TT and TT/ZZ particle motions both contain characteristics similar to a figure eight (Fig. 5.20e\&f). This shape may be produced from the components' different frequency content, which can be seen in their spectrograms (Fig. 5.19), particularly the lack of energy above $0.7 \mathrm{~Hz}$ in the TT stack.

\subsubsection{4 $\mathrm{V}_{S}$ inversion}

Overall, the R0 and L0 Vs profiles have well constrained layer depths and velocities, except for the halfspace of R0. All three inversions have layer velocities increasing with depth (Fig. 5.21 , Table 5.9). Shallower than $1 \mathrm{~km}, \mathrm{Vs}<1400 \mathrm{~m} / \mathrm{s}$ in all the inversions; the acceptable velocity ranges of $\mathrm{R} 0$ are faster than the $\mathrm{L} 0$ acceptable range. At $1-2.5 \mathrm{~km}$ depth, the best L0 profile is approximately the same as the best R0 profile (Table 5.9).

\begin{tabular}{|c|c|c|c|c|c|c|c|c|c|c|}
\hline \multirow{3}{*}{ Layer } & \multicolumn{4}{|c|}{ R0 model } & \multicolumn{4}{|c|}{ L0 model } & \multicolumn{2}{|c|}{ R0L0 model } \\
\hline & \multicolumn{2}{|c|}{$\operatorname{Vs}(\mathbf{m} / \mathbf{s})$} & \multicolumn{2}{|c|}{$\begin{array}{l}\text { Bottom depth } \\
\text { (m) }\end{array}$} & \multicolumn{2}{|c|}{$\operatorname{Vs}(\mathbf{m} / \mathbf{s})$} & \multicolumn{2}{|c|}{$\begin{array}{c}\text { Bottom } \\
\text { depth (m) }\end{array}$} & $\begin{array}{c}\text { Vs } \\
(\mathrm{m} / \mathrm{s})\end{array}$ & $\begin{array}{c}\text { Bottom } \\
\text { depth (m) }\end{array}$ \\
\hline & Best & Range & Best & Range & Best & Max & Best & Max & & Best \\
\hline 1 & 1100 & $\begin{array}{l}1025- \\
1170\end{array}$ & 275 & $\begin{array}{l}215- \\
360\end{array}$ & 1050 & $\begin{array}{l}1000- \\
1100\end{array}$ & 120 & $70-430$ & 910 & 175 \\
\hline 2 & 1170 & $\begin{array}{l}1120- \\
1210\end{array}$ & 530 & $\begin{array}{c}490- \\
670\end{array}$ & 1095 & $\begin{array}{l}1045- \\
1160\end{array}$ & 720 & $\begin{array}{c}670- \\
930\end{array}$ & 1150 & 500 \\
\hline 3 & 1235 & $\begin{array}{l}1220- \\
1260\end{array}$ & 1320 & $\begin{array}{l}1260- \\
1440\end{array}$ & 1325 & $\begin{array}{l}1250- \\
1510\end{array}$ & 1450 & $\begin{array}{c}1170- \\
1610\end{array}$ & 1245 & 1400 \\
\hline 4 & 1360 & $\begin{array}{l}1330- \\
1375\end{array}$ & $3500 *$ & $\begin{array}{l}3000- \\
3500 *\end{array}$ & 1535 & $\begin{array}{l}1350- \\
1550\end{array}$ & 3000 & $\begin{array}{l}2580- \\
3500 *\end{array}$ & 1400 & $3500 *$ \\
\hline Halfspace & 1470 & $\begin{array}{l}1400- \\
1500\end{array}$ & - & - & 2120 & $\begin{array}{l}1800- \\
2390\end{array}$ & - & - & 1620 & - \\
\hline
\end{tabular}

Table 5.9: Best models from Vs inversions of S10-S28 R0/L0 dispersion: Best values correspond to the lowest misfit profile of the relevant model (Fig. 5.21); †denotes the parameter's acceptable range; ${ }^{*}$ denotes minimum/maximum depth permitted in the inversion.

The halfspace's velocity and depth in each model are the poorest resolved variables in the inversion, due to the increase in both the R0 and L0 dispersion uncertainties below 
Mt. Ruapehu: S10-S28

Fundamental mode Vs inversions

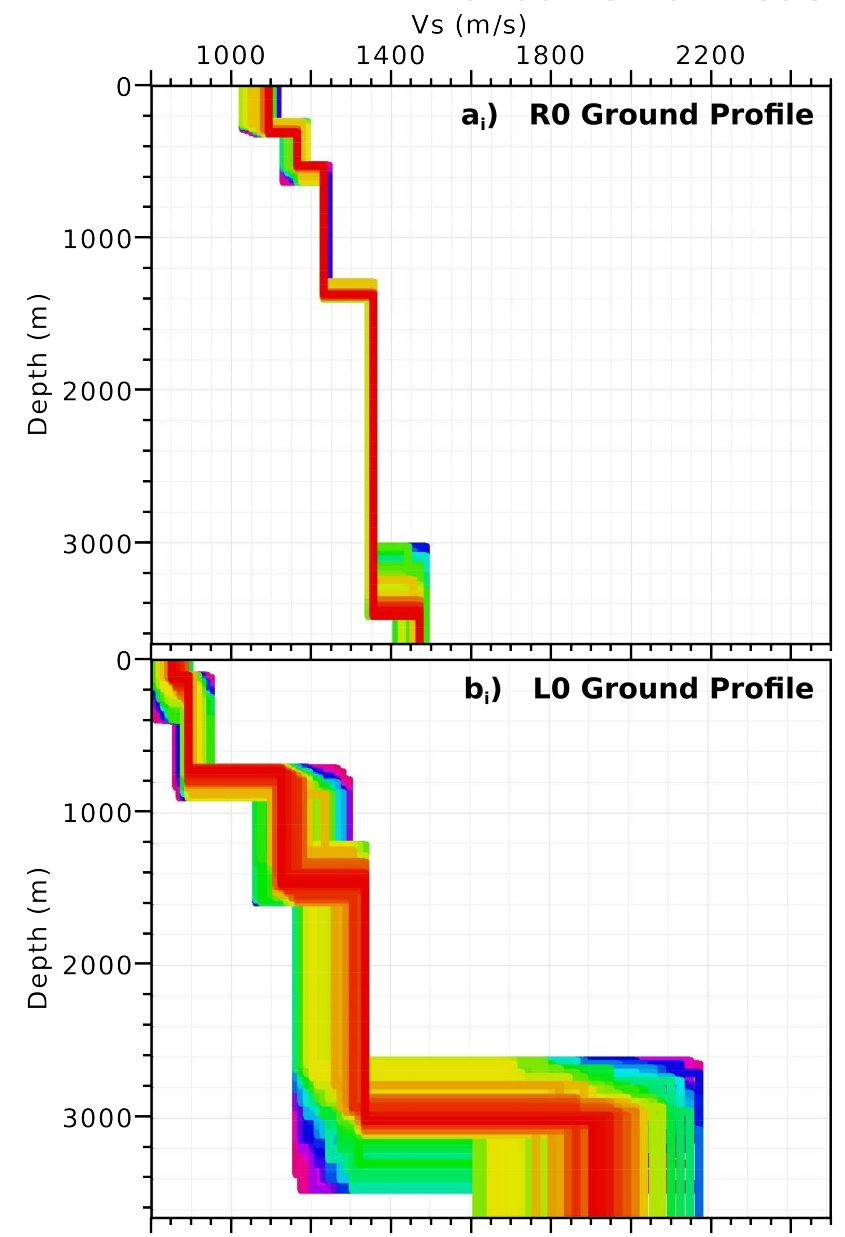

R0 Ground Profile / Dispersion Misfit

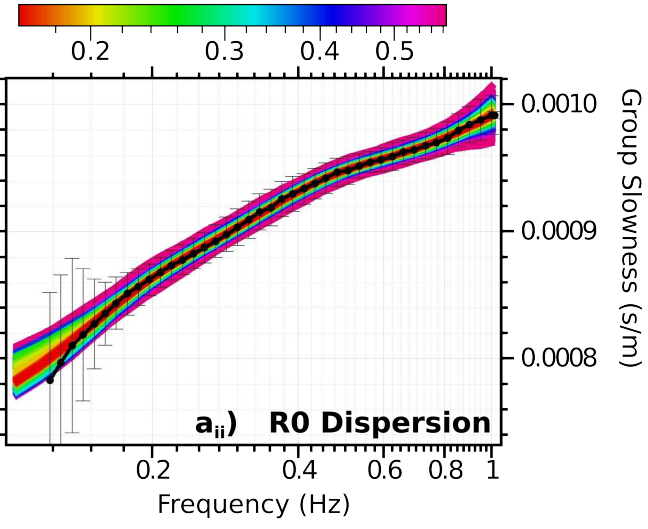

LO Ground Profile / Dispersion Misfit
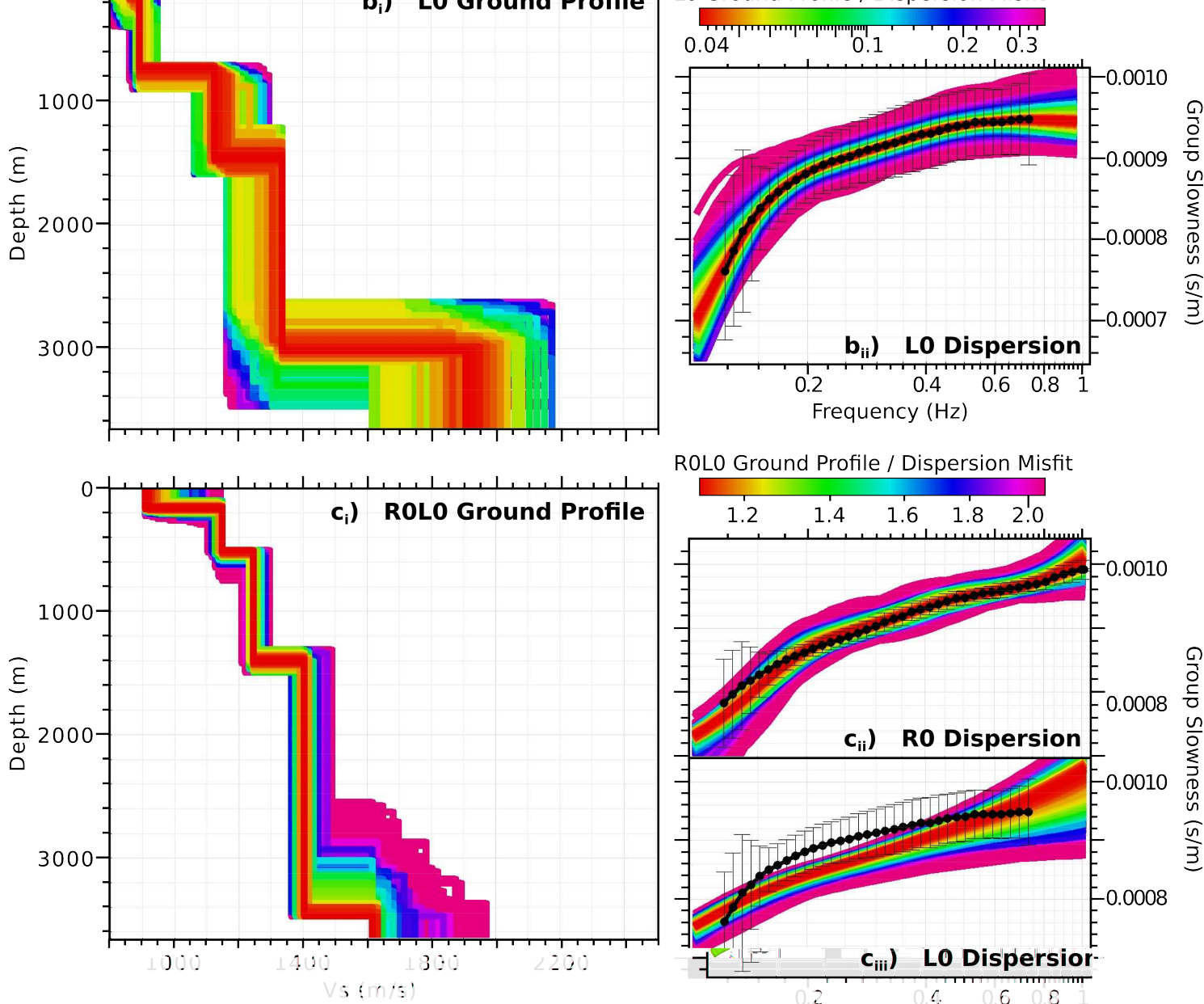

ROLO Ground Profile / Dispersion Misfit

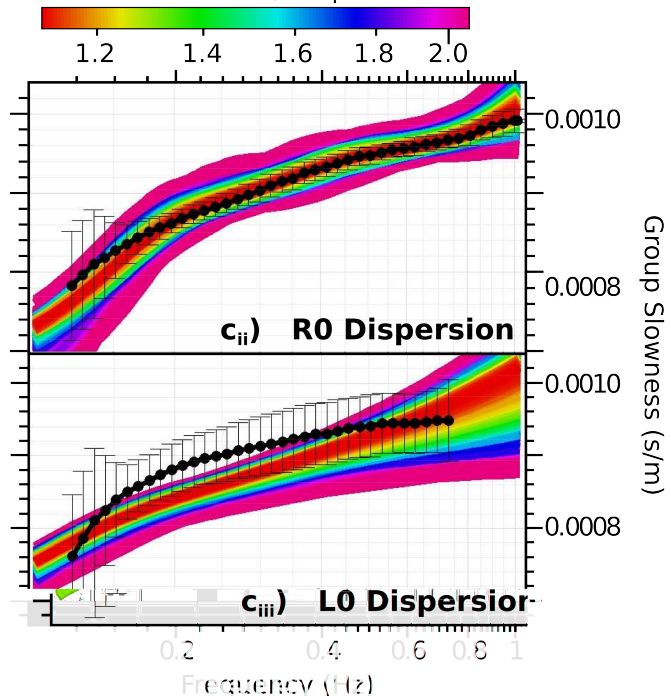

Figure 5.21: Fundamental mode $V_{S}$ Dinver inversions for station pair S10-S28. Dispersion curves match the adjacent ground profile, dispersion measurement is superimposed black line with uncertainty N.B. misfit colour schemes are consistent for dispersion and ground profile of each inversion but differ between inversions: a) RO inversion; b) LO; c) joint RO LO. 
$0.18 \mathrm{~Hz}$. All profiles with total misfit values below 0.58 ( $\mathrm{R} 0$ inversion) and 0.33 (L0) are viable models (Fig. 5.21aii\&bii). Although the L0 inversion's maximum total misfit value is lower than the R0 misfit, the L0 model's acceptable ranges for all layers are larger. This is because the number of points has a greater impact on the misfit calculation than the magnitude of the uncertainty at a specific point (Equation 4.4).

The R0L0 inversion's calculated R0 and L0 dispersion agree with the measurements between $0.5-0.72 \mathrm{~Hz}$ (the upper L0 dispersion limit). Between 0.19-0.4 Hz, however, the calculated L0 dispersion are towards the measured L0 data's upper uncertainty limit, with the best model a tight match (Fig. 5.21ciii). The best calculated- and measured R0 dispersion, however, are almost equal in this frequency range. Between $0.17 \mathrm{~Hz}$ (our lower limit) and $0.19 \mathrm{~Hz}$, the calculated R0 dispersion of the R0L0 inversion is slightly greater than the measurement. The corresponding calculated L0 dispersion changes from being slower than, to faster than the measured data at these frequencies.

\subsubsection{OTVZ-WTVZ}

OTVZ and WTVZ were permanent, short-period GeoNet stations in 2008. Their $8.4 \mathrm{~km}$ interstation path is an approximate E-W oriented transect across the Mount Tongariro (Fig. 4.1). We select this primary pair because it is the only one that has station locations favourable to Tongariro Volcano and for which we are able to make A-grade RR, ZZ and TT component dispersion measurements.

\subsubsection{Cross-correlations}

Most of the $<1 \mathrm{~Hz}$ independent station record-sections show moveout of a single phase, the exception being OTVZ-RR, which has two (Fig. 5.22a). The energy is strong for interstation distances $<10 \mathrm{~km}$, but signal strength then decreases significantly. At OTVZ, the ZZ, TT and slow RR phases' velocities are $1.4 \mathrm{~km} / \mathrm{s}$, with the fast RR $0.7 \mathrm{~km} / \mathrm{s}$ quicker and likely to be the higher mode. The velocities at WTVZ are all similar magnitude to each other but faster than OTVZ.

There is more energy in the 1-2 $\mathrm{Hz}$ frequency range for the OTVZ-WTVZ crosscorrelations than for S10-S28, however, both pairs' full-stacks share many other characteristics. Firstly, E-W propagating phases have much larger amplitudes than W-E propagating phases (Fig. 5.22bi). Also, the RZ and ZR CCF have the strongest phases, and highest 
SNR of all nine-components, but are not inverses of each other (Fig. 5.22bii). Finally, there is significant energy on the acausal TZ component. However, unlike S10-S28, this energy is only slightly stronger than that in the other three transverse-cross components and is largely cancelled out in the symmetric function.

\subsubsection{Dispersion}

The ZZ and TT stacks of OTVZ-WTVZ have strong phases travelling at approximately $1.5 \mathrm{~km} / \mathrm{s}$; however the TT CCF also contains a weak, slower phase (approximately 0.84 $\mathrm{km} / \mathrm{s}$ ) that dominates the MFT at 0.6-1 Hz (Fig. 5.23b\&c). Like S10-S28, the ZZ group velocities do not vary significantly above $0.2 \mathrm{~Hz}$. The $\mathrm{RR}$ stack has a strong phase with a group velocity of approximately $2 \mathrm{~km} / \mathrm{s}$ at the lowest frequencies (Fig. 5.23a), which decreases with increasing frequency until it begins to merge with the $\mathrm{ZZ}$ phase at $0.9 \mathrm{~Hz}$ (Fig. 5.23d).

Although the estimated Green's functions are not as clearly observed in the OTVZWTVZ CCF as in S10-S28, the measured dispersive phases are temporally stable. The station pair was viable for the whole of 2008, with 365 daily CCF comprising the fullstack. For the dispersion uncertainty calculation, we break the full-stack into six blocks of 59-61 days. The average RR, ZZ and TT dispersion uncertainties above $0.2 \mathrm{~Hz}$ are 22, 19 and $27 \mathrm{~m} / \mathrm{s}$, respectively, lower than the RR and ZZ components of S10-S28.

\subsubsection{Particle motion}

The OTVZ-WTVZ particle motion plots are lower quality than for S10-S28 (Fig. 5.24). Large amplitude elliptical motion is present on the $\mathrm{ZR} / \mathrm{ZZ}$ plot, indicating that the time window contains R0. The maxima, however, are located off axis, suggesting that the phase difference between the components is more (or less) than the $1 / 4 \lambda$ expected. Lower amplitude, irregular ellipses are present in the RR/RZ, RZ/ZZ and RR/ZR plots, which could be the result of incoherent, higher frequency energy superimposed on the Green's functions. The maxima of the RZ/ZR and RR/ZZ particle motion are off-axis, as expected, however they are more elliptical than linear. The RR/TT and TT/ZZ motion are also highly elliptical with off-axis maxima. 


\section{OTVZ-WTVZ}
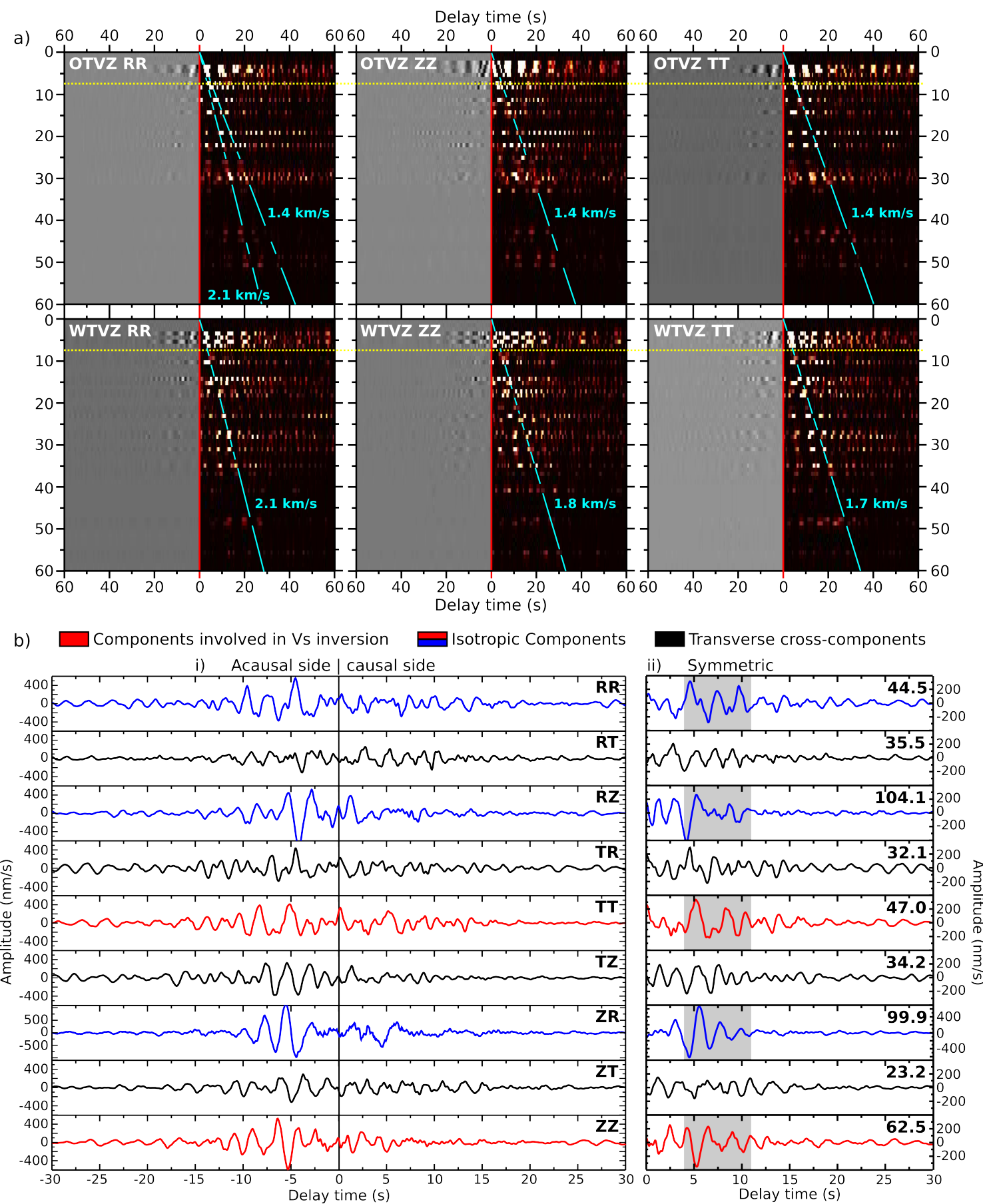

Figure 5.22: Cross-correlations of OTVZ and WTVZ: a) RR, ZZ and TT record sections $(<1 \mathrm{~Hz})$ of all station pairs involving OTVZ (top) and WTVZ (bottom). Left (greyscale) plots are unaltered amplitudes, right (colour) plots have CCF amplitudes normalised to 1. Superimposed yellow dotted line is interstation distance of OTVZ-WTVZ pair; blue dashed lines indicate phase moveout, with approximate velocity. b) nine-component fullstacks for OTVZ-WTVZ at 0.2-2 Hz. Colours represent component type/use, N.B. different amplitude scale for ZR component: i) the two-sided functions; ii) symmetric CCF. Topright numbers are SNR; grey area shows time window for particle motion. 


\section{OTVZ-WTVZ MFT and dispersion measurements}
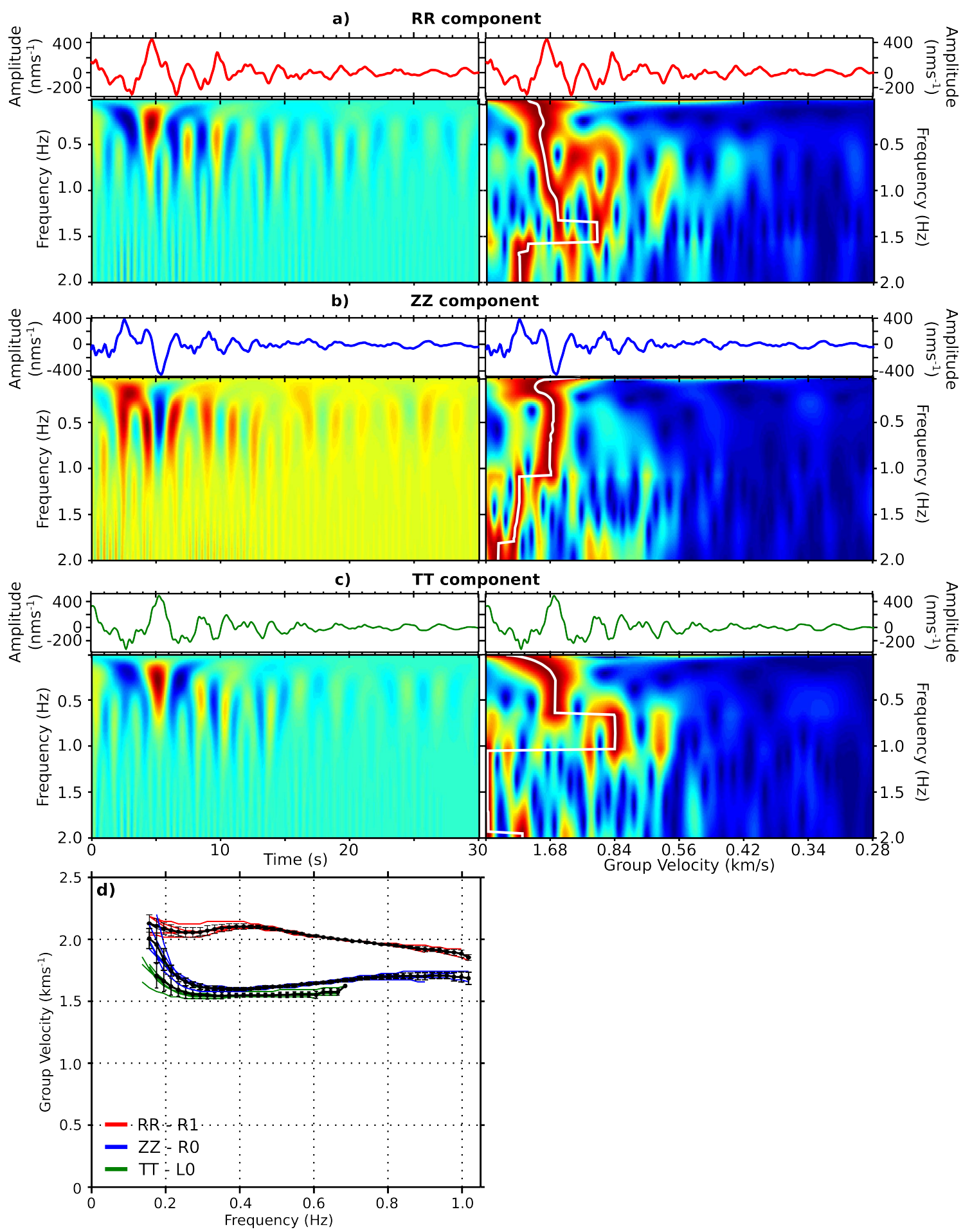

Figure 5.23: Dispersion measurement summary for station OTVZ-WTVZ: a) RR component full stack spectrogram and MFT analysis with automatically picked dispersion; b) full stack ZZ component; c) full stack TT component; d) RR, ZZ and TT dispersion curves, with mode identification. Coloured lines represent dispersion picks for blocks, black lines represent pick for full stack, with error bars from standard deviations of blocks. 


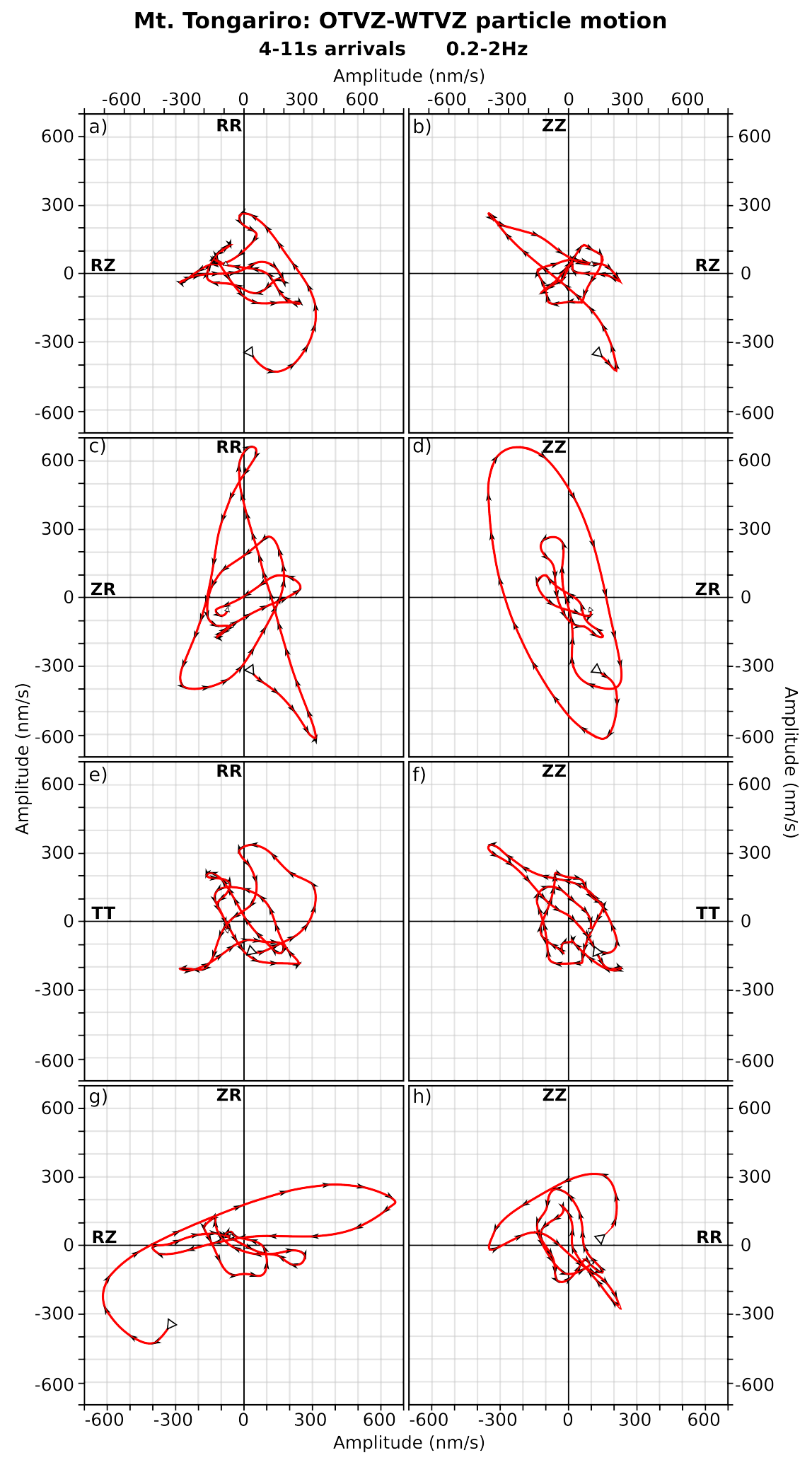

Figure 5.24: Particle motion for fundamental mode time window (Fig. 5.22, grey area), plotted for different CCF component pairs. Larger white triangle denotes starting point, small white triangle denotes end. Small triangles indicate direction of movement: a) $R R / R Z$; b) $R Z / Z Z$; c) $R R / Z R$; d) $Z R / Z Z$; e) $R R / T T$; f) $T T / Z Z$; g) $R Z / Z R$; h) $R R / Z Z$. 


\subsubsection{4 $\mathrm{V}_{S}$ inversion}

All three OTVZ-WTVZ inversions are faster than the S10-S28 inversions, although the S10-S28 inversions are slightly better resolved. The R0 Vs inversion is well constrained, with small acceptable ranges for the profile's layer depths and velocities (Fig. 5.25a, Table 5.10). Shallower than $2 \mathrm{~km}$, the acceptable R0 profile range is faster than L0 acceptable range, however, the L0 dispersion has higher uncertainty (Fig. 5.25b). Deeper than $2 \mathrm{~km}$, the L0 inversion is poorly resolved.

\begin{tabular}{|c|c|c|c|c|c|c|c|c|c|c|}
\hline \multirow{3}{*}{ Layer } & \multicolumn{4}{|c|}{ R0 model } & \multicolumn{4}{|c|}{ L0 model } & \multicolumn{2}{|c|}{ R0L0 model } \\
\hline & \multicolumn{2}{|c|}{ Vs (m/s) } & \multicolumn{2}{|c|}{$\begin{array}{c}\text { Bottom depth } \\
\text { (m) }\end{array}$} & \multicolumn{2}{|c|}{ Vs (m/s) } & \multicolumn{2}{|c|}{$\begin{array}{c}\text { Bottom } \\
\text { depth (m) }\end{array}$} & $\begin{array}{c}\text { Vs } \\
(\mathrm{m} / \mathrm{s})\end{array}$ & $\begin{array}{c}\text { Bottom } \\
\text { depth (m) }\end{array}$ \\
\hline & Best & Range & Best & Range & Best & Max & Best & Max & & Best \\
\hline 1 & 1920 & $\begin{array}{l}1740- \\
1960\end{array}$ & 110 & $85-340$ & 1335 & $\begin{array}{l}800- \\
1605\end{array}$ & 95 & $50-390$ & 1080 & 260 \\
\hline 2 & 1955 & $\begin{array}{l}1895- \\
1970\end{array}$ & 1845 & $\begin{array}{c}1750- \\
1980\end{array}$ & 1630 & $\begin{array}{c}1240- \\
1750\end{array}$ & 1000 & $\begin{array}{l}325- \\
1190\end{array}$ & 1890 & 490 \\
\hline 3 & 2230 & $\begin{array}{l}2030- \\
2265\end{array}$ & 1950 & $\begin{array}{l}1895- \\
2520\end{array}$ & 1770 & $\begin{array}{c}1530- \\
1800\end{array}$ & 1370 & $\begin{array}{c}1555- \\
3190\end{array}$ & 1950 & 1980 \\
\hline 4 & 2290 & $\begin{array}{l}2160- \\
2305\end{array}$ & $3500 *$ & $\begin{array}{l}3200- \\
3500 *\end{array}$ & 2360 & $\begin{array}{l}1670- \\
2500\end{array}$ & 2680 & $\begin{array}{l}1880- \\
3500 *\end{array}$ & 2400 & 3170 \\
\hline Halfspace & 2730 & $\begin{array}{c}2590- \\
2750\end{array}$ & - & - & 2460 & $\begin{array}{l}2100- \\
2500\end{array}$ & - & - & 2450 & - \\
\hline
\end{tabular}

Table 5.10: Best models from $\mathrm{V}_{S}$ inversions of OTVZ-WTVZ R0/L0 dispersion: "Best" values correspond to lowest misfit profile of the relevant model (Fig. 5.25); "Range" is the parameter's acceptable range; *denotes minimum/maximum depth permitted in the inversion; †denotes parameter is poorly resolved.

We cannot quantify the R0L0 models' uncertainty from the dispersion uncertainty, as the differences between the R0 and L0 dispersion measurements are greater than our layered model process can manage (Fig. 5.25c). The best R0L0 profile returns theoretical L0 dispersion curves faster than the upper velocity uncertainty below $0.4 \mathrm{~Hz}$. This suggests that another structural property impacts surface-wave dispersion between OTVZ and WTVZ. 
Mt. Tongariro: OTVZ-WTVZ

\section{Fundamental mode Vs inversions}

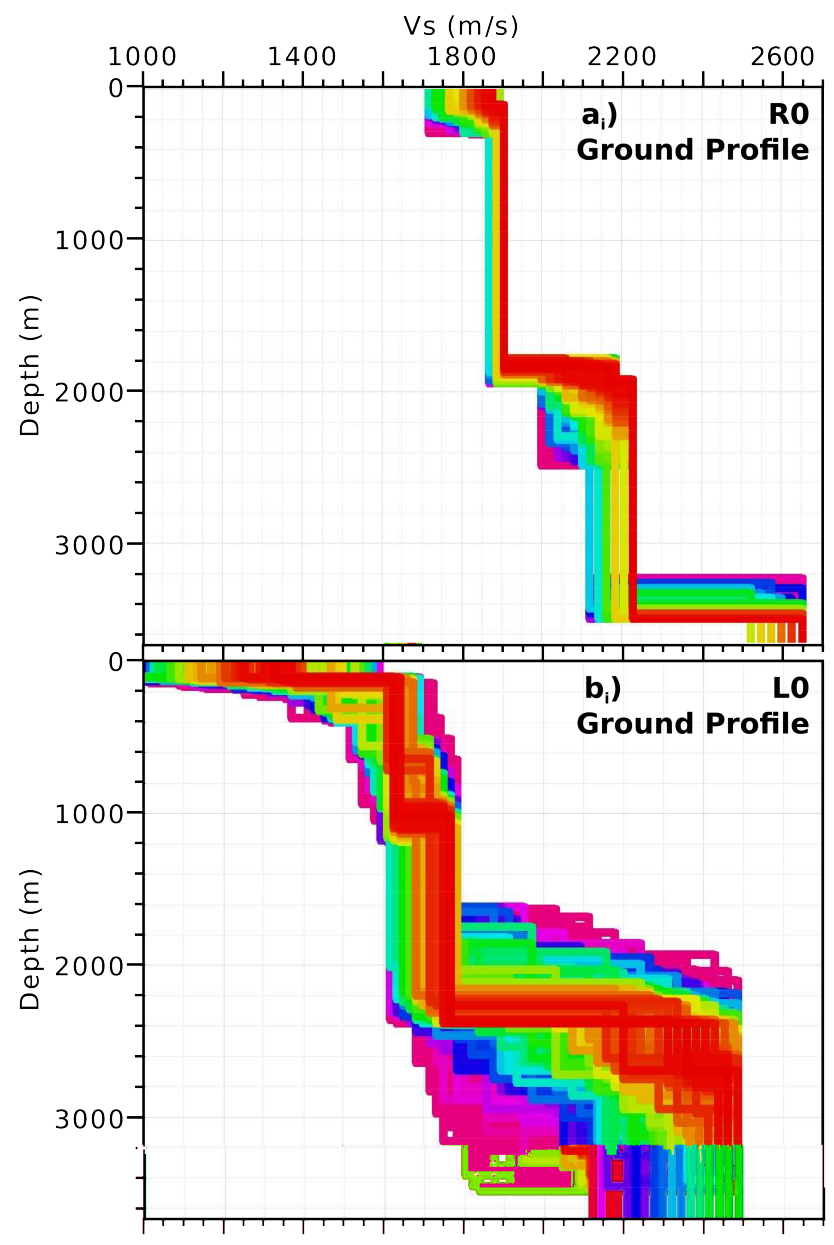

R0 Ground Profile / Dispersion Misfit

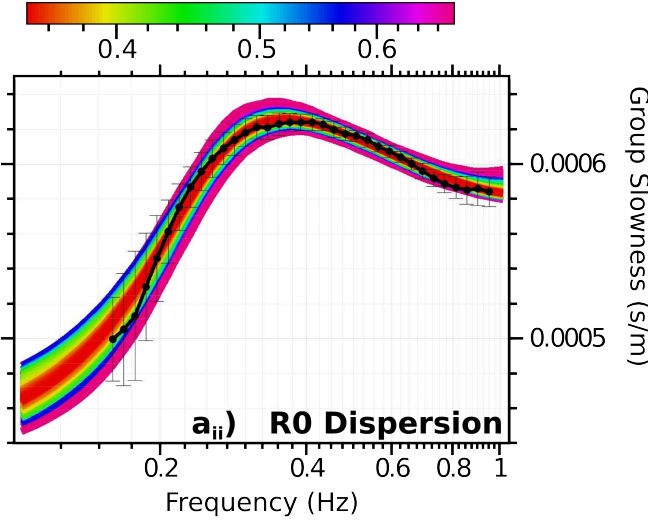

0
0
$\frac{1}{0}$
$n$
0
0
$\frac{n}{2}$
0
$n$
$n$
$\frac{1}{3}$
3
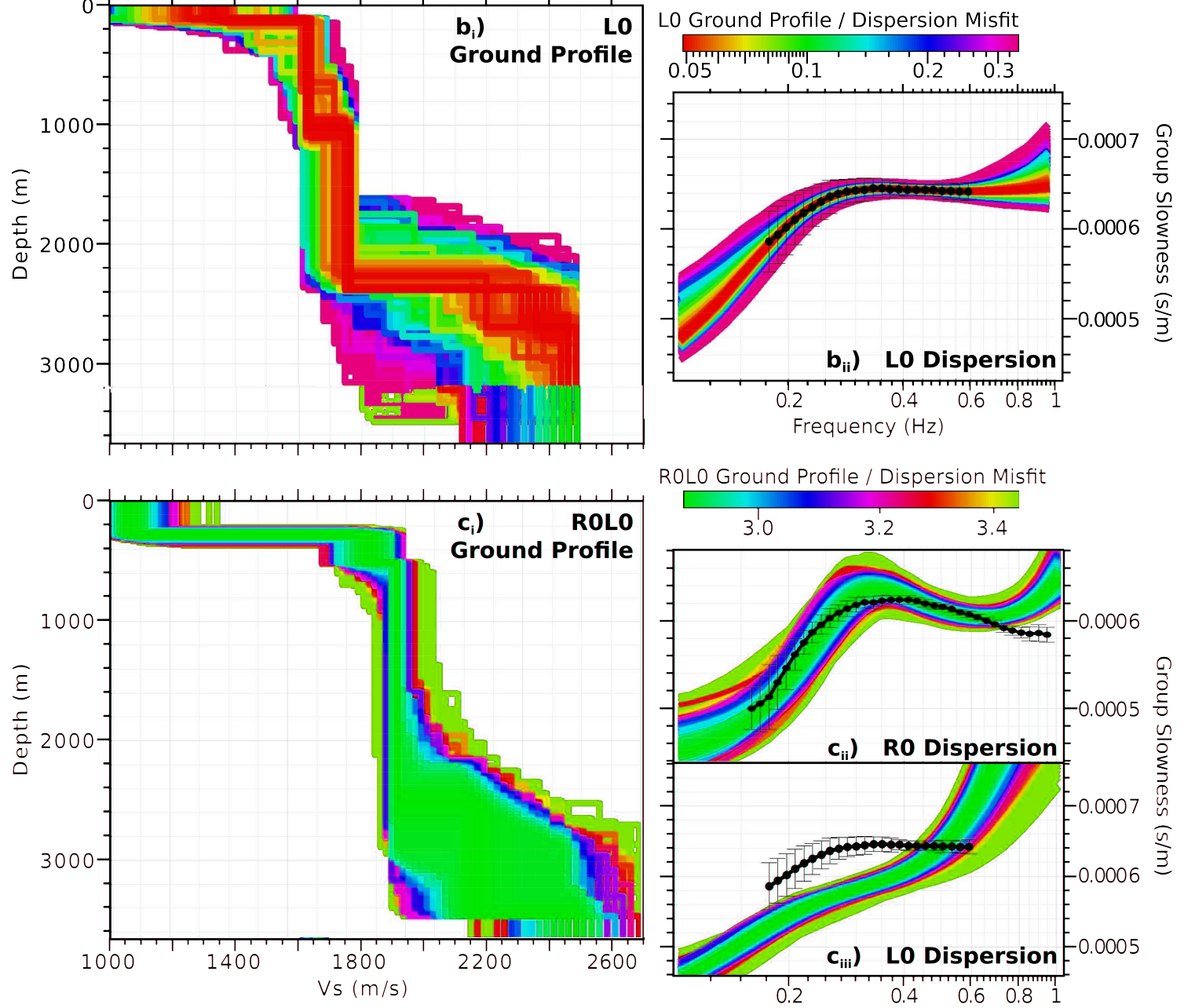

b $_{\mathrm{ii}}$ ) LO Dispersion-

$\begin{array}{llll}0.2 & 0.4 & 0.6 & 0.8\end{array}$

ROLO Ground Profile / Dispersion Misfit

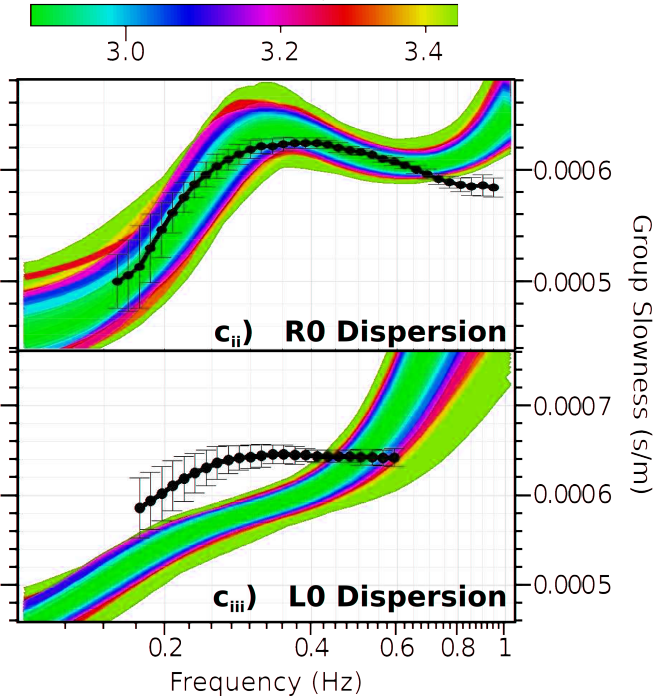

Figure 5.25: Fundamental mode Vs Dinver inversions for station pair OTVZ-WTVZ. Dispersion curves match the adjacent ground profile. N.B. misfit colour schemes are consistent for dispersion and ground profile of each inversion but differ between inversions. 


\subsection{Average dispersion curves and Vs inversions}

We calculate average dispersion curves for Ruapehu and Tongariro including all valid measurements, and make R0, L0 and joint R0+L0 Vs inversions. The measurements' standard deviations, which we use as the averages' uncertainties, are very high, suggesting large spatial variation. Therefore, we also select two, semi-perpendicular transects of each volcano for which we make average R0/L0 dispersion curves and joint R0L0 Vs inversions.

\subsubsection{Ruapehu Volcano}

For our average Ruapehu model, we define an area containing stations S02, S08, S10, S11, S23, S26, S28, FWVZ, DRZ and TUVZ from 2001 and stations BLYT, DRZ, FWVZ, MASHUT, TRVZ, TUVZ, WNVZ and WPVZ from 2008 (Fig. 4.1). Of the 66 dispersion measurements that meet our quality criteria (section 4.4.3), there are no data involving stations BLYT, MASHUT or TRVZ. Consequently, interstation path coverage of the volcano is good in the north, east and SE, but poor in the NW and SW (Fig. 5.26). The two transects we select for further analysis (Fig. 5.28) cross Ruapehu summit on an N-S orientation (involving stations DRZ, FWVZ, S03, S23, S26, WNVZ and WPVZ) and on a E-W orientation (DRZ, FWVZ, S08, S10, S23 and S28).

\subsubsection{Total averages}

The average $\mathrm{R} 0$ dispersion contains the highest number of measurements, at 24 . The R1, L0 and L1 averages contain 17, 20 and 5 measurements, respectively. Overall, the group velocities of most measurements vary little above $0.4 \mathrm{~Hz}$. Between $0.4-0.8 \mathrm{~Hz}$, a significant proportion of the R0 measurements have group velocities of $0.9-1.2 \mathrm{~km} / \mathrm{s}$, with few around $1.5 \mathrm{~km} / \mathrm{s}$ (Fig. 5.26a). Some R0 group velocities are faster than some R1 measurements. The L0 measurements are more scattered, with two apparent populations at $0.7-1.2 \mathrm{~km} / \mathrm{s}$ and $1.3-1.5 \mathrm{~km} / \mathrm{s}$ (Fig. 5.26b).

The averages have large uncertainties, on the order of $1100 \pm 180 \mathrm{~m} / \mathrm{s}(\mathrm{R} 0), 1750 \pm 270$ (R1), $1200 \pm 240$ (L0) and $1700 \pm 255 \mathrm{~m} / \mathrm{s}$ (L1) between 0.4-0.8 Hz. R0/L0 and R1/L1 uncertainties slightly overlap towards the frequency limits for the Rayleigh- and Love dispersion. 


\section{Mount Ruapehu A-grade group velocity dispersion}
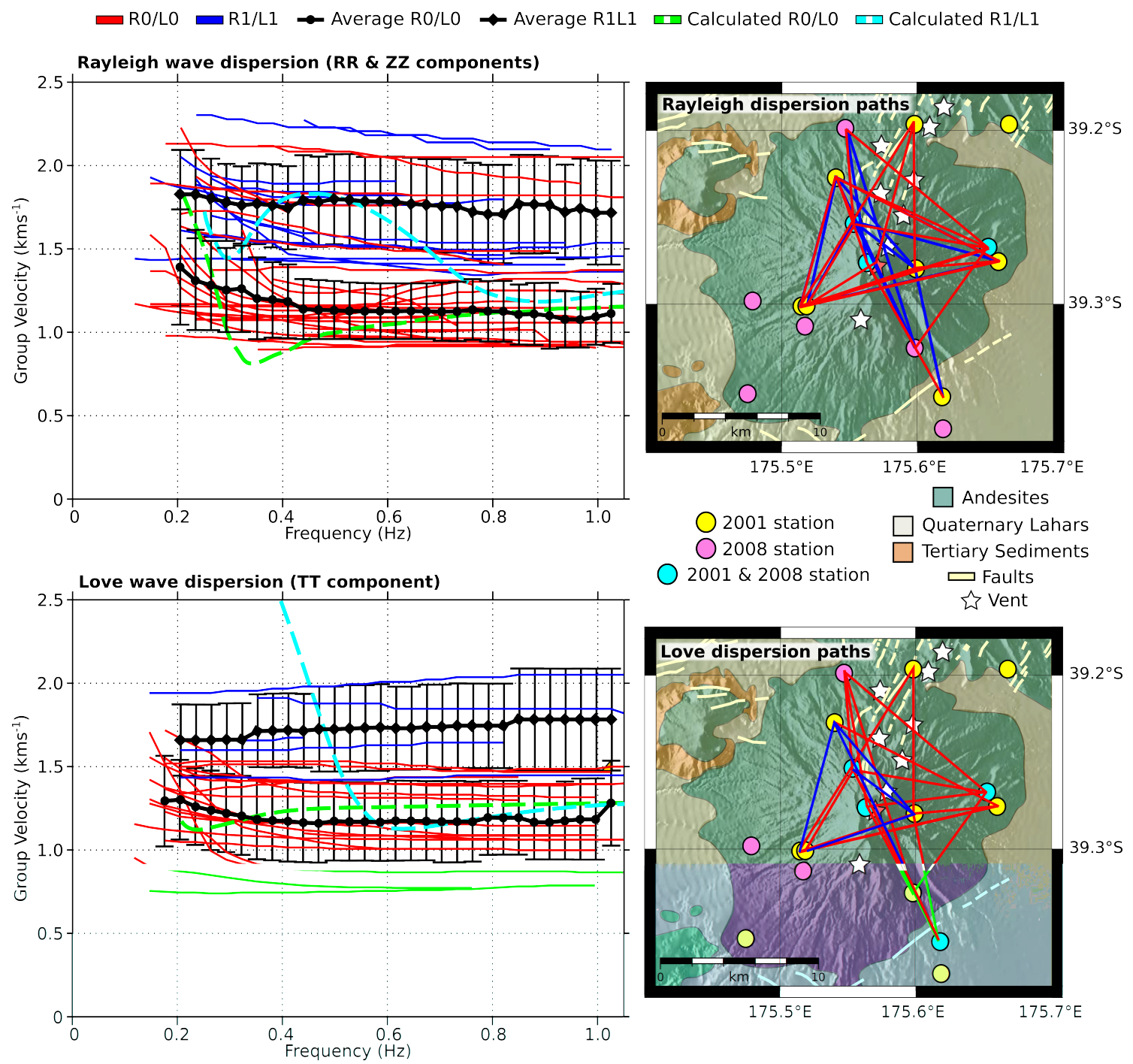

Figure 5.26: A-grade Rayleigh- and Love-wave dispersion measurements from the Ruapehu area. Red lines are R0/L0 measurements, blue are R1/L1. Dashed lines are calculated dispersion curves from FR model (Fig. 5.13b). Black lines are averages of measurements with \pm one standard deviation as uncertainty. Interstation paths of individual measurements of plot illustrated on adjacent map.

Similarities exist between the average dispersion curves for Ruapehu and those calculated using the FR model (section 5.3.1). The average and calculated R0 dispersion are similar above $0.5 \mathrm{~Hz}$, as are the average and calculated $\mathrm{R} 1$ dispersion at $0.4-0.5 \mathrm{~Hz}$ (Fig. 5.26a). Above $0.3 \mathrm{~Hz}$, the average measured L0 dispersion is slightly slower than that of the calculated L0, although the calculated L0 falls within the average's uncertainty at all frequencies (Fig. 5.26). The calculated L1 is completely different from the average measured L1. 


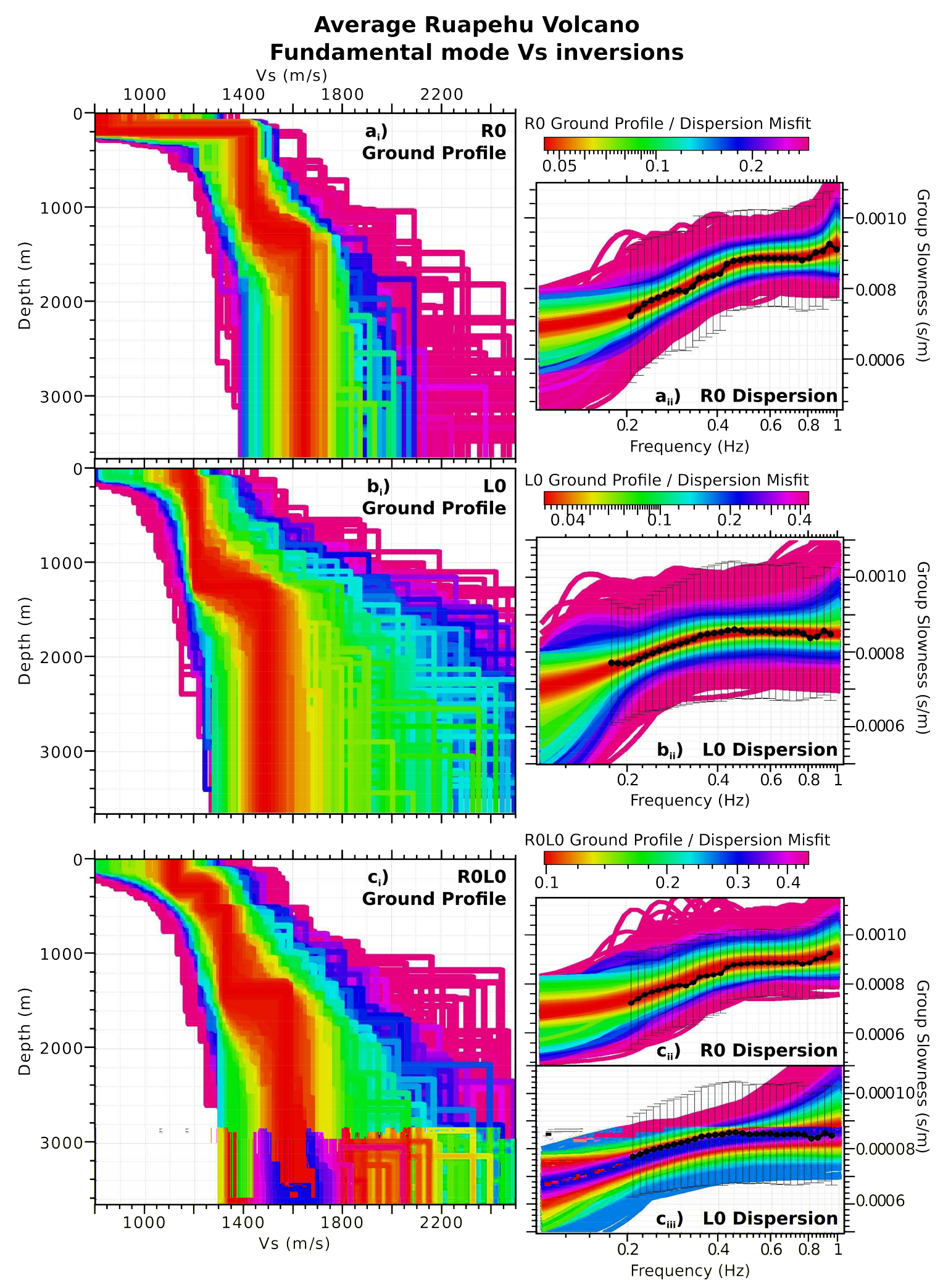

Figure 5.27: Fundamental mode $V_{S}$ Dinver inversions for average Ruapehu dispersion curves. Dispersion curves match the adjacent ground profile. N.B. misfit colour schemes are consistent for dispersion and ground profile of each inversion but differ between inversions. 
All three $\mathrm{V}_{S}$ inversions using the average $\mathrm{R} 0$ and $\mathrm{L} 0$ dispersion curves are very poorly constrained, as we must consider any model with a calculated dispersion curve within the averages' uncertainty to be valid. The minimum acceptable velocities are better constrained than the maxima and increase almost linearly from $1.1-1.4 \mathrm{~km} / \mathrm{s}$ at $0.5-3.5 \mathrm{~km}$ depth (Fig. $5.27 \mathrm{a} \& b)$.

Ignoring the uncertainty, the best profiles the three inversions (Fig. 5.27, red areas) are similar. They show velocity increasing with depth, with the largest impedance contrast at $1-1.5 \mathrm{~km}$ depth. The best R0 profile is approximately $20 \%$ and $10 \%$ faster than the best L0 profiles above and below $1 \mathrm{~km}$, respectively. The best R0L0 profile slightly overestimates and underestimates the average R0 and L0 group velocities, respectively. The R0L0 model's maximum acceptable velocities above $1 \mathrm{~km}$ are well constrained, increasing from 1.4-1.85 $\mathrm{km} / \mathrm{s}$.

\subsubsection{Oriented averages}

The average R0 and L0 dispersion curves for the N-S transect each contain 6 measurements, whereas for the E-W transect they contain 10 (R0) and 7 (L0). The oriented averages have similar magnitude uncertainties to the total averages, and are on the order of $1000 \pm 150$ $\mathrm{m} / \mathrm{s}(\mathrm{R} 0, \mathrm{~N}-\mathrm{S}), 1300 \pm 240 \mathrm{~m} / \mathrm{s}(\mathrm{L} 0, \mathrm{~N}-\mathrm{S}), 1200 \pm 200 \mathrm{~m} / \mathrm{s}(\mathrm{R} 0, \mathrm{E}-\mathrm{W})$ and $1100 \pm 240 \mathrm{~m} / \mathrm{s}$ (L0, E-W) at 0.4-0.8 Hz (Fig. 5.28). The N-S R0 dispersion is slower than the E-W R0 dispersion curve, with statistical significance for measurements below $0.6 \mathrm{~Hz}$ at $90 \%$ confidence. Conversely, the N-S L0 dispersion curve is slower than the E-W L0 dispersion, but there is $90 \%$ significant difference only below $0.3 \mathrm{~Hz}$.

The R0L0 inversions of the two transects (Fig. 5.29) are very different. The N-S model has well constrained minimum velocities, which are similar to the other Ruapehu models (averages and primary pairs) above $1 \mathrm{~km}$, but much faster below a significant impedance contrast at $1.7 \mathrm{~km}$ depth. Below $1 \mathrm{~km}$ depth, the NNE-SSE Ruapehu model (Fig. 5.27a) is strikingly similar to the total average $\mathrm{R} 0$ inversion for Tongariro (section 5.5.2.1 Fig. 5.27). The best N-S profile is the fastest and has the strongest impedance contrasts of all the Ruapehu inversions. Unlike the other Ruapehu R0L0 inversions, the N-S best profile does not under/overestimate the group velocities of either input dispersion curve, however, it is the only inversion where the Love-wave dispersion measurement is faster than the Rayleigh-wave dispersion measurement. 
The theoretical R0 and L0 dispersions of the best E-W transect profile are underestimated and overestimated, respectively, compared to the R0 and L0 measurements (Fig. 5.29bii\&iii). The best R0L0 profile of the E-W oriented paths is similar to the total average Ruapehu R0L0 (Fig. 5.27) and S10-S28 R0L0 models (Fig. 5.21), with shear-wave velocity increasing from approximately 1.2 to $1.6 \mathrm{~km} / \mathrm{s}$ at $0.2-3.5 \mathrm{~km}$ depth.

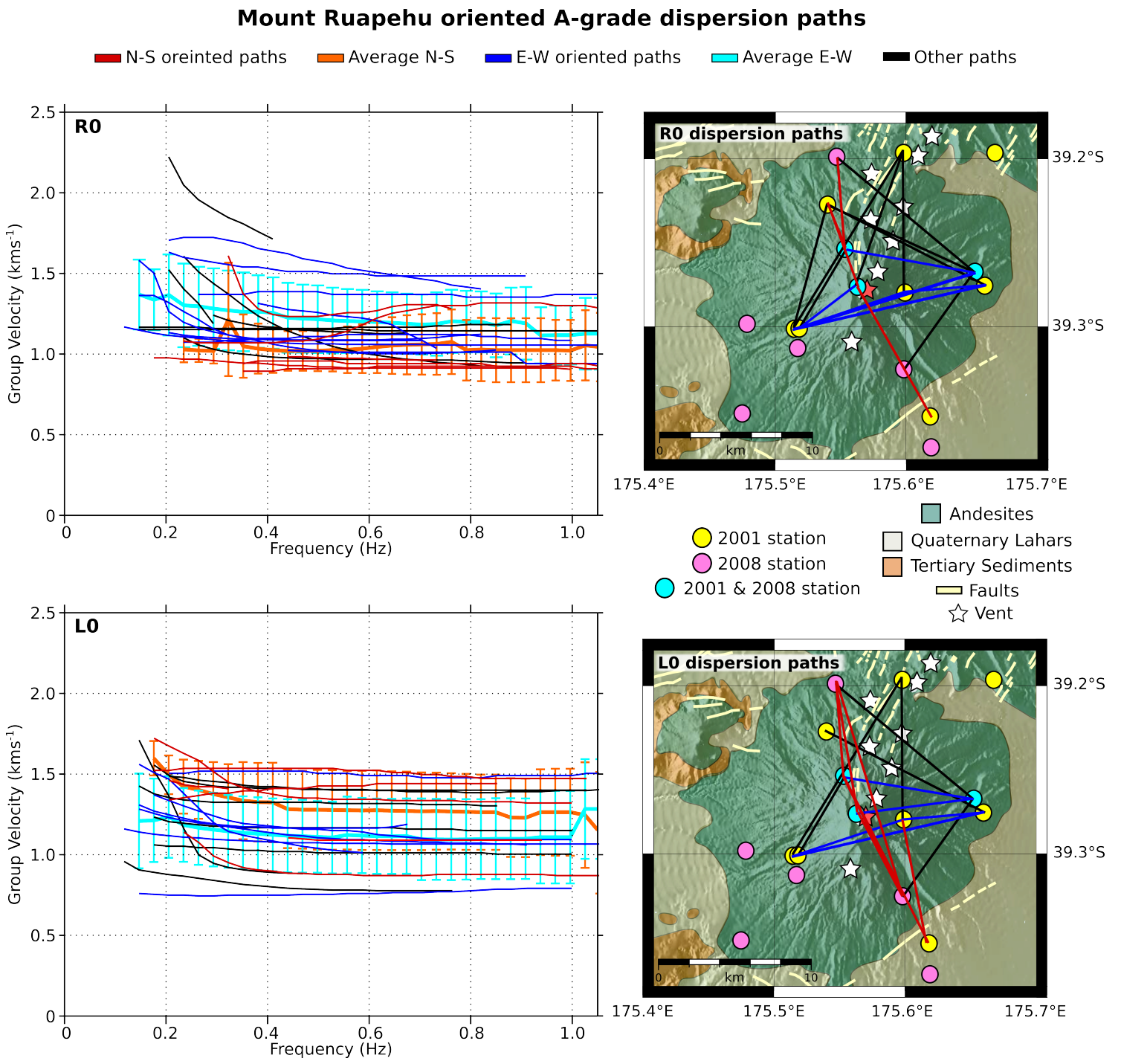

Figure 5.28: A-grade RO (a) and LO (b) dispersion measurements of the Ruapehu area, grouped by path orientation. Dark red and blue lines are individual measurements of $N$-S and E-W transects, respectively; black lines are other orientations. Thick orange and pale blue lines are averages of $N-S$ and $E-W$ measurements with \pm one standard deviation as uncertainty. Interstation paths of individual measurements of plot illustrated on adjacent map with same colour scheme. 


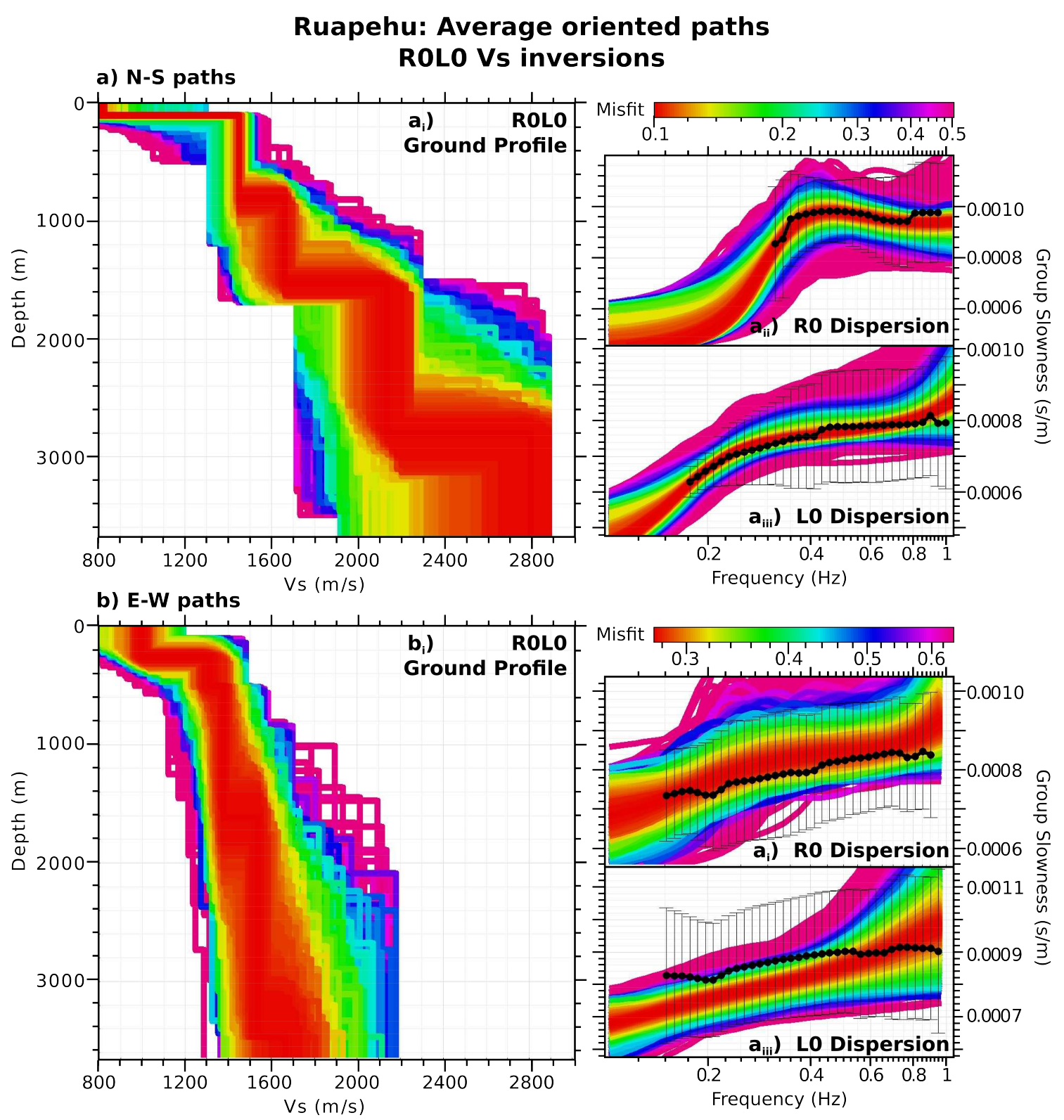

Figure 5.29: Joint ROLO Vs Dinver inversions of the oriented average RO and LO dispersion curves for Ruapehu. Dispersion curves match the adjacent ground profile. N.B. misfit colour schemes are consistent for dispersion and ground profile of each inversion but differ between inversions: a) $N$-S oriented paths; b) E-W oriented paths.

\subsubsection{Tongariro Volcano}

The Tongariro area includes stations KAVZ, NGZ, S06, S09, S13, S14 and S18 from 2001 and KRVZ, NGA4, NGA5, NGA6, NGZ, OTVZ and WTVZ from 2008 (Figs. 4.1, 5.30). The 39 dispersion measurements for this area involve all stations in this sub-network except for KAVZ. The chosen transects of the volcano are oriented NE-SW (stations KRVZ, NGA4, NGA5, NGA6, NGZ, S06 and S13) and NW-SE (NGA4, NGA5, NGA6, OTVZ, 
S06, S18 and WTVZ).

\subsubsection{Total averages}

We use less data to calculate average R0 (14 measurements), R1 (9), and L0 (16) dispersion curves for Tongariro than for Ruapehu. There are two populations of L0 dispersion measurements, the larger having group velocities of $0.8-1.1 \mathrm{~km} / \mathrm{s}$ at $0.4 \mathrm{~Hz}$ (Fig. 5.30, bottom plot). The smaller, faster population contains four measurements which fall outside the L0 average's uncertainty (which averages $280 \mathrm{~m} / \mathrm{s}$ ). While none of the four have a common interstation path, however two have almost identical paths as measurements within the slower L0 population. Typically, we interpret such a distribution as due to the presence of a higher mode (section 5.2.2); however, none of these measurements were identified as L1 in the station grouping analysis, and after closely re-inspecting their MFT plots, we are confident we correctly identified the measurements' modes.

The R0 and R1 populations of measurements are more distinct for Tongariro than Ruapehu (Fig. 5.30, top plot). The uncertainty of the average R1 dispersion is the lowest for all the averages calculated for Ruapehu and Tongariro, at approximately $95 \mathrm{~m} / \mathrm{s}$ above $0.4 \mathrm{~Hz}$. The R0 dispersion measurements do not have any distinct populations. The average $\mathrm{R} 0$ and $\mathrm{R} 1$ dispersion curves are significantly faster than the dispersion curves calculated from the JR model (Fig. 5.30, top plot). The calculated L0 is very similar to the slower L0 measurement populations above $0.4 \mathrm{~Hz}$ (Fig. 5.30, bottom). There is no relationship between the faster measured L0 population and the calculated L1 dispersion.

The Tongariro R0 inversion is the best constrained of all the average Ruapehu and Tongariro inversions. The minimum acceptable velocities of the R0 inversion steadily increase with depth of a similar gradient to the total average Ruapehu inversions (Fig. $5.27)$.

Unlike the Ruapehu models, the best Tongariro R0 and L0 inversions are very different. Firstly, the best L0 Vs profile is much slower than the R0 (Fig. 5.31). The best R0 profile is comparable to a stepped function, with large impedance contrasts at approximately 1 and $3 \mathrm{~km}$ depth. The L0 model has a similar magnitude impedance contrast at $1 \mathrm{~km}$, which is the profile's major feature. The source of the $3 \mathrm{~km}$ boundary in the best R 0 profile may be the sharp dispersion change at $0.3 \mathrm{~Hz}$ and lower uncertainty, both features that are absent 
in the L0 dispersion.

The best R0L0 inversion does not fit the measured R0 or L0 dispersion well; the dispersion uncertainty cannot be completely modelled (Fig. 5.31cii\&iii). Below $0.5 \mathrm{~Hz}$, the average R0 and L0 dispersion curves are faster and slower than the theoretical ones produced for the best profile, respectively.

\section{Mount Tongariro A-grade group velocity dispersion}

$\square$ R0/L0 $\square$ R1 $\rightarrow$ Average R0/L0 $\nrightarrow$ Average R1/L1 Calculated R0/L0 $\varpi$ Calculated R1/L1
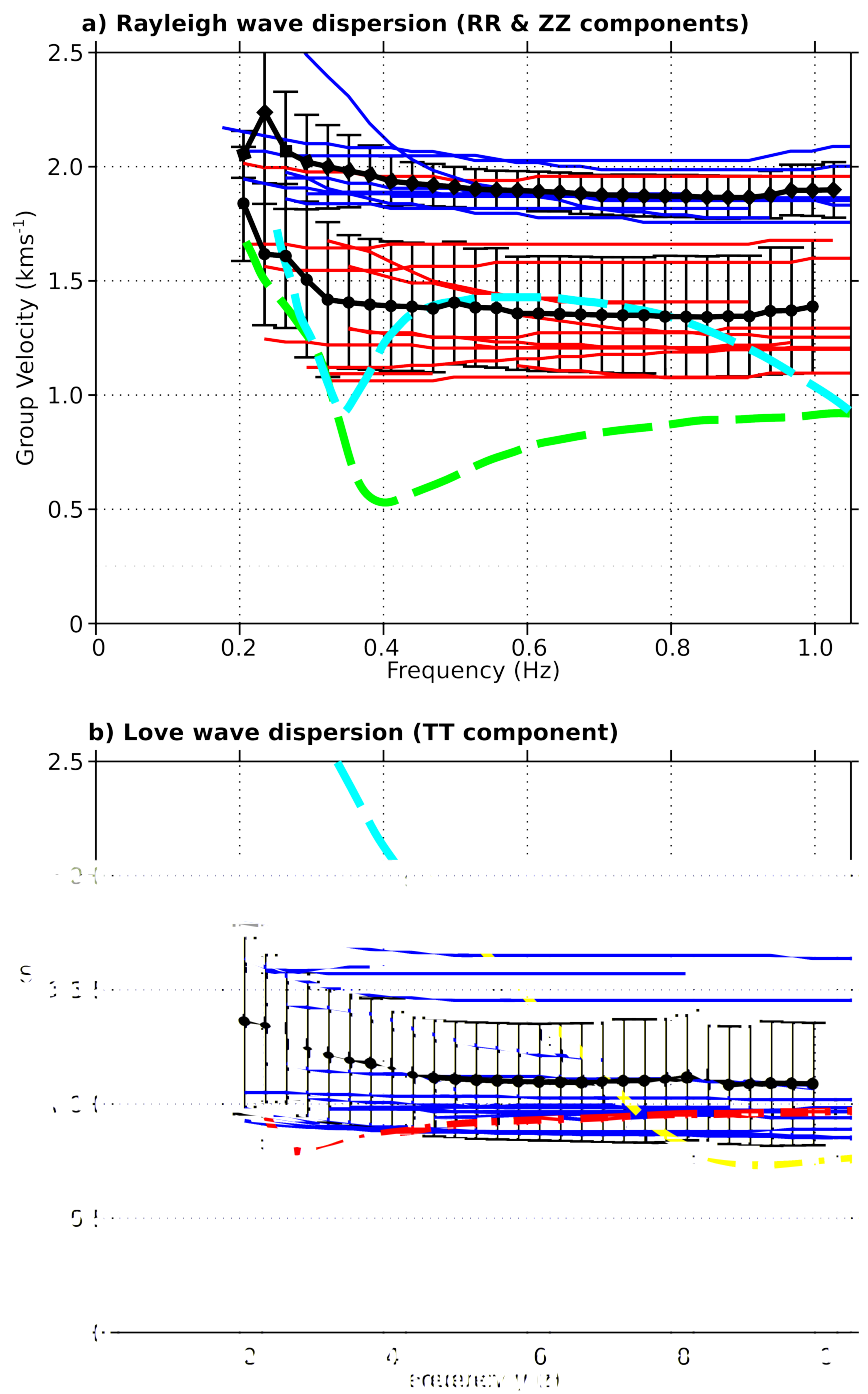

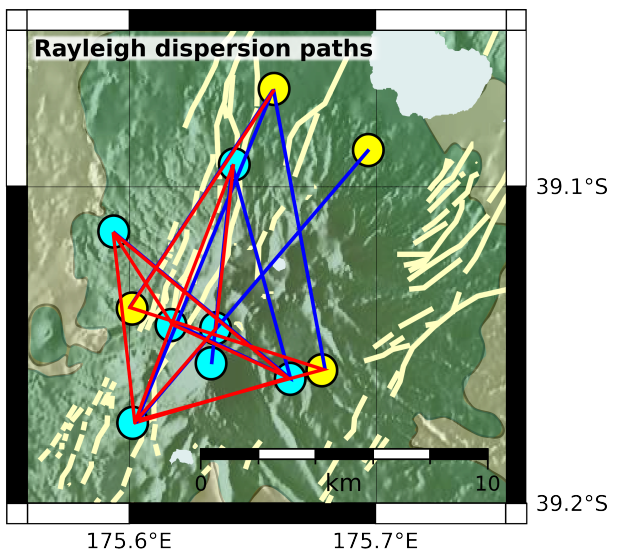

Andesites

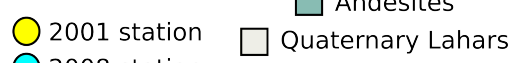

○2008 station $\square$ Faults is Vent

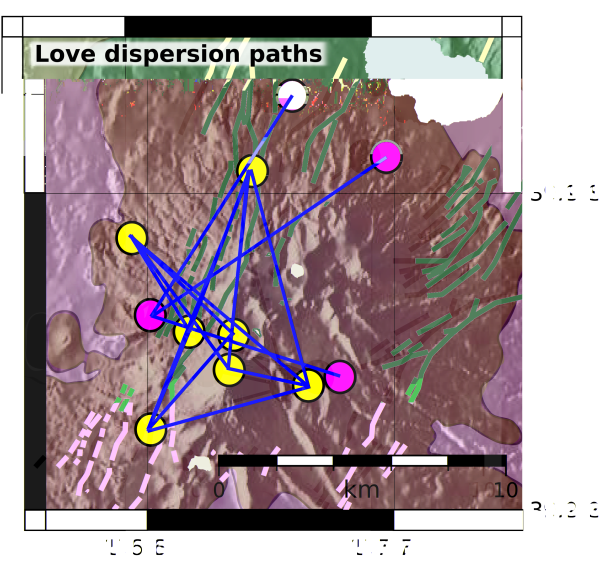

Figure 5.30: A-grade Rayleigh-and Love-wave dispersion measurements from the Tongariro area. Red lines are R0/L0 measurements, blue are R1/L1. Dashed lines are calculated dispersion curves from JR model (Fig. 5.13b). Black lines are averages of measurements with \pm one standard deviation as uncertainty. Interstation paths of individual measurements of plot illustrated on adjacent map. 


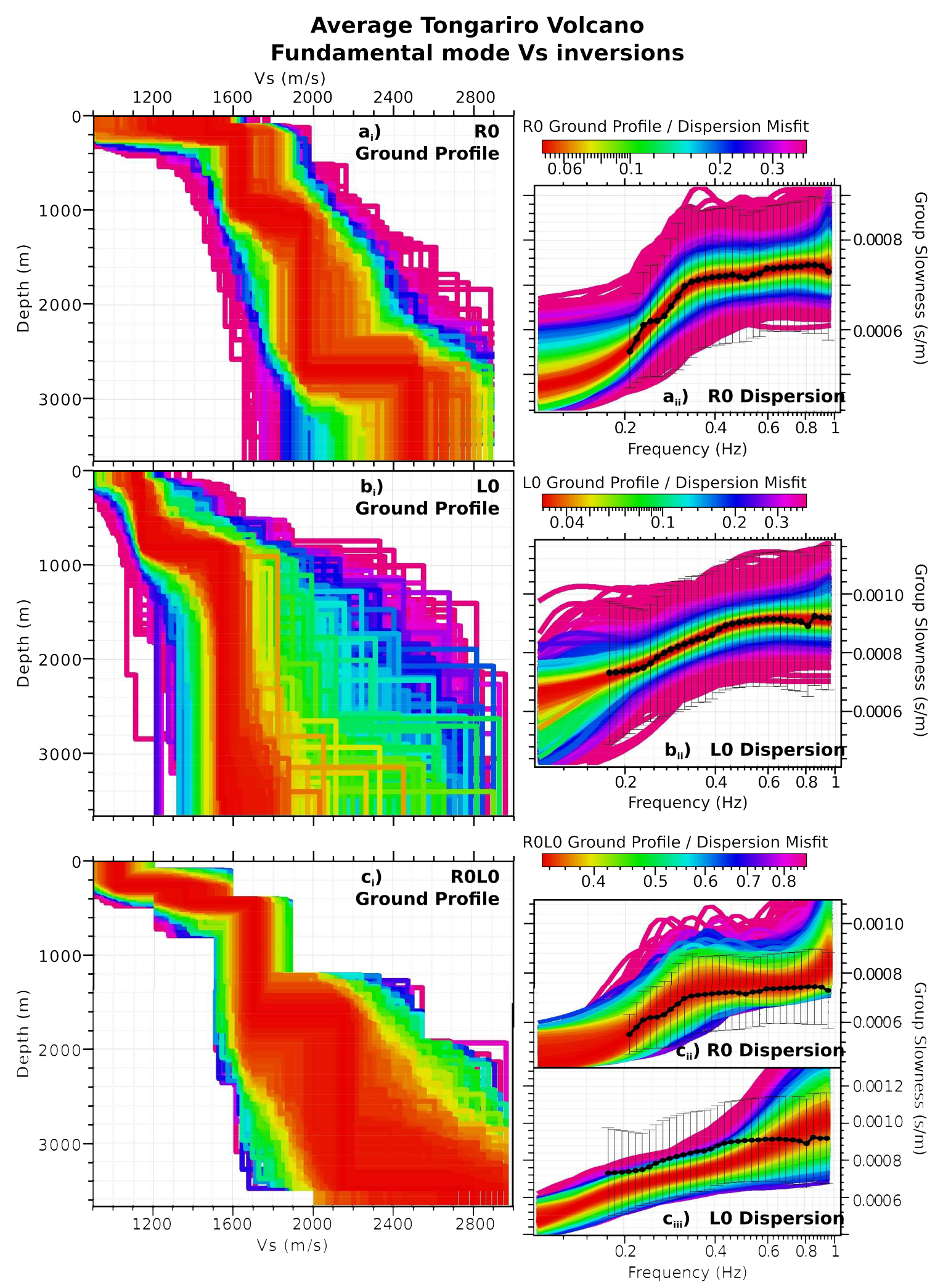

Figure 5.31: Fundamental mode $V_{S}$ Dinver inversions for average Tongariro dispersion curves. Dispersion curves match the adjacent ground profile. N.B. misfit colour schemes are consistent for dispersion and ground profile of each inversion but differ between inversions. 


\subsubsection{Oriented averages}

Although technically part of the NE-SW transect, we have excluded the R0 and L0 data from station pair S06-S09 (Fig. 5.32, pink lines). This is because both measurements are faster than all others; however, we are confident that they are not higher modes. Due to the small number of NE-SW oriented measurements, the impact of the outlying S06-S09 data on the oriented average is significant. Furthermore, as the S06-S09 path is tangential to, rather than crossing the Tongariro massif (Fig. 4.1), we think that excluding the data does not compromise the integrity of the oriented averages and inversions.

At $0.4-0.8 \mathrm{~Hz}$, the averages are approximately $1200 \pm 80 \mathrm{~m} / \mathrm{s}$ (NE-SW R0, 4 measurements), 1100 \pm 180 (NE-SW L0, 7 measurements), 1500 \pm 170 (NW-SE R0, 5 measurements) and $1100 \pm 300$ (NW-SE L0, 6 measurements). The two oriented L0 dispersion averages are almost identical and slower than the R0 (Fig. 5.32); however, at 90\% confidence, the NWSE R0 dispersion is significantly faster than the NE-SW R0 dispersion at all frequencies.

The NE-SW R0L0 inversion does not fully account for the L0 dispersion uncertainty, therefore its minimum and maximum velocities are not properly constrained (Fig. 5.33aii). The best R0L0 profile has two impedance contrasts, at 0.2 and $1.7 \mathrm{~km}$ and with much smaller velocity variation than the other Tongariro profiles (primary pairs and averages) except for the total average best L0 profile (Fig. 5.31bi). The shear-wave velocities are the slowest of all the Tongariro profiles, and are similar to what we observe at Ruapehu.

The NW-SE inversion has a well constrained minimum shear-wave velocity, which increases linearly from $1300-1700 \mathrm{~m} / \mathrm{s}$ at $0.6-2 \mathrm{~km}$ depth (Fig. 5.33bi). Shallower than $3 \mathrm{~km}$, the best NW-SE profile is similar to the best total average R0L0 profile; however the NW-SE lacks the large impedance at approximately $3 \mathrm{~km}$ depth that is common to most Tongariro inversions. This is because the NW-SE averages' R0/L0 group velocities do not increase much below $0.3 \mathrm{~Hz}$ (Fig. 5.33bii\&iii). 


\section{Mount Tongariro oriented fundamental mode A-grade dispersion paths}

$\square$ NE-SW oreinted paths $\square$ Average NE-SW NW-SE oriented paths $\square$ Average NW-SE $\square$ Other paths
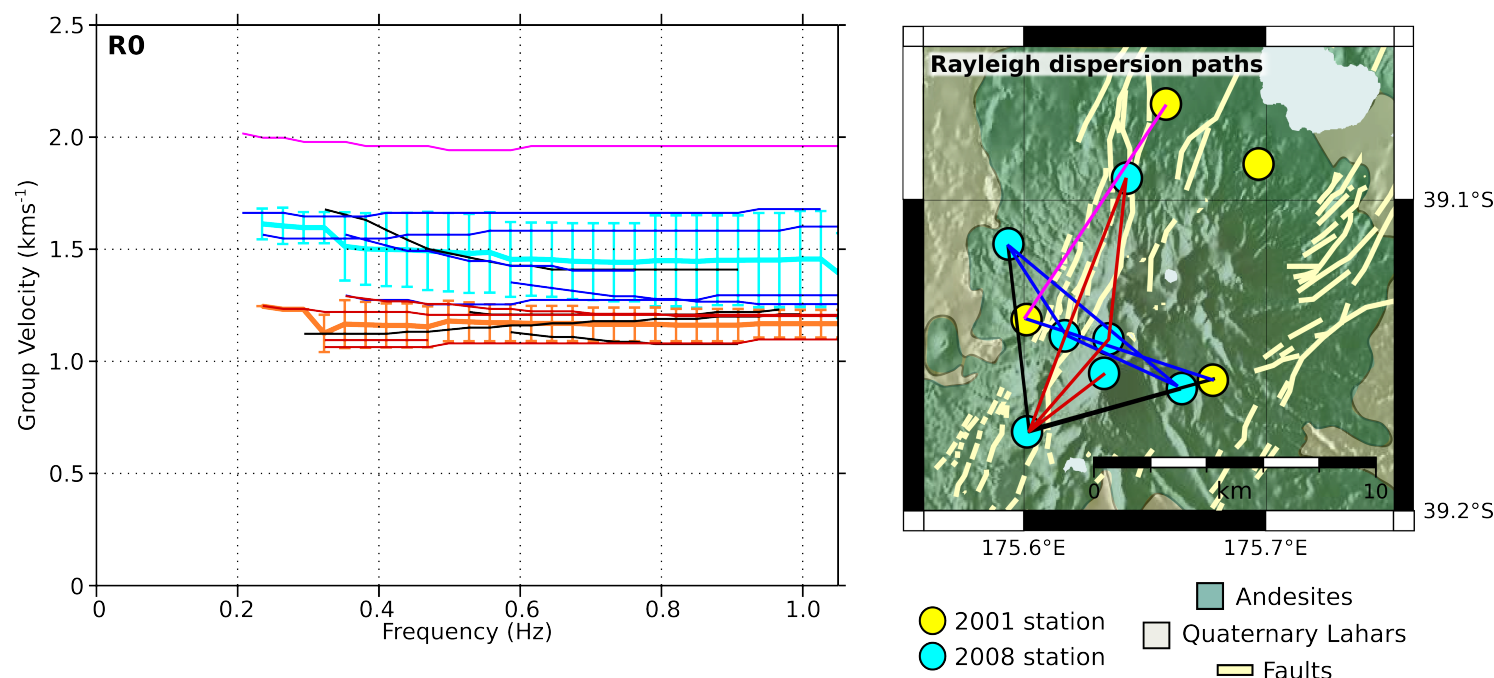

$\square$ Andesites

2008 station

Quaternary Lahars $\square$ Faults
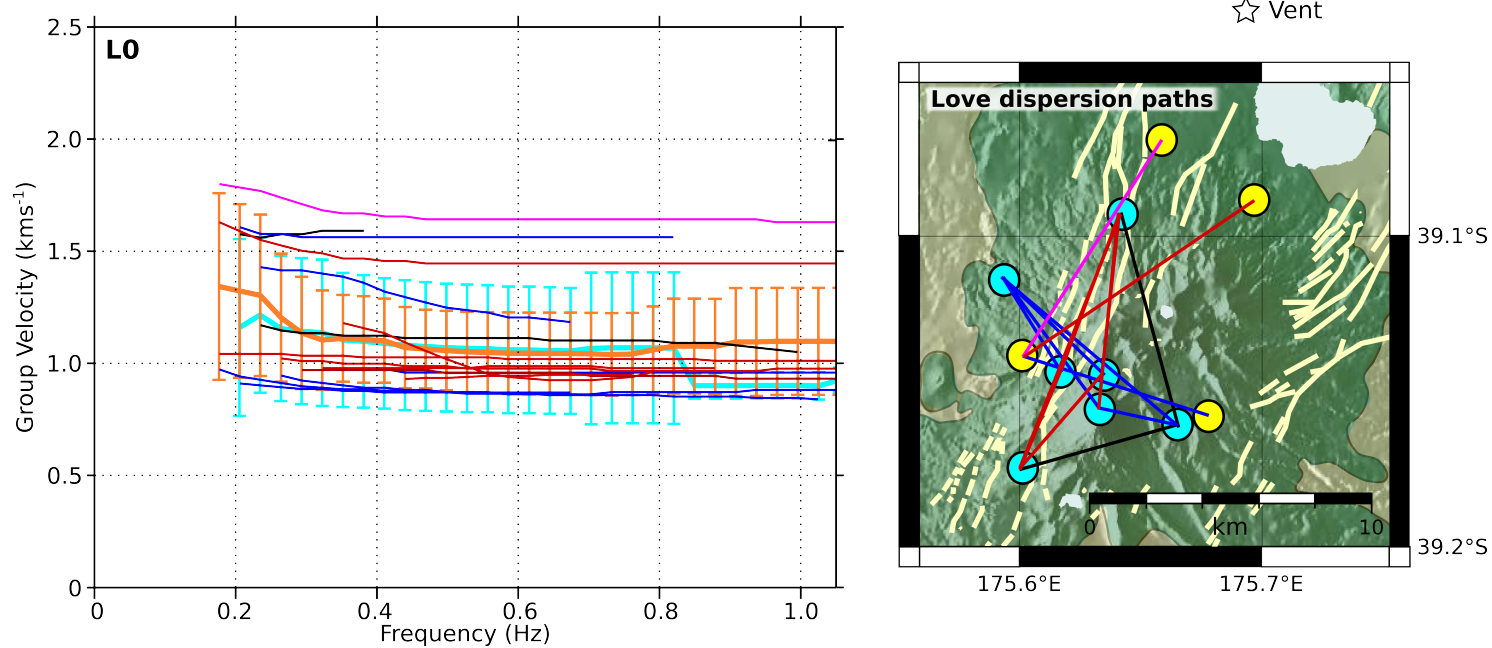

Figure 5.32: A-grade RO (a) and LO (b) dispersion measurements of the Tongariro area, grouped by path orientation. Dark red and blue lines are individual measurements of $N$-S and E-W transects, respectively; pink is outlying S06-S09; black lines are other orientations. Thick orange and pale blue lines are averages of $N-S$ and $E-W$ measurements with \pm one standard deviation as uncertainty. Interstation paths of individual measurements of plot illustrated on adjacent map with same colour scheme. 


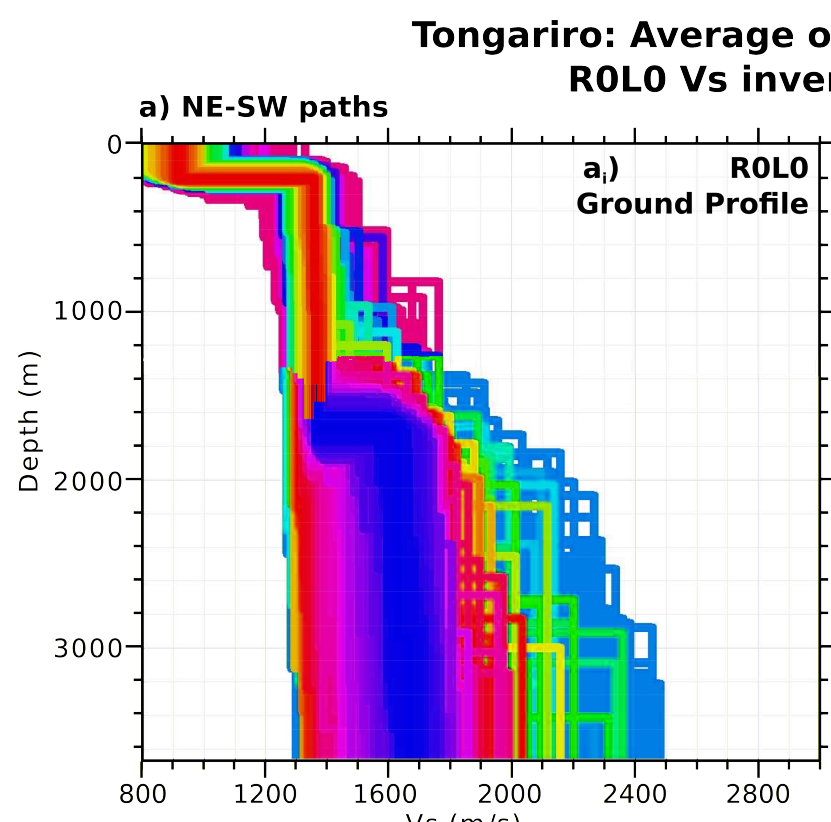

b) NW-SE paths

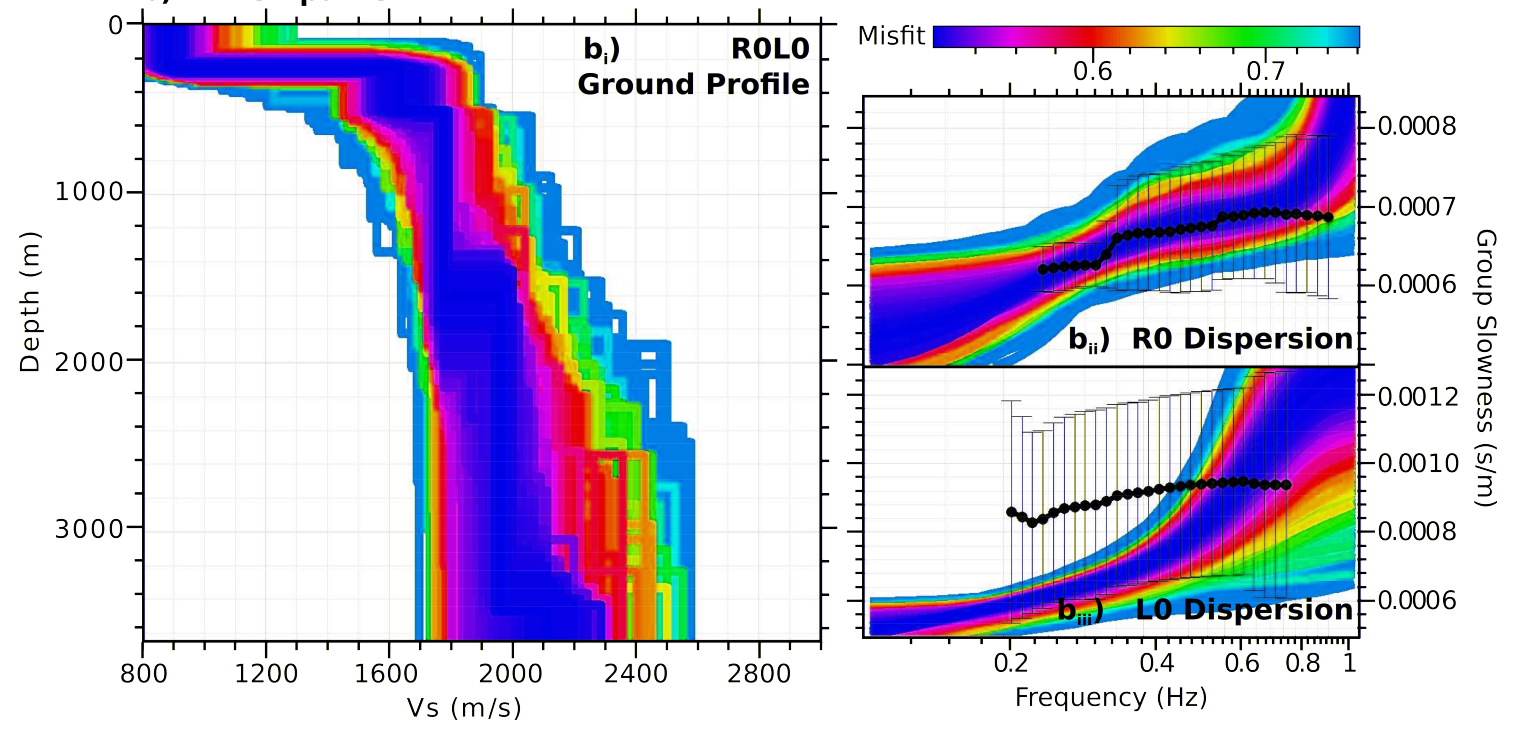

Figure 5.33: Joint ROLO $V_{S}$ Dinver inversions of the oriented average R0 and LO dispersion curves for Tongariro. Dispersion curves match the adjacent ground profile. N.B. misfit colour schemes are consistent for dispersion and ground profile of each inversion but differ between inversions: a) NE-SW oriented paths; b) NW-SE oriented paths. 


\section{Chapter 6}

\section{Discussion}

Here, we explain and interpret the results presented in the previous chapter. First, we discuss the quality and accuracy of our cross-correlations, dispersion measurements and $\mathrm{V}_{S}$ inversions. Next we interpret our group-velocity maps and $\mathrm{V}_{S}$ models and compare them to previous studies. Finally, we discuss our observations of relative surface-wave and shear-wave velocities, and present our final models of Ruapehu and Tongariro Volcanoes.

\subsection{Data quality and accuracy}

This section addresses the quality and accuracy of our data. We first discuss our crosscorrelations and the sources of variation in their SNR. Then we review our dispersion uncertainties and discuss the resolution of our $\mathrm{V}_{S}$ inversions.

\subsubsection{Cross-correlations}

We think the CCF computed using data from the START (2001) deployment are very high quality, due to the high sensor SNR and strength of dispersive phases with respect to the rest of the coda. It is unexpected and alarming that overall short-period sensors appear to outperform the broadband sensors in 2008 (Table 5.3), especially as most Guralp sensors' response functions are similar. As stated in section 4.2.1, we did not observe any issues with the instrument response correction for all stations when using local and teleseismic earthquakes. The two GeoNet broadband stations have the highest sensor SNR in 2008, therefore it is the 2008 temporary broadband sensors that are underperforming. 
Typically, CCF stacks of longer time periods contain stronger Green's functions. This explains the difference between the SNR of the NGA deployment, which was only 20 days long and the high quality START data (approximately 6 months) and permanent GeoNet stations (the whole of 2008). However, this does not explain the lower quality of the SADAR CCF.

\subsubsection{Timing errors}

The way we obtained and pre-processed the SADAR data was different to our other data (section 4.2), which may have created timing errors in the data. Unlike our other data, which was initially in 24-hour SAC traces, we had to merge and convert miniseed files to get 24-hour seismograms in SAC format. There were small discrepancies between beginning and end times of some of the converted files, which we addressed by removing the first and last 15 minutes of the trace and resampling it at $20 \mathrm{~Hz}$ to match our other data. We observe more instrumental glitches and dropouts in the SADAR data than in the 2008 GeoNet or 2001 datasets.

We observe two distinct types of timing errors in a sample set of daily cross-correlations between SADAR stations. The first results in the apparent velocities of the phases of the daily cross-correlations to drift through time, potentially occurring when the clock of one of the cross-correlated stations runs slightly faster than the other. Sudden timing changes may occur when a temporarily disrupted sensor comes back online a certain time period out of synch, introducing a static phase shift in the cross-correlations from before and after the glitch. The discrepancies in the start and end times of the SADAR SAC data may also have caused both types of errors.

Figure 6.1 presents 10 consecutive daily RR cross-correlations for station pairs S10-S28 (two Guralp 40T sensors), and ASHAW-ATKR (two Guralp 3-ESP sensors). In the case of S10-S28 (Fig. 6.1a), the velocities of phases are stable between days and when stacked, have a high SNR. The daily ASHAW-ATKR cross-correlations show phase drift and a static change (Fig. 6.1b). Phase drift, on the order of $+0.5 \mathrm{~s} /$ day occurs through days 090-096. Between days 096 and 097, a -8 s phase shift occurs. There is then a $+0.6 \mathrm{~s} /$ day drift from then onwards. These errors mean that the high amplitudes of the individual day CCF cancel out in the 10-day stack. 
Example daily and 10-day CCF stacks

a) S10-S28 RR component: no drift

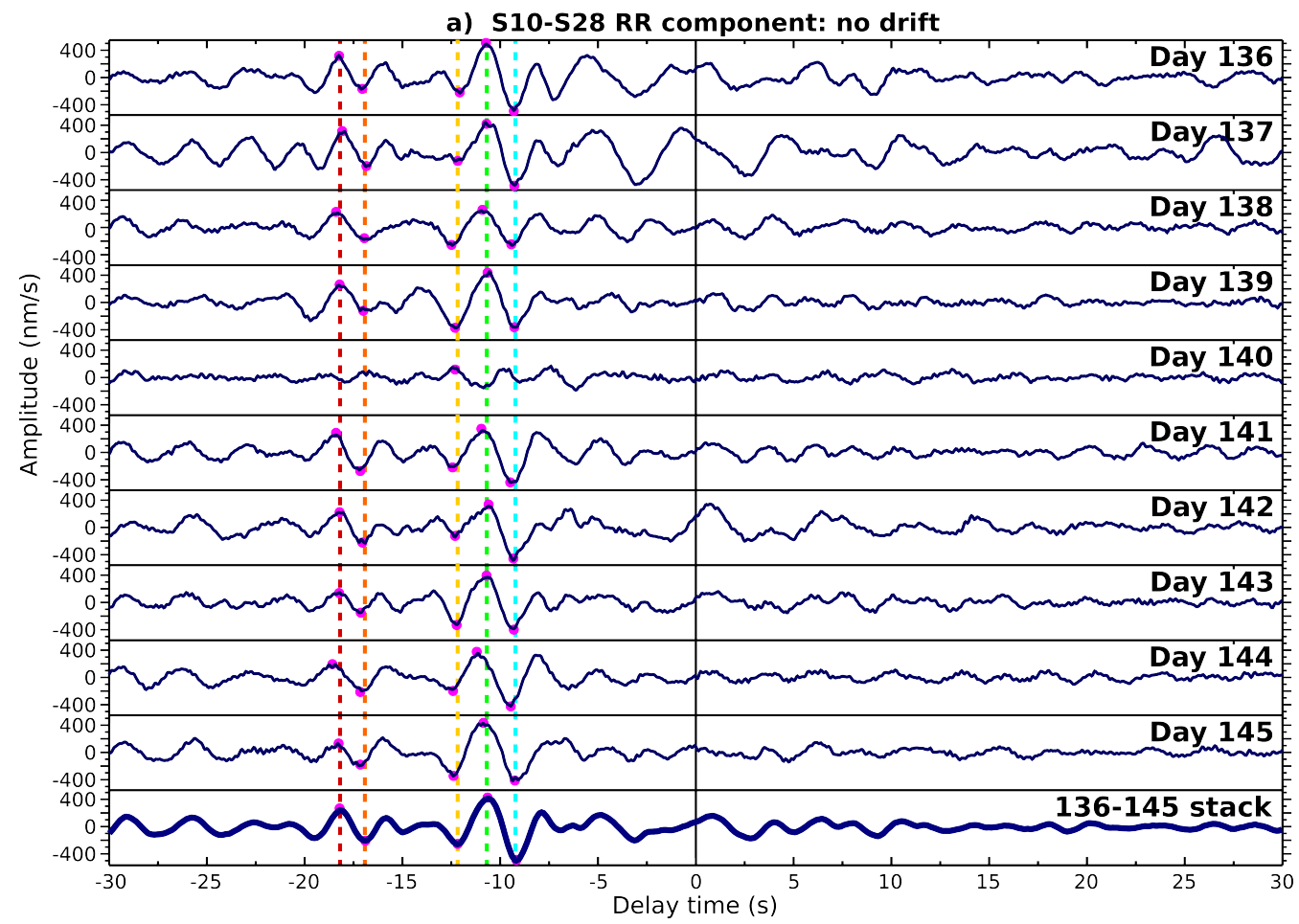

b) ASHAW-ATKR RR component: 0.5-0.6 s/day drift

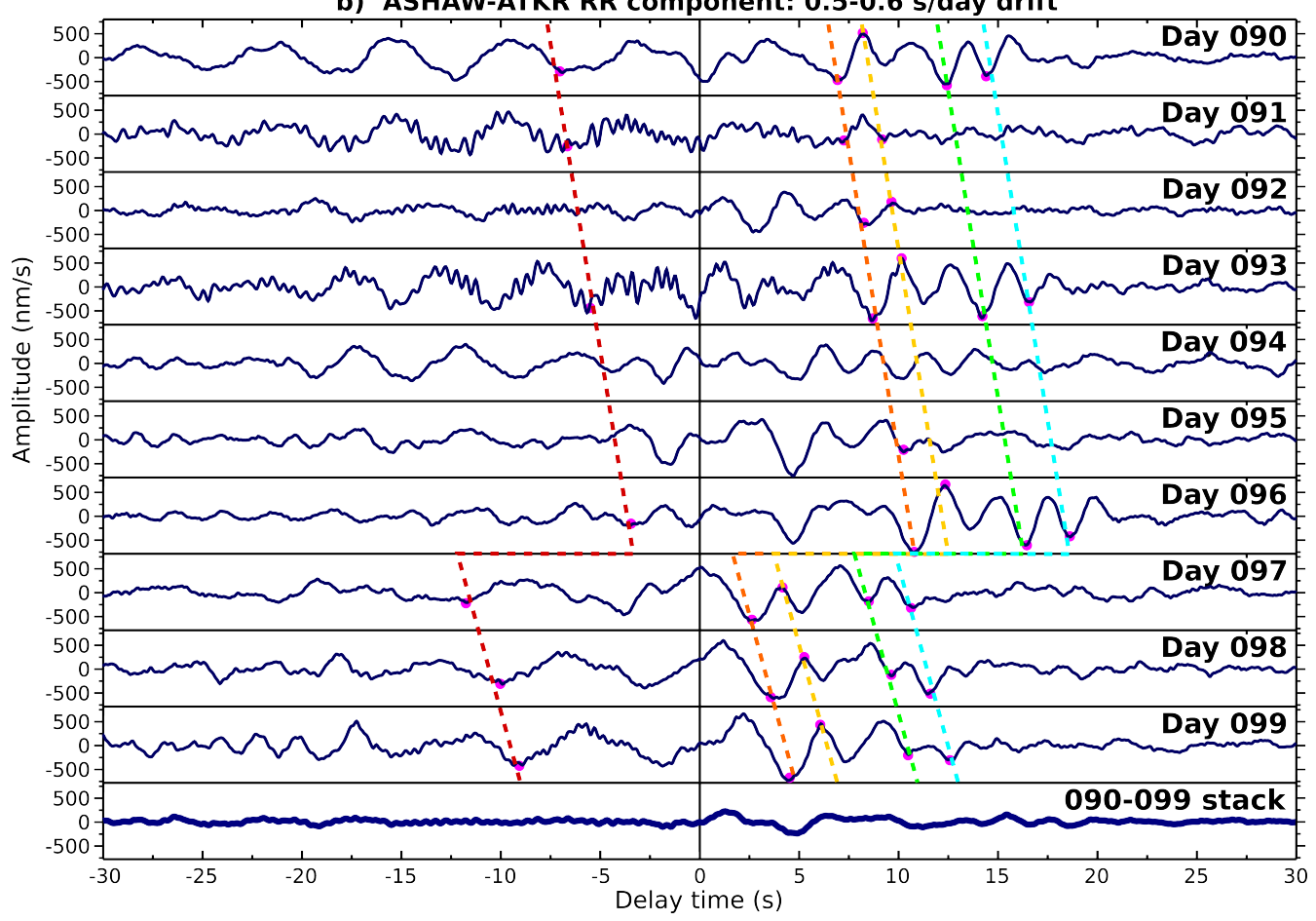

Figure 6.1: Examples of 10 consecutive daily two-sided CCF and the 10-day stack for: a) a station pair with no phase drift; b) a station pair with significant phase drift. Dashed lines are guides joining the peaks and troughs of specific phases between CCF (highlighted by purple circles). Note that relative times between highlighted phases within each CCF are constant. Days are numbered by Julian convention; waveforms have been lowpassed at 2 $H z$. 
Sudden timing errors can be resolved using the method proposed by Sens-Schonfelder (2008) which correlates each daily CCF with the full-stack. Time shifts are applied to the daily CCF to align them with the full-stack if the daily CCF's correlation coefficient exceeds a set threshold. Behr et al. (2011) successfully corrected static timing errors in their daily cross-correlations for START and CNIPSE stations across the TVZ using this method, which increased the SNR of their full-stacks.

We think that low SNR in the SADAR stacks are primarily caused by timing errors. However, given the prevalence of both time-drift and static changes in our CCF, we do not think it is possible to align them without compromising the validity of subsequent dispersion measurements.

\section{Synthetic RZ/ZR CCF and averages}

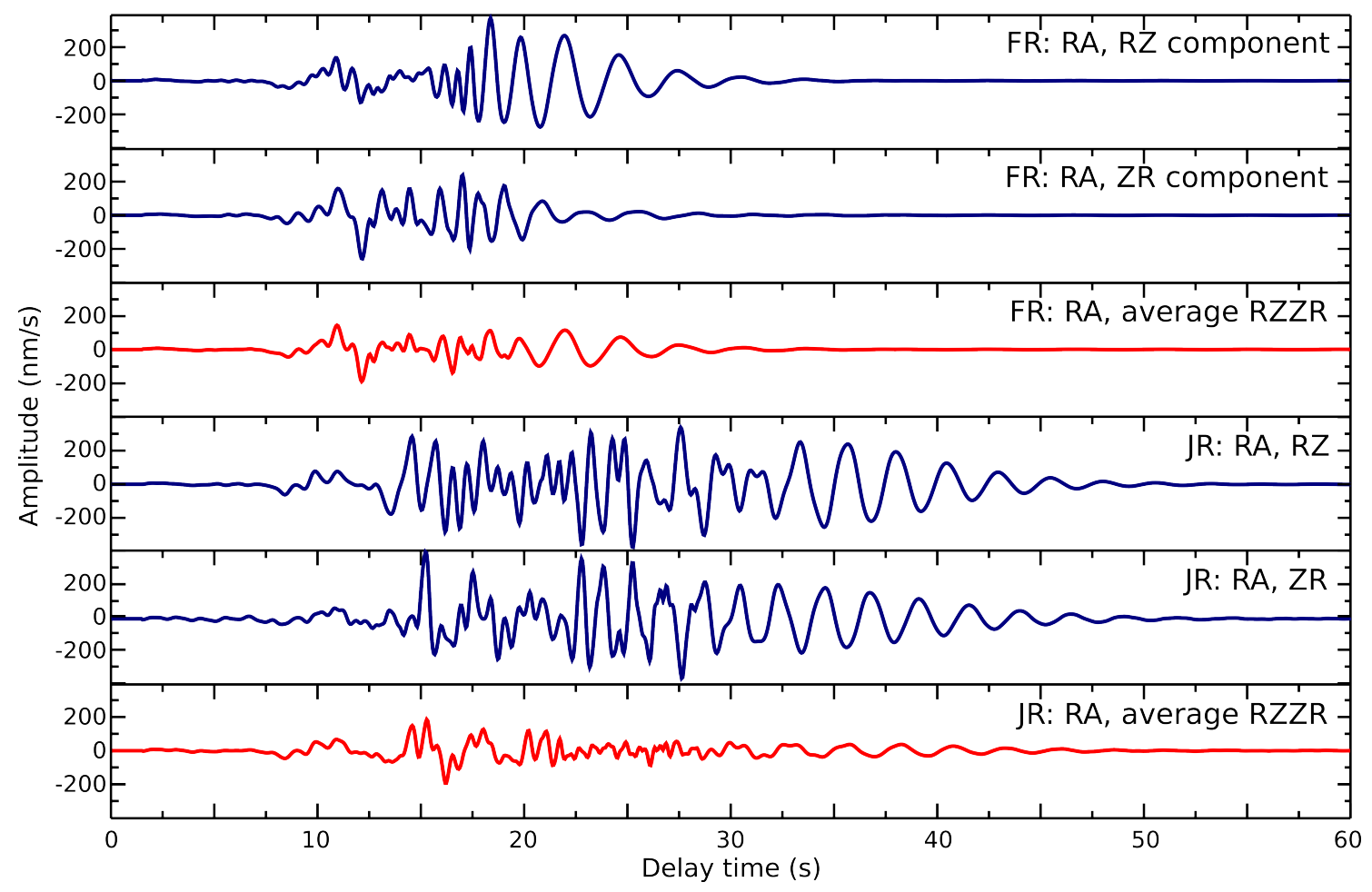

Figure 6.2: Example of synthetic, sum of all modes $R Z$ and $Z R$ CCF for the FR and JR models, with a simulated interstation distance of $20 \mathrm{~km}$. Dark blue waveforms are the $R Z$ and $Z R C C F$, red lines are the average of the two components

\subsubsection{RZ/ZR asymmetry}

As previously explained, the RZ and ZR CCF, being out of phase by $180^{\circ}$ (or $1 / 2 \lambda$ ), should be inverses of each other, i.e. would average to zero functions. This is not what 
we observe, even for high quality station pairs where the daily cross-correlations are very consistent (e.g. S10-S28). However, our synthetic RZ and ZR modal sum CCF for both the FR and JR models are also not inverses (e.g. Fig. 6.2). Consequently, the factor inducing the RZ/ZR phase differences must be related to the subsurface structure or interaction of different modes in some way.

\subsubsection{Dispersion measurements}

We made our group velocity dispersion measurements on symmetric CCF. This procedure is common (e.g. Jay et al., 2012; Masterlark et al., 2010; Mordret et al., 2015) as adding the causal and acausal CCF together reduces the effect of a heterogeneous noise field. Stankiewicz et al. (2010) observed significant differences between the frequencies containing the strongest signals on the acausal and causal functions at Lake Toba (Philippines), possibly due to the lack of surface-wave diffusivity.

Where calculated, the uncertainties of individual dispersion measurements (the standard deviation of measurements over different time blocks, see section 4.4.2) are very low, on the order of a few percent (Table 6.1). The highest dispersion uncertainties are from station pair S10-S28, which although viable for just $8 \%$ of the time period of the other three pairs, gave well-constrained $\mathrm{V}_{S}$ profiles

\begin{tabular}{|c|ccc|}
\hline Pair & R0 & L0 & R1 \\
\hline S10-S28 & $1.10 \%$ & $4.50 \%$ & $4.40 \%$ \\
OTVZ-WTVZ & $0.67 \%$ & $0.14 \%$ & $0.57 \%$ \\
WNVZ-WPVZ* & N/A & $0.62 \%$ & $0.85 \%$ \\
KRVZ-NGZ** & $1.40 \%$ & $2.30 \%$ & N/A \\
\hline
\end{tabular}

Table 6.1: Average percent (2 s.f.) uncertainties of A-grade individual dispersion measurements at 0.4-0.8 Hz.*example station pair from Ruapehu N-S transect; **example station pair from Tongariro NE-SW transect.

The majority of our averages' uncertainties are above $15 \%$ at $0.4-0.8 \mathrm{~Hz}$ (Table 6.2). Although we consider these uncertainties to be quite large, most are much smaller than the $30 \%$ uncertainty (also standard deviations) of the average R0 and L0 dispersion curves calculated for Piton de la Fournaise (PdF, Mordret et al., 2015) 


\begin{tabular}{|c|c|c|c|c|c|}
\hline \multicolumn{2}{|c|}{ Average } & R0 & L0 & R1 & L1 \\
\hline \multirow{3}{*}{ 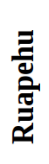 } & Total & $16 \%$ & $20 \%$ & $15 \%$ & $14 \%$ \\
\hline & N-S & $15 \%$ & $19 \%$ & - & - \\
\hline & E-W & $17 \%$ & $21 \%$ & - & - \\
\hline \multirow{3}{*}{ 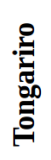 } & Total & $19 \%$ & $24 \%$ & $4.70 \%$ & - \\
\hline & NE-SE & $7.10 \%$ & $17 \%$ & - & - \\
\hline & NW-SE & $12 \%$ & $28 \%$ & - & - \\
\hline
\end{tabular}

Table 6.2: Average percent (2 s.f.) uncertainties of average dispersion curves at 0.4-0.8 Hz.

As a set, our Love dispersion curves are higher quality than our Rayleigh-wave measurements. Greater proportions of A-grade TT measurements and clearer distinctions between what we class as L0 and L1 are evidence for this. This result conflicts with the findings of Behr et al. (2011), who calculated cross-correlations from the START deployment (section 4.1) data in addition to other deployments in the central North Island. Although their calculated SNR of TT correlations $0.8-1 \mathrm{~Hz}$ (their upper limit) were higher than the SNR of ZZ correlations, they found TT SNR to be much lower than ZZ SNR at 0.1-0.7 Hz. However, they used periods up to $20 \mathrm{~s}$, and a sampling rate of $1 \mathrm{~Hz}$ (compared to our 20 $\mathrm{Hz})$.

Jay et al. (2012), found their 0.15-0.5 Hz Love-wave measurements to be more consistent than Rayleigh-wave measurements at Uturuncu, in Bolivia. Although they acknowledge the potential presence of higher mode Rayleigh waves complicating their data, they suggest that Love waves are more reliably extracted from the ambient noise at $0.15-0.5$ Hz. Savage et al. (2013) also observed that TT CCF in the Canterbury region were more symmetric than $\mathrm{RR}$ or $\mathrm{ZZ}$, indicating that the Love-waves were more diffuse than Rayleigh-waves in the ambient noise. Behr et al. (2013) also observe that Love waves are more diffuse than Rayleigh waves in their beamforming analysis of stations in Taranaki.

\subsection{3 $\mathrm{V}_{S}$ inversions}

Surface-wave velocities at a specific frequency do not directly correspond to the shear-wave velocity at a specific depth. Although they are most sensitive to a certain depth, they are influenced by the structure over a depth range (Stein and Wysession, 2009). This is illustrated by the differences between the synthetic dispersion curves (of the same mode) for the JR and FR models, which have identical structure below $2 \mathrm{~km}$ (Fig. 6.3). The maximum frequency at which the two models' R0 and L0 dispersion curves are approx- 
imately equal is $0.1 \mathrm{~Hz}$, showing that structure above $2 \mathrm{~km}$ still influences dispersion at long periods. Consequently, the depth of layer boundaries in $\mathrm{V}_{S}$ inversions of dispersion data can be poorly resolved. To examine the resolution of our $\mathrm{V}_{S}$ inversions, we make R0, L0 and R0L0 inversions of our JR and FR synthetic dispersion curves (Figs. 6.4, 6.5). To be consistent with our Ruapehu and Tongariro inversions, we only use frequencies of 0.19-1 $\mathrm{Hz}$ and set a maximum inversion depth of $3.5 \mathrm{~km}$. We set the maximum $\mathrm{V}_{S}$ allowed in the models at $3.5 \mathrm{~km} / \mathrm{s}$.

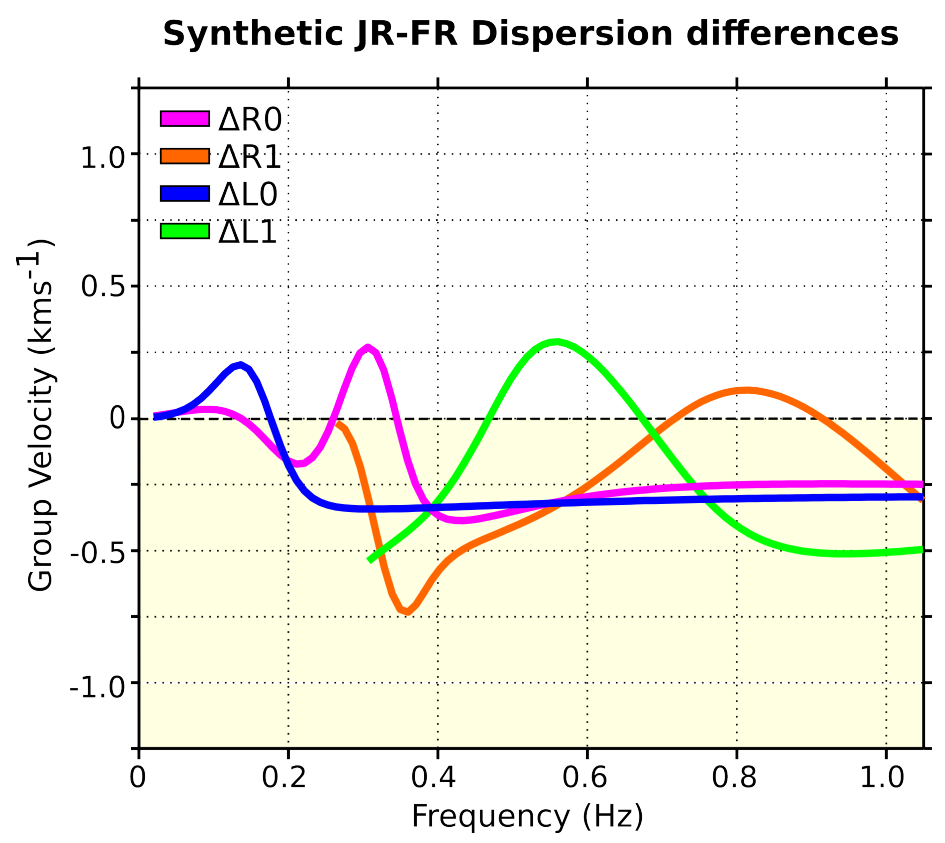

Figure 6.3: Differences between FR and JR dispersion curves

For each inversion, the velocity of the top layer is well resolved. However, very slight differences between the 50,000 theoretical dispersion curves produce very different $\mathrm{V}_{S}$ profiles below $1 \mathrm{~km}$. This is because the relationship between dispersion curves and $\mathrm{V}_{S}$ structure is often non-unique (e.g. Foti et al., 2009). As explained in section 4.8, doing multiple runs with multiple modes places greater constraints on the model, however, we are still unable to replicate the initial JR model in our R0, L0 or R0L0 inversions (Fig. 6.4). In all three models, the velocity and depth of the top layer is well resolved, however, the $2.1 \mathrm{~km} / \mathrm{s}$ second layer is overestimated and its lower boundary is inaccurate in all but the L0 best-profile (Fig. 6.4bi, red area). The $1 \mathrm{~km}$ boundary is best resolved by the R0L0 inversion. Below $1 \mathrm{~km}$, the layer velocities and depths of the R0L0 inversion, although appearing well constrained, are the least accurate of all three inversions. 


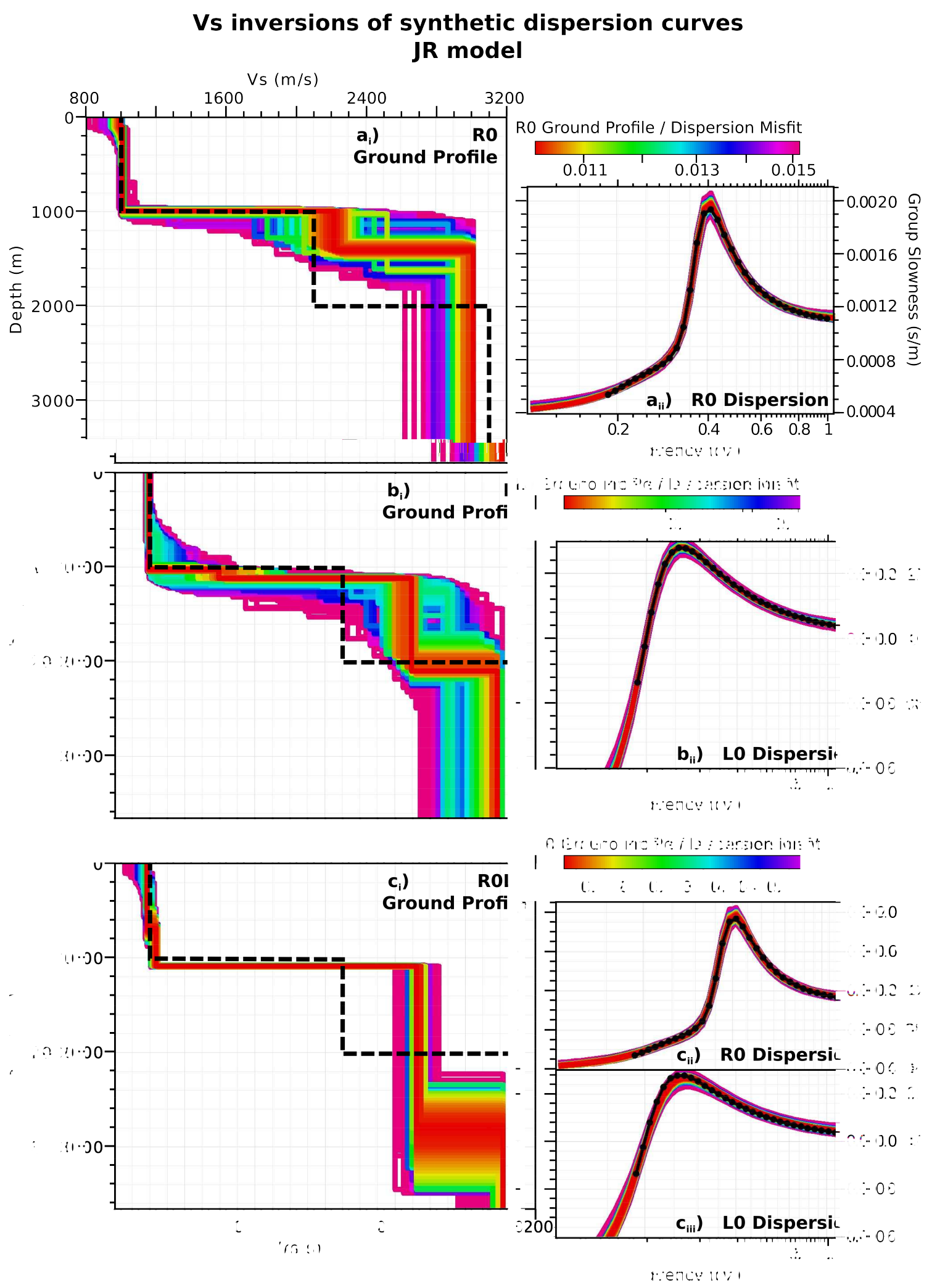

Figure 6.4: Dinver $V_{S}$ inversions for fundamental mode synthetic dispersion curves. Dispersion curves match the adjacent ground profile. N.B. misfit colour schemes are consistent for dispersion and ground profile of each inversion, but differ between inversions. Superimposed black dashed line in ground profile is the initial JR model: a) R0 inversion; b) LO inversion; c) joint ROLO inversion. 


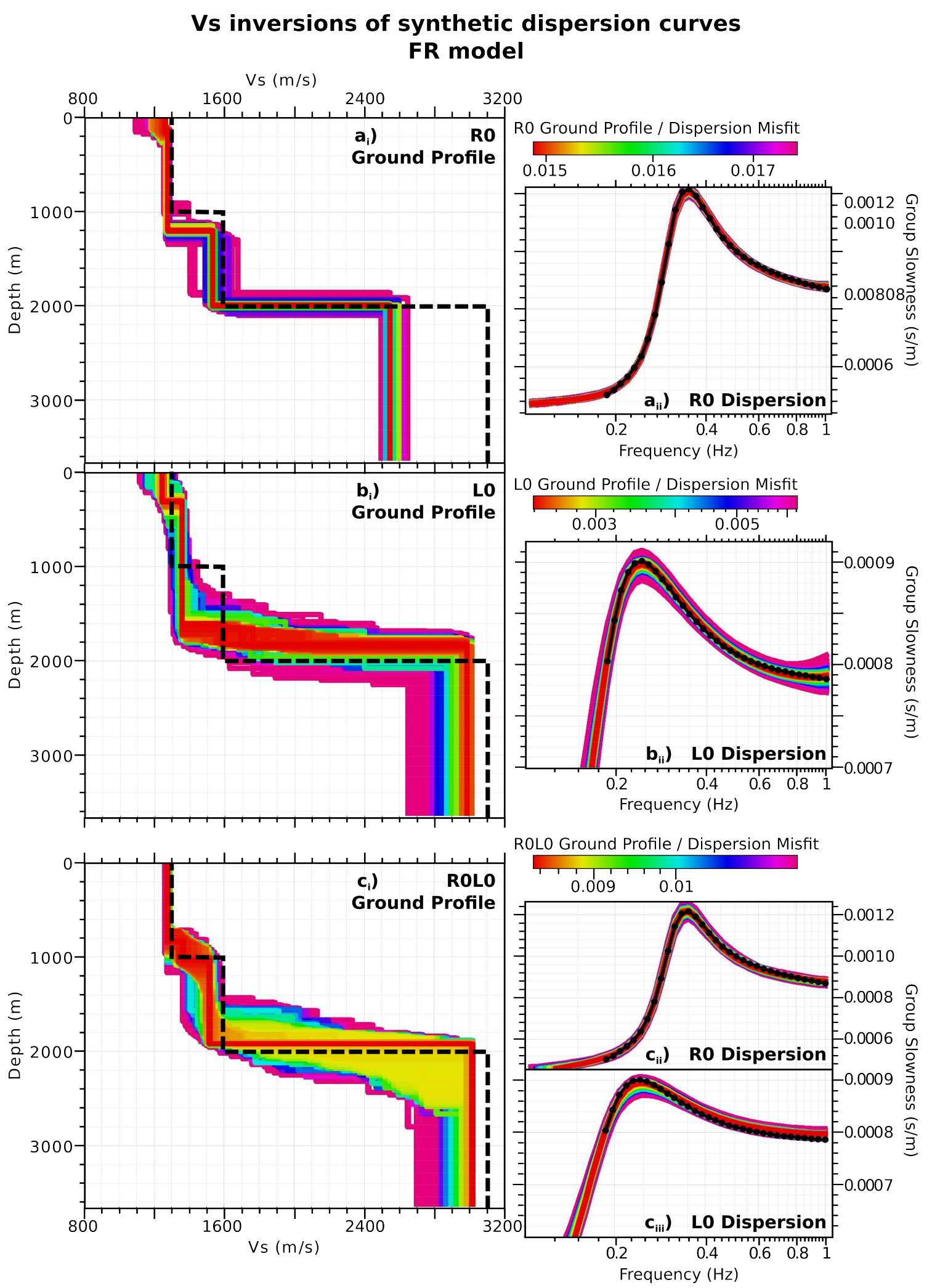

Figure 6.5: Dinver $V_{S}$ inversions for fundamental mode synthetic dispersion curves. Dispersion curves match the adjacent ground profile. N.B. misfit colour schemes are consistent for dispersion and ground profile of each inversion, but differ between inversions. Superimposed black dashed line in ground profile is the initial FR model: a) R0 inversion; b) LO inversion; c) joint ROLO inversion. 
In contrast, the $\mathrm{FR} \mathrm{V}_{S}$ inversions are similar to the initial model (Fig. 6.5). The $\mathrm{R} 0$ inversion accurately resolves the FR model layer depths and velocities above $2 \mathrm{~km}$. However, it greatly underestimates the deeper velocity. The L0 inversion does not resolve the $1 \mathrm{~km}$ boundary, and constrains the $2 \mathrm{~km}$ boundary to $1.6-2.2 \mathrm{~km}$. Overall, the FR R0L0 inversion is the most accurate of the synthetic data. The R0L0 best profile is very similar to the initial FR, however the resolution of the $2 \mathrm{~km}$ boundary is approximately equal to that of the L0.

The strength of the impedance contrasts in the subsurface structure is an important factor in the resolution of the $\mathrm{V}_{S}$ structure. The top three $\mathrm{km}$ of the JR model is a step function, with similar magnitude velocity changes. However, in the FR model, the $2 \mathrm{~km}$ boundary is much more significant, and consequently observed by all inversions. The 1 $\mathrm{km}$ boundary is more prominent, and resolved in the JR inversions, whereas in the FR inversions, the $1 \mathrm{~km}$ boundary is only $0.3 \mathrm{~km} / \mathrm{s}$, and not observed in the L0 inversion. These results suggest that layer velocities are likely better resolved than depths, with shallow velocities $(<1 \mathrm{~km})$ best resolved. Additionally, unless shallow layer boundaries have large impedance contrasts, we are more likely to detect them in the R0 and R0L0 inversions than in the L0 inversions. We observe such disparities in our average Tongariro inversions (section 5.5.2.1). The final implication of our synthetic inversions is that, even by jointly inverting R0 and L0 dispersion, the ambiguity of dispersion curves may be problematic.

\subsection{Isotropic velocity structure of the $\mathrm{TgVC}$}

\subsubsection{Surface-wave group velocities}

The R0 group velocity ranges (Table 6.1) are consistent with other studies of shallow volcanic structure that use ambient noise. At Okmok (a shield volcano in Alaska), R0 group velocities ranging from $1.5-2.5 \mathrm{~km} / \mathrm{s}$ have been observed within an approximate area of $40 \times 40 \mathrm{~km}$ at $0.3 \mathrm{~Hz}$ (Masterlark et al., 2010). At PdF, R0 group velocities measured by Mordret et al. (2015) range from $0.75-1.9 \mathrm{~km} / \mathrm{s}$ and $0.4-1.6 \mathrm{~km} / \mathrm{s}$ at $0.5 \mathrm{~Hz}$ and 1 $\mathrm{Hz}$, respectively. At Lake Toba (Philippines), Stankiewicz et al. (2010) observe R0 group velocities at $1.5-3 \mathrm{~km} / \mathrm{s}$ in a $0.4 \mathrm{~Hz} 2 \mathrm{D}$ tomographic inversion at $0.4 \mathrm{~Hz}$.

Our maximum R0 group velocities of our dispersion measurements are slightly lower than the group velocity range of the average R0 dispersion measured by Behr et al. (2011) 
in the TVZ. Their average velocities range $2.3-2.4 \mathrm{~km} / \mathrm{s}$ and $2.3-2.5 \mathrm{~km} / \mathrm{s}$ at 0.5 and $1 \mathrm{~Hz}$, respectively. However, their maximum R0 velocity exceeds $2.75 \mathrm{~km} / \mathrm{s}$ only below $0.07 \mathrm{~Hz}$.

\subsubsection{Spatial heterogeneity and/or multiple modes?}

Our biggest challenge has been determining whether variation of apparent surface-wave velocities in our dispersion measurements is due to heterogeneous velocity structure in the $\mathrm{TgVC}$ or to the presence of multiple modes. The group velocity ranges for what we have designated as fundamental and higher-order mode dispersion curves (section 5.5.2) greatly overlap (Table 6.3). The dispersion curves of our primary pairs further illustrate this diversity (section 5.4), with the R1 dispersion of S10-S28 slightly slower than the R0/L0 dispersion of OTVZ-WTVZ (Figs. 5.19d, 5.23d).

\begin{tabular}{|c|c|cccccc|}
\hline Mode & Frequency & No. & $\boldsymbol{\mu ( \mathbf { k m } / \mathbf { s } )}$ & $\boldsymbol{m i n}(\mathbf{k m} / \mathbf{s})$ & $\boldsymbol{m a x}(\mathbf{k m} / \mathbf{s})$ & $\boldsymbol{\sigma}(\mathbf{k m} / \mathbf{s})$ & $\boldsymbol{\sigma}(\mathbf{\%})$ \\
\hline \multirow{2}{*}{ R0 } & $0.5 \mathrm{~Hz}$ & 320 & 1.6 & 0.6 & 2.4 & 0.4 & 23 \\
& $1 \mathrm{~Hz}$ & 135 & 1.6 & 0.5 & 2.4 & 0.4 & 23 \\
\hline \multirow{2}{*}{$\mathrm{R} 1$} & $0.5 \mathrm{~Hz}$ & 305 & 2.2 & 1.4 & 3.7 & 0.3 & 15 \\
& $1 \mathrm{~Hz}$ & 187 & 2.2 & 1.4 & 3.6 & 0.3 & 15 \\
\hline \multirow{2}{*}{$\mathrm{L} 0$} & $0.5 \mathrm{~Hz}$ & 170 & 1.3 & 0.6 & 2 & 0.3 & 24 \\
& $1 \mathrm{~Hz}$ & 66 & 1.2 & 0.6 & 2 & 0.3 & 28 \\
\hline \multirow{2}{*}{$\mathrm{L} 1$} & $0.5 \mathrm{~Hz}$ & 107 & 2.1 & 1.7 & 2.9 & 0.2 & 11 \\
& $1 \mathrm{~Hz}$ & 60 & 2.1 & 1.7 & 2.6 & 0.2 & 11 \\
\hline
\end{tabular}

Table 6.3: Modal velocity ranges and statistics of A-grade dispersion measurements at 0.5 $\mathrm{Hz}$ and $1 \mathrm{~Hz} . \mu$ denotes mean, $\sigma$ denotes standard deviation.

The distribution of Love-wave group velocity measurements suggests the presence of a higher-order mode in addition to the fundamental (e.g. Fig.5.7). Further evidence supporting this is shown by two phases with different moveout in some of our record sections (e.g. Fig. 5.18a), and many MFT with two phases (e.g. Fig. 5.6d). Additionally, the maximum L0 group velocities measured by Behr et al. (2011) are $2.3 \mathrm{~km} / \mathrm{s}$ above 0.5 $\mathrm{Hz}$, and exceed $2.5 \mathrm{~km} / \mathrm{s}$ only below $0.18 \mathrm{~Hz}$. However, the steep gradient of the synthetic L1 dispersion for the FR and JR models (Fig. 5.13) is significantly different from the slight velocity variations within the L1 measurements. Our L1 measurements have the same form as the synthetic L0, but have higher velocities.

Higher-order modes have can deeper sensitivities than the fundamental mode at some frequencies (Xia et al., 2003). Savage et al. (2013) demonstrated that in low-velocity 
sedimentary basins, $\mathrm{R} 1$ waves can dominate the $\mathrm{RR}$ component cross-correlation. They propose that the significant R1 energy in their CCF is caused by basement resonance and the source of the higher-mode in the ambient noise is due to ocean waves approaching or breaking at the shoreline, located 30-40 km away from their stations.

The TgVC is a rift basin comparable to a low-velocity sedimentary basin, and the nearest coast to the $\mathrm{TgVC}$ is approximately $65 \mathrm{~km} \mathrm{SW}$ of Ruapehu, therefore the same mechanism may excite the higher-modes we observe in our CCF. However, we have been unable to find another case where L1 waves have been reported in ambient noise crosscorrelations on our scale of observation. Furthermore, strong higher-modes have not been documented in ZZ CCF. Further work is required to determine the source of higher-mode surface-waves in ambient noise in the TgVC.

\subsubsection{Shear-wave velocities}

Our $\mathrm{V}_{S}$ profiles for Ruapehu and Tongariro are very different. However at each volcano, the primary-pair, isotropic average and oriented average inversions are fairly consistent (Fig. 6.6).

\subsubsection{Ruapehu}

All Ruapehu best-profiles contain a very low velocity layer approximately $200 \mathrm{~m}$ thick at the surface (Figs. 5.21, 5.27, 5.29). We interpret this layer as recent, unconsolidated, tephras and loose eroded material from the volcano. This layer coincides with similarly thick, highly resistive material observed by Jones et al. (2008) and (Ingham et al., 2009) in magnetotelluric investigations of Ruapehu (see section 2.4.4).

The N-S inversion is anomalous in comparison to the other Ruapehu Dinver inversions (Fig. 5.29a), but is similar to the Olson (1985) and Latter (1981b) profiles (Fig. 6.6). Shallower than $1.5 \mathrm{~km}, \mathrm{~V}_{S}$ is consistent with the other models; however at depth, $\mathrm{V}_{S}$ is considerably faster than all our other profiles. At approximately $3 \mathrm{~km}$ depth, there is a significant impedance contrast in the profile, below which the best-profile $\mathrm{V}_{S}$ is 2.8 $\mathrm{km} / \mathrm{s}$, similar to velocities interpreted as greywacke in previous 1D models (Fig. 6.6). The discrepancy between the N-S and our other inversions may be in part due to the lack of R0 data below $0.3 \mathrm{~Hz}$ (Fig. 5.29a) and to the influence of station S26, located slightly beyond the SE edge of the massif. S26 was identified as a relatively "fast" station during Love-wave 
mode identification using the station-grouping method, (section 5.2.2), and is positioned where refraction data suggests that the depth to the basement greywacke is shallower (Fig. 6.6, Sissons and Dibble, 1981).

The S10-S28 L0 dispersion curve (Fig.5.18) has a gradient change at approximately 0.2 Hz. This resolves a significant boundary at approximately $3 \mathrm{~km}$ depth, but the velocity below the boundary is slower than the greywacke interpreted in other models. However, the S10-S28 L0 inversion does resemble a smoothed version of the Hurst (1998) and Jolly et al. (2010) profiles (Fig. 6.6).

\section{Comparison of existing and proposed Vs models}
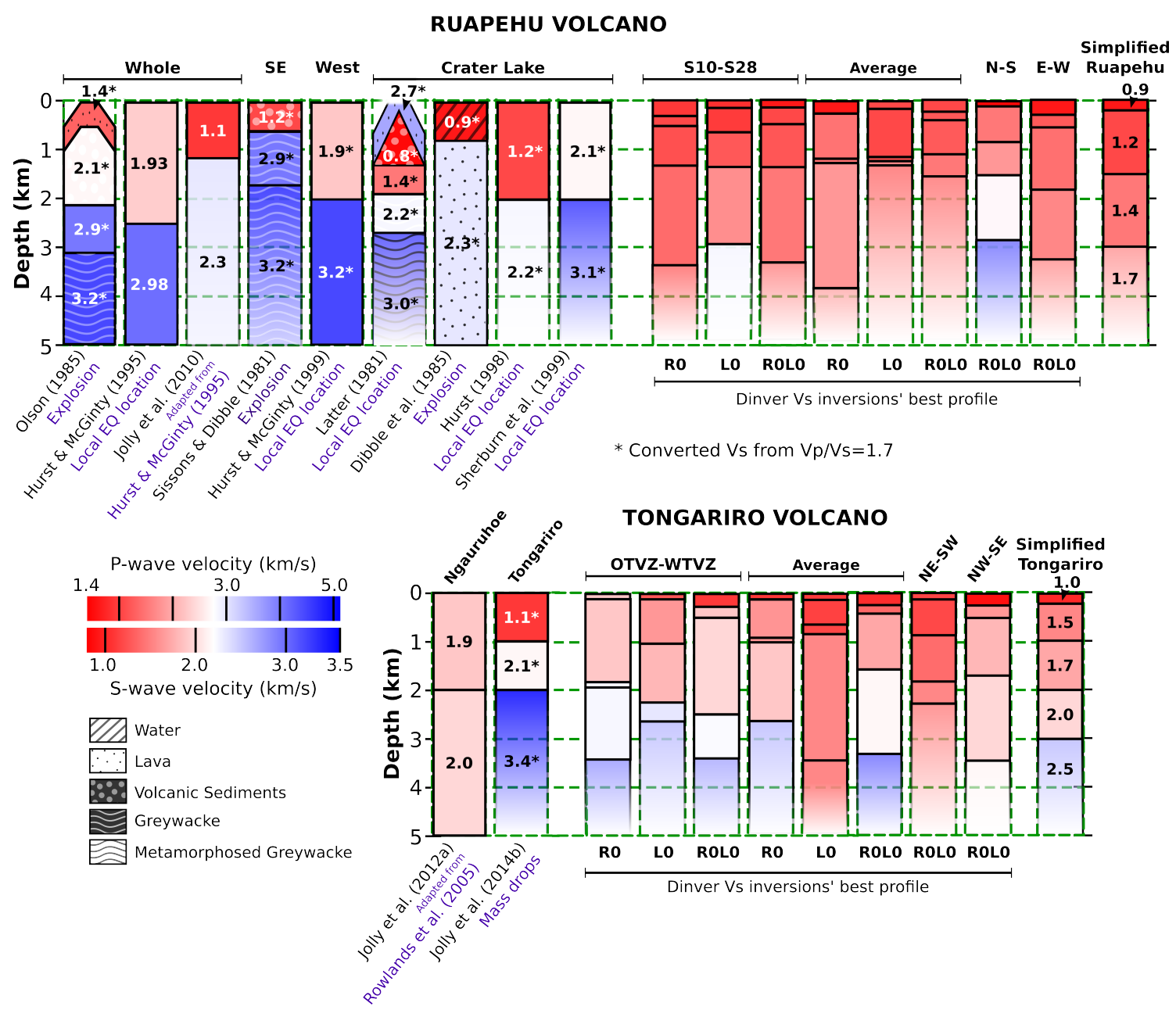

Figure 6.6: Comparison of Dinver inversions and simplified models to existing $1 D V_{S}$ profiles of Ruapehu and Tongariro volcanoes (Fig. 2.5), with depths projected relative to the surface. Note elevations of Mounts Ruapehu, Ngauruhoe and Tongariro at $2797 \mathrm{~m}$, $2291 \mathrm{~m}$ and $1978 \mathrm{~m}$ MSL, respectively. 
The rest of the Ruapehu inversions are similar to each other, presenting a linear increase in velocity with depth, without any significant boundaries encountered (Fig. 6.6). $\mathrm{V}_{S}$ increases with depth may reflect the presence of multiple layers of tephra, lava and eroded material that compact as they are buried, and low velocities could represent hot, highly fractured, hydrothermally altered material in Ruapehu's geothermal system. This interpretation is consistent with that of Ingham et al. (2009), for the low resistivities observed at 0.2-2 km depth below the surface beneath Ruapehu summit.

\begin{tabular}{|c|c|c|c|}
\hline Layer & $\begin{array}{l}\text { Velocity } \\
(\mathbf{k m} / \mathbf{s})\end{array}$ & $\begin{array}{c}\text { Bottom } \\
\text { depth }(\mathbf{k m})\end{array}$ & Interpretation \\
\hline 1 & 0.9 & 0.2 & Recent, unconsolidated tephra / loose eroded material \\
\hline 2 & 1.2 & 1.5 & $\begin{array}{l}\text { Layers of fluid-filled volcanic deposits with some hydrothermal } \\
\text { alteration }\end{array}$ \\
\hline 3 & 1.4 & 3 & $\begin{array}{l}\text { More compacted volcanic deposits and highly fractured/ altered } \\
\text { material of the geothermal system with small magma intrusions }\end{array}$ \\
\hline Halfspace & 1.7 & - & $\begin{array}{l}\text { Hot, highly fractured/altered material of the geothermal system and } \\
\text { larger magma intrusions }\end{array}$ \\
\hline
\end{tabular}

Table 6.4: Simplified $V_{S}$ model of Ruapehu with geological interpretation

Across the best profiles the layer depths vary, however we think they do not accurately reflect depths of impedance contrasts, but rather an overall increasing velocity with depth. This is because the velocity changes across the layers are so small, and inversion of our synthetic dispersion showed that our inversion procedure is unlikely to resolve small impedance contrasts (section 6.1.3). Consequently, we generate a simplified $\mathrm{V}_{S}$ model for Ruapehu (Table 6.4, Fig. 6.6). Due to the large misfits of the oriented averages' inversions, we do not consider their profiles when making the simplified model.

Slow layers $\left(\mathrm{V}_{S}<1.4\right)$ have been observed at 1-2 km depth in multiple profiles, some of which have been interpreted as low velocity volcanic material (Fig. 6.6, Olson, 1985; Latter, 1981b, Dibble et al., 1995 and Hurst, 1998). However, in the majority of our inversions, we do not observe the large impedance contrasts between the slow volcanic material and faster basement greywacke present at approximately $2-3 \mathrm{~km}$ depth in most of the models. If the inversion of the N-S oriented averages does reflect a shallower contact with the basement, it is possible that beneath Ruapehu summit, the greywacke is deeper than the depths to which our dispersion curves are sensitive. 


\subsubsection{Tongariro}

With the exception of the total average L0- and both oriented-average inversions, the Tongariro $\mathrm{V}_{S}$ best-profiles have greater velocity variation with depth than at Ruapehu. However, common to all Tongariro profiles (with the exception of the OTVZ-WTVZ R0 inversion), is the same low velocity, $200 \mathrm{~m}$ thick layer at the surface observed at Ruapehu.

\begin{tabular}{|c|c|c|c|}
\hline Layer & $\begin{array}{c}\text { Velocity } \\
(\mathbf{k m} / \mathbf{s})\end{array}$ & $\begin{array}{c}\text { Bottom } \\
\text { depth }(\mathbf{k m})\end{array}$ & Interpretation \\
\hline 1 & 1 & 0.2 & Recent, unconsolidated tephra / loose eroded material \\
\hline 2 & 1.5 & 1 & $\begin{array}{l}\text { Highly fractured, predominantly liquid-filled volcanic deposits } \\
\text { (condensate) }\end{array}$ \\
\hline 3 & 1.7 & 2 & $\begin{array}{l}\text { Highly fractured material transitioning from fluid- to vapour } \\
\text { dominanted reservoir }\end{array}$ \\
\hline 4 & 2 & 3 & Highly fractured vapour dominanted reservoir \\
\hline Halfspace & 2.5 & - & Altered greywacke and magma intrusions \\
\hline
\end{tabular}

Table 6.5: Simplified $V_{S}$ model of Tongariro with geological interpretation

Combining the results of the R0, L0 and R0L0 OTVZ-WTVZ inversions and the totalaverage R0 and R0L0 inversions, we make a simplified $\mathrm{V}_{S}$ model of Tongariro (Table 6.5, Fig. 6.6). Although it has no features in common with the Jolly et al. (2012b) profile for Ngauruhoe, our simplified model resembles a smoothed and vertically elongated version of the Jolly et al. (2014b) profile (Fig. 6.6). The Jolly et al. (2014b) profile was calculated based upon high-impact helicopter mass drops on the northern flanks of Mount Tongariro, near the Te Maari Craters (north-easternmost two vents of Tongariro in Fig. 4.1). Variation between the elevations of the drop sites with respect to the Mount Tongariro topography may be the source of the depth discrepancies between our simplified model and the Jolly et al. (2014b) profile.

Hagerty and Benites (2003) present a 2D (oriented approximately N-S) structural model of Mount Tongariro derived from magnetotelluric and DC resistivity measurements by Walsh et al. (1998). In this model there is a laterally varying, 300-500 m thick condensate layer at depths of 200-500 m across Mount Tongariro, but extending to the surface at Ketetahi Hot-Springs (north-westernmost vent at Tongariro in Fig. 4.1). Below the 
condensate, Walsh et al. (1998) and Hagerty and Benites (2003) think there is a vapour dominated reservoir at least $1 \mathrm{~km}$ thick, largely extending to depths greater than their maximum resolution. Jolly et al. (2014a) also infer the presence of a liquid condensate overlying a gas dominated reservoir in their investigation of the source processes of the 2012 Te Maari eruptions. We think that the layers of our simplified model, broadly correlate with these regions of Tongariro's geothermal system; however, we think that the halfspace of our model reflects the presence of altered greywacke.

\subsection{Anisotropic velocity structure of the $\mathrm{TgVC}$}

The misfits of the joint R0L0 inversions show that isotropic velocity models cannot explain the variation between the velocities of vertically and horizontally polarised shear-waves (SV and $\mathrm{SH}$-waves) that comprise surface-waves (section 3.1). A discrepancy between $\mathrm{V}_{S V}$ and $\mathrm{V}_{S H}$ is well documented (e.g. Endrun et al., 2008), and typically attributed to radial anisotropy (Anderson, 1961). In the mantle and lower crust, positive radial anisotropy is generally observed (where Rayleigh waves are slower than Love waves, e.g. Behr et al., 2010). However, the recurring observation in our velocity measurements and models is that Love waves travel slower than Rayleigh waves in the TgVC. Furthermore, the Love-Rayleigh discrepancy varies with station pair.

To illustrate the differences between Love and Rayleigh-wave group velocities, we compute the difference between the two dispersion measurements (at all overlapping frequencies) of the same mode and station pair. We refer to these difference curves as $\Delta \mathrm{LR}$, which are positive for positive radial anisotropy (Love $>$ Rayleigh) and are termed $\Delta \mathrm{L} 0 \mathrm{R} 0$ and $\Delta \mathrm{L} 1 \mathrm{R} 1$ for fundamental and higher-order modes, respectively. Although Rayleigh and Love waves have different depth sensitivities, the $\Delta \mathrm{LR}$ curves allow us to compare the differences' magnitude for different frequencies, modes, areas, time periods or components. We also determine $\Delta \mathrm{LR}$ for our synthetic dispersion curves (section 5.3), which were calculated under the assumption of isotropy.

\subsubsection{All A-grade measurements}

First, we plot the $\Delta \mathrm{L} 0 \mathrm{R} 0$ and $\Delta \mathrm{L} 1 \mathrm{R} 1$ from the TT-RR and TT-ZZ components for 2001 and 2008 (Fig. 6.7). Although there are more $\Delta$ L0R0 in 2001, there do not appear to be significant differences in the distribution of $\Delta$ LR between 2001 and 2008. 
There are very few $\Delta \mathrm{LR}$ measurements above $+0.5 \mathrm{~km} / \mathrm{s}$ and the number of curves significantly decreases below $-0.5 \mathrm{~km} / \mathrm{s}$, with the exception of the $\Delta \mathrm{L} 0 \mathrm{R} 0 \mathrm{TT}-\mathrm{RR}$. For both modes and components, an overwhelming proportion of $\Delta \mathrm{LR}$ measurements are negative and vary little above $0.4 \mathrm{~Hz}$. Below $0.4 \mathrm{~Hz}$, there are two trends. Most measurements have $\Delta \mathrm{LR}$ becoming more negative with increasing frequency (negative-trend), however, some (mostly $\Delta$ L0R0 TT-RR) do the opposite (positive-trend). For many of the positive-trend measurements, $\Delta \mathrm{LR}>0$ above $0.4 \mathrm{~Hz}$, up to $+0.25 \mathrm{~km} / \mathrm{s}$, and their steep gradients start to plateau around $0.5 \mathrm{~Hz}$.

Differences between Love and Rayleigh wave group velocities

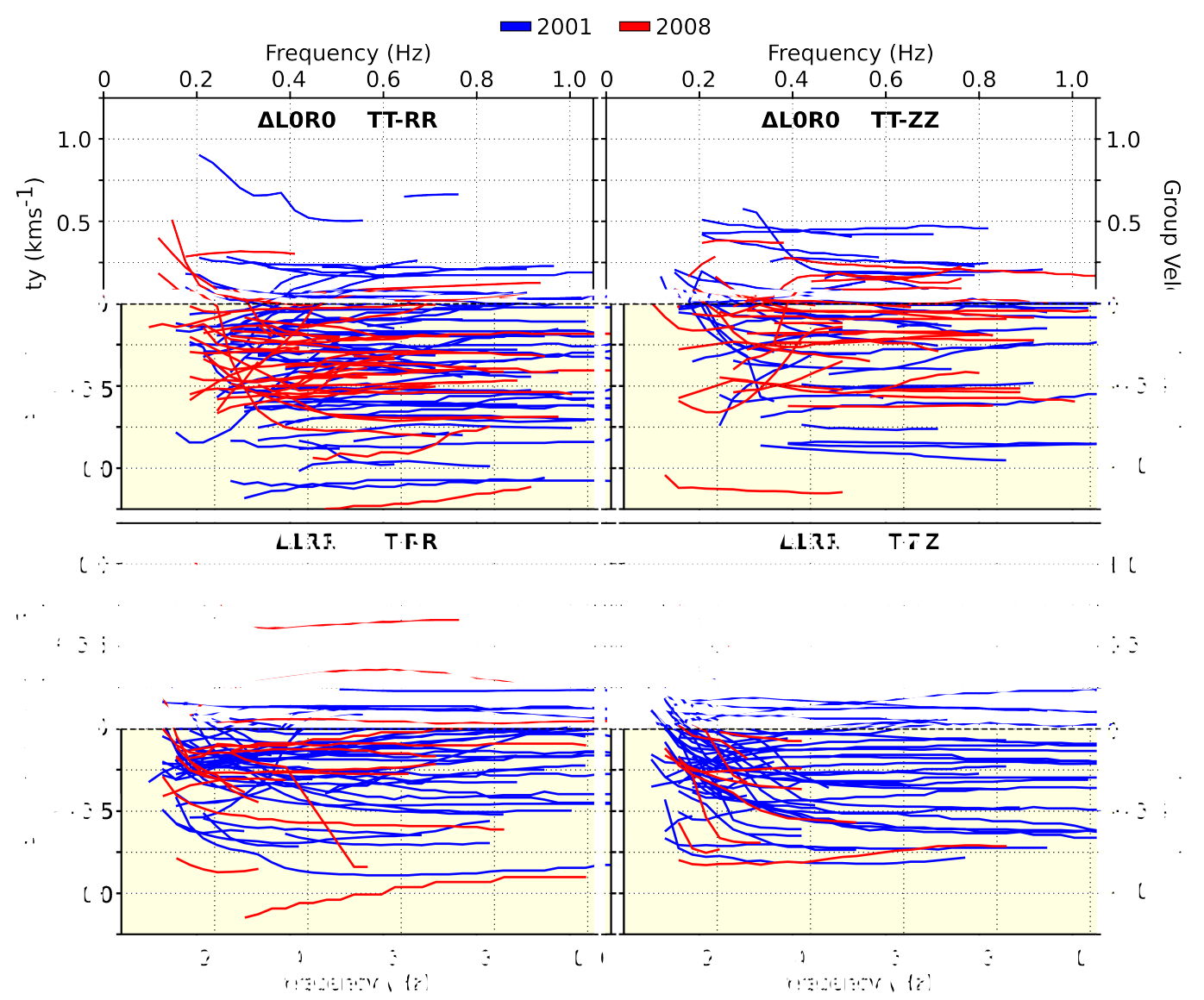

Figure 6.7: Differences between Love- and Rayleigh group velocities, separated by mode, year and component for station pairs with A-grade TT and RR/ZZ dispersion measurements

The negative-trend gradients below $0.4 \mathrm{~Hz}$ suggest that for most of our data, $\Delta \mathrm{LR}$ decreases with depth. If the Love-Rayleigh discrepancy is due to radial anisotropy in the $\mathrm{TgVC}$, then this trend would indicate that the magnitude of the radial anisotropy decreases with depth. However, as previously stated, our dispersion measurements may be contaminated with mode jumping below $0.3 \mathrm{~Hz}$. 
We consider large absolute values of $\Delta \mathrm{LR}$ that are sustained over a large frequency range to be geologically unreasonable, as they infer a very high percent anisotropy. We do not think the measurements where $\Delta \mathrm{LR}$ values greater/less than $0.5 \mathrm{~km} / \mathrm{s}$ are sustained across the frequency range to be correct, but rather examples where one of the curves' modes has been incorrectly identified. This is because this difference is similar that observed between the $\mathrm{R} 0$ and $\mathrm{R} 1$ dispersion of our primary pairs (section 5.4). If large $\Delta \mathrm{LR}$ are due to incorrect mode identification, positive outliers would correspond to $\Delta \mathrm{L} 1 \mathrm{R} 0$, and negative would be $\Delta \mathrm{L} 0 \mathrm{R} 1$.

\subsubsection{Comparison to synthetic dispersion curves}

$\Delta$ LR curves of our synthetic dispersion curves are similar for the JR and FR models, but are different to the $\Delta \mathrm{LR}$ of the majority of our real data. With increasing frequency, the synthetic $\Delta \mathrm{L} 0 \mathrm{R} 0$ curves (Fig. 6.8, solid blue/purple lines) begin positive and steeply decrease to $-0.75 \mathrm{~km} / \mathrm{s}$ at $0.2 \mathrm{~Hz}$. Then, they increase to +0.3 at approximately $0.4 \mathrm{~Hz}$ and gently decrease towards 0 . The large, negative $\Delta \mathrm{L} 0 \mathrm{R} 0$ values likely reflect the different depth sensitivities of Love- and Rayleigh-waves and the different frequencies at which there are sharp inflections in the curves. As we think our dispersion measurements largely smooth over the inflections of the curves, large $\Delta \mathrm{L} 0 \mathrm{R} 0$ values at $0.2 \mathrm{~Hz}$ in the dispersion measurements are likely to be unrelated.

The synthetic $\Delta \mathrm{L} 1 \mathrm{R} 1$ curves (Fig. 6.8 , solid green/orange lines) are positive below 0.5 Hz. Above $0.5 \mathrm{~Hz}$, they decrease rapidly to approximately $-0.6 \mathrm{~km} / \mathrm{s}$, before increasing towards zero. None of our real $\Delta \mathrm{LR}$ measurements resemble the synthetic $\Delta \mathrm{L} 1 \mathrm{R} 1$, primarily because our L1 dispersion measurements do not contain the steep velocity gradients of synthetic L1 dispersion.

The synthetic $\Delta \mathrm{L} 0 \mathrm{R} 1$ and $\Delta \mathrm{L} 1 \mathrm{R} 0$ curves do not have characteristics that would automatically identify them as using a misidentified mode. Above $0.6 \mathrm{~Hz}$, the FR model $\Delta \mathrm{L} 1 \mathrm{R} 0$ is almost identical to the $\Delta \mathrm{L} 0 \mathrm{R} 0$ curves (Fig. 6.8, dotted and solid blue lines, respectively). The synthetic JR-model $\Delta \mathrm{L} 0 \mathrm{R} 1$ curve is at approximately $-0.4 \mathrm{~km} / \mathrm{s}$ at $0.4-$ $0.8 \mathrm{~Hz}$ (Fig. 6.8 , dotted purple line); however, the synthetic $\Delta \mathrm{L} 0 \mathrm{R} 0$ and $\Delta \mathrm{L} 1 \mathrm{R} 1$ are more negative than that at $<0.3 \mathrm{~Hz}$ and $>0.75 \mathrm{~Hz}$, respectively. 


\section{Differences between synthetic dispersion curves}

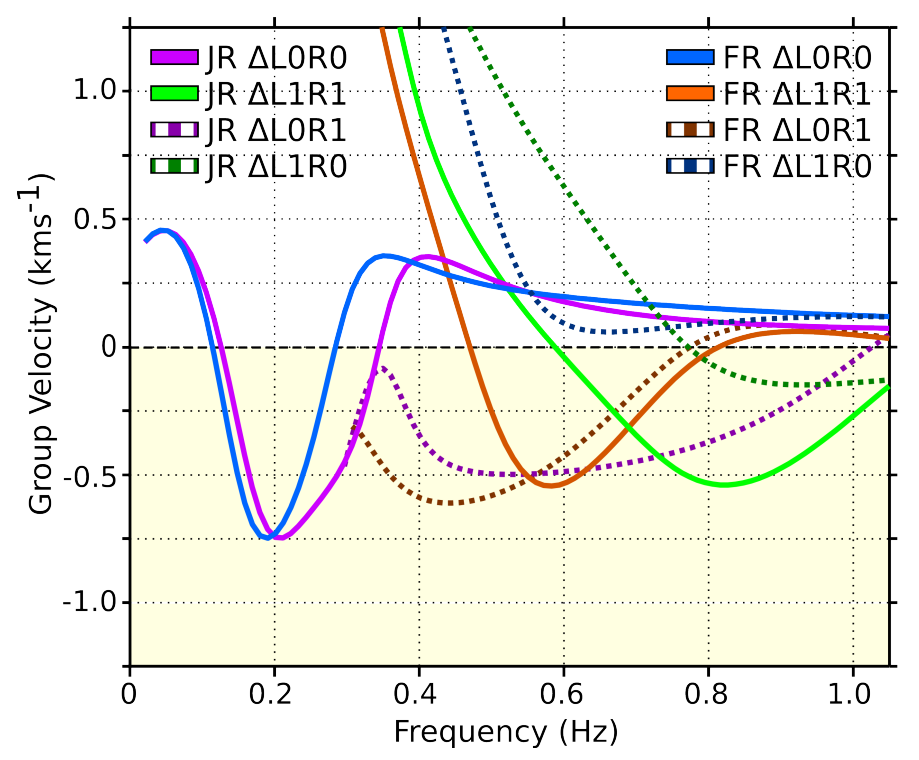

Figure 6.8: Differences between synthetic Love- and Rayleigh-wave dispersion curves. Solid lines are $\Delta L R$ for two curves with the same mode, dashed lines are different modes.

\subsubsection{Spatial variation}

We make maps of $\Delta \mathrm{L} 0 \mathrm{R} 0$ and $\Delta \mathrm{L} 1 \mathrm{R} 1$ at $0.5 \mathrm{~Hz}$ and $1 \mathrm{~Hz}$ from station pairs. There are very few $\Delta \mathrm{L} 0 \mathrm{R} 0$ and $\Delta \mathrm{L} 1 \mathrm{R} 1$ measurements at $1 \mathrm{~Hz}$ in 2008 (Fig. 6.9, 6.10). Overall, $\Delta \mathrm{L} 0 \mathrm{R} 0$ measurements tend to be for station pairs more closely spaced than the $\Delta \mathrm{L} 1 \mathrm{R} 1$ measurements, the majority of which involve stations located on greywacke (Fig. 4.1).

The magnitude of $\Delta \mathrm{L} 0 \mathrm{R} 0$ and $\Delta \mathrm{L} 1 \mathrm{R} 1$ at 0.5 and $1 \mathrm{~Hz}$ appears to be mostly spatially random. However, $\triangle \mathrm{L} 0 \mathrm{R} 0$ and $\Delta \mathrm{L} 1 \mathrm{R} 1$ measurements involving $\mathrm{S} 16$ (at the edge of the greywacke ranges in the east), tend to be more positive than the rest of the measurements.

There are a number of station pairs across both modes that have $\Delta \mathrm{LR}<-0.9$, which we have already discussed as likely due to poor mode identification. However, none of these pairs cross Ruapehu or Tongariro in a way that includes them in our average dispersion curves (section 5.5). 
Difference between fundamental mode Love and Rayleigh group velocities

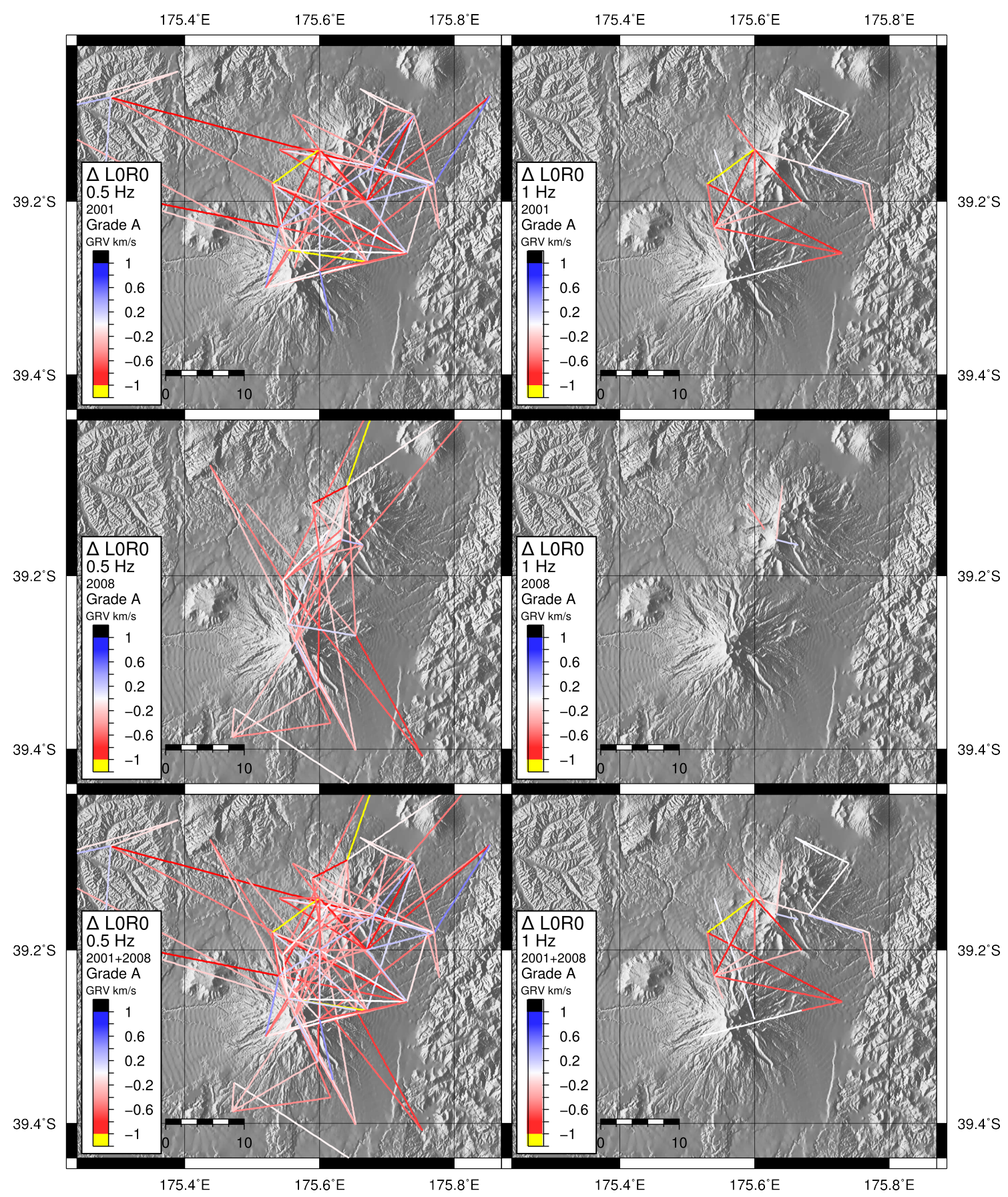

Figure 6.9: Map of $\triangle L 0 R 0$ of A-grade dispersion measurements, plotted by interstation path and coloured by magnitude. Left and right plots are $0.5 \mathrm{~Hz}$ and $1 \mathrm{~Hz}$, respectively, top, middle and bottom are 2001, 2008 and 2001+2008, respectively 
Difference between higher mode Love and Rayleigh group velocities

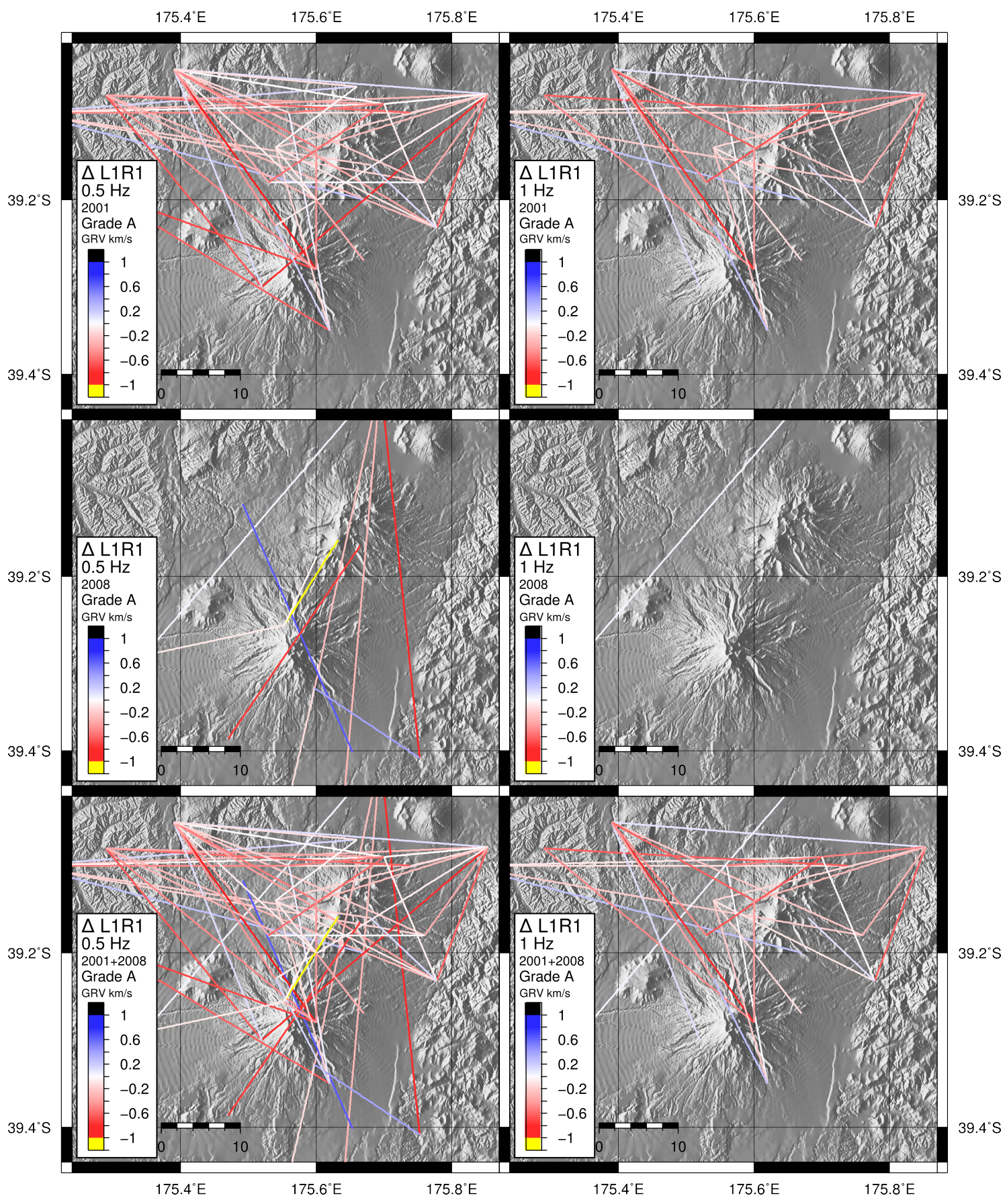

Figure 6.10: Map of $\triangle L 1 R 1$ of A-grade dispersion measurements, plotted by interstation path and coloured by magnitude. Left and right plots are $0.5 \mathrm{~Hz}$ and $1 \mathrm{~Hz}$, respectively, top, middle and bottom are 2001, 2008 and 2001+2008, respectively 


\subsubsection{Comparison to other ambient noise studies}

Concentrating on periods longer than 5s and using stations from across the TVZ, Behr et al. (2011) measured Love-wave group velocities to be slower than Rayleigh-wave velocities at $0.5-1 \mathrm{~Hz}$. Their L0 velocities were $2.1-2.3 \mathrm{~km} / \mathrm{s}$ and $1.8-2.2 \mathrm{~km} / \mathrm{s}$ at 0.5 and $1 \mathrm{~Hz}$, respectively, whereas their $\mathrm{R} 0$ velocities at those frequencies were $2.3-2.4 \mathrm{~km} / \mathrm{s}$ and $2.3-2.5$ $\mathrm{km} / \mathrm{s}$. These velocity ranges are faster than that of our R0 and L0 measurements (Table 6.3), likely because Behr et al. (2011) averaged over a much larger area than we did.

The $0.3 \mathrm{~Hz}$ record sections for Uturuncu Volcano (Bolivia) presented by Jay et al. (2012) show moveout, which although scattered, suggest that fundamental mode Rayleigh waves may travel slightly faster or equal to the fundamental mode Love waves.

At Piton de la Fournaise (PdF), average L0 group velocities measured by Mordret et al. (2015) are slower than R0 group velocities. Although their dispersion averages between $0.17-1 \mathrm{~Hz}$ have error on the order of $30 \%$, and their is R0 and L0 uncertainty limits overlap, there is statistical significance in the difference between the two means at $99 \%$ confidence.

In their subsequent inversion for radial anisotropy, between 1.5-6 km depth, Mordret et al. (2015) observe negative anisotropy, reaching $-5 \%$ at $2-4 \mathrm{~km}$, which they interpret as the volcanic structure being dominated by vertical dyke intrusions. However, they also observe strong positive anisotropy at $0-1.5 \mathrm{~km}$ depth, peaking at $+10 \%$ at $200 \mathrm{~m}$, which they interpret as the effect of horizontal layering of lava flows.

\subsubsection{Ruapehu and Tongariro Volcanoes}

We observe variation of $\mathrm{R} 0$ and $\mathrm{L} 0$ group velocities, and $\Delta \mathrm{L} 0 \mathrm{R} 0$ measurements with path orientation across Ruapehu and Tongariro volcanoes. We can define relationships between horizontally and vertically polarised shear-wave velocities based upon this variation. 


\section{Differences between A-grade RO/LO measurements}

a) Ruapehu Volcano
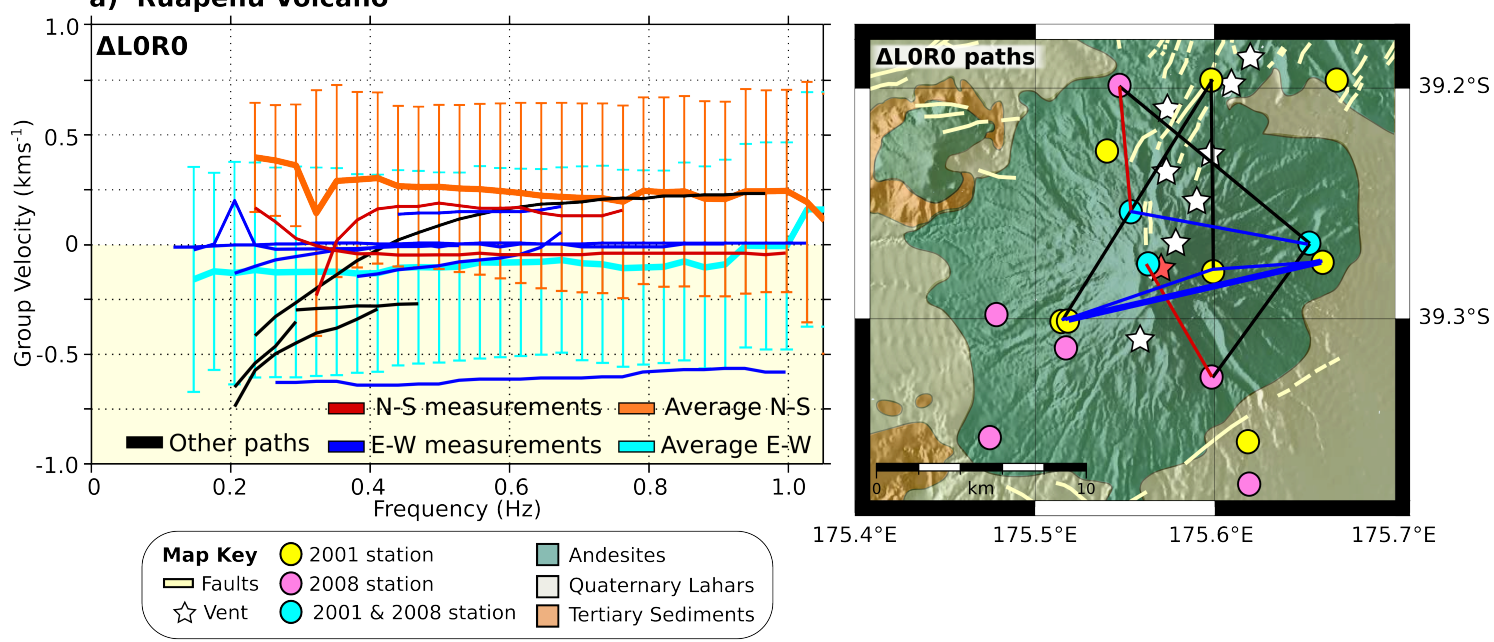

b) Tongariro Volcano

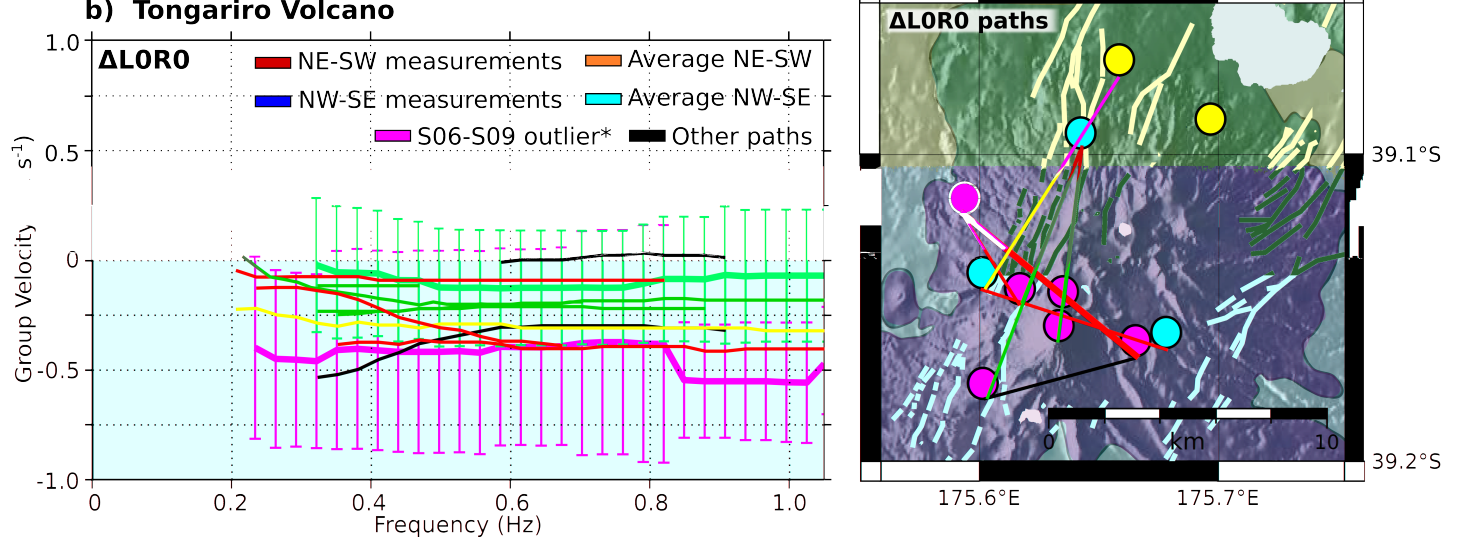

Figure 6.11: Differences between LO and RO dispersion measurements for individual station pairs (coloured by interstation path orientation and shown on map) and oriented averages with uncertainty for: a) Ruapehu; b) Tongariro.

\subsubsection{Ruapehu}

Overall, at Ruapehu volcano, most individual station pair $\Delta \mathrm{L} 0 \mathrm{R} 0$ measurements are positive-trending ( $\Delta \mathrm{L} 0 \mathrm{R} 0$ (Fig. 6.11a). This suggests that at shallow depths (high frequencies), horizontal layering is the most significant factor in the relative SV and $\mathrm{SH}$ velocities $\left(\mathrm{V}_{S V}, \mathrm{~V}_{S H}\right)$, while at greater depths (low frequencies), vertical structures, such as dykes or cracks, may become increasingly dominant, as $\Delta \mathrm{L} 0 \mathrm{R} 0$ becomes increasingly negative. Mordret et al. (2015) make the same interpretation of their positive and negative radial anisotropy anomalies at PdF. 
The observations of relative shear-wave velocities from our dispersion measurements are:

1. E-W propagating $\mathrm{V}_{S V}>\mathrm{N}-\mathrm{S}$ propagating $\mathrm{V}_{S V}$

Reason: E-W R0 group velocities are faster than N-S R0 group velocities (section 5.5.1.2, Fig. 5.28).

Disclaimer: Their difference is statistically significant only below $0.5 \mathrm{~Hz}$ at $95 \%$ confidence.

2. N-S propagating $\mathrm{V}_{S H}>\mathrm{E}-\mathrm{W}$ propagating $\mathrm{V}_{S H}$

Reason: N-S L0 group velocities are faster than E-W L0 group velocities (Fig. 5.28).

Disclaimer: Their difference is statistically significant below only $0.2 \mathrm{~Hz}$ at $95 \%$ confidence.

3. N-S propagating $\mathrm{V}_{S H}>\mathrm{N}-\mathrm{S}$ propagating $\mathrm{V}_{S V}$

Reason: N-S $\Delta$ L0R0 is positive (Fig. 6.11).

Disclaimer: Their difference is statistically significant only below $0.3 \mathrm{~Hz}$ at $95 \%$ confidence.

4. E-W propagating $\mathrm{SH}>\mathrm{E}-\mathrm{W}$ propagating $\mathrm{V}_{S V}$

Reason: E-W $\Delta \mathrm{L} 0 \mathrm{R} 0$ is negative (Fig. 6.11).

Disclaimer: The difference is not statistically significant at any frequency at $95 \%$ confidence.

\subsubsection{Tongariro}

Overall, all but two of the individual $\Delta \mathrm{L} 0 \mathrm{R} 0$ measurements at Tongariro are negativetrend (Fig. 6.11b). Most $\Delta \mathrm{L} 0 \mathrm{R} 0$ measurements are only slightly negative below $0.4 \mathrm{~Hz}$, indicating that the dominance of vertical structures over horizontal layering decreases with depth.

The observations of relative shear-wave velocities from our dispersion measurements are (numbering continued from Ruapehu observations):

5. NE-SW propagating $\mathrm{V}_{S V}<\mathrm{NW-SE}$ propagating $\mathrm{V}_{S V}$

Reason: NW-SE R0 group velocities are faster than NE-SW R0 group velocities (section 5.5.2.2, Fig. 5.32). 
Disclaimer: The difference is statistically significant (at $95 \%$ confidence) only at frequencies below $0.75 \mathrm{~Hz}$.

6. NE-SW propagating $\mathrm{V}_{S H} \approx \mathrm{NW}-\mathrm{SE}$ propagating $\mathrm{V}_{S H}$

Reason: NE-SW L0 group velocities are the same as NW-SE L0 group velocities (, Fig. $5.32)$.

7. NW-SE propagating $\mathrm{V}_{S V}>\mathrm{NW}-\mathrm{SE}$ propagating $\mathrm{V}_{S H}$

Reason: NW-SE $\Delta \mathrm{L} 0 \mathrm{R} 0$ is negative (Fig. 6.11).

Disclaimer: The difference is only statistically significant (at $95 \%$ confidence) below 0.7 $\mathrm{Hz}$ and above $0.85 \mathrm{~Hz}$.

8. NE-SW propagating $\mathrm{V}_{S V}>$ NE-SW propagating $\mathrm{V}_{S H}$

noindent Reason: NE-SE $\Delta \mathrm{L} 0 \mathrm{R} 0$ is negative (Fig. 6.11).

Disclaimer: The difference is not significant at $95 \%$ confidence.

\subsubsection{Orthorhombic anisotropy}

Our observations of the variation of $\mathrm{V}_{S H}$ and $\mathrm{V}_{S V}$ at Ruapehu and Tongariro have two implications. First, the velocity structure of the $\mathrm{TgVC}$ is both radially and azimuthally anisotropic, i.e. anisotropy has orthorhombic symmetry (e.g. Fig. 6.12). This means that the fourth-order tensor that describes the elastic properties of the material has nine independent coefficients, rather than two or six, which describe isotropy and hexagonal anisotropy, respectively (e.g. Babuška and Cara, 1991). Radial anisotropy is hexagonal anisotropy with a vertical axis, whereas azimuthal anisotropy is hexagonal with a horizontal axis (Savage, 1999).

Second, anisotropy is spatially heterogeneous across the TgVC. Our observations suggest that the orientations of the horizontal symmetry axes at Ruapehu and Tongariro Volcanoes are different. Furthermore, the relationship between $\mathrm{V}_{S V}$ and $\mathrm{V}_{S H}$ also differ across the $\mathrm{TgVC}$ (section 6.3.1). 


\section{Structure with orthorhobmic anisotropy}

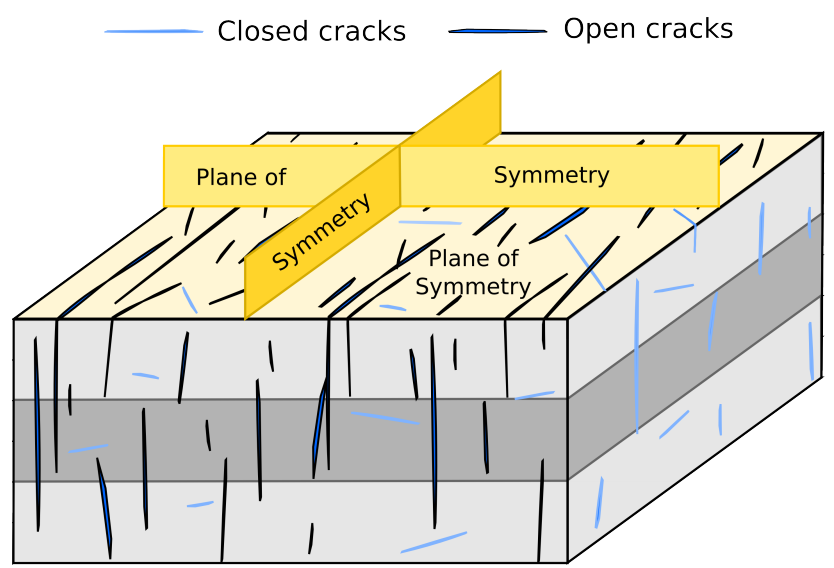

Figure 6.12: Schematic of subsurface structure with orthorhomic anisotropy with three planes of symmetry

\subsection{Final models and interpretations}

We use our observations of the relationships between $\mathrm{V}_{S V}$ and $\mathrm{V}_{S H}$ to characterise the influence of vertical cracks and dykes, compared to horizontal layering on surface-wave propagation. We also incorporate our simplified isotropic $\mathrm{V}_{S}$ profiles into our interpretation (Fig. 6.13).

The top $200 \mathrm{~m}$ of both volcanoes is very slow, and likely reflects recent, unconsolidated tephras and material that has eroded from the complexes.

We think that shallow structure at Ruapehu is characterised by several thin layers of volcanic deposits (Fig. 6.13a). Layers have low $\mathrm{V}_{S}$, likely due to the presence of fluid, hydrothermally altered materials and volcanic heat. Layering has a strong influence on $\mathrm{V}_{S V}$, which is slower than $\mathrm{V}_{S H}$. The orientation of open fluid-filled cracks creates discrepancies between $\mathrm{V}_{S H}$ of waves propagating in different directions.

At Tongariro, vertical structures affect anisotropy more than horizontal layering (Fig. $6.13 \mathrm{~b})$, resulting in $\mathrm{V}_{S V}>\mathrm{V}_{S H}$. The alignment of these vertical structures, likely fluidfilled cracks and faults, is spatially heterogeneous around Tongariro. Shear-wave velocities increase with depth; volcanic deposits are underlain by a liquid filled material, above gasfilled material, and then altered basement greywacke. 


\section{Structural models with orthorhobmic anisotropy}

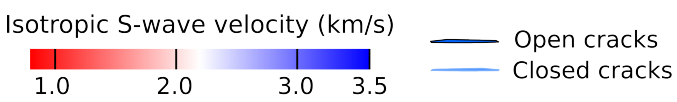

a) Ruapehu

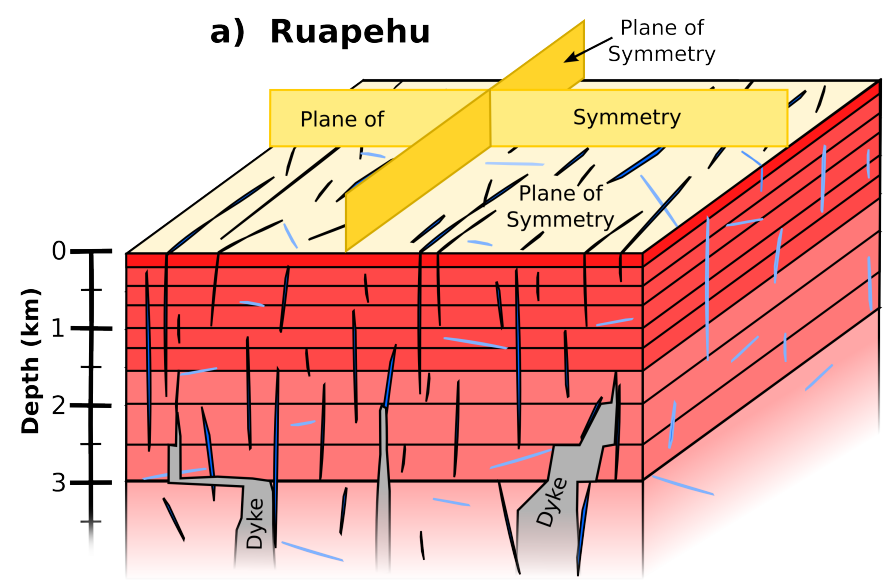

b) Tongariro

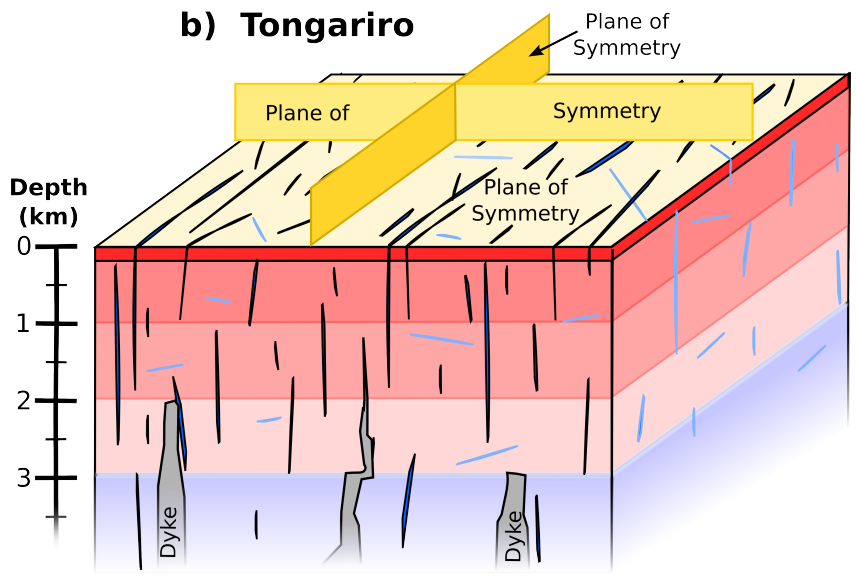

Figure 6.13: Final models of the seismic velocity structure of: a) Ruapehu Volcano; b) Tongariro Volcano. Isotropic $V_{S}$ from simplified $1 D$ profiles 6.2.2 are projected onto the horizontal layers. 


\section{Chapter 7}

\section{Summary and conclusions}

\subsection{Fulfilment of project aims}

We have realised the three primary aims of this research, which we first outlined in chapter 1.

- Create a database of daily, reference CCF for all possible seismograph station pairs and components, operating in 2001 (Jan-June) and 2008.

The database contains $1,048,968$ daily CCF, with 7458 full-stacks for 955 viable station pairs during the two periods (437 in 2001, 518 in 2008).Cross-correlation quality varies across the networks, with some pairs (particularly those involving a station with a Guralp 3ESP sensor) possibly containing timing errors, resulting in poor quality full-stacks. Daily CCF of pairs from the START deployment in 2001 are high quality and temporally stable, making full-stacks with high SNR (sections 5.1, 6.1.1).

- Measure group velocity dispersion of Rayleigh- and Love waves in the TgVC.

We measured dispersive phases in 3646 of the 4235 symmetric RR, RZ, TT, ZR and ZZcomponent full-stacks for which we performed MFT analyses, with 2641 measurements classed as grade A or A2 (section 5.2.1). We did not make phase corrections to the RZ and ZR CCF prior to dispersion analysis, but later applied $1 / 4$ wavelength subtraction from the ZZ component. Overall, we found that Love-wave measurements (from TT component 
$\mathrm{CCF})$ are better quality than Rayleigh-wave measurements ( $\mathrm{R} / \mathrm{Z}$ components), potentially due to higher diffusivity in the noise field, as observed by Savage et al. (2013) and Behr et al. (2013) (section 6.1.1).

Correctly identifying the modes associated with our dispersion measurements was challenging, particularly distinguishing between group velocity ranges that reflect structural hetorgeneity or the presence of multiple modes. We observed multiple dispersive phases in approximately $1 / 4$ of our MFT analyses (on all five components). However, in $83 \%$ of the measurements, we were unable to confidently assign the mode (section 5.2.1).

We assigned modes to over 1939 RR, ZZ and TT dispersion measurements, primarily by using the station-grouping method (section 5.2.2), where we plot all RR/ZZ or TT dispersion measurements involving a specific station, and look at clustering and the nearstation geology to define group velocity ranges for different modes (section 4.4.1). Of these, 1373 measurements are grade A or A2.

We used standard deviations as our dispersion curve uncertainty. Individual station pair measurements (broken up into 4-6 time blocks), have very low uncertainties (on the order of a few percent), however, the uncertainties of most of our average dispersion curves for Ruapheu and Tongariro Volcanoes are on the order of 10-20\% (section 6.1.1).

For most station pairs containing Love- and Rayleigh-wave dispersion measurements, we observe Love-wave group velocities to be slower than Rayleigh-wave velocities, although the difference between the two diminishes at lower frequencies (sections 5.2.3, 5.5, 6.3). We also observe some measurements where $\Delta \mathrm{LR}$ is positive at high frequencies but is increasingly negative with decreasing frequency (section 6.3). The latter trend is similar to what we observe from the differences between our synthetic dispersion curves, which were calculated for isotropic layers above a halfspace (sections 5.3, 6.3.1.1).

- Construct and interpret 1D S-wave velocity models of Ruapehu and Tongariro Volcanoes.

We inverted our dispersion measurements to make R0, L0 and R0L0 inversions for primary pairs S10-S28 (Ruapehu) and OTVZ-WTVZ (Tongariro, section 5.4)) and for average dispersion curves for the two volcanoes. We also isolated and averaged measurements with similar interstation path orientations (N-S and E-W at Ruapehu; NE-SW, NW-SE at 
Tongariro) and made R0L0 inversions (section 5.5).

In almost all our $\mathrm{V}_{S}$ inversions at Ruapehu and Tongariro, we observe very slow velocities $(0.9-1 \mathrm{~km} / \mathrm{s})$ in the top $200 \mathrm{~m}$ of the crust, which we interpret as unconsolidated tephra or loose eroded material from the volcanoes (Fig. 6.6). Our Ruapehu profiles show little velocity variation with depth, suggesting that volcanic edifice is made of material that is compacting and being hydrothermally altered with depth, and that we are not sensitive to basement greywacke (section 6.2.2.1). At Tongariro, we observe larger increases in velocity with depth, which we interpret as different layers within Tongariro's volcanic system above basement greywacke (section 6.2.2.2).

At both volcanoes we observe discrepancies between measured Rayleigh and Love-wave group velocities $(\Delta \mathrm{L} 0 \mathrm{R} 0)$ that cannot be compensated for in $\mathrm{V}_{S}$ inversions when under the assumption of isotropy (sections 5.5, 6.3.2). Variation of $\Delta \mathrm{L} 0 \mathrm{R} 0$ with interstation path orientation indicates azimuthal anisotropy, whereas differences between R0 group velocites at different orientations indicate radial anisotropy (as do azimuthally variable L0 measurements). Anisotropy at Ruapehu and Tongariro Volcanoes therefore has orthorhombic symmetry (section 6.3.3).

\subsection{Fulfilment of research questions}

We began this project with three clear research questions. We think that our results and interpretations give answers to two of them.

\section{- What is the TgVC's S-wave velocity structure?}

Our group velocity maps and $\mathrm{V}_{S}$ profiles suggest that overall, the shallow $\mathrm{V}_{S}$ structure of the $\mathrm{TgVC}$ is very slow, with velocities comparable to other volcanoes around the world such as Piton de la Fournaise (la Reunion, Mordret et al., 2015). Furthermore, our results suggest that there is great lateral vairation in the $\mathrm{V}_{S}$ structure of the $\mathrm{TgVC}$ with depth.

The predominantly negative $\Delta \mathrm{L} 0 \mathrm{R} 0$ and $\Delta \mathrm{L} 1 \mathrm{R} 1$ measurements suggest that $\mathrm{V}_{S V}$ is greater than $\mathrm{V}_{S H}$ in the TgVC. We think this is due to structures such as dykes or cracks in the vertical plane having greater influence on wave propagation than horizontal layering. However, the presence of the few measurements with positive trending $\Delta \mathrm{LR}$ with increasing frequency suggests that in places, such as at the top of Mount Ruapehu, horizontal layering is the stronger influence (section 6.4). 
- How do our models compare to existing models and present geophysical understanding of the $\mathrm{TgVC}$, in particular the magnetotelluric surveys at Ruapehu?

In our Ruapehu models, the velocities of the uppermost layers of our $\mathrm{V}_{S}$ inversions and simplified model are similar to some of the existing 1D profiles (section 6.2.2.1). However, we do not observe the large impedence contrast of the volcanic material and the basement greywacke that is present in the majority of velocity profiles using other methods. We think this is because the contact is deeper than we can resolve from our data (section 6.1.3). We do observe such a boundary in most of our Tongariro models, likely because the topography of the volcano is lower than at Ruapehu, and consequently the greywacke is closer to the surface (section 6.5).

The uppermost $200 \mathrm{~m}$ thick slow layer at Ruapehu, which we interpret as unconsolidated tephra, correlates well with the highly resistivitive material inferred in the magntetotelluric surveys by Ingham et al. (2009) at the same depth range. Furthermore, the overall low $\mathrm{V}_{S}$ we observe throughout our Ruapehu profiles, which we attribute to hot, highly fractured and hydrothermally altered material, is concordant with their region of low resistivity at 0.2-2 km depth below Ruapehu summit (section 6.3.2.1).

The layer depths of our simplified Tongariro model broadly correlate with the changes in resistivity measured by Walsh et al. (1998). Our layer velocities for Tongariro are also similar to the recent profile by Jolly et al. (2014b). We think that the discrepancies between the layer depths of the Jolly et al. (2014) profile and our simplified model are due to the different topography at the centre of the model (section 6.3.2.2).

- On what scale can we observe temporal variation of surface- and shearwave velocities in the $\mathrm{TgVC}$ ?

We observe significant differences between our 2001 and 2008 datasets, such as the strength of the phases with moveout in our record sections (section 5.1, Figs. 5.1 \& 5.2). The signalto-noise ratios of the full-stacks for 2001 are also much higher than for 2008 (section 5.1.1. These differences, however, can be explained by variation of data quality, rather than changes in subsurface structure (section 6.1.1).

Between 2001 and 2008, we cannot detect changes in group velocities at $0.5 \mathrm{~Hz}$ and $1 \mathrm{~Hz}$, when mapped (section 5.B.3). However, differences in the station distribution and 
availability of high quality dispersion measurements makes comparison of the two time periods difficult.

We were unable to investigate potential temporal variation in our $\mathrm{V}_{S}$ inversions. The stations around Tongariro in 2001 yielded few A-grade dispersion measurements and there was a similar lack of data at Ruapehu in 2008. This means that we were unable to isolate the two time periods in our average dispersion curves or specific station locations to act as primary pairs.

\subsection{New questions}

Our results and interpretations provoke new questions. We think the following deserve thoughtful consideration.

- What fast/slow orientations of $\mathbf{S}_{V^{-}}$and $\mathbf{S}_{H^{-}}$waves can be derived for $\mathbf{R u}$ apehu and Tongariro from our surface-wave data, and how do they do they compare to previous research using SWS?

Further research, perhaps comparing more interstation path azimuths and performing anisotropic inversions, is required to characterise the fast/slow orientations of shear-waves and model the three-dimensional anisotropic structure of Ruapehu and Tongariro Volcanoes, as well as the wider TgVC.

- Are observations of isotropic velocities and/or orthorhombic anisotropy at Ruapehu and Tongariro temporally stable?

Previous research has shown that azimuthal anisotropy in the $\mathrm{TgVC}$ is temporally variable, which is generally attributed to stress changes and the orientation of open cracks (section 2.4.3). If the spatially varied radial anisotropy that we observe at Ruapehu and Tongariro is due to the relative dominance of horizontal layering and vertical cracks, could changes in crack aspect ratios cause measurable changes in radial anisotropy?

\subsection{Reflections and recommendations}

We have obtained very high quality CCF and dispersion measurements from broadband data spanning less than 20 days (NGA deployment). This means that data from other, short, broadband temporary deployments, may also yield quality results. However, our lower quality CCF using short-period sensors suggests that more than 1 year of stacked 
data is necessary to obtain robust Green's functions, similar to the findings of Mordret et al. (2015).

To further improve the quality of a dataset, we would compute SNR for all the 15 minute $\mathrm{CCF}$ that constitute the individual day stacks and only include those above a threshold value in the daily-stacks and full-stack. If large timing errors occurred throughout the day at a station, then the daily stack of all the 15 minute CCF would have a low SNR, and could be separated from the rest of the data.

The station-grouping method for classifying dispersion curve modes could be improved by using statistical clustering assessments rather than human eyes. The difficulty in distinguishing higher order modes from structural variability could further be addressed by examining the dispersion curves as a function of back-azimuth relative to the station being analysed. This may also yield interesting results on the orientational $\Delta$ LR measurements we observe.

Data from the 1994/1998/2002 deployments (which contain reoccupied sites) at Ruapheu would be ideal to use to investigate potential temporal variation in radial anisotropy using surface-waves, and the relationship to reported changes in azimuthal anistropy at those times.

Finally, ambient noise studies aimed at investigating subsurface velocity structure or surface-wave propagation should use data from the horizontal seismograph components, rather than solely focus on the vertical. 


\section{Bibliography}

- Aki, K., 1957. Space and time spectra of stationary stochastic waves, with special reference to microtremors. Bulletin of the Earthquake Research Institute, 35: 415-457.

Aki, K., and Richards, P.G., 2002. Quantitative Seismology, 2nd ed. University Science Books, 700 pp.

Anderson, D.L., 1961. Elastic wave propagation in layered anisotropic media. Journal of Geophysical Research, 66(9): 2953-2963.

Anderson, E.M., 1905. The dynamics of faulting. Transactions of the Edinburgh Geological Society, 8(3): 387-402.

Ardhuin, F., Stutzmann, E., Schimmel, M. and Mangeney, A., 2011. Ocean wave sources of seismic noise. Journal of Geophysical Research: Oceans (1978-2012), 116(C9).

Babuska, V. and Cara, M., 1991. Seismic Anisotropy in the Earth. Kluwer Academic Publishers, 217 pp.

Bannister, S., Bryan, C.J. and Bibby, H.M., 2004. Shear wave velocity variation across the Taupo Volcanic Zone, New Zealand, from receiver function inversion. Geophysical Journal International, 159(1): 291-310.

Behr, Y., 2011. Imaging New Zealand's crustal structure using ambient seismic noise recordings from permanent and temporary instruments. Awarded Doctoral Thesis, Victoria University of Wellington. 
Behr, Y., Townend, J., Bannister, S. and Savage, M.K., 2010. Shear velocity structure of the Northland Peninsula, New Zealand, inferred from ambient noise correlations. Journal of Geophysical Research: Solid Earth, 115(B5): B05309.

Behr, Y., Townend, J., Bannister, S. and Savage, M.K., 2011. Crustal shear wave tomography of the Taupo Volcanic Zone, New Zealand, via ambient noise correlation between multiple three-component networks. Geochemistry Geophysics Geosystems, 12.

Behr, Y., Townend, J., Bowen, M., Carter, L., Gorman, R., Brooks, L. and Bannister, S., 2013. Source directionality of ambient seismic noise inferred from three-component beamforming. Journal of Geophysical Research-Solid Earth, 118(1): 240-248.

Bensen, G., Ritzwoller, M., Barmin, M., Levshin, A., Lin, F., Moschetti, M., Shapiro, N. and Yang, Y., 2007. Processing seismic ambient noise data to obtain reliable broadband surface wave dispersion measurements. Geophysical Journal International, 169(3): 1239-1260.

Brenguier, F., Campillo, M., Takeda, T., Aoki, Y., Shapiro, N.M., Briand, X., Emoto, K. and Miyake, H., 2014. Mapping pressurized volcanic fluids from induced crustal seismic velocity drops. Science, 345(6192): 80-82.

Brenguier, F., Clarke, D., Aoki, Y., Shapiro, N.M., Campillo, M. and Ferrazzini, V., 2011. Monitoring volcanoes using seismic noise correlations. Comptes Rendus Geoscience, 343(8-9): 633-638.

Brenguier, F., Shapiro, N.M., Campillo, M., Ferrazzini, V., Duputel, Z., Coutant, O. and Nercessian, A., 2008. Towards forecasting volcanic eruptions using seismic noise. Nature Geoscience, 1(2): 126-130.

Brenguier, F., Shapiro, N.M., Campillo, M., Nercessian, A. and Ferrazzini, V., 2007. 3-D surface wave tomography of the Piton de la Fournaise volcano using seismic noise correlations. Geophysical Research Letters, 34(2).

Brooks, L.A., Townend, J., Gerstoft, P., Bannister, S. and Carter, L., 2009. Fundamental and higher-mode Rayleigh wave characteristics of ambient seismic noise in New Zealand. Geophysical Research Letters, 36(23): L23303. 
Bryan, C. and Sherburn, S., 1999. Seismicity associated with the 1995-1996 eruptions of Ruapehu volcano, New Zealand: narrative and insights into physical processes. Journal of volcanology and geothermal research, 90(1): 1-18.

Campbell, H. and Mortimer, N., 2014. Zealandia: Our Continent Revealed. Penguin Group New Zealand, Limited, 272 pp.

Campillo, M., 2006. Phase and Correlation in 'Random' Seismic Fields and the Reconstruction of the Green Function. Pure and Applied Geophysics, 163(2-3): 475-502.

Campillo, M. and Paul, A., 2003. Long-range correlations in the diffuse seismic coda. Science, 299(5606): 547-549.

Cassidy, J., Ingham, M., Locke, C.A. and Bibby, H., 2009. Subsurface structure across the axis of the Tongariro Volcanic Centre, New Zealand. Journal of Volcanology and Geothermal Research, 179(3): 233-240.

Christenson, B., 2000. Geochemistry of fluids associated with the 1995-1996 eruption of Mt. Ruapehu, New Zealand: signatures and processes in the magmatic-hydrothermal system. Journal of Volcanology and Geothermal Research, 97(1): 1-30.

Christenson, B., Reyes, A., Young, R., Moebis, A., Sherburn, S., Cole-Baker, J. and Britten, K., 2010. Cyclic processes and factors leading to phreatic eruption events: Insights from the 25 September 2007 eruption through Ruapehu Crater Lake, New Zealand. Journal of Volcanology and Geothermal Research, 191(1): 15-32.

Claerbout, J.F., 1968. Synthesis of a layered medium from its acoustic transmission response. Geophysics, 33(2): 264-269.

Clarke, D., Zaccarelli, L., Shapiro, N. and Brenguier, F., 2011. Assessment of resolution and accuracy of the Moving Window Cross Spectral technique for monitoring crustal temporal variations using ambient seismic noise. Geophysical Journal International, 186(2): $867-882$.

Cole, J. and Spinks, K., 2009. Caldera volcanism and rift structure in the Taupo Volcanic Zone, New Zealand. Geological Society, London, Special Publications, 327(1): 
9-29.

Cole, J.W., 1978. Andesites of the Tongariro volcanic centre, North Island, New Zealand. Journal of Volcanology and Geothermal Research, 3(1-2): 121-153.

Cole, J.W., 1990. Structural control and origin of volcanism in the Taupo volcanic zone, New Zealand. Bulletin of Volcanology, 52(6): 445-459.

Cole, J.W. and Nairn, I.A., 1975. Catalogue of the active volcanoes of the world including solfatara fields - Part 22, New Zealand, Naples, 156 pp.

Conway, C.E., Townsend, D.B., Leonard, G.S., Wilson, C., Calvert, A. and Gamble, J.A., 2015. Lava-ice interaction on a large composite volcano: a case study from Ruapehu, New Zealand. Bulletin of Volcanology, 77(3): 1-18.

Crampin, S., 1981. A review of wave motion in anisotropic and cracked elastic-media. Wave motion, 3(4): 343-391.

Cronin, S.J., 2015. Heat and gas influences on liquid sulphur viscosity - re-evaluating conditions for building gas overpressure and priming "blue sky" eruptions, Central Plateau Volcanic Advisory Group (CPVAG) meeting, 7 May 2015, Waiouru, New Zealand.

Crowly, J., 2015. Proximal-medial pyroclastic density current deposits at Mt Ruapehu, Central Plateau Volcanic Advisory Group (CPVAG) meeting, 7 May 2015, Waiouru, New Zealand.

Cupillard, P., Stehly, L. and Romanowicz, B., 2011. The one-bit noise correlation: A theory based on the concepts of coherent and incoherent noise. Geophysical Journal International, 184(3): 1397-1414.

Dibble, R., Olson, J. and Sissons, B., 1985. A seismic travel-time graph to $25 \mathrm{~km}$ from explosions in Ruapehu Crater Lake. New Zealand Volcanological Record: Volcano and Geothermal Observations 1983, 13: 62-65.

Donoghue, S. and Neall, V., 1996. Tephrostratigraphic studies at Tongariro volcanic centre, New Zealand: an overview. Quaternary international, 34: 13-20. 
Donoghue, S.L., Vallance, J., Smith, I.E. and Stewart, R.B., 2007. Using geochemistry as a tool for correlating proximal andesitic tephra: case studies from Mt Rainier (USA) and Mt Ruapehu (New Zealand). Journal of Quaternary Science, 22(4): 395-410.

Duputel, Z., Ferrazzini, V., Brenguier, F., Shapiro, N., Campillo, M. and Nercessian, A., 2009. Real time monitoring of relative velocity changes using ambient seismic noise at the Piton de la Fournaise volcano (La Réunion) from January 2006 to June 2007. Journal of Volcanology and Geothermal Research, 184(1): 164-173.

Durand, S., Montagner, J.P., Roux, P., Brenguier, F., Nadeau, R.M. and Ricard, Y., 2011. Passive monitoring of anisotropy change associated with the Parkfield 2004 earthquake. Geophysical Research Letters, 38(13): L13303.

Endrun, B., Meier, T., Lebedev, S., Bohnhoff, M., Stavrakakis, G. and Harjes, H.-P., 2008. S velocity structure and radial anisotropy in the Aegean region from surface wave dispersion. Geophysical Journal International, 174(2): 593-616.

Fah, D., 2010. Dispersion curve interpretation, Available from httop://www.geopsy.org/ wiki/index.php/Dispersion_curve_interpretation\#Mode_identification (last accessed October 2015).

Foti, S., Comina, C., Boiero, D. and Socco, L., 2009. Non-uniqueness in surfacewave inversion and consequences on seismic site response analyses. Soil Dynamics and Earthquake Engineering, 29(6): 982-993.

Fry, B., Davey, F., Eberhart-Phillips, D. and Lebedev, S., 2014. Depth variable crustal anisotropy, patterns of crustal weakness, and destructive earthquakes in Canterbury, New Zealand. Earth and Planetary Science Letters, 392: 50-57.

Fry, B., Deschamps, F., Kissling, E., Stehly, L. and Giardini, D., 2010. Layered azimuthal anisotropy of Rayleigh wave phase velocities in the European Alpine lithosphere inferred from ambient noise. Earth and Planetary Science Letters, 297(1): 95-102.

Gamble, J.A., Price, R.C., Smith, I.E., McIntosh, W.C. and Dunbar, N.W., 2003. $40 \mathrm{Ar} / 39 \mathrm{Ar}$ geochronology of magmatic activity, magma flux and hazards at Ruapehu Volcano, Taupo volcanic zone, New Zealand. Journal of volcanology and geothermal research, 
120(3): 271-287.

Gardner, G. H. F., L. W. Gardner, and Gregory, A.R., 1974. Formation velocity and density-the diagnostic basics for stratigraphic traps. Geophysics 39(6) : 770-780.

Gerst, A. and Savage, M.K., 2004. Seismic anisotropy beneath Ruapehu Volcano: A possible eruption forecasting tool. Science, 306(5701): 1543-1547.

Godfrey, H.J., Shelley, A. and Savage, M.K., 2014. Search for temporal changes in shear-wave splitting associated with the 2012 Te Maari Eruptions at Mount Tongariro, New Zealand. Journal of Volcanology and Geothermal Research, 286(0): 277-293.

Goldstein, P. and Snoke, A., 2005. SAC Availability for the IRIS Community, Incorporated Institutions for Seismology Data Management Center Electronic Newsletter.

Gouedard, P., Stehly, L., Brenguier, F., Campillo, M., Colin de Verdiere, Y., Larose, E., Margerin, L., Roux, P., Sanchez-Sesma, F.J. and Shapiro, N., 2008. Cross-correlation of random fields: mathematical approach and applications. Geophysical prospecting, 56(3): 375-393.

Graham, I.J., Cole, J.W., Briggs, R.M., Gamble, J.A. and Smith, I.E.M., 1995. Petrology and petrogenesis of volcanic rocks from the Taupo Volcanic Zone: a review. Journal of Volcanology and Geothermal Research, 68(1-3): 59-87.

Grandke, T., 1983. Interpolation algorithms for discrete Fourier transforms of weighted signals. Instrumentation and Measurement, IEEE Transactions on, 32(2): 350-355.

Hackett, W. and Houghton, B., 1989. A facies model for a Quaternary andesitic composite volcano: Ruapehu, New Zealand. Bulletin of volcanology, 51(1): 51-68.

Hagerty, M. and Benites, R., 2003. Tornillos beneath Tongariro Volcano, New Zealand. Journal of Volcanology and Geothermal Research, 125(1-2): 151-169.

Haney, M.M., Mikesell, T.D., van Wijk, K. and Nakahara, H., 2012. Extension of the spatial autocorrelation (SPAC) method to mixed-component correlations of surface waves. Geophysical Journal International, 191(1): 189-206. 
Havskov, J. and Alguacil, G., 2010. Instrumentation in earthquake seismology. Springer.

Healy, J., 1964. Volcanic mechanisms in the Taupo volcanic zone, New Zealand. New Zealand journal of geology and geophysics, 7(1): 6-23.

Herrmann, R.B., 2013. Computer programs in seismology: An evolving tool for instruction and research. Seismological Research Letters, 84(6): 1081-1088.

Hobden, B., Houghton, B., Davidson, J. and Weaver, S., 1999. Small and short-lived magma batches at composite volcanoes: time windows at Tongariro volcano, New Zealand. Journal of the Geological Society, 156(5): 865-868.

Hobden, B.J., Houghton, B.F. and Nairn, I.A., 2002. Growth of a young, frequently active composite cone: Ngauruhoe volcano, New Zealand. Bulletin of volcanology, 64(6): 392-409.

Horspool, N.A., 2003. Bending stress and faulting linked to the load of Ruapehu Volcano. Honor's Thesis Thesis, Victoria University of Wellington.

Houghton, B. and Hackett, W., 1984. Strombolian and phreatomagmatic deposits of Ohakune Craters, Ruapehu, New Zealand: a complex interaction between external water and rising basaltic magma. Journal of volcanology and geothermal research, 21(3): 207231.

Houghton, B., Latter, J. and Hackett, W., 1987. Volcanic hazard assessment for Ruapehu composite volcano, Taupo volcanic zone, New Zealand. Bulletin of volcanology, 49(6): 737-751. Hurst, A., 1998. Shallow seismicity beneath Ruapehu Crater Lake: results of a 1994 seismometer deployment. Bulletin of volcanology, 60(1): 1-9.

Hurst, A., Bibby, H., Scott, B. and McGuinness, M., 1991. The heat source of Ruapehu Crater Lake; deductions from the energy and mass balances. Journal of volcanology and geothermal research, 46(1): 1-20.

Hurst, A. and McGinty, P., 1999. Earthquake swarms to the west of Mt Ruapehu preceding its 1995 eruption. Journal of Volcanology and Geothermal Research, 90(1): $19-28$. 
Hurst, A.W. and McGinty, P., 1995. Seismicity of Ruapehu Volcano recorded during the 1994 seismometer deployment. Institute of Geological and Nuclear Sicences science report $95 / 45,13 \mathrm{pp}$.

Hurst, T., Jolly, A.D. and Sherburn, S., 2014. Precursory characteristics of the seismicity before the 6 August 2012 eruption of Tongariro volcano, North Island, New Zealand. Journal of Volcanology and Geothermal Research, 286(0): 294-302.

Ingham, M., Bibby, H., Heise, W., Jones, K., Cairns, P., Dravitzki, S., Bennie, S., Caldwell, T. and Ogawa, Y., 2009. A magnetotelluric study of Mount Ruapehu volcano, New Zealand. Geophysical Journal International, 179(2): 887-904.

Jaxybulatov, K., Shapiro, N.M., Koulakov, I., Mordret, A., Landès, M. and SensSchönfelder, C., 2014. A large magmatic sill complex beneath the Toba caldera. Science, 346(6209): 617-619.

Jay, J.A., Pritchard, M.E., West, M.E., Christensen, D., Haney, M., Minaya, E., Sunagua, M., McNutt, S.R. and Zabala, M., 2012. Shallow seismicity, triggered seismicity, and ambient noise tomography at the long-dormant Uturuncu Volcano, Bolivia. Bulletin of volcanology, 74(4): 817-837.

Johnson, J.H., 2011. Discriminating Between Spatial and Temporal Variations in Seismic Anisotropy at Active Volcanoes. Awarded Doctoral Thesis, Victoria University of Wellington.

Johnson, J.H. and Savage, M.K., 2012. Tracking volcanic and geothermal activity in the Tongariro Volcanic Centre, New Zealand, with shear wave splitting tomography. Journal of Volcanology and Geothermal Research, 223: 1-10.

Johnson, J.H., Savage, M.K. and Townend, J., 2011. Distinguishing between stressinduced and structural anisotropy at Mount Ruapehu volcano, New Zealand. Journal of Geophysical Research-Solid Earth, 116.

Jolly, A., Chardot, L., Neuberg, J., Fournier, N., Scott, B. and Sherburn, S., 2012a. High impact mass drops from helicopter: A new active seismic source method applied in an active volcanic setting. Geophysical Research Letters, 39(12). 
Jolly, A., Neuberg, J., Jousset, P. and Sherburn, S., 2012b. A new source process for evolving repetitious earthquakes at Ngauruhoe volcano, New Zealand. Journal of Volcanology and Geothermal Research, 215: 26-39.

Jolly, A., Sherburn, S., Jousset, P. and Kilgour, G., 2010. Eruption source processes derived from seismic and acoustic observations of the 25 September 2007 Ruapehu eruption-North Island, New Zealand. Journal of Volcanology and Geothermal Research, 191(1): 33-45.

Jolly, A.D., Jousset, P., Lyons, J.J., Carniel, R., Fournier, N., Fry, B. and Miller, C., 2014a. Seismo-acoustic evidence for an avalanche driven phreatic eruption through a beheaded hydrothermal system: An example from the 2012 Tongariro eruption. Journal of Volcanology and Geothermal Research, 286(0): 331-347.

Jolly, A.D., Lokmer, I., Kennedy, B., Keys, H.J.R., Proctor, J., Lyons, J.J. and Jolly, G.E., 2014b. Active seismic sources as a proxy for seismic surface processes: An example from the 2012 Tongariro volcanic eruptions, New Zealand. Journal of Volcanology and Geothermal Research, 286(0): 317-330.

Jones, K., Ingham, M. and Bibby, H., 2008. The hydrothermal vent system of Mount Ruapehu, New Zealand - a high frequency MT survey of the summit plateau. Journal of Volcanology and Geothermal Research, 176(4): 591-600.

Keats, B.S., Johnson, J.H. and Savage, M.K., 2011. The Erua earthquake cluster and seismic anisotropy in the Ruapehu region, New Zealand. Geophysical Research Letters, 38.

Lacoss, R.T., Kelly, E.J. and Toksöz, M.N., 1969. Estimation of seismic noise structure using arrays. Geophysics, 34(1): 21-38.

Latter, J., 1981a. Location of zones of anomalously high S-wave attenuation in the upper crust near Ruapehu and Ngauruhoe volcanoes, New Zealand. Journal of Volcanology and Geothermal Research, 10(1): 125-156.

Latter, J., 1981b. Volcanic earthquakes, and their relationship to eruptions at Ruapehu and Ngauruhoe volcanoes. Journal of Volcanology and Geothermal Research, 9(4): 293- 
309.

Lin, F.C., Ritzwollerl, M.H., Townend, J., Bannister, S. and Savage, M.K., 2007. Ambient noise Rayleigh wave tomography of New Zealand. Geophysical Journal International, 170(2): 649-666.

Lobkis, O.I. and Weaver, R.L., 2001. On the emergence of the Green's function in the correlations of a diffuse field. The Journal of the Acoustical Society of America, 110(6): 3011-3017.

Londono, J.M. and Sudo, Y., 2002. A warning model based on temporal changes of coda Q for volcanic activity at Nevado Del Ruiz Volcano, Colombia. Bulletin of volcanology, 64(5): 303-315.

Longuet-Higgins, M.S., 1950. A theory of the origin of microseisms. Philosophical Transactions of the Royal Society of London A: Mathematical, Physical and Engineering Sciences, 243(857): 1-35. Louie, J.N., 2001. Faster, better: shear-wave velocity to 100 meters depth from refraction microtremor arrays. Bulletin of the Seismological Society of America, 91(2): 347-364.

Masterlark, T., Haney, M., Dickinson, H., Fournier, T. and Searcy, C., 2010. Rheologic and structural controls on the deformation of Okmok volcano, Alaska: FEMs, InSAR, and ambient noise tomography. Journal of Geophysical Research: Solid Earth (1978-2012), 115(B2).

Meier, T., Dietrich, K., Stöckhert, B. and Harjes, H.-P., 2004. One-dimensional models of shear wave velocity for the eastern Mediterranean obtained from the inversion of Rayleigh wave phase velocities and tectonic implications. Geophysical Journal International, 156(1): $45-58$.

Miller, V. and Savage, M., 2001. Changes in seismic anisotropy after volcanic eruptions: Evidence from Mount Ruapehu. Science, 293(5538): 2231-2233.

Moebis, A., Cronin, S.J., Neall, V.E. and Smith, I.E., 2011. Unravelling a complex volcanic history from fine-grained, intricate Holocene ash sequences at the Tongariro Volcanic Centre, New Zealand. Quaternary International, 246(1-2): 352-363. 
Mordret, A., Jolly, A.D., Duputel, Z. and Fournier, N., 2010. Monitoring of phreatic eruptions using Interferometry on Retrieved Cross-Correlation Function from Ambient Seismic Noise: Results from Mt. Ruapehu, New Zealand. Journal of Volcanology and Geothermal Research, 191(1-2): 46-59.

Mordret, A., Rivet, D., Landes, M. and Shapiro, N.M., 2015. Three-dimensional shear velocity anisotropic model of Piton de la Fournaise Volcano (La Reunion Island) from ambient seismic noise. Journal of Geophysical Research: Solid Earth, 120(1): 406-427.

Nairn, I. and Scott, B., 1996. Volcanic eruption at a New Zealand ski resort prompts reevaluation of hazards. Eos, Transactions American Geophysical Union, 77(20): 189-191.

Nairn, I. and Self, S., 1978. Explosive eruptions and pyroclastic avalanches from Ngauruhoe in February 1975. Journal of Volcanology and Geothermal Research, 3(1): 39-60.

Nur, A., 1972. Dilatancy, pore fluids, and premonitory variations of ts/tp travel times. Bulletin of the Seismological society of America, 62(5): 1217-1222.

O’Neill, A. and Matsuoka, T., 2005. Dominant Higher Surface-wave Modes and Possible Inversion Pitfalls. Journal of Environmental and Engineering Geophysics, 10(2): 185-201.

Olson, J., 1985. Earthquakes in the Tongariro Volcanic Centre area, 1983 February 19-March 6. New Zealand Volcanological Record: Volcano and Geothermal Observations 1983, 13: 73-74.

Pao, Y.H. and Varatharajulu, V., 1976. Huygens' principle, radiation conditions, and integral formulas for the scattering of elastic waves. The Journal of the Acoustical Society of America, 59(6): 1361-1371.

Poli, P., Campillo, M., Pedersen, H. and Group, L.W., 2012a. Body-Wave Imaging of Earth's Mantle Discontinuities from Ambient Seismic Noise. Science, 338(6110): 10631065 .

Poli, P., Pedersen, H. and Campillo, M., 2012b. Emergence of body waves from crosscorrelation of short period seismic noise. Geophysical Journal International, 188(2): 549558. 
Poli, P., Pedersen, H. and Campillo, M., 2013. Noise directivity and group velocity tomography in a region with small velocity contrasts: the northern Baltic shield. Geophysical Journal International, 192(1): 413-424.

Price, R.C., Gamble, J.A., Smith, I.E., Maas, R., Waight, T., Stewart, R.B. and Woodhead, J., 2012. The anatomy of an Andesite volcano: a time-stratigraphic study of andesite petrogenesis and crustal evolution at Ruapehu Volcano, New Zealand. Journal of Petrology: egs 050 .

Price, R.C., Gamble, J.A., Smith, I.E., Stewart, R.B., Eggins, S. and Wright, I.C., 2005. An integrated model for the temporal evolution of andesites and rhyolites and crustal development in New Zealand's North Island. Journal of Volcanology and Geothermal Research, 140(1): 1-24.

Rogan, M., 1982. A geophysical study of the Taupo Volcanic Zone New Zealand. Journal of Geophysical Research: Solid Earth, 87(B5): 4073-4088.

Roux, P., 2009. Passive seismic imaging with directive ambient noise: application to surface waves and the San Andreas Fault in Parkfield, CA. Geophysical Journal International, 179(1): 367-373.

Roux, P., Sabra, K.G., Gerstoft, P., Kuperman, W. and Fehler, M.C., 2005. P-waves from cross-correlation of seismic noise. Geophysical Research Letters, 32(19).

Rowland, J. and Sibson, R., 2001. Extensional fault kinematics within the Taupo Volcanic Zone, New Zealand: Soft-linked segmentation of a continental rift system. New Zealand Journal of Geology and Geophysics, 44(2): 271-283.

Rowlands, D.P., 2004. Seismic Investigations of Active Volcanoes in Extensional Tectonic Settings. Awarded Doctoral Thesis, University of Cambridge.

Rowlands, D.P., White, R.S. and Haines, A.J., 2005. Seismic tomography of the Tongariro Volcanic Centre, New Zealand. Geophysical Journal International, 163(3): 11801194.

Sambridge, M., 1999. Geophysical inversion with a neighbourhood algorithm-I. Search- 
ing a parameter space. Geophysical Journal International, 138(2): 479-494.

Sánchez-Sesma, F.J. and Campillo, M., 2006. Retrieval of the Green's function from cross correlation: the canonical elastic problem. Bulletin of the Seismological Society of America, 96(3): 1182-1191.

Savage, M.K., 1999. Seismic anisotropy and mantle deformation: What have we learned from shear wave splitting? Reviews of Geophysics, 37(1): 65-106.

Savage, M.K., Lin, F.C. and Townend, J., 2013. Ambient noise cross-correlation observations of fundamental and higher-order mode Rayleigh wave propagation governed by basement resonance. Geophysical Research Letters, 40(14): 3556-3561.

Scherbaum, F., 2007. Of poles and zeros: Fundamentals of digital seismology. Springer.

Scott, B., 2013. A revised catalogue of Ruapehu volcano eruptive activity: 1830-2012, GNS Science Report, 113pp, GNS Science.

Scott, B.J. and Potter, S.H., 2014. Aspects of historical eruptive activity and volcanic unrest at Mt. Tongariro, New Zealand: 1846-2013. Journal of Volcanology and Geothermal Research, 286(0): 263-276.

Sens-Schonfelder, C. and Larose, E., 2010. Lunar noise correlation, imaging and monitoring. Earthq Sci, 23(5): 519-530.

Sens-Schonfelder, C., 2008. Synchronizing seismic networks with ambient noise. Geophysical Journal International, 174(3): 966-970.

Sens-Schonfelder, C. and Wegler, U., 2006. Passive image interferometry and seasonal variations of seismic velocities at Merapi Volcano, Indonesia. Geophysical research letters, $33(21)$.

Shapiro, N.M. and Campillo, M., 2004. Emergence of broadband Rayleigh waves from correlations of the ambient seismic noise. Geophysical Research Letters, 31(7).

Shapiro, N.M., Campillo, M., Stehly, L. and Ritzwoller, M.H., 2005. High-resolution 
surface-wave tomography from ambient seismic noise. Science, 307(5715): 1615-1618.

Sherburn, S., Bannister, S. and Bibby, H., 2003. Seismic velocity structure of the central Taupo Volcanic Zone, New Zealand, from local earthquake tomography. Journal of Volcanology and Geothermal Research, 122(1): 69-88.

Sherburn, S., Bryan, C., Hurst, A., Latter, J. and Scott, B., 1999. Seismicity of Ruapehu volcano, New Zealand, 1971-1996: a review. Journal of Volcanology and Geothermal Research, 88(4): 255-278.

Sissons, B. and Dibble, R., 1981. A seismic refraction experiment southeast of Ruapehu volcano. New Zealand Journal of Geology and Geophysics, 24(1): 31-38.

Snieder, R. and Fleury, C., 2010. Cancellation of spurious arrivals in Green's function retrieval of multiple scattered waves. The Journal of the Acoustical Society of America, 128(4): 1598-1605.

Stankiewicz, J., Ryberg, T., Haberland, C. and Natawidjaja, D., 2010. Lake Toba volcano magma chamber imaged by ambient seismic noise tomography. Geophysical Research Letters, $37(17)$.

Starostin, A., Barmin, A. and Melnik, O., 2005. A transient model for explosive and phreatomagmatic eruptions. Journal of volcanology and geothermal research, 143(1): 133151.

Stehly, L., Fry, B., Campillo, M., Shapiro, N., Guilbert, J., Boschi, L. and Giardini, D., 2009. Tomography of the Alpine region from observations of seismic ambient noise. Geophysical Journal International, 178(1): 338-350.

Stein, S. and Wysession, M., 2009. An Introduction to Seismology, Earthquakes, and Earth Structure. John Wiley \& Sons, 512 pp.

Stern, T. and Davey, F., 1987. A seismic investigation of the crustal and upper mantle structure within the Central Volcanic Region of New Zealand. New Zealand journal of geology and geophysics, 30(3): 217-231. 
Stern, T., Stratford, W., Seward, A., Henderson, M., Savage, M., Smith, E., Benson, A., Greve, S. and Salmon, M., 2010. Crust-mantle structure of the central North Island, New Zealand, based on seismological observations. Journal of Volcanology and Geothermal Research, 190(1): 58-74.

Syuhada, 2010. Seismic attenuation anisotropy in the southern part of the Taupo Volcanic Zone, North Island, New Zealand. Awarded Master's Thesis, Victoria University of Wellington, New Zealand.

Tanaka, H., Kawamura, K., Nagao, K. and Houghton, B.F., 1997. K-Ar ages and paleosecular variation of direction and intensity from Quaternary rava sequences in the Ruapehu Volcano, New Zealand. Journal of geomagnetism and geoelectricity, 49(4): 587599.

Thomas, A.P.W., 1889. Notes of the Geology of Tongariro and the Taupo District. Trans. N.Z. Inst., 21: 338-351.

Titzschkau, T., Savage, M. and Hurst, T., 2010. Changes in attenuation related to eruptions of Mt. Ruapehu Volcano, New Zealand. Journal of Volcanology and Geothermal Research, 190(1-2): 168-178.

Topping, W.W., 1974. Some Aspects of Quaternary History of Tongariro Volcanic Centre. Awarded Doctoral Thesis, Victoria University of Wellington, New Zealand.

Townsend, D., Leonard, G., Eaves, S., Conway, C., Wilson, C., Gamble, J.A. and Calvert, A., 2013. New Geologial Map of Tongariro National Park - an update, Geosciences 2013 Conference. Geoscience Society of New Zealand Miscellaneous Publication 136A, Christchurch, New Zealand.

Tsai, V.C., 2009. On establishing the accuracy of noise tomography travel-time measurements in a realistic medium. Geophysical Journal International, 178(3): 1555-1564.

van Wijk, K., Mikesell, T.D., Schulte-Pelkum, V. and Stachnik, J., 2011. Estimating the Rayleigh-wave impulse response between seismic stations with the cross terms of the Green tensor. Geophysical Research Letters, 38(16). 
Villamor, P. and Berryman, K., 2006a. Evolution of the southern termination of the Taupo Rift, New Zealand. New Zealand Journal of Geology and Geophysics, 49(1): 23-37.

Villamor, P. and Berryman, K., 2006b. Late Quaternary geometry and kinematics of faults at the southern termination of the Taupo Volcanic Zone, New Zealand. New Zealand journal of geology and geophysics, 49(1): 1-21.

Wallace, L.M., Beavan, J., McCaffrey, R. and Darby, D., 2004. Subduction zone coupling and tectonic block rotations in the North Island, New Zealand. Journal of Geophysical Research: Solid Earth, 109(B12): n/a-n/a.

Walsh, F., Hochstein, M. and Bromley, C., 1998. The Tongariro geothermal system (NZ): review of geophysical data, Proceedings 20th NZ Geothermal Workshop, pp. 317324.

Wathelet, M., 2008. An improved neighborhood algorithm: parameter conditions and dynamic scaling. Geophysical Research Letters, 35(9).

Wathelet, M., Jongmans, D. and Ohrnberger, M., 2004. Surface-wave inversion using a direct search algorithm and its application to ambient vibration measurements. Near surface geophysics, 2(4): 211-221.

Weaver, R.L. and Lobkis, O.I., 2004. Diffuse fields in open systems and the emergence of the Green's function (L). The Journal of the Acoustical Society of America, 116(5): 2731-2734.

Wessel, P. and Smith, W.H., 1998. New, improved version of Generic Mapping Tools released. EOS Trans. Am. Geophys. Union, 79 (47) (1998), p. 579.

Wilson, C., Houghton, B., McWilliams, M., Lanphere, M., Weaver, S. and Briggs, R., 1995. Volcanic and structural evolution of Taupo Volcanic Zone, New Zealand: a review. Journal of volcanology and geothermal research, 68(1): 1-28.

Wilson, C.J. and Rowland, J.V., 2015. The volcanic, magmatic and tectonic setting of the Taupo Volcanic Zone, New Zealand, reviewed from a geothermal perspective. Geothermics. 
Xia, J., Miller, R.D. and Park, C.B., 2000. Advantages of calculating shear-wave velocity from surface waves with higher modes, Proceedings of the 70th Annual International Meeting, SEG, Expanded Abstracts, pp. 1295-1298.

Xia, J., Miller, R.D., Park, C.B. and Tian, G., 2003. Inversion of high frequency surface waves with fundamental and higher modes. Journal of Applied Geophysics, 52(1): 45-57.

Yang, Y. and Ritzwoller, M.H., 2008. Characteristics of ambient seismic noise as a source for surface wave tomography. Geochemistry Geophysics Geosystems, 9(2): Q02008.

Yang, Y., Ritzwoller, M.H., Levshin, A.L. and Shapiro, N.M., 2007. Ambient noise Rayleigh wave tomography across Europe. Geophysical Journal International, 168(1): 259274 .

Yao, H. and Van Der Hilst, R.D., 2009. Analysis of ambient noise energy distribution and phase velocity bias in ambient noise tomography, with application to SE Tibet. Geophysical Journal International, 179(2): 1113-1132. 
Appendix A: Station metadata 


\begin{tabular}{|c|c|c|c|c|c|c|c|c|c|c|}
\hline $\begin{array}{c}\text { Deployment } \\
\text { (2001) }\end{array}$ & Code & Name & Latitude & Longitude & \begin{tabular}{|c|} 
Elevation \\
(m)
\end{tabular} & Start-Date & End-Date & $\begin{array}{l}\text { No. } \\
\text { Days }\end{array}$ & Sensor & Serial No. \\
\hline START & S03 & Iwikau & -39.233 & 175.543 & 1496 & 2001-009 & $2001-178$ & 118 & Guralp 40TD & - \\
\hline START & S05 & Manga_Road & -39.136 & 175.541 & 975 & 2001-011 & $2001-179$ & 129 & Guralp 40TD & - \\
\hline START & S06 & Manga_Hut & -39.145 & 175.601 & 1215 & $2001-013$ & $2001-170$ & 137 & Guralp 40TD & - \\
\hline START & S07 & Whakapapa & -39.182 & 175.529 & 1020 & 2001-011 & 2001-179 & 142 & Guralp 40TD & - \\
\hline START & S10 & Tukino_Road & -39.272 & 175.674 & 1248 & $2001-018$ & 2001-171 & 132 & Guralp 40TD & - \\
\hline START & S11 & Lower_Tama_Lake & -39.210 & 175.604 & 1359 & $2001-013$ & $2001-085$ & 57 & Guralp 40TD & - \\
\hline START & S12 & Oppwaipak & -39.264 & 175.730 & 1073 & 2001-014 & $2001-180$ & 124 & Guralp 40TD & - \\
\hline START & S13 & Patena & -39.094 & 175.703 & 833 & 2001-014 & $2001-172$ & 119 & Guralp 40TD & - \\
\hline START & S14 & Tekoteko & -39.112 & 175.738 & 810 & 2001-015 & 2001-171 & 129 & Guralp 40TD & - \\
\hline START & S15 & Pylon & -39.178 & 175.760 & 901 & $2001-015$ & $2001-070$ & 40 & Guralp 40TD & - \\
\hline START & S21 & Gunton & -39.187 & 175.280 & 320 & 2001-017 & 2001-161 & 112 & Guralp 40TD & - \\
\hline START & S22 & Ngamoturiki & -39.107 & 175.169 & 220 & $2001-019$ & 2001-139 & 103 & Guralp 40TD & - \\
\hline START & S23 & Tukinoski & -39.278 & 175.610 & 1733 & $2001-018$ & 2001-159 & 113 & Gualp 3TD & - \\
\hline START & S24 & Oio & -39.048 & 175.393 & 502 & $2001-020$ & $2001-177$ & 132 & Gualp 3TD & - \\
\hline START & S25 & Prison & -39.079 & 175.853 & 556 & $2001-027$ & 2001-166 & 117 & Guralp 40TD & - \\
\hline START & S26 & Karioi & -39.350 & 175.619 & 1109 & $2001-081$ & $2001-122$ & 36 & Guralp 40TD & - \\
\hline START & S27 & New_Pylon & -39.178 & 175.766 & 830 & 2001-127 & $2001-172$ & 42 & Guralp 40TD & - \\
\hline START & S28 & New_Turoa & -39.310 & 175.522 & 1580 & $2001-129$ & $2001-168$ & 37 & Guralp 40TD & - \\
\hline
\end{tabular}




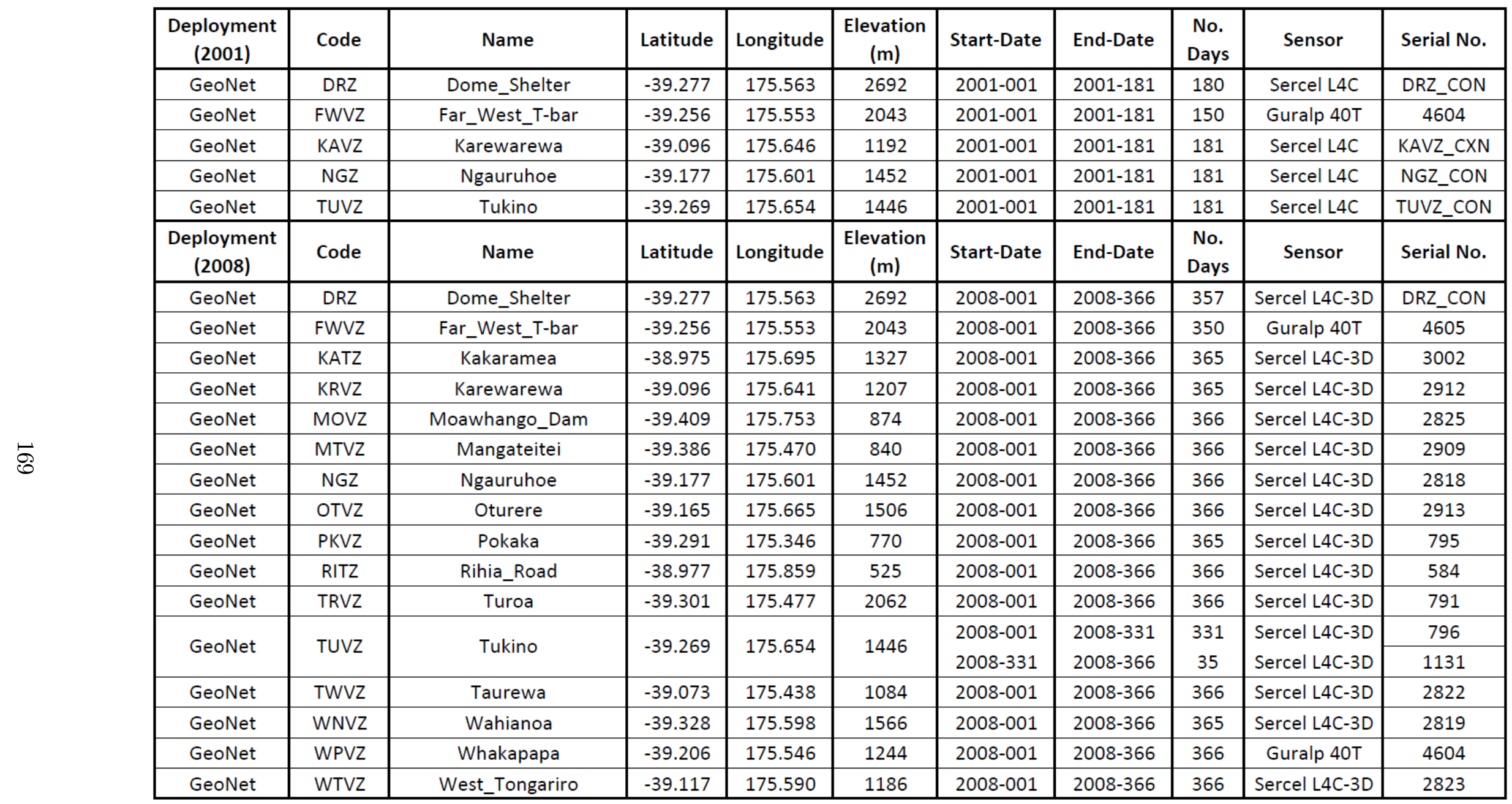




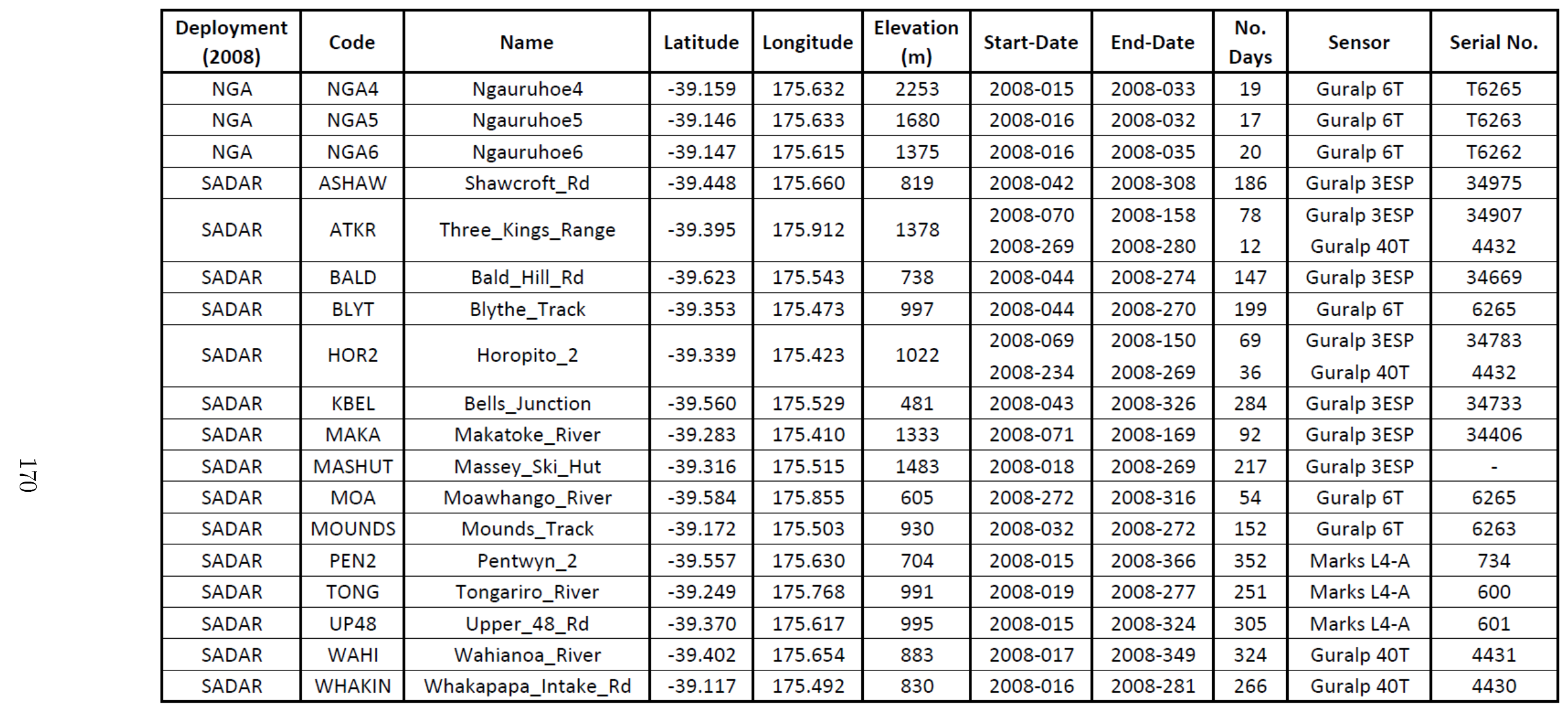




\title{
Appendix B: Instrument response functions for SADAR stations
}

N.B. Poles and zeroes for the $\mathrm{E}, \mathrm{N}$ and $\mathrm{Z}$ components of each station are equal.

\author{
ASHAW \\ Guralp CMG-3ESP Serial No: 34975 \\ Start date: 2008042 End date: 2008308 \\ ZEROES 3 \\ POLES 5 \\ $-0.07412-0.07412$ \\ $-0.074120 .07412$ \\ $-1005.30$ \\ $-502.70$ \\ $-11310$ \\ East-CONSTANT $1.8525 \mathrm{e}+10$ \\ North-CONSTANT $1.8468 \mathrm{e}+10$ \\ Vertical-CONSTANT $1.8506 \mathrm{e}+10$
}


ATKR

Guralp CMG-3ESP Serial No: 34907

Start date: 2008070 End date: 2008212

ZEROES 3

POLES 5

$-0.07412-0.07412$

$-0.074120 .07412$

$-1005.30$

$-502.70$

$-11310$

East-CONSTANT $1.8581 \mathrm{e}+10$

North-CONSTANT $1.8525 \mathrm{e}+10$

Vertical-CONSTANT $1.8600 \mathrm{e}+10$

ATKR

Guralp CMG-40T Serial No: 4432

Start date: 2008270 End date: 2008280

ZEROES 4

999.03

POLES 3

$-0.148-0.148$

$-0.1480 .148$

$-314.16$

East-CONSTANT $-1.5717 \mathrm{e}+3$

North-CONSTANT $-1.5453 \mathrm{e}+3$

Vertical-CONSTANT $-1.5530 \mathrm{e}+3$ 


\section{BALD}

\section{Guralp CMG-3ESP Serial No: 34669}

Start date: 2008044 End date: 2008274

ZEROES 3

POLES 5

$$
\begin{gathered}
-0.07412-0.07412 \\
-0.074120 .07412 \\
-1005.30 \\
-502.70 \\
-11310
\end{gathered}
$$

East-CONSTANT $1.8658 \mathrm{e}+10$

North-CONSTANT $1.8581 \mathrm{e}+10$

Vertical-CONSTANT $1.8619 \mathrm{e}+10$

\section{BLYT}

\section{Guralp CMG-6T Serial No: 6265}

Start date: 2008044 End date: 2008270

$$
\begin{gathered}
\text { ZEROES } 3 \\
\text { POLES } 6 \\
-0.148-0.148 \\
-0.1480 .148 \\
-391.96850 .69 \\
-391.96-850.69 \\
-2199.110 \\
-471.240
\end{gathered}
$$

East-CONSTANT $2.3115 \mathrm{e}+12$

North-CONSTANT $2.3173 \mathrm{e}+12$

Vertical-CONSTANT $2.3438 \mathrm{e}+12$ 


\section{HOR2}

\section{Guralp CMG-3ESP Serial No: 34783}

Start date: 2008069 End date: 2008150

ZEROES 3

POLES 5

$-0.074-0.074$

$-0.0740 .074$

$-1005.30$

$-502.70$

$-11310$

East-CONSTANT $1.8677 \mathrm{e}+10$

North-CONSTANT $1.8638 \mathrm{e}+10$

Vertical-CONSTANT $1.8619 \mathrm{e}+10$

\section{HOR2}

Guralp CMG-40T Serial No: 4432

Start date: 2008234 End date: 2008269

ZEROES 4

999.03

POLES 3

$-0.148-0.148$

$-0.1480 .148$

$-314.16$

East-CONSTANT $-1.5717 \mathrm{e}+3$

North-CONSTANT $-1.5453 \mathrm{e}+3$

Vertical-CONSTANT $-1.5530 \mathrm{e}+3$ 
KBEL

Guralp CMG-3ESP Serial No: 34733

Start date: 2008043 End date: 2008326

ZEROES 3

POLES 5

$-0.074-0.074$

$-0.0740 .074$

$-1005.30$

$-502.70$

$-11310$

East-CONSTANT $1.8658 \mathrm{e}+10$

North-CONSTANT $1.8562 \mathrm{e}+10$

Vertical-CONSTANT $1.8792 \mathrm{e}+10$

MAKA

Guralp CMG-3ESP Serial No: 34406

Start date: 2008071 End date: 2008168

ZEROES 3

POLES 5

$-0.074-0.074$

$-0.0740 .074$

$-1005.30$

$-502.70$

$-11310$

East-CONSTANT $1.8525 \mathrm{e}+10$

North-CONSTANT $1.8544 \mathrm{e}+10$

Vertical-CONSTANT $1.8619 \mathrm{e}+10$ 
MASHUT

Guralp CMG-3ESP Serial No: ?

Start date: 2008018 End date: 2008269

$$
\begin{gathered}
\text { ZEROES } 3 \\
\text { POLES } 5 \\
-0.074-0.074 \\
-0.0740 .074 \\
-1005.30 \\
-502.70 \\
-11310
\end{gathered}
$$

East-CONSTANT $1.8600 \mathrm{e}+10$

North-CONSTANT $1.8544 \mathrm{e}+10$

Vertical-CONSTANT $1.8619 \mathrm{e}+10$

MOA

Guralp CMG-6T Serial No: 6265

Start date: 2008272 End date: 2008325

ZEROES 3

POLES 6

$-0.148-0.148$

$-0.1480 .148$

$-391.96850 .69$

$-391.96-850.69$

$-2199.110$

$-471.240$

East-CONSTANT $2.3115 \mathrm{e}+12$

North-CONSTANT $2.3173 \mathrm{e}+12$

Vertical-CONSTANT $2.3438 \mathrm{e}+12$ 


\section{MOUNDS}

\section{Guralp CMG-6T Serial No: 6263}

Start date: 2008044 End date: 2008272

$$
\begin{gathered}
\text { ZEROES } 3 \\
\text { POLES } 6 \\
-0.148-0.148 \\
-0.1480 .148 \\
-391.96850 .69 \\
-391.96-850.69 \\
-2199.110 \\
-471.240
\end{gathered}
$$

East-CONSTANT $2.3115 \mathrm{e}+12$

North-CONSTANT $2.3173 \mathrm{e}+12$

Vertical-CONSTANT $2.3438 \mathrm{e}+12$

\section{WAHI}

Guralp CMG-40T Serial No: 4431

Start date: 2008014 End date: 2008349

ZEROES 4

999.03

POLES 3

$-0.148-0.148$

$-0.1480 .148$

$-314.16$

East-CONSTANT $-1.5727 \mathrm{e}+3$

North-CONSTANT $-1.5424 \mathrm{e}+3$

Vertical-CONSTANT $-1.5697 \mathrm{e}+3$ 


\section{WHAKIN}

\section{Guralp CMG-40T Serial No: 4430}

Start date: 2008016 End date: 2008366

ZEROES 3

POLES 5

$-0.149-0.149$

$-0.1490 .149$

$-11310$

$-1005.30$

$-502.70$

East-CONSTANT $1.1454 \mathrm{e}+10$

North-CONSTANT $1.1336 \mathrm{e}+10$

Vertical-CONSTANT $1.1444 \mathrm{e}+10$ 